\title{
ANAEROBIC MANGANESE- OR IRON-MEDIATED PHARMACEUTICAL DEGRADATION IN WATER
}

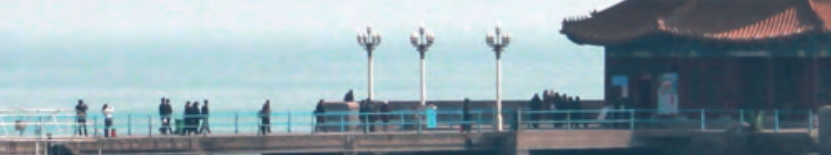

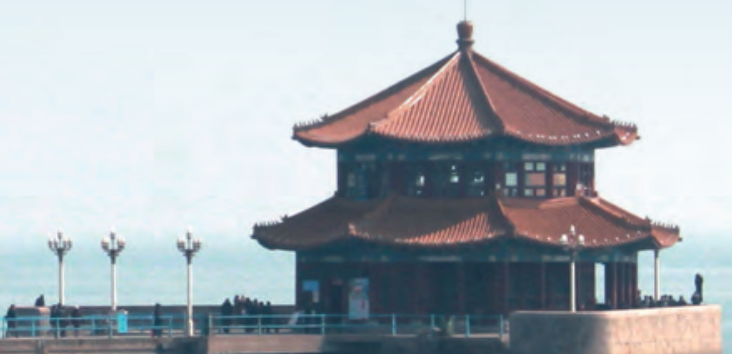

Wenbo Liu 


\section{Propositions}

1. Anaerobic technology is the most sustainable and efficient application for Mnor Fe-mediated pharmaceutical degradation.

(this thesis)

2. The challenges of cultivating $\mathrm{Mn}(\mathrm{IV})$ - and $\mathrm{Fe}(\mathrm{III})$-reducing bacteria is rewarded by their degradation of highly recalcitrant pharmaceuticals. (this thesis)

3. Priority for water safety goes to nutrient recovery instead of removing micropollutants.

4. Playing computer or video games solves scientific problems.

5. Remote control and communication systems promote the spread of knowledge but ruin sunny holidays.

6. Men remain kids throughout their life.

7. Fear of the unknown drives exploration.

Propositions belonging to the thesis, entitled

“Anaerobic manganese- or iron-mediated pharmaceutical degradation in water"

Wenbo Liu

Wageningen, 26 January 2018 


\section{Anaerobic manganese- or iron-mediated \\ pharmaceutical degradation in water}

Wenbo Liu 


\section{Thesis committee}

\section{Promotor}

Prof. Dr H.H.M Rijnaarts

Professor of Environmental Technology

Wageningen University \& Research

\section{Co-promotors}

Dr. A.A.M. Langenhoff

Associate professor, Sub-department of Environmental Technology

Wageningen University \& Research

Dr. N.B. Sutton

Assistant professor, Sub-department of Environmental Technology

Wageningen University \& Research

\section{Other members}

Prof. Dr R.N.J. Comans, Wageningen University \& Research

Dr. K. Roest, KWR Watercycle Research Institute, the Netherlands

Dr. A. Butkovskyi, Helmholtz-Zentrum für Umweltforschung UFZ, Germany

Prof. Dr P.J. van den Brink, Wageningen University \& Research

This research was conducted under the auspices of the Graduate School for Socio-Economic and Natural Sciences of the Environment (SENSE) 


\title{
Anaerobic manganese- or iron-mediated \\ pharmaceutical degradation in water
}

\author{
Wenbo Liu
}

Thesis

submitted in fulfilment of the requirements for the degree of doctor at Wageningen University

by the authority of the Rector Magnificus,

Prof. Dr A.P.J. Mol, in the presence of the

Thesis Committee appointed by the Academic Board to be defended in public on Friday 26 January 2018 at 1:30 p.m. in the Aula 
Wenbo Liu

Anaerobic manganese- or iron-mediated pharmaceutical degradation in water

224 pages.

$\mathrm{PhD}$ thesis, Wageningen University, Wageningen, the Netherlands (2017) With references, with summaries in English and Chinese

ISBN: 978-94-6343-221-4

DOI: $10.18174 / 425246$ 
To my parents and family 谨以此书献给我的父母和家人 



\section{Contents}

Summary

Chapter 1

Introduction: Pharmaceuticals in the environment and pharmaceutical removal technologies

Chapter 2

Pharmaceutical removal from water with manganese- or iron-based technologies: A review

Chapter 3

Anaerobic biodegradation of pharmaceutical compounds coupled to dissimilatory manganese (IV) or iron (III) reduction

\section{Chapter 4}

Anaerobic conditions are favourable for abiotic diclofenac removal from water with manganese oxides

Chapter 5

Application of manganese oxides under anaerobic conditions to remove diclofenac from water

\section{Chapter 6}

Biological regeneration of manganese (IV) using oxygen and iron (III) using nitrate for anaerobic metal oxide mediated removal of pharmaceuticals from water

Chapter 7

General Discussion: Towards a sustainable technology for removing pharmaceuticals from water using metal oxides

Supplementary materials

Bibliography 

Summary 



\section{Summary}

Pharmaceutical compounds, originating mainly from industrial production and public consumption, are detected at extremely low levels (ng $\left.\cdot \mathrm{L}^{-1}-\mu \mathrm{g} \cdot \mathrm{L}^{-1}\right)$ in groundwater, surface water, and wastewater. So far, the adverse effects of pharmaceuticals and their intermediates have been widely reported, and include toxicity to humans and ecosystem, and enhancement of antimicrobial resistance. These effects call for the elimination of pharmaceuticals from water. This can be done by both abiotic and biotic degradation in the presence of oxygen (aerobic conditions) or in the absence of oxygen (anaerobic conditions). The technologies under anaerobic conditions are generally more sustainable and attractive because they require less energy and produce less pollutants, such as greenhouse gas, compared to technologies under aerobic conditions. Anaerobic degradation with metal oxides such as manganese $(\mathrm{Mn})$ or iron $(\mathrm{Fe})$ oxides has clear advantages in both drinking water treatment and wastewater treatment. Therefore, anaerobic degradation of pharmaceuticals in water with $\mathrm{Mn}$ or Fe is promising to study and develop into applicable techniques. This thesis investigates the feasibility of anaerobic degradation of pharmaceuticals in $\mathrm{Mn}$ - and Fe-mediated systems via both abiotic removal processes and by biodegradation. In Chapter 1, the scientific and technological motivation of the thesis is proposed.

Applications and scientific developments of $\mathrm{Mn}$ - or Fe-based technologies to remove pharmaceuticals from water are reviewed and discussed in Chapter 2. Based on the removal mechanisms found in nature and technical systems, these Mn- or Fe-based technologies can be classified into 3 groups - physico-chemical removal, chemical removal, and biologically-related removal. A review of previous research indicates that pharmaceutical removal with $\mathrm{Mn}$ - or Fe-based technologies from water is efficient, and the removal efficiency varies whit the different technologies applied. Positive and negative aspects of these processes, such as (non-)specificity, treatment conditions, formation of and effects of 
intermediates and by-products, and effects of $\mathrm{Mn}$ or Fe compounds were evaluated. Based on that, new and promising Mn- or Fe-based technologies are proposed as future potential effective and sustainable pharmaceutical removal technologies. Among these proposed technologies, the dissimilatory $\mathrm{Mn}$ or $\mathrm{Fe}$ reduction is identified as a most attractive, sustainable, and low-cost technology because this novel technology requires neutral conditions and the bacteria involved are able to completely mineralize the pharmaceuticals.

The anaerobic biodegradation of pharmaceuticals coupled to dissimilatory $\mathrm{Mn}(\mathrm{IV})$ or $\mathrm{Fe}(\mathrm{III})$ reduction is tested with different types of $\mathrm{Mn}(\mathrm{IV})$ and $\mathrm{Fe}(\mathrm{III})$ (Chapter 3). With a mixture of adapted sediment to metoprolol and chemically synthesized $\mathrm{Mn}(\mathrm{IV})$, anaerobic biodegradation with amorphous, chemically synthesized Mn(IV) can effectively remove caffeine $(26 \%)$ and naproxen (52\%) after 42 days of incubation. Further experiments with $\mathrm{Mn}(\mathrm{IV})$ obtained from drinking water treatment plants show that this type of $\mathrm{Mn}(\mathrm{IV})$ can be used to remove metoprolol and propranolol, with respectively $96 \%$ and $31 \%$ after 72 days of incubation. The inoculum can also use Fe(III) as alternative electron acceptor to degrade metoprolol. Results show that metoprolol degradation with insoluble chemically synthesized Fe(III) and soluble Fe(III)-citrate reaches $57 \%$ and $52 \%$, respectively. No significant removal is observed in all the abiotic controls, showing that the biodegradation is the main removal mechanism in pharmaceutical removal with $\mathrm{Mn}(\mathrm{IV})$ or $\mathrm{Fe}(\mathrm{III})$. 
Abiotic removal of selected pharmaceuticals with $\mathrm{MnO}_{2}$ is compared under aerobic conditions and anaerobic conditions (Chapter 4). Results show that anaerobic conditions promote diclofenac removal, while it inhibits removal of metoprolol and propranolol. In demineralized water (demiwater), diclofenac removal under anaerobic conditions is $78 \%$, and higher than the $59 \%$ found under aerobic conditions. In $50 \mathrm{mM}$ phosphate buffer, and under aerobic conditions, the diclofenac removal achieves complete removal. Under anaerobic conditions the observed removal is similar as in demiwater. Preliminary investigation shows that diclofenac removal with $\mathrm{MnO}_{2}$ under anaerobic condition is better at acidic $\mathrm{pH}(\mathrm{pH} 4$ -5) and the removal is higher when applying amorphous $\mathrm{MnO}_{2}$ compared to applying crystalline $\mathrm{MnO}_{2}$. The key factors determining the extent of pharmaceutical removal with $\mathrm{MnO}_{2}$ under anaerobic conditions are the following: the chemical structure and molecular properties of the pharmaceuticals, and the properties and activity of reactive sites on the $\mathrm{MnO}_{2}$ surface.

Applying $\mathrm{MnO}_{2}$ under anaerobic conditions to remove diclofenac from water is further investigated (Chapter 5). Results show that increasing the temperature from 10 to $30^{\circ} \mathrm{C}$ leads to an increase in the diclofenac removal, whereas further increase of temperature to $40^{\circ} \mathrm{C}$ results in a decrease in the removal. The latter effect is possibly due to Ostwald ripening and/or aging processes. Increasing the amount of $\mathrm{MnO}_{2}$ increases the diclofenac degradation, as this provides more reactive sites for diclofenac conversions. Further shifting the molar ratio of $\mathrm{MnO}_{2}$ and diclofenac from 2200:1 to 8900:1, however, does not further increase diclofenac removal, probably due to limited oxidation capacity of $\mathrm{MnO}_{2}$. The presence of metal ions strongly inhibits the diclofenac removal following the order of $\mathrm{Mn}^{2+}>\mathrm{Ca}^{2+}$ $\approx \mathrm{Mg}^{2+}>\mathrm{Fe}^{3+}$. The metal ions appear to adsorb onto the $\mathrm{MnO}_{2}$ surface and compete with diclofenac for reactive sites. Phosphate has a diverse effect on diclofenac degradation: low concentrations inhibit and high concentrations promote the removal. The humic acids significantly promotes diclofenac 
removal, probably caused by affecting $\mathrm{MnO}_{2}$ reactive surface sites.

To reuse the $\mathrm{Mn}$ or Fe during pharmaceutical removal under anaerobic conditions, biological production of $\mathrm{Mn}$ (IV) or Fe(III) is investigated under oxygen-limiting conditions, or with nitrate as electron acceptor (Chapter 6). $\mathrm{Mn}(\mathrm{IV})$ is successfully produced with $\mathrm{Mn}(\mathrm{II})$-oxidizing bacteria under $\mathrm{O}_{2}$ limiting conditions, and the produced $\mathrm{Mn}(\mathrm{IV})$ is amorphous. Pharmaceutical removal with the Mn(II)-oxidizing bacteria is not observed. In abiotic pharmaceutical removal, using Mn(IV) from a drinking water production plant, is effective to remove metoprolol and propranolol. The successful production of $\mathrm{Fe}(\mathrm{III})$ is also observed under $\mathrm{NO}_{3}{ }^{-}$-reducing conditions via biological processes. The biologically produced $\mathrm{Fe}(\mathrm{III})$ is also amorphous. There is no significant removal of pharmaceuticals coupled to the biological $\mathrm{Fe}(\mathrm{III})$ production. When comparing the biologically produced $\mathrm{Fe}(\mathrm{III})$ and other types of $\mathrm{Fe}(\mathrm{III})$, only $\mathrm{Fe}(\mathrm{III})$ from a drinking water production plant and one $\mathrm{Fe}(\mathrm{III})$-based sorbent can remove propranolol.

Finally, the outcomes of this thesis are discussed and provide insights into the application of anaerobic degradation of pharmaceuticals with mediation of $\mathrm{Mn}$ and Fe oxides (Chapter 7). The removal mechanisms include adsorption, chemical oxidation, and biodegradation and are identified to contribute to the different removal processes. The anaerobic $\mathrm{Mn}(\mathrm{IV})$ - and $\mathrm{Fe}(\mathrm{III})$-mediated pharmaceutical degradation processes are evaluated on the basis of removal performance, environmental and operational conditions, sustainability of the processes, as well as the Mn and Fe types involved. Results described in this thesis provide a proof of principal for anaerobic $\mathrm{Mn}(\mathrm{IV})$ - or $\mathrm{Fe}(\mathrm{III})$-mediated degradation in removing pharmaceuticals from water. To translate the process into a pharmaceutical removal technology for water treatment, three steps are proposed including (1) exploring the limits of anaerobic $\mathrm{Mn}$ - or Femediated pharmaceutical degradation processes; (2) simulating the process in practice with a controlled systems, and (3) translating the processes to a 
pilot-scale system before a full-scale application. In addition, research topics are identified that can help to meet these challenges in the future. In summary, anaerobic Mn(IV)- or Fe(III)-mediated systems can remove pharmaceuticals from water through both abiotic removal and biotic degradation. These are promising processes which can be developed into a robust, sustainable, affordable, and environmentally friendly technology to remove pharmaceuticals from water. 



\section{Chapter 1}

Introduction: Pharmaceuticals in the environment and pharmaceutical removal technologies 


\subsection{Pharmaceuticals in water}

Pharmaceuticals, commonly known as medicines or drugs, are chemical compounds used in the medical diagnosis, cure, treatment, or prevention of disease. These compounds have been detected in the aquatic environment including surface water and groundwater. Pharmaceuticals in water originate from waste streams of human activities, such as industrial production and an increase in consumption and emissions due to population growth, aging, and rising levels of obesity ${ }^{[161]}$. In the European Union (EU), production by the pharmaceutical industry increased 76\% from 2000 to $2014{ }^{[57]}$. More production leads to more wastewater from manufacturing containing the raw materials as well as pharmaceuticals. Moreover, pharmaceutical consumption keeps increasing. The World Health Organization (WHO) reports that the pharmaceutical consumption in the investigated countries increased $20-30 \%$ from 2000 to $2008^{[181]}$. It is predicted that the global pharmaceutical consumption in 2020 will increase $24 \%$ from that in 2015, reaching 4.5 trillion dosages ${ }^{[2]}$. Pharmaceuticals consumed for curing illness or increasing animal productivity are generally not completely degraded in humans or animals. These pharmaceuticals, together with pharmaceuticals disposal from household, healthcare facilities, and industries, will enter the aquatic environment primarily through discharged wastewaters (Table 1.1, Figure 1.1) ${ }^{[30,367,369]}$.

Pharmaceuticals can be transformed to intermediates in the body, water treatment facility, and in the environment, and both parent and intermediates can be toxic to ecosystems ${ }^{[41]}$. One well-documented case is the $34-95 \%$ decrease of vulture population in Pakistan between 2000 and 2003 due to the indirect consumption of diclofenac and its residues ${ }^{[219]}$. Studies also describe the "cocktail effects" of pharmaceuticals, which may lead to more significant effects than predicted based on the individual compounds. For example, a higher toxicity on Daphnia magna is observed with a mixture of diclofenac, ibuprofen, and clofibric acid, than the individual compounds ${ }^{[88]}$. 
While toxic effects on ecosystems are relevant, the public focuses more on human exposure to pharmaceuticals, especially the pharmaceuticals in drinking water. Some pharmaceuticals have mutagenic activity, which may cause a somatic mutation that can lead to cancer ${ }^{[234,236]}$. Previous studies evaluated 1048 marketed pharmaceuticals, and nearly half of them are positive in the genotoxicity test or conflicting in results from different studies ${ }^{[24,283]}$. Furthermore, despite the extremely low concentrations of which pharmaceuticals are found in water resources, concern can be raised. Considering the toxicity of the individual compound, one pharmaceutical can have negligible effects at this low concentration on human's health or an ecosystem. However, the multitude of these compounds present in water potentially inducing synergistic long-term toxic effects are still unclear ${ }^{[129]}$. Results show that the long-term toxicity (chronic toxicity) of pharmaceuticals occurred at lower concentration (at $\left.\mu \mathrm{g} \cdot \mathrm{L}^{-1}\right)$ than short-term toxicity (acute toxicity, at $\mathrm{mg} \cdot \mathrm{L}^{-1}$ ) ${ }^{[233]}$. The antimicrobial resistance developed by microorganisms when exposed to antimicrobial pharmaceuticals, cause an increase in human mortality as a result of antimicrobial resistant pathogens ${ }^{[343]}$. To deal with all these potential threats, it is vital to better understand the sources causing emissions of pharmaceuticals to the environment, the fate, and effects of these chemicals on the environment. Moreover, specific technologies should be developed to remove these compounds from water, which is the focus of this thesis.

\subsection{Pharmaceutical degradation techniques}

Due to their unclear eco- and human toxic effects and their association with antimicrobial resistance, pharmaceuticals are considered as unwanted chemicals, even at the low concentrations currently observed in water resources $\left(\mathrm{ng} \cdot \mathrm{L}^{-1}-\mu \mathrm{g} \cdot \mathrm{L}^{-1}\right){ }^{[297,298]}$. Many processes have been used to remove pharmaceuticals from water ${ }^{[170,255]}$. In some processes, physical or chemical mechanisms are used to remove the compound. These abiotic removal processes include various types of advanced oxidation, activated 
carbon adsorption, or membrane filtration, and usually can achieve high removal efficiencies. For example, photodegradation catalysed by $\mathrm{TiO}_{2}$ can completely remove diclofenac and propranolol, and remove over $70 \%$ of carbamazepine and ibuprofen in both demineralised water and WWTP effluent ${ }^{[95,354]}$. Activated carbon (AC) adsorption including both powder and granular activated carbons is widely studied and used to remove pharmaceuticals as well as other micropollutants ${ }^{[50]}$. The AC adsorption capacities differ for specific pharmaceuticals. For less hydrophobic pharmaceuticals such as ibuprofen, $\mathrm{AC}$ has a relatively low adsorption capacity of $12-56 \mathrm{mg} \cdot \mathrm{g}^{-1}$. For hydrophobic pharmaceuticals like trimethoprim and paracetamol, the $\mathrm{AC}$ adsorption capacity is much higher, in the range of $120-300 \mathrm{mg} \cdot \mathrm{g}^{-1}[255,280]$.

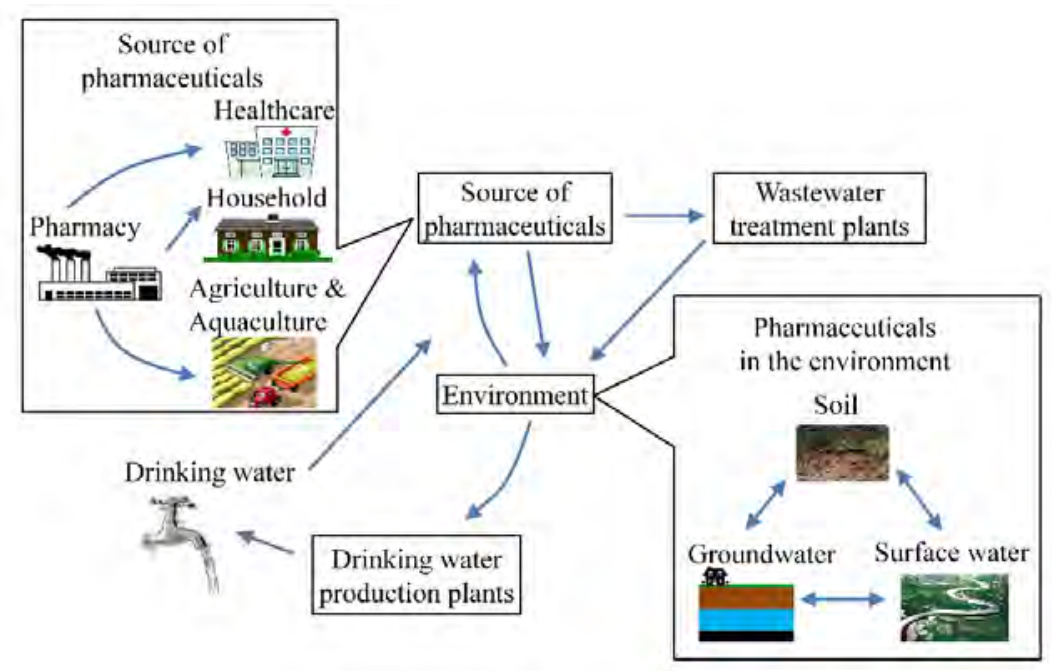

FIGURE 1.1 Source and pathways of pharmaceuticals in the environment 


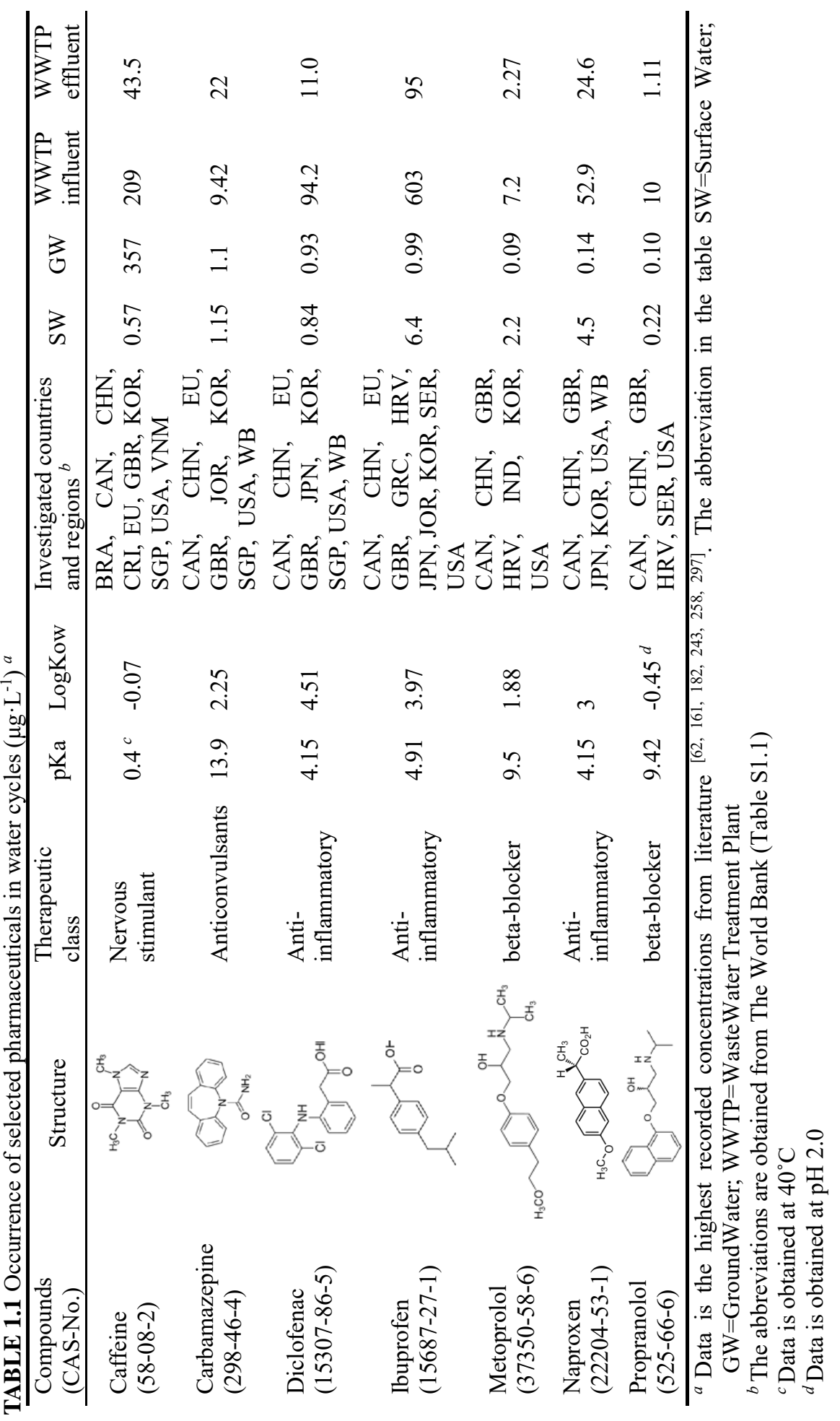


In contrast to abiotic processes, biotic processes are regarded as costeffective and environmentally friendly measures for removing pharmaceuticals from the aquatic environment (Table 1.2). In conventional wastewater treatment processes, both activated sludge and membrane bioreactor systems proved efficient in removing ibuprofen, atenolol, and some other pharmaceuticals ${ }^{[151,198,289]}$. A wide range of biological species including bacteria, plants, fungi, and algae can remove pharmaceuticals from water. Pure microbial cultures like Rhodococcus rhodochrous or Pseudomonas have been reported to efficiently degrade various types of medical chemicals ${ }^{[72,364]}$. Mixed microbial cultures, for instance, obtained from activated sludge and adapted to the specific pharmaceuticals, show an improved removal compared to unadapted groups, such as for ibuprofen and diclofenac ${ }^{[151]}$. Complete removal of ibuprofen has been demonstrated by the plant Phragmites australis, often used in wetlands ${ }^{[94]}$. The white-rot fungus Trametes versicolor has been tested, and it can degrade pharmaceuticals including ibuprofen, clofibric acid, and carbamazepine ${ }^{[192]}$. In the algae-based water treatment systems, both biodegradation and photolysis contributed to the complete removal of ibuprofen ${ }^{[49]}$.

TABLE 1.2 Comparison of abiotic and biotic processes in pharmaceutical removal

\begin{tabular}{|c|c|c|}
\hline & Advantages & Challenges \\
\hline $\begin{array}{l}\text { Abiotic processes } \\
\text { (chemical and } \\
\text { physical removal) }\end{array}$ & $\begin{array}{l}\text { - High and fast removal } \\
\text { - Relatively high } \\
\text { mineralization } \\
\text { - Efficient for nearly all } \\
\text { pharmaceuticals } \\
\text { - Efficient for other } \\
\text { (micro)pollutants } \\
\text { - Improve the } \\
\text { biodegradability }\end{array}$ & $\begin{array}{l}\text { - High cost } \\
\text { - Special operation conditions } \\
\text { - Radical formation } \\
\text { - Toxic intermediates }\end{array}$ \\
\hline $\begin{array}{l}\text { Biotic processes } \\
\text { (biodegradation) }\end{array}$ & $\begin{array}{l}\text { - Commonly moderate } \\
\text { operation conditions } \\
\text { - Less energy input, cost- } \\
\text { effective } \\
\text { - Less toxic intermediates } \\
\text { - Resistance to shock }\end{array}$ & $\begin{array}{l}\text { - Slow removal \& } \\
\text { mineralization } \\
\text { - Developing antimicrobial } \\
\text { resistant } \\
\text { - Only efficient for selected } \\
\text { pharmaceuticals } \\
\text { - Produce waste sludge }\end{array}$ \\
\hline
\end{tabular}




\subsection{Pharmaceutical degradation techniques using metal species}

The role of metal species in organic compound degradation is widely studied, and can either have a purely chemical, heterogenic catalytic nature or can occur in interaction with biotic processes ${ }^{[248]}$. In previous studies, manganese $(\mathrm{Mn})$ - or iron (Fe)-based technologies have been shown to remove pharmaceuticals via both abiotic removal and biodegradation [170]. Using $\mathrm{Mn}$ or Fe to remove pharmaceuticals has some clear advantages (Table 1.3). Mn and Fe are abundant, and they are essential to transforming organic contaminants in nature ${ }^{[175]}$. Hence, these materials can be easily and cheaply obtained from natural resources. Furthermore, $\mathrm{Mn}$ is unwanted in drinking water because it is toxic to humans ${ }^{[226]}$ and needs to be removed from drinking water resources. Fe is an unwanted species in drinking water as well, since it affects the appearance and taste of the water, and can lead to clogging of water pipes and hinder the functioning of faucets and valves. Using these waste metal species to remove pharmaceuticals is economically and environmentally attractive in drinking water and wastewater treatment. Therefore, the abiotic removal and biodegradation of pharmaceuticals by these metals in various speciation are worth studying. Studying the Mn- and Fe-mediated pharmaceutical removal will contribute to an increased basic understanding of the fate, and specifically the transformation of pharmaceuticals in the environment. Also, investigating Mn or Fe species to remove pharmaceuticals from water is promising for the development of a novel cost-effective water treatment technology. To achieve this goal, further research is required to meet the challenges mentioned for various processes (Table 1.3). 
TABLE 1.3 Comparison of using $\mathrm{Mn}$ or Fe, and other chemicals in pharmaceutical removal processes

\begin{tabular}{|c|c|c|}
\hline & Advantages & Challenges \\
\hline Using $\mathrm{Mn}$ or $\mathrm{Fe}$ & $\begin{array}{l}\text { - } \text { Abundant in nature, easy to } \\
\text { obtain } \\
\text { - } \text { Cheap } \\
\text { - } \text { Reuse Mn or Fe } \\
\text { - High removal efficiency }\end{array}$ & $\begin{array}{ll}\text { - } & \text { Extra pollutants } \mathrm{Mn}^{2+} \text { or } \\
& \mathrm{Fe}^{2+} \\
\text { - } & \text { Strict anaerobic } \\
\text { condition requires } \\
\text { (biodegradation) } \\
\text { - } & \text { Slow growth of bacteria } \\
& \text { (biodegradation) }\end{array}$ \\
\hline $\begin{array}{l}\text { Using other } \\
\text { chemicals } \\
\left(\mathrm{O}_{3}, \mathrm{NO}_{3}^{-} \text {, etc. }\right)\end{array}$ & $\begin{array}{l}\text { - High \& rapid removal efficiency } \\
\text { - Bacteria are easy to cultivate } \\
\text { (biodegradation) }\end{array}$ & $\begin{array}{l}\text { - High cost of materials } \\
\text { - High operational skills }\end{array}$ \\
\hline
\end{tabular}

Eliminating pharmaceuticals from water is an important step to reduce the negative effects of these compounds on ecosystem and human. The ideal pharmaceutical removal technology should produce less direct and indirect pollution including toxic intermediates and greenhouse gases, and consume less energy. The technologies under anaerobic conditions (absence of oxygen) are most suitable for this purpose. Previous studies with various metal species have shown pharmaceutical degradation under anaerobic conditions via abiotic and biological processes ${ }^{[74,170,182]}$.

Using $\mathrm{Mn}$ or $\mathrm{Fe}$ in anaerobic abiotic processes to remove pharmaceuticals is considered as more sustainable compared to aerobic processes (presence of oxygen) due to the low energy input needed for aeration. Some studies find that the presence oxygen can both promote the $\mathrm{Mn}$ or Fe mediated removal of sulfamethazine ${ }^{[69]}$, inhibit the removal of metoprolol and propranolol ${ }^{[172]}$, or does not affect the removal of levofloxacin ${ }^{[163]}$. In the absence of oxygen, the use of Mn oxides to remove pharmaceuticals from water is widely studied ${ }^{[248]}$, and the role and function of oxygen vary among the different investigations. Mohatt, et al. [206] have reported the abiotic removal of sulfamethoxazole in soil by the mediation of Fe species. Further detailed investigations on the underlying mechanisms are missing. Therefore, the abiotic removal of pharmaceuticals with Mn or Fe under anaerobic conditions is essential for further studies. 
Biodegradation under anaerobic conditions is known to be more efficient to degrade some recalcitrant pollutants, like highly halogenated aromatic compounds ${ }^{[324]}$. Under anaerobic conditions, microorganisms can use different alternative electron acceptors, including nitrate, $\mathrm{Mn}, \mathrm{Fe}$, sulphate, and $\mathrm{CO}_{2}{ }^{\left[{ }^{[74}\right.}$. The biodegradation of various pharmaceuticals has been observed under these different redox conditions ${ }^{[74,339]}$. However, in comparison with other redox conditions, biodegradation of pharmaceuticals under $\mathrm{Mn}$ and $\mathrm{Fe}$ reducing conditions has been insufficiently addressed. The biodegradation of organic compounds under $\mathrm{Mn}$ and Fe reducing conditions is through dissimilatory $\mathrm{Mn}$ or Fe reduction ${ }^{[175]}$. A promising process is dissimilatory $\mathrm{Mn}(\mathrm{IV})$ or $\mathrm{Fe}(\mathrm{III})$ reduction process. In these anaerobic $\mathrm{Mn}$ or Fe-mediated systems, bacteria use $\mathrm{Mn}$ (IV) or Fe(III) as the electron

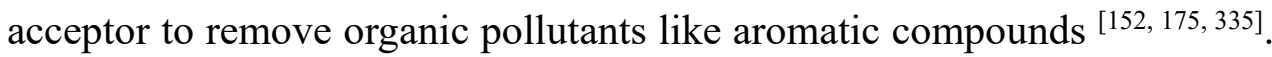
Since pharmaceuticals are mainly aromatic compounds, these processes potentially can also remove pharmaceuticals. Therefore, studying the process can form the basis for developing a specific removal technology for aromatic structure based pharmaceuticals. Previous studies on pharmaceutical degradation with different electron acceptors show that pharmaceuticals like naproxen can be efficiently removed under $\mathrm{Mn}$ and $\mathrm{Fe}$ reducing conditions ${ }^{[268]}$. The limited studies so far indicate that further studies on anaerobic biodegradation of pharmaceuticals with $\mathrm{Mn}$ or Fe are desired.

In the $\mathrm{Mn}$ - and Fe-mediated system, the $\mathrm{Mn}$ and Fe species is important. The Mn(IV)- and Fe(III)-(hydr)oxides are widely studied Mn and Fe species, and they can efficiently remove pharmaceuticals in both abiotic and biotic processes ${ }^{[65,170,327]}$. The $\mathrm{Mn}$ and Fe species from drinking water production are also (hydr)oxides, and could be suitable metal species to start detailed studies on anaerobic abiotic removal and anaerobic biodegradation of pharmaceuticals with $\mathrm{Mn}$ or Fe. 


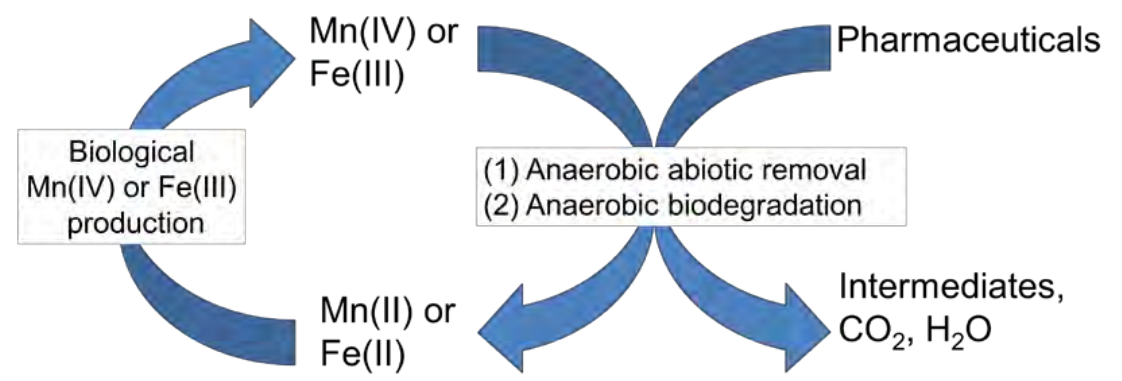

FIGURE 1.2 Anaerobic Mn(IV)- or Fe(III)-mediated pharmaceutical removal processes through (1) anaerobic abiotic removal and (2) anaerobic biodegradation

In summary, anaerobic $\mathrm{Mn}(\mathrm{IV})$ or $\mathrm{Fe}(\mathrm{III})$ mediated abiotic and biotic degradation (Figure 1.2) offers the potential for developing a sustainable technology to remove pharmaceuticals from water. Such a technology requires limited energy and therefore produces little indirect pollution in the form of greenhouse gasses $\left(\mathrm{CO}_{2}\right)$. Moreover, $\mathrm{Mn}(\mathrm{IV})$ and $\mathrm{Fe}(\mathrm{III})$ containing waste sludge of the drinking water industry may be reused for the degradation of pharmaceuticals.

\subsection{Aim and Scope of this thesis}

As discussed, Mn(IV) or Fe(III) mediated abiotic and biotic anaerobic degradation of pharmaceuticals is promising in water treatment and attractive to both drinking water and wastewater treatment. The objective of this dissertation is to first provide a proof of principle and subsequently further explore anaerobic $\mathrm{Mn}(\mathrm{IV})$ - or $\mathrm{Fe}(\mathrm{III})$-mediated pharmaceutical degradation processes (Figure 1.3). This pharmaceutical removal process needs to be based on new fundamental insights into the transformation of pharmaceuticals in the Mn(IV)- or Fe(III)-mediated systems. Both Mn(IV) and Fe(III) are studied in abiotic and biotic systems to assess the potential of the various processes to remove pharmaceuticals as well as the potential of the recycling of the Mn(IV) and Fe(III) used.

Developing Mn- or Fe-based technologies for pharmaceutical removal is discussed by reviewing current and past studies reported in the literature 
(Chapter 2). All reported Mn- or Fe-mediated systems are classified into three groups according to their removal mechanisms - physico-chemical processes, chemical processes, and biological processes. Removal efficiency and relevant parameters of these technologies and processes are put in inventory, and the advantages and challenges of these technologies and processes are discussed. Based on the review, several promising Mnand Fe-mediated systems are proposed, which are currently not yet used to remove pharmaceuticals. The dissimilatory $\mathrm{Mn}(\mathrm{IV})$ or $\mathrm{Fe}(\mathrm{III})$ reduction process is identified and expected to have a high potential for removing pharmaceuticals from water.

After that, the biodegradation of pharmaceuticals in the anaerobic Mnor Fe-mediated systems is tested by laboratory research (Chapter 3). The degree to which $\mathrm{Mn}$ and $\mathrm{Fe}$ species can function as electron acceptors in pharmaceutical biodegradation is studied. Batch experiments are carried out with pharmaceutical mixtures in water, using a microbial inoculum adapted to $\mathrm{Mn}(\mathrm{IV})$ and metoprolol. The removal efficiency of selected pharmaceuticals with $\mathrm{Mn}(\mathrm{IV})$ is subsequently investigated. The same microbial inoculum ((Mn(IV) adapted) is cultivated with metoprolol and $\mathrm{Fe}$ (III) species, namely Fe(III) hydroxides and Fe(III)-citrate, to test Fe(III) as an electron acceptor. Further tests with $\mathrm{Mn}$ (IV) and Fe(III) from drinking water treatment plants, and two $\mathrm{Fe}(\mathrm{III})$-based sorbents are performed to find the best source of $\mathrm{Mn}$ (IV) and $\mathrm{Fe}$ (III) for pharmaceutical degradation.

After the biological studies, the studies into the potential of abiotic Mn and $\mathrm{Fe}$ mediated removal processes are described in Chapter 4. The anaerobic abiotic removal of pharmaceuticals is compared to that under aerobic conditions, to test and reveal the influence of oxygen. In addition, the effects of process parameters such as phosphate, $\mathrm{pH}$, and $\mathrm{MnO}_{2}$ morphologies are investigated. To this end batch experiments are carried out in the different matrices including solutions of the seven test pharmaceuticals as a mixture and as single compound (diclofenac) in demineralized water or phosphate buffer. The abiotic removal of diclofenac 
in the absence of oxygen is described in detail because anaerobic conditions promote diclofenac removal, which has not been reported before. The next chapter (Chapter 5), continues with the $\mathrm{MnO}_{2}$ based abiotic processes to further elucidate the effects of parameters relevant for technology application. In this chapter, diclofenac is selected as a model pharmceutical to study the influence of temperature, amount of $\mathrm{MnO}_{2}$ per volume or per amount of pharmaceutical dosed, and co-solutes such as metal ions, phosphate, and organics in wastewater treatment plant effluents.

The $\mathrm{Mn}(\mathrm{IV})$ and $\mathrm{Fe}(\mathrm{III})$ can be regenerated from the $\mathrm{Mn}$ (II) and $\mathrm{Fe}(\mathrm{II})$ produced during the anaerobic $\mathrm{Mn}$ - or Fe-mediated pharmaceutical degradation. The biological production of $\mathrm{Mn}(\mathrm{IV})$ and $\mathrm{Fe}(\mathrm{III})$ is tested (Chapter 6). To better reuse, the regenerated $\mathrm{Mn}(\mathrm{IV})$ and $\mathrm{Fe}(\mathrm{III})$, the production of these metals is carried out under oxygen-limiting conditions for $\mathrm{Mn}(\mathrm{IV})$, and nitrate-reducing conditions for $\mathrm{Fe}$ (III). Removal of pharmaceuticals is tested during the biological metal production processes. In addition, anaerobic abiotic removal of pharmaceuticals with $\mathrm{Mn}(\mathrm{IV})$ and $\mathrm{Fe}(\mathrm{III})$ from different sources are compared.

In the final synthesis chapter, all processes described in the thesis are discussed regarding scientific progress, technology development and application potential (Chapter 7). A system for evaluating the performance of metal-oxide based pharmaceutical removal from water is presented. The potential remaining challenges of this proposed pharmaceutical removal technology are identified and discussed. Finally, an outlook and recommendation for research and application in water reuse are presented. 


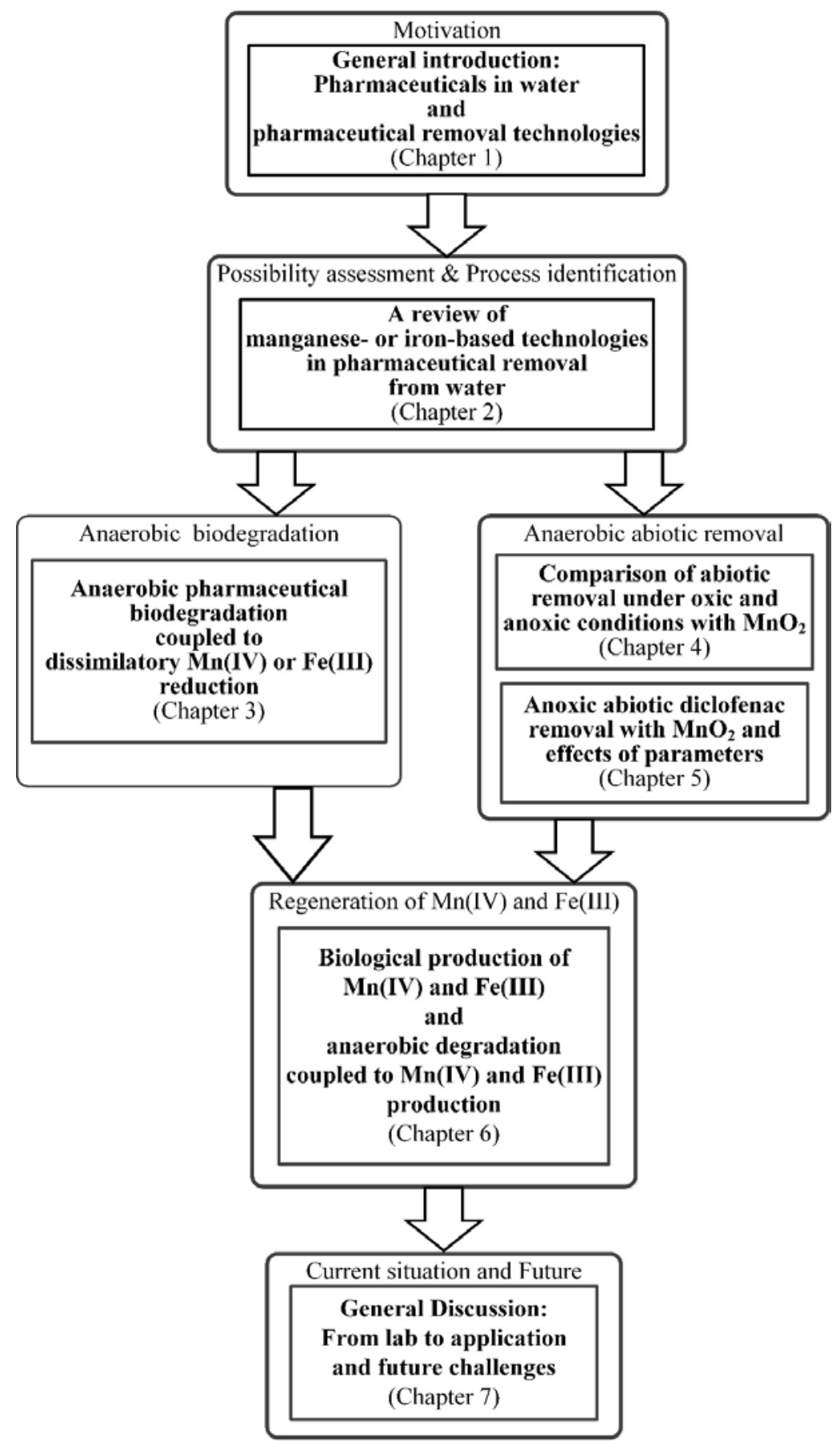

FIGURE 1.3 Schematic outline of the research topics in this thesis 



\section{Chapter 2}

\section{Pharmaceutical removal from water with manganese- or iron-based technologies: A review}

A modified version of this chapter is published as

Liu, W.; Sutton, N. B.; Rijnaarts, H. H. M.; Langenhoff, A. A. M., Pharmaceutical removal from water with iron- or manganese-based technologies: A review. Critical Reviews in Environmental Science and Technology 2016, 46, (19-20), 1584-1621, DOI: $10.1080 / 10643389.2016 .1251236$ 


\section{ABSTRACT}

Pharmaceuticals are detected at trace levels in waters. Their adverse effects on aquatic ecosystems and human health demand novel pharmaceutical removal technologies for treating wastewater effluents. Manganese (Mn) or iron $(\mathrm{Fe})$ may play important roles in these new technologies since these metals are abundantly available at low costs and are known to contribute to organic conversions via physico-chemical, chemical, and biologically related processes. Few reviews describe and discuss Mn- or Fe-based technologies for the purpose to remove pharmaceuticals from water. Therefore we review the current literature sorted into the three removal mechanisms, that is, through physico-chemical, chemical and biological processes. The principals, performance, and influential parameters of these three types of technologies are described. Current and potential applications of these technologies are critically evaluated in order to identify advantages and challenges. In addition, the Fe- or Mn-based technologies which are currently not used but promising to further develop to remove pharmaceuticals cost efficiently are proposed.

KEYWORDS: biologically-related removal; chemical removal; iron- or manganese-based technology; pharmaceutical removal; physico-chemical removal; water 


\subsection{Introduction}

Removing pollutants from water is crucial to human as well as ecosystem health. Micropollutants are a growingly popular subject due to their low concentration and potential hazard. Among the micropollutants, pharmaceuticals are well studied and can be used as a representative case for a variety of micropollutants. Pharmaceuticals, commonly known as medicines or drugs, are a vast array of chemical compounds used for medical diagnosis, cure, treatment, or prevention of disease [255]. Improvements in analytical technologies have resulted in detection techniques to quantify pharmaceuticals at trace concentrations $\left(\mathrm{ng} \cdot \mathrm{L}^{-1}\right.$ $\mu \mathrm{g} \cdot \mathrm{L}^{-1}$ ) in wastewater, groundwater and surface water, and even in drinking water $[38,54,106,194]$. Pharmaceuticals in water can threaten the quality of drinking water resources, can lead to spread of antibiotic resistance ${ }^{[241,348]}$ and can be toxic to some aquatic organisms ${ }^{[147,263]}$. The presence and fate of these compounds have become a growing worldwide concern for politicians and the general public ${ }^{[118,342]}$. For example, U.S. Environmental Protection Agency and European Union have added pharmaceuticals to their watch list for water quality ${ }^{[60,314]}$. Due to adverse effects of pharmaceuticals in water on the quality of drinking water and food supply to humans, and on the functioning of ecosystems, regulators start to call for cost-efficient removal technologies to reduce emissions of such compounds.

Pharmaceuticals from human consumption, excretion, and disposal mainly enter the environment via wastewater ${ }^{[113]}$. If they are not removed, these compounds will pass through wastewater treatment trains and enter water bodies directly ${ }^{[207,306]}$. Advanced technologies are employed to remove these pharmaceuticals from water ${ }^{[11,68,95,139,270,357]}$. Manganese (Mn) and iron (Fe) play important roles in many water treatment technologies, including physico-chemical removal (e.g. polyferric coagulation) ${ }^{[345]}$, chemical removal (e.g. Fenton) ${ }^{[160,186]}$, and biologically related removal (e.g. biogenic Mn oxides oxidation) ${ }^{[65,67]}$. Mn- or Fe-based technologies for 
treating organic chemicals and heavy metals in general are reviewed in the literature $[45,158,300]$. None of these is specifically oriented on Pharmaceuticals. The number of studies that have examined the processes and applications of $\mathrm{Mn}$ - or Fe-based technologies to remove pharmaceuticals is growing. These studies indicate the special character of pharmaceuticals, that is, their complex chemical structures, which strongly influence compound specific physico-chemical and biological processes related to $\mathrm{Mn}$ or Fe reactive species. Therefore, an integrated review of this literature, on $\mathrm{Mn}$ - or Fe-based technologies and assessment of their scientific soundness, application potential, and main prevailing knowledge gaps is highly needed.

This paper reviews Mn- or Fe-based technologies which are used to remove pharmaceuticals from water. All these technologies are sorted based on 3 removal mechanisms: physico-chemical removal, chemical removal, and biologically related removal. We evaluate the benefits and limitations of these technologies and discuss their application. In addition, we suggest promising Mn- or Fe-based technologies that should be explored for pharmaceutical removal. The results of this review are thus a critical assessment of the currently available and future potential Mn- or Fe-based technologies for pharmaceutical removal.

\subsection{Processes review}

\subsubsection{Physico-chemical removal}

$\mathrm{Mn}$ and $\mathrm{Fe}$ compounds are used in water treatments, which involve physical and physico-chemical processes such as flocculation and coagulation, adsorption, and co-precipitation. These processes will be discussed in more detail in the following sections. Generally, pollutants are immobilized by interaction with Mn or Fe particles, which are subsequently settled. These physico-chemical technologies are used to remove pharmaceuticals from the water phase but not to convert or to degrade them. 


\subsubsection{Flocculation and coagulation}

In flocculation and coagulation, the soluble or colloidal compounds are taken out of solution or suspension in the form of a floc or flake by using chemical flocculants or coagulants; subsequently, the formed particles are settled. Flocculation is the aggregation of particles while coagulation is a physico-chemical destabilization of the colloidal system ${ }^{[18]}$. In literature, the flocculation and coagulation is interchangeable, and in this review, we will use the term "flocculation and coagulation" to refer to either or both of these related processes as used in Bratby ${ }^{[25]}$. These flocculants and coagulants can be organic polymers, metal salts such as $\mathrm{FeCl}_{3}$, and prehydrolized metal salts such as polyferric sulphate ${ }^{[18,203]}$.

Ferric salts, including $\mathrm{FeCl}_{3}$ and $\mathrm{Fe}_{2}\left(\mathrm{SO}_{4}\right)_{3}$, are commonly used in flocculation and coagulation processes for organic matter removal from drinking water and wastewater ${ }^{[28,168,199]}$. Excess Fe(III) is generated by zero-valent iron $/ \mathrm{H}_{2} \mathrm{O}_{2}$ system and improves flocculation and coagulation of organic pollutants ${ }^{[131,212]}$. Recently, polyferric sulphate (PFS), an inorganic polymeric flocculant, is used as a new coagulant to remove pharmaceuticals. In wastewater from a pharmaceutical production facility where the main organic COD (chemical oxygen demand) consisted of the pharmaceuticals, such as cefpirome, latomoxef, aztreonam, cefoperazone, cefatridine, ceftazidime, and other chemicals like propylene glycol, over $70 \%$ of 3300 $\mathrm{mg} \cdot \mathrm{L}^{-1} \mathrm{COD}$ was removed by flocculation and coagulation with PFS ${ }^{[345]}$. Results indicate that both the $\mathrm{pH}$ and PFS concentration influenced the removal, with the highest removal being obtained at an optimum $\mathrm{pH}$ of $\sim 4$ with $300 \mathrm{mg} \cdot \mathrm{L}^{-1} \mathrm{PFS}$. At $\mathrm{pH} 4$, the COD removal increases from 0 to $80 \%$ with increasing PFS concentrations from 0 to $200 \mathrm{mg} \cdot \mathrm{L}^{-1}$; when $200-900$ $\mathrm{mg} \cdot \mathrm{L}^{-1} \mathrm{PFS}$ was dosed, COD removal only increased $10 \%{ }^{[345]}$. PFS contains large amounts of polynuclear complex ions such as $\left(\mathrm{Fe}_{2}(\mathrm{OH})_{3}\right)^{3+}$, $\left(\mathrm{Fe}_{2}(\mathrm{OH})_{2}\right)^{4+},\left(\mathrm{Fe}_{8}(\mathrm{OH})_{20}\right)^{4+}$, which leads to higher removal performance of organic compounds ${ }^{[318,379]}$, as compared to conventional flocculation and coagulation like $\mathrm{FeSO}_{4}$ and $\mathrm{FeCl}_{3}$. 


\subsubsection{Adsorption}

$\mathrm{Mn}, \mathrm{Fe}$ and their oxides can be used as adsorbents, especially when present as nanoparticles, that is, particles ranging in size between 10 and $100 \mathrm{~nm}$. During adsorption, the pollutant is removed from the liquid phase through transfer to the surface of adsorbent. Especially nanoscale metal oxides, have an extremely large specific surface area supporting efficient removal of pharmaceuticals ${ }^{[310]}$. If the adsorbent has a preferential affinity for certain compounds in the liquid phase, the efficiencies can then be further enlarged with orders of magnitude ${ }^{[203]}$.

$\mathrm{MnO}_{2}$ can be used to remove pharmaceuticals and other pollutants by adsorption including antibacterial agents like sulfonamides and tetracycline, and endocrine disruptors ${ }^{[19,248]}$. Results showed that clarithromycin and roxithromycin can be rapidly absorbed onto this amorphous $\mathrm{MnO}_{2}$ at $\mathrm{pH} 5$ [61], but adsorption did not contribute to carbamazepine removal with amorphous $\mathrm{MnO}_{2}{ }^{[93,248]}$. Adsorption of pharmaceuticals onto $\mathrm{MnO}_{2}$ is through surface complex forming. The different properties of pharmaceuticals affect the surface complex and will lead to different performances of adsorption.

The performance of pharmaceutical adsorption to $\mathrm{Fe}(\mathrm{III})$ has been evaluated by previous studies [26, 61, 358]. Two human-used macrolide antibacterial agents, clarithromycin and roxithromycin, are strongly adsorbed $(>90 \%)$ to $\mathrm{Fe}(\mathrm{III})$ in the form of ferrihydrate. This is probably due to the macrolide antibacterial agents that can form a complex on the surface of $\mathrm{Fe}(\mathrm{III})^{[61]}$. Due to the different properties of pharmaceuticals, the ability to form a complex with $\mathrm{Fe}(\mathrm{III})$ is different for each pharmaceutical, which leads to selective adsorption. The results indicate that the efficiency of adsorption is closely related to the process condition. For example, at weakly acidic $\mathrm{pH}(\sim 6)$, the highest adsorption is achieved due to changes in the Fe(III) surface chemistry, thus making Fe(III) more selective for the carboxylic group of the investigated pharmaceuticals such as ${ }^{[358]}$. 
Nanoparticles and nanoscale materials including nano Fe species can also remove pollutants by adsorption. Due to their small size, ranging from 10 to $100 \mathrm{~nm}$, and large specific surface area, nanoscale materials such as nanoscale zero-valent iron (nZVI) can efficiently remove pharmaceuticals via adsorption ${ }^{[138]}$. For example, nZVI adsorption can contribute to the removal of carbamazepine ${ }^{[277]}$, amoxicillin, and ampicillin ${ }^{[76]}$. Supportive materials such as polyethylene glycol (PEG) and zeolite are used to improve the performance of nZVI as an adsorbent. Results show 10\% more amoxicilline removal and 30\% more ampicilline removal by PEG-nZVI, while nearly $30 \%$ more ampicilline removal is found by zeolite-nZVI ${ }^{[76]}$. Another nanoscale Fe-related adsorbent in pharmaceutical removal is magnetic permanently confined micelle arrays (Mag-PCMAs), which has a magnetite core confined in a silica porous layer ${ }^{[104,331]}$. Pharmaceuticals including atenolol, gemfibrozil, and sulfamethoxazole can be absorbed and removed at $\mathrm{mg} \cdot \mathrm{L}^{-1}$ level by these Mag-PCMAs from water ${ }^{[104]}$. Magnetic iron oxide nanoparticles $\left(\mathrm{M}_{\mathrm{x}} \mathrm{Fe}_{3-\mathrm{x}} \mathrm{O}_{4}\right)$ are used to remove organic pollutants via adsorption, where $\mathrm{M}$ represents one or more components from $\mathrm{Fe}, \mathrm{Mn}$, $\mathrm{Co}, \mathrm{Li}, \mathrm{Ni}, \mathrm{Zn}$, etc. $\mathrm{MFe}_{2} \mathrm{O}_{4}(\mathrm{M}=\mathrm{Fe}, \mathrm{Mn}, \mathrm{Co}, \mathrm{Zn})$ can remove more than $96 \%$ of tetracycline, oxytetracycline, and chlortetracycline at $100 \mu \mathrm{g} \cdot \mathrm{L}^{-1}$ by adsorption within $5 \mathrm{~min}^{[12]}$. Incorporation of $\mathrm{M}_{\mathrm{x}} \mathrm{Fe}_{3-\mathrm{x}} \mathrm{O}_{4}$ into other chemicals like activated carbon (AC) can also be used to remove pharmaceuticals. For example, the maximum adsorption capacity of $\mathrm{MnFe}_{2} \mathrm{O}_{4} / \mathrm{AC}$ to sulfamethoxazole is $159 \mathrm{mg} \cdot \mathrm{g}^{-1}$ at $\mathrm{pH} 7^{[325]}$, and maximum adsorption of hierarchically porous $\mathrm{MgFe}_{2} \mathrm{O}_{4} / \gamma-\mathrm{Fe}_{2} \mathrm{O}_{3}$ magnetic microspheres to minocycline is $201 \mathrm{mg} \cdot \mathrm{g}^{-1}{ }^{[180]}$. Metal-organic framework (MOF) is a class of highly crystalline porous materials consisting of a metal ion and an organic linker molecule ${ }^{[136]}$. It is used to remove hazardous organics from water by adsorption and photocatalysis ${ }^{[136,332]}$. MIL-100-Fe is a type of Feorganic framework, and it is used in adsorption processes to remove pharmaceuticals including naproxen and clofibric acid ${ }^{[91]}$, as well as other organic pollutants like bisphenol $\mathrm{A}^{[110,242]}$. The adsorption capacity of MOF 
MIL-100-Fe can reach $100 \mathrm{mg} \cdot \mathrm{g}^{-1}$, which is even higher than granular activated carbon $\left(\sim 50 \mathrm{mg} \cdot \mathrm{g}^{-1}\right)^{[91]}$.

\subsubsection{Co-precipitation}

Coprecipitation is a process in which soluble compounds are removed by sequestration in a precipitating phase ${ }^{[218,240]}$. Pharmaceutical removal through coprecipitation is observed with Fe species including Fe corrosion products [63, 76, 218]. For example, amoxicillin and ampicillin can be sequestered by precipitation with $\mathrm{Fe}(\mathrm{OH})_{3}{ }^{[76]}$. Triazole, the raw material to produce antimycotic drugs such as terconazole, is also removed with zerovalent iron (ZVI) by co-precipitation ${ }^{[120,216]}$.

\subsubsection{Chemical removal}

In chemical removal of pharmaceuticals, $\mathrm{Mn}$ and Fe play important roles as oxidants, reductants, or catalysts such as Fe(II) in Fenton processes [31, 87, 140, 248, 271]. Chemical removal of pharmaceuticals in water treatment occurs through chemical oxidation via oxidizing agents (Fe(III), $\mathrm{Fe}(\mathrm{VI})$, $\mathrm{Mn}(\mathrm{IV}), \mathrm{Mn}(\mathrm{VII}))$ or chemical reduction via reducing agents like nZVI to

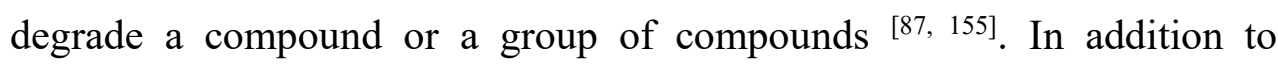
conventional oxidation processes, advanced oxidation processes (AOPs) including Fenton, photolysis, and ozonation are used to remove pharmaceuticals. In these processes, $\mathrm{Mn}$ and Fe species work as catalysts in the formation of free radicals such as hydroxyl radicals $\left(\mathrm{OH}^{\circ}\right)$ and sulfate radicals $\left(\mathrm{SO}_{4}{ }^{-}\right)$, which are used as strong oxidants to destroy organic compounds. 


\subsubsection{Chemical oxidation}

(1) Mn and Fe as oxidants

$\mathrm{Mn}(\mathrm{VII})$ and $\mathrm{Mn}(\mathrm{IV})$ are used to remove pharmaceutical compounds and other pollutants in water and wastewater due to their high standard redox potential $(+1.23 \mathrm{~V}$ for $\mathrm{Mn}(\mathrm{IV})$ and $+1.52 \mathrm{~V}$ for $\mathrm{Mn}(\mathrm{VII})$, see Figure 2.1(a) ${ }^{[69,93,163,200,248,312]}$. Permanganate $\left(\mathrm{MnO}_{4}^{-}\right)$can be used to remove pharmaceuticals and other micropollutants containing electron-rich moieties [87, 96]. One study found that ciprofloxacin, lincomycin, and trimethoprim are removed in a second-order reaction from drinking water by $\mathrm{Mn}(\mathrm{VII})$, with rate constants of $0.61,1.6,3.6 \mathrm{M}^{-1} \cdot \mathrm{s}^{-1}$, respectively ${ }^{[102,103]}$. In a second study, more than $90 \%$ of sulfamethoxazole at concentrations between 0.5 and $5 \mathrm{mg} \cdot \mathrm{L}^{-1}$ is removed with $2 \mathrm{mg} \cdot \mathrm{L}^{-1} \mathrm{Mn}$ (VII) at $\mathrm{pH} 7{ }^{\text {[70] }}$. $\mathrm{Mn}$ (VII) is also used to oxidize nonsteroidal anti-inflammatory drugs ibuprofen, diclofenac, naproxen, ketoprofen, fenoprofen, indomethacime, and salicylic acid ${ }^{[256]}$. Results showed diclofenac and indomethacime were completely removed, while the others decrease less than $30 \%{ }^{[256]}$.

$\mathrm{Mn}(\mathrm{IV})(+1.23 \mathrm{~V})$ has a stronger oxidation potential than the $\mathrm{Fe}(\mathrm{III})$ $(+0.77 \mathrm{~V})$. This is observed in the faster transformation of clarithromycin and roxithromycin by $\mathrm{Mn}(\mathrm{IV})$, which has a $2-3$ times higher reaction rate

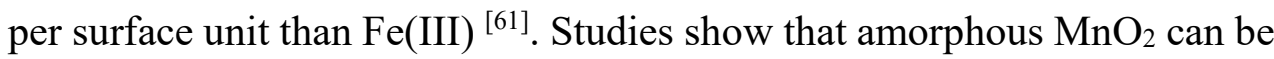
used to remove pharmaceuticals such as carbamazepine, sulfamethazine, and diclofenac $[69,93,163,200,312]$. This chemical removal process is $\mathrm{pH}$ dependent, and effective when $\mathrm{pH}<6^{[69,93]}$. Over $70 \%$ of diclofenac at about $3 \mathrm{mg} \cdot \mathrm{L}^{-1}$ is removed by oxidation in a $\mathrm{MnO}_{2}$ bed filter with amorphous $\mathrm{MnO}_{2}$ in natural environment, where adsorption of both parent compound and by-products of diclofenac oxidation is observed [108, 109]. Similarly, $95 \%$ of amoxicillin at around $360 \mathrm{mg} \cdot \mathrm{L}^{-1}$ is oxidised in 4 hours with $1 \times 1$ molecular sieve-structured $\mathrm{MnO}_{2}$ while only $4.5 \%$ of amoxicillin is removed by adsorption ${ }^{[146]}$. 

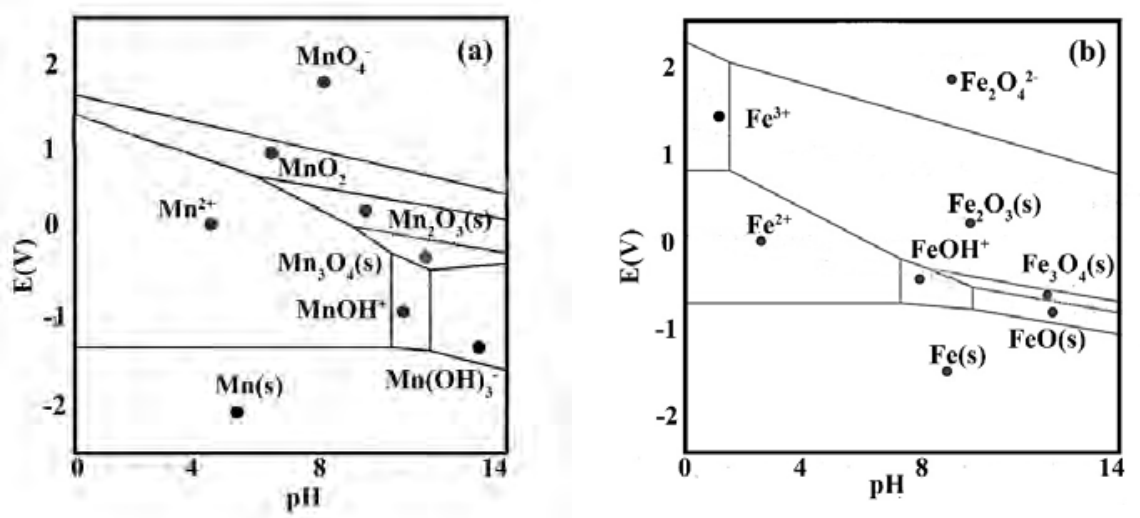

FIGURE 2.1 Eh-pH diagram for Metal in water at $25^{\circ} \mathrm{C}$ ((a) for Mn; (b) for Fe). Adapted from previous data ${ }^{[294]}$ using Material Project website ${ }^{[116]}$

In addition to $\mathrm{pH}$, other environmental parameters also affect chemical oxidation of pharmaceuticals by $\mathrm{MnO}_{2}$. For instance, $\mathrm{MnO}_{2}$ oxidation is negatively influenced by cosolute compounds, such as metal ions and natural organic compounds which inhibit the chemical reaction by occupying the reactive surface site of $\mathrm{MnO}_{2}[93,96,167,360]$. In addition, reactant loading has influence on this oxidation process. For example, loading for triclosan, ciprofloxacin, and carbadox has no effect on reaction rate constants because of the fixed number of reactive surface sites on $\mathrm{MnO}_{2}$ surface ${ }^{[359]}$. In contrast, higher loading for tetracycline leads to lower reaction rate constants because of the self-competition for the same reactive surface sites of $\mathrm{MnO}_{2}{ }^{[359]}$.

Most studies using $\mathrm{MnO}_{2}$ to remove pharmaceuticals are carried out under aerobic condition. There are only two published studies using anaerobic condition as control group. Results show that anaerobic condition has no influence on fluoroquinolone removal ${ }^{[361]}$ while it can inhibit the sulfamethazine removal ${ }^{[69]}$. 
$\mathrm{Fe}(\mathrm{III}), \mathrm{Fe}(\mathrm{V})$ and $\mathrm{Fe}(\mathrm{VI})$ are used to oxidize pharmaceuticals from water, including tetracycline, clarithromycin, and roxithromycin ${ }^{[328]}$. Both $\mathrm{Fe}(\mathrm{V})$ and $\mathrm{Fe}(\mathrm{VI})$ have a higher standard redox potential of $+2.2 \mathrm{~V}$ under acidic $\mathrm{pH} 4-5$ than under neutral pH 7 (Figure 2.1(b)) ${ }^{[34,122,123]}$. These ferrate compounds can react with pharmaceuticals which contain electronrich moieties ${ }^{[121,124,155,349]}$, which leads to the formation of nontoxic byproducts and $\mathrm{Fe}(\mathrm{III}){ }^{[121,274]}$. The removal efficiency varies for the different compounds at $10-100 \mu \mathrm{g} \cdot \mathrm{L}^{-1}$ were: ciprofloxacin $>60 \%$, naproxen $>40 \%$, and n-acetyl sulphamethoxazole $<10 \%{ }^{[121,124,349]}$. In addition, $88 \%$ removal efficiencies were achieved for selected pharmaceuticals and other micropollutants by combining oxidation, and flocculation and coagulation with $\mathrm{Fe}(\mathrm{VI}){ }^{[349]}$. Owing to the high standard redox potential of $\mathrm{Fe}(\mathrm{III})$ species $(+0.770 \mathrm{~V}$, Figure $2.1(\mathrm{~b}))$, the removal of tetracycline antibiotics, including tetracycline, oxytetracycline, and chlorotetracycline, with Fe(III) is $2-20$ times higher than without Fe(III) ${ }^{[328]}$. This process is influenced by pharmaceutical concentrationas well as the concentration of Fe(III) ${ }^{[328]}$. At $\mathrm{pH} 7$ and $20^{\circ} \mathrm{C}$, increasing of initial tetracycline concentration caused a decrease in the reaction rate, while increasing the initial Fe(III) concentration resulted in an increases in the reaction rate.

(2) Mn and Fe as catalysts

Mn can function as catalyst to remove pharmaceuticals. Manganese oxide supported or doped by other compounds has been used in catalytic ozonation process. Alumina-supported manganese oxide suspension is used as catalyst in ozonation to remove phenazone, ibuprofen, diphenhydramine, phenytoin, and diclofenac. Results show that more than $90 \%$ TOC of pharmaceuticals mixture is removed with alumina-supported manganese oxide whereas only $20 \%$ is removed without a catalyst ${ }^{[350]}$. Carbon nanotube-supported manganese oxides are used to assist ozone to remove ciprofloxacin. Ciprofloxacin removal increases within $15 \mathrm{~min}$ from $26.7 \%$ of $10 \mathrm{mg} \cdot \mathrm{L}^{-1}$ to $87.5 \%$ when the catalyst was added ${ }^{[296]}$. $\mathrm{MnO}_{2}-\mathrm{CuO} / \gamma-\mathrm{Al}_{2} \mathrm{O}_{3}$ catalyst is also used to remove ibuprofen in ozonation ${ }^{[21]}$. Ibuprofen 
removal increases from $27 \%$ of $5 \mathrm{mg} \cdot \mathrm{L}^{-1}$ to $55 \%$ in the presence of the catalyst. A novel Ce-doped manganese oxide octahedral molecular sieve is generated recently and used as a catalyst in ozonation ${ }^{[365]}$. 81\% ciprofloxacin of $10 \mathrm{mg} \cdot \mathrm{L}^{-1}$ was removed in the ozonation process with the catalyst. Both Mn-Ce-O catalyst prepared in the laboratory and commercial Fe-Mn-O catalyst are used in catalytic ozonation process and show similar catalytic capacity ${ }^{[195]}$. Approximately $60 \%$ COD of the mixture of sulfamethoxazole and diclofenac is removed in the presence of either catalyst within $120 \mathrm{~min}$. Tetracycline can complex with dissolved $\mathrm{Mn}^{2+}$ ions, thus improving tetracycline removal by oxygen. At $\mathrm{pH} 8-9.5$, over $90 \%$ removal of tetracycline is achieved in $\mathrm{Mn}^{2+}$-mediated system, and the reactivity trend is as follows: oxytetracycline $>$ tetracycline $>>$ isochlorotetracycline ${ }^{[35]}$.

In classic Fenton's reagent $\left(\mathrm{Fe} / \mathrm{H}_{2} \mathrm{O}_{2}\right.$ system), a mixture of $\mathrm{Fe}(\mathrm{II})$ and hydrogen peroxide generates $\mathrm{OH}^{\bullet}$ (Figure 2.2) ${ }^{[212,238]}$. $\mathrm{OH}^{\bullet}$ can oxidize pharmaceuticals ${ }^{[10,111,160]}$ together with another oxidant produced in the process, for instance $\mathrm{Fe}(\mathrm{IV})$ species at $\mathrm{pH}>5$ (Equation 2.1) ${ }^{[107,221]}$. For example, more than $90 \%$ berberine at around $1000 \mathrm{mg} \cdot \mathrm{L}^{-1}$ and over $70 \%$ metronidazole at $1 \mathrm{mg} \cdot \mathrm{L}^{-1}$ are removed in $\mathrm{Fe} / \mathrm{H}_{2} \mathrm{O}_{2}$ oxidation systems ${ }^{[44,275]}$. In addition, nearly complete removal of paracetamol, chloramphenicol, and diclofenac is obtained ${ }^{[10]}$. In Fenton's reaction, ethylenediaminetetraacetic acid (EDTA) is used to improve the removal performance ${ }^{[15,133,150,375]}$. The complex of $\mathrm{Fe}(\mathrm{II})$ and EDTA reduces dissolved $\mathrm{O}_{2}$ and produces $\mathrm{H}_{2} \mathrm{O}_{2}$ and $\mathrm{OH}^{\bullet}[15,150]$. In addition, the presence of EDTA enhances the Fe(III) solubility, thus preventing $\mathrm{Fe}(\mathrm{III})$ precipitation as well as possible $\mathrm{Fe}(\mathrm{II})$ coprecipitation with Fe(III) ${ }^{[15,133]}$. Additional flocculation and coagulation by $\mathrm{Fe}(\mathrm{III})$ improves removal in Fenton's reaction ${ }^{[302]}$.

$$
\mathrm{Fe}(\mathrm{II})+\mathrm{H}_{2} \mathrm{O}_{2} \longrightarrow \mathrm{Fe}(\mathrm{IV})\left(\text { e.g. } \mathrm{FeO}^{2+}\right)+\mathrm{H}_{2} \mathrm{O}
$$


Other Fe species or compounds containing Fe can work as catalysts in Fenton's reactions. In these processes, pharmaceuticals and other micropollutants can be removed via oxidation ${ }^{[48,270,277]}$. For example, ZVI and nZVI are used as a catalyst in Fenton's reaction with $\mathrm{H}_{2} \mathrm{O}_{2}$ to remove pharmaceuticals [270, 277] and other pollutants [145, 159, 271]. Under acidic conditions ( $\mathrm{pH}<3$ ), ZVI is oxidized to Fe(II) on the surface of the metal and then $\mathrm{Fe}(\mathrm{II})$ catalyzes the Fenton process. In the presence of $1.2 \mathrm{~g} \cdot \mathrm{L}^{-1}$ ZVI, $3.2 \mathrm{~g} \cdot \mathrm{L}^{-1} \mathrm{H}_{2} \mathrm{O}_{2}$, and $0.1 \mathrm{~g} \cdot \mathrm{L}^{-1}$ total organic carbon (TOC), $80 \%$ of a mixture of pharmaceuticals and other organic pollutants are removed in 1 hour from pharmaceutical wastewater with a $\mathrm{pH}$ of $3^{[270]}$. Similarly, carbamazepine can be totally removed from both distilled water and groundwater with $20 \mathrm{mg} \cdot \mathrm{L}^{-1} \mathrm{nZVI}$ and $25 \mathrm{mg} \cdot \mathrm{L}^{-1} \mathrm{H}_{2} \mathrm{O}_{2}{ }^{[277]}$.

Furthermore, the Fenton's reaction can be enhanced by ultravioletvisible photo, electronic, and ultrasonic irradiation ${ }^{[8,9]}$, which are photo/ $\mathrm{Fe} / \mathrm{H}_{2} \mathrm{O}_{2}$ system, electro/ $\mathrm{Fe} / \mathrm{H}_{2} \mathrm{O}_{2}$ system, and sono $/ \mathrm{Fe} / \mathrm{H}_{2} \mathrm{O}_{2}$ system, respectively. In the photo/ $\mathrm{Fe} / \mathrm{H}_{2} \mathrm{O}_{2}$ system, it is reported that a wavelength below $254 \mathrm{~nm}$, or higher than $300 \mathrm{~nm}$ enhances the photolysis of $\mathrm{Fe}$ (III) to $\mathrm{Fe}(\mathrm{II})$ (Figure 2.2) ${ }^{[47,311,316]}$. Via photo/ $\mathrm{Fe} / \mathrm{H}_{2} \mathrm{O}_{2}$ system, completely removal of $16 \mathrm{mg} \cdot \mathrm{L}^{-1}$ metoprolol and $17.6 \mathrm{mg} \cdot \mathrm{L}^{-1}$ atenolol are obtained within $150 \mathrm{~min}{ }^{[316]}$, while $76 \%$ of $10 \mathrm{mg} \cdot \mathrm{L}^{-1}$ sulfamethoxazole is removed within 7 hours ${ }^{[311]}$.

Electro- $\mathrm{Fe}(\mathrm{II}) / \mathrm{H}_{2} \mathrm{O}_{2}$ system is another advanced process in which $\mathrm{H}_{2} \mathrm{O}_{2}$ is generated continuously if sufficient $\mathrm{O}_{2}$ is present at a suitable cathode (Equation 2.2, Figure 2.2) ${ }^{[27]}$. In addition, the production of $\mathrm{OH}^{\cdot}$ is accelerated by the regeneration of $\mathrm{Fe}$ (II) from soluble $\mathrm{Fe}(\mathrm{III})$ (Equation 2.3).

$$
\begin{aligned}
& \mathrm{O}_{2}(\mathrm{~g})+2 \mathrm{H}^{+}+2 \mathrm{e}^{-} \longrightarrow \mathrm{H}_{2} \mathrm{O}_{2} \\
& \mathrm{Fe}^{3+}+\mathrm{e}^{-} \longrightarrow \mathrm{Fe}^{2+}
\end{aligned}
$$




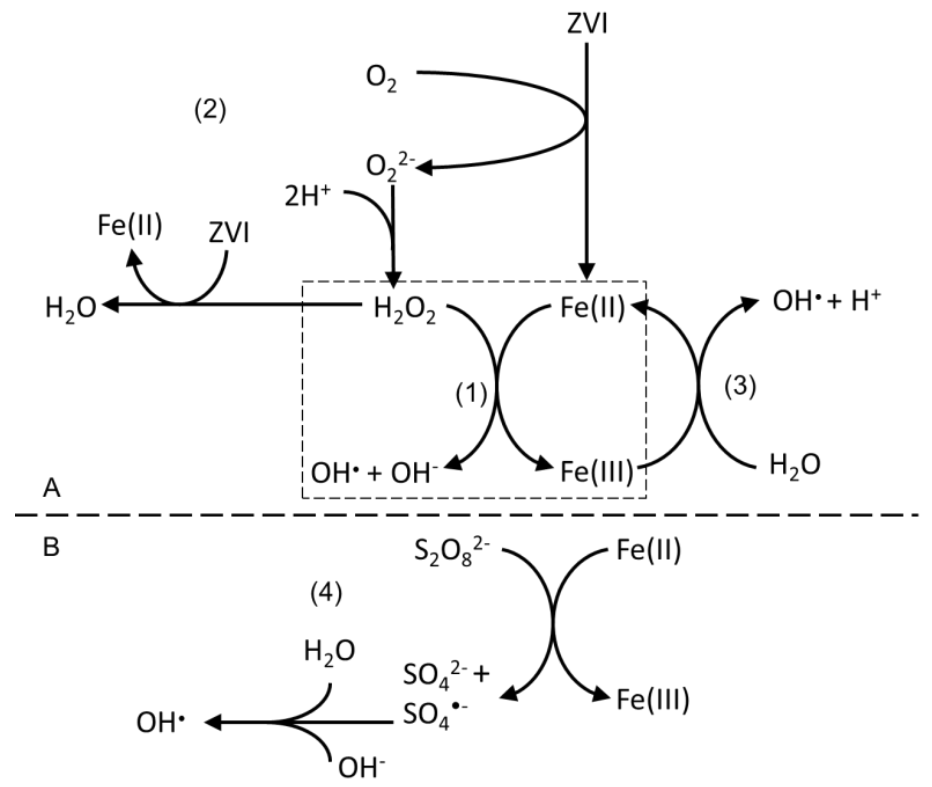

FIGURE 2.2 Activated species generated in Fe-based advanced oxidation processes (AOPs) where (A) is for $\mathrm{OH}^{*}$ based AOPs ${ }^{[48,90,212,238]}$ and (B) is for $\mathrm{SO}_{4}{ }^{--}$based AOPs ${ }^{[75,119]},(1)$ generated activated species from $\mathrm{Fe} / \mathrm{H}_{2} \mathrm{O}_{2}$, photo/Fe/ $\mathrm{H}_{2} \mathrm{O}_{2}$, electro $/ \mathrm{Fe} / \mathrm{H}_{2} \mathrm{O}_{2}$, sono/ $/ \mathrm{Fe} / \mathrm{H}_{2} \mathrm{O}_{2}$, etc.; (2) generated activated species from $\mathrm{ZVI} / \mathrm{O}_{2}$; (3) generated activated species from photo degradation, electro degradation, sono degradation, etc.; (4) generated activated species from $\mathrm{Fe} /$ persulfate

Experiments with electro $/ \mathrm{Fe} / \mathrm{H}_{2} \mathrm{O}_{2}$ system indicate that this process is efficient for pharmaceutical removal $[114,224,282]$. For example, 40\% mineralization of atenolol at $158 \mathrm{mg} \cdot \mathrm{L}^{-1}{ }^{[114]}$ and nearly $30 \%$ mineralization of ranitidine at $33.8 \mathrm{mg} \cdot \mathrm{L}^{-1}{ }^{[224]}$ are obtained. Additionally, a combination of photo and electro irradiation for photo- electro/ $\mathrm{Fe} / \mathrm{H}_{2} \mathrm{O}_{2}$ system increases the performance in pharmaceutical removal even further ${ }^{[114,224]}$. Results showed the complete removal of atenolol and $80 \%$ mineralization of ranitidine by photo-electro/ $\mathrm{Fe} / \mathrm{H}_{2} \mathrm{O}_{2}$ system with solar radiation. This is due to (1) the production of more $\mathrm{OH}^{*}$ than photo/ $/ \mathrm{Fe} / \mathrm{H}_{2} \mathrm{O}_{2}$ system or electro/ $\mathrm{Fe} / \mathrm{H}_{2} \mathrm{O}_{2}$ system alone (Figure 2.2), and (2) the regeneration of $\mathrm{Fe}(\mathrm{II})$ also contributes to the removal ${ }^{[114,224]}$. Sono $/ \mathrm{Fe} / \mathrm{H}_{2} \mathrm{O}_{2}$ system has been employed to remove pharmaceuticals as ultrasonic irradiation improves the Fenton's reaction. Complete removal of levofloxacin is obtained by sono/ $\mathrm{Fe} / \mathrm{H}_{2} \mathrm{O}_{2}$ system in the presence of $\mathrm{Fe}_{3} \mathrm{O}_{4}$ magnetic nanoparticles ${ }^{[336]}$. 
Persulfate can be activated at $\mathrm{pH} 6$ by different Fe species, such as ZVI, $\mathrm{Fe}(\mathrm{II})$, and $\mathrm{Fe}_{3} \mathrm{O}_{4}$. This process generates free $\mathrm{SO}_{4}{ }^{-}$as well as other active species, such as $\mathrm{OH}^{*}$ (Figure 2.2) ${ }^{[75,119,347]}$. Standard redox potential of $\mathrm{SO}_{4}{ }^{-}$ is $+2.6 \mathrm{~V}$, which is similar to $\mathrm{OH}^{\cdot}$ with $+2.72 \mathrm{~V}^{[211]}$. Sulfate radical-based advanced oxidation processes (SR-AOPs) are new methods to oxidize

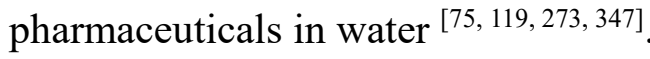

In previous studies, Fe-activated persulfate has been used to remove pharmaceuticals. Fe(II)-activated persulfate oxidation removes 50\% carbamazepine at $6 \mathrm{mg} \cdot \mathrm{L}^{-1}{ }^{[245]}$, and $96 \%$ ciprofloxacin and $75 \%$ sulfamethoxazole both at $7.6 \mathrm{mg} \cdot \mathrm{L}^{-1}{ }^{[119]}$. In micrometric ZVI-activated persulfate oxidation, $10 \mathrm{mg} \cdot \mathrm{L}^{-1}$ sulfamethoxazole is completely removed after $60 \mathrm{~min}{ }^{[75]}$. Additionally, more than $90 \%$ removal efficiency of sulfamonomethoxine at $16.8 \mathrm{mg} \cdot \mathrm{L}^{-1}$ is observed with $\mathrm{Fe}_{3} \mathrm{O}_{4}$-activated persulfate oxidation ${ }^{[347]}$. Together with simulated solar light irradiation, complete removal of carbamazepine is obtained by an Fe(II)/persulfate/UVVis system, in which persulfate is activated by Fe(II) ${ }^{[1]}$. Furthermore, Fe can activate peroxymonosulfate $\left(\mathrm{KHSO}_{5}, \mathrm{PMS}\right)$ to generate $\mathrm{SO}_{4}{ }^{\circ}$. One study shows that this Fe(II)-activated PMS can completely remove triclosan, sulfamethoxazole, and acetaminophen, which is more effective than Fe(II)activated persulfate under the same conditions ${ }^{[213]}$.

$\mathrm{MxFe}_{3-\mathrm{X}} \mathrm{O}_{4}$, including incorporation of $\mathrm{M}_{\mathrm{X}} \mathrm{Fe}_{3-\mathrm{X}} \mathrm{O}_{4}$ to other chemicals, has also been used in catalytic oxidation processes to remove pharmaceuticals. A new synthetic material, core-shell structured $\mathrm{Fe}_{3} \mathrm{O}_{4} / \alpha$ $\mathrm{MnO}_{2}$ microspheres $\left(\mathrm{Fe}_{3} \mathrm{O}_{4} / \alpha-\mathrm{MnO}_{2}\right)$, is used to remove pharmaceuticals via catalytic oxidation with persulfate. In one previous study, removal is observed for ciprofloxacin: $90 \%$ of $50 \mathrm{mg} \cdot \mathrm{L}^{-1}$ by $\mathrm{Fe}_{3} \mathrm{O}_{4} / \alpha-\mathrm{MnO}_{2}$-activated persulfate, $80 \%$ by $\alpha-\mathrm{MnO}_{2}$-activated persulfate, and almost $30 \%$ by $\mathrm{Fe}_{3} \mathrm{O}_{4}$ activated persulfate ${ }^{[370]}$. 
Similarly to Fenton's reaction, Fe can work as a catalyst in other advanced oxidation processes including photo degradation, sono degradation, and ozonation. However, as opposed to Fenton or Fenton-like processes, these AOPs do not use $\mathrm{H}_{2} \mathrm{O}_{2}$ to generate $\mathrm{OH}^{\cdot[5,31,51,112]}$. Fe-ZnO is used in catalytic photo degradation, catalytic sono degradation, and catalytic photo-sono degradation, in which irradiation of ultrasonic frequencies or/and visible light can generate reactive radicals from water through forming vapor cavities ${ }^{[187]}$. Results show that the removal rates for diclofenac increase in the following order: catalytic photo degradation $\left(0.4 \times 10^{-7} \mathrm{M} \cdot \mathrm{min}^{-1}\right)<$ catalytic sono degradation $\left(14.3 \times 10^{-7} \mathrm{M} \cdot \mathrm{min}^{-1}\right)<$ catalytic photo-sono degradation $\left(15.3 \times 10^{-7} \mathrm{M} \cdot \mathrm{min}^{-1}\right)^{[187]}$.

Even without $\mathrm{H}_{2} \mathrm{O}_{2}$, ZVI can catalyse processes in the presence of $\mathrm{O}_{2}$ (Figure 2.2) ${ }^{[15,48,84]} .96 \%$ diazepam at $25 \mathrm{mg} \cdot \mathrm{L}^{-1}$ is removed by the $\mathrm{ZVI} / \mathrm{O}_{2}$ system after $60 \mathrm{~min}$. Moreover, $60 \%$ diazepam is mineralized ${ }^{[15]}$. However, complexation of Fe may increase yield of $\mathrm{H}_{2} \mathrm{O}_{2}$ and change the nature of the reactive oxidant such as $\mathrm{Fe}(\mathrm{V})^{[133]}$.

Ozonation effectively removes pharmaceuticals because ozone is a strong oxidant with a standard redox potential of $+2.08 \mathrm{~V}^{[17,105]}$. Fe species are used in catalytic ozonation process and showed a high, stable catalytic activity ${ }^{[183]}$. Removal efficiencies of more than $90 \%$ of herbicides and pharmaceuticals were achieved within 40 min with magnetic cobalt-doped $\mathrm{Fe}_{3} \mathrm{O}_{4}(\mathrm{FeCo})$, whereas less than $40 \%$ is removed without the catalyst. Hematite $\left(\alpha-\mathrm{Fe}_{2} \mathrm{O}_{3}\right)$ and $\mathrm{Fe}_{3} \mathrm{O}_{4}$ show catalytic activity in ozonation as well. The order of catalytic activity is $\mathrm{FeCo}>\mathrm{Fe}_{3} \mathrm{O}_{4}>\alpha-\mathrm{Fe}_{2} \mathrm{O}_{3}{ }^{[184]}$. 


\subsubsection{Chemical reduction}

Chemical reduction is often used to remove pollutants such as heavy metals ${ }^{[320]}$ and nitrate ${ }^{[100]}$. However, its application for pharmaceutical removal has not been extensively studied. During chemical reduction, pharmaceuticals receive electrons from other chemical compounds. For example, (n)ZVI can reduce pharmaceuticals, resulting in the oxidation of Fe; this occurs alone or in conjunction with other removal processes such as adsorption [76, 217, 247, 277, 376]. Previous studies showed that pharmaceutical compounds with certain functional groups (such as $\mathrm{C}-\mathrm{N}, \mathrm{N}=\mathrm{N}$, nitro or halogens) can be reduced by (n)ZVI via chemical reduction ${ }^{[247]}$. Results indicated rapid reduction of amoxicillin and ampicillin, while less than $12.6 \%$ removal of carbamazepine is observed [76]. Diazepam is removed by chemical reduction for almost $65 \%{ }^{[15]}$. In addition, complete removal of chloramphenicol is obtained ${ }^{[344]}$.

\subsubsection{Biological-related removal}

There are pharmaceutical removal processes related to the metalrelated activity of different types of microorganisms, including bacteria and fungi ${ }^{[130,225]}$. In these processes, microorganisms can produce $\mathrm{Mn}-$ or Feoxides, which are used to remove pharmaceuticals by chemical oxidation. In addition, bacteria or fungi can work in advanced oxidation together with Fe which is known as biologically catalyzed advanced oxidation ${ }^{[86,192]}$.

Biogenic Mn oxides (bioMnOx, also known as Mn bio-oxides) can efficiently remove pharmaceuticals ${ }^{[64,67]}$ and other pollutants ${ }^{[97,202]}$. These bioMnOx are produced by oxidation of $\mathrm{Mn}$ (II) by bacteria such as Pseudomonas putida MnB6 (BCCM/LMG 2322) and Bacillus sp. SG-1, or fungi ${ }^{[97,301]}$. Enrichment of $P$. putida which was used to generate bioMnOx was achieved under nitrifying conditions in a down flow sponge reactor with artificial wastewater ${ }^{[29]}$. As compared to synthetic $\mathrm{MnO}_{2}$, microbially produced bioMnOx has a unique structure, yielding a variety of advantages for oxidation. BioMnOx are reactive under neutral $\mathrm{pH}(\sim 7)$, instead of the 
acidic conditions required for abiotically produced $\mathrm{MnOx}[146,248]$. Additionally, the bacteria can bind the intermediate Mn(III) compounds via ligands, thus effectively increasing the oxidative power of a Mn-bacteria mixture ${ }^{[200]}$. As a result, diclofenac removal via adsorption and chemical oxidation with bioMnOx is 10-times faster than with synthetic $\mathrm{MnO}_{2}{ }^{[65]}$. Additionally, complete removal of ciprofloxacin ${ }^{[312]}$, and $17 \%$ removal of carbamazepine is obtained ${ }^{[64]}$. Studies also show that the performance will increase in the presence of trace metals, such as $\mathrm{Ag}$ or $\mathrm{Pb}$. The interaction between the metals and the microorganism cell leads to formation of reactive oxygen species ${ }^{[200]}$. These reactive species can improve the pharmaceutical removal ${ }^{[200,321]}$.

Manganese peroxidase $(\mathrm{MnP})$ is an extracellular enzyme from the lignin-degrading basidiomycetes fungi such as Phanerochaete chrysosporium, which can oxidize $\mathrm{Mn}^{2+}$ to $\mathrm{Mn}^{3+}$. $\mathrm{Mn}^{3+}$ can act as a mediator to oxidize phenolic compounds. The presence of $\mathrm{Mn}^{2+}$ also stimulates the $\mathrm{MnP}$ production and functions as a substrate for $\mathrm{MnP}$. The $\mathrm{MnP}$ is a key factor for fungi to remove pharmaceuticals including carbamazepine ${ }^{[80,265]}$. Recently, a crude MnP is produced by white-rot fungi Phanerochaete chrysosporium and used as a biocatalyst to remove tetracycline and oxytetracycline via enzymatic degradation ${ }^{[337]}$. Results show that $72.5 \%$ of $50 \mathrm{mg} \cdot \mathrm{L}^{-1}$ tetracycline and $84.3 \%$ of $50 \mathrm{mg} \cdot \mathrm{L}^{-1}$ oxytetracycline are removed at $40 \mathrm{U} \cdot \mathrm{L}^{-1}$ within $4 \mathrm{~h}$.

Biological Fenton-like system is a recently discovered biological advanced oxidation process in which radicals are generated in the presence of white-rot fungi Trametes versicolor. The biological Fenton-like reaction occurs in the presence of lignin-derived quinone (2,6,-dimethoxy-1,4benzoquinone, DBQ) and Fe(III) (Figure 2.3) ${ }^{[86,192]}$. In this process, DBQ is reduced to hydroquinone $\left(\mathrm{DBQH}_{2}\right)$ in the presence of an intracellular quinone reductase produced from the fungi, followed by the generation of semiquinone radicals (DBQ $\left.\bullet^{-}\right)$via subsequent oxidation of $\mathrm{DBQH}_{2}$ by lignin-modifying enzymes (laccases and peroxidases) which are also from 
the white-rot fungi. Fenton's reagent is formed by DBQ-- auto-oxidation catalyzed by $\mathrm{Fe}(\mathrm{III})$, and $\mathrm{OH}^{*}$ is produced via this cycling ${ }^{[81,193]}$. In this system, removal efficiencies of $80 \%$ were achieved for lofibric acid, carbamazepine, atenolol, and propranolol; more than $20 \%$ of the observed carbamazepine removal could be attributed to biological activity by this white-rot fungi ${ }^{[193]}$.

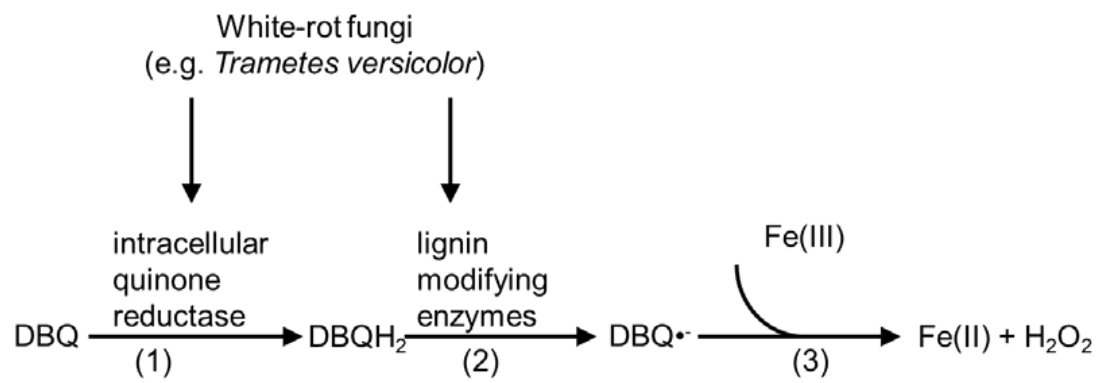

FIGURE 2.3 Biological Fenton's-like system catalysed by white-rot fungi ${ }^{[193]}$ (1) fungi catalyse the conversion of $\mathrm{BDQ}$ to $\mathrm{DBQH}_{2}$ by an intracellular quinone reductase from the fungi; (2) oxidation of $\mathrm{DBQH}_{2}$ to $\mathrm{DBQ} \bullet^{-}$by lignin modifying enzymes (laccases and peroxidases) from the white-rot fungi; (3) Fenton's reagent is formed by semiquinone radicals autoxidation catalyzed by $\mathrm{Fe}(\mathrm{III})$ 


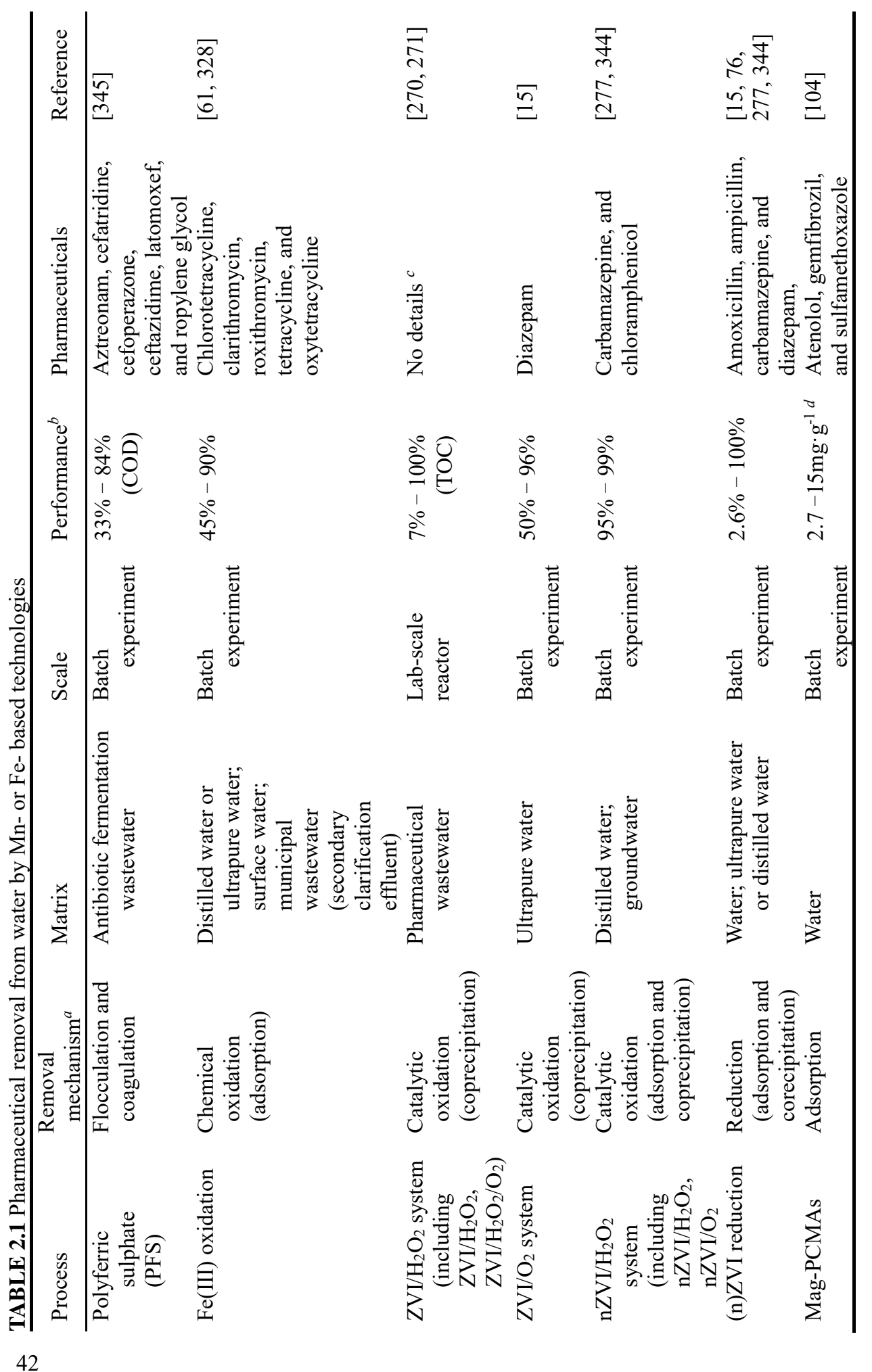




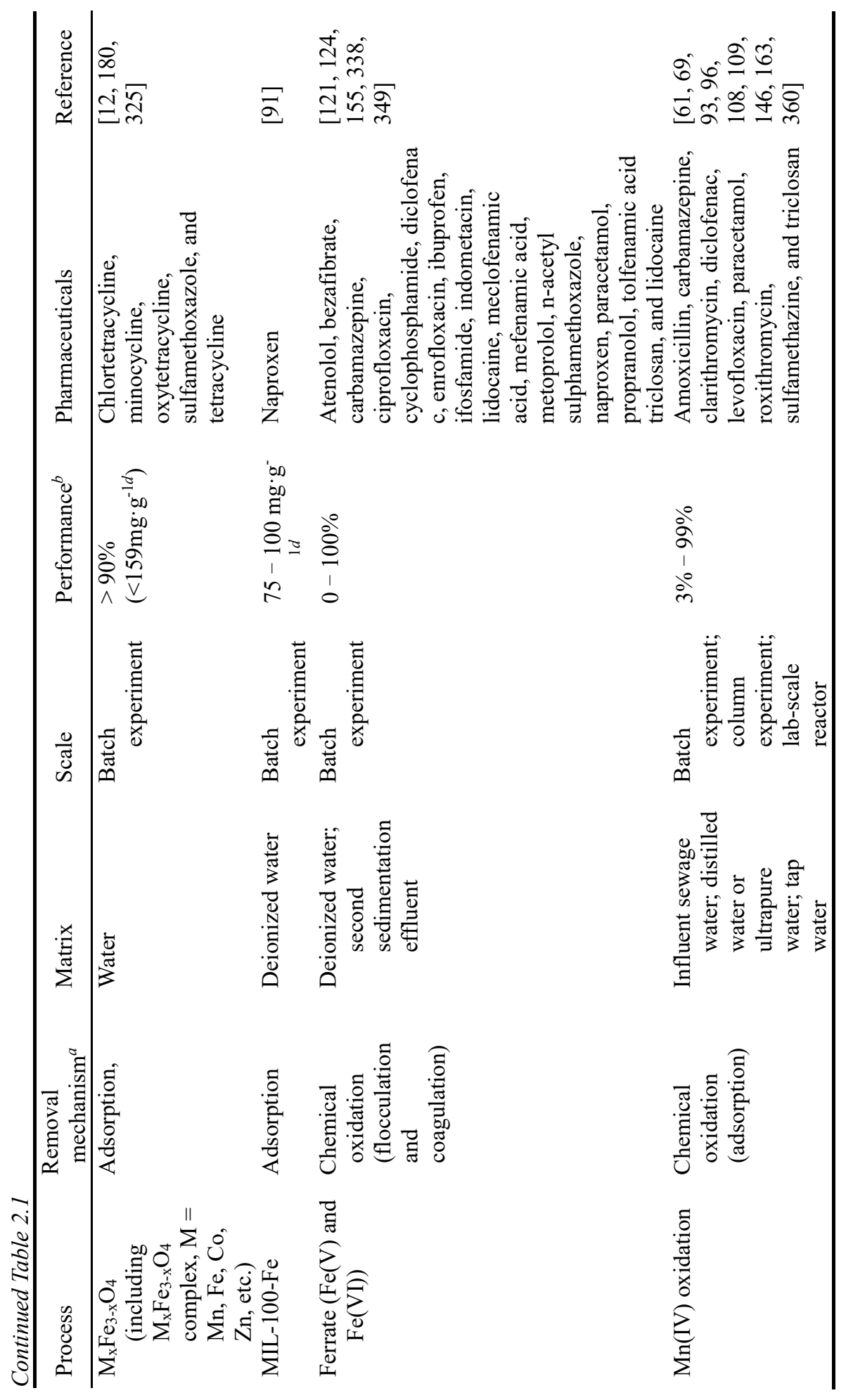




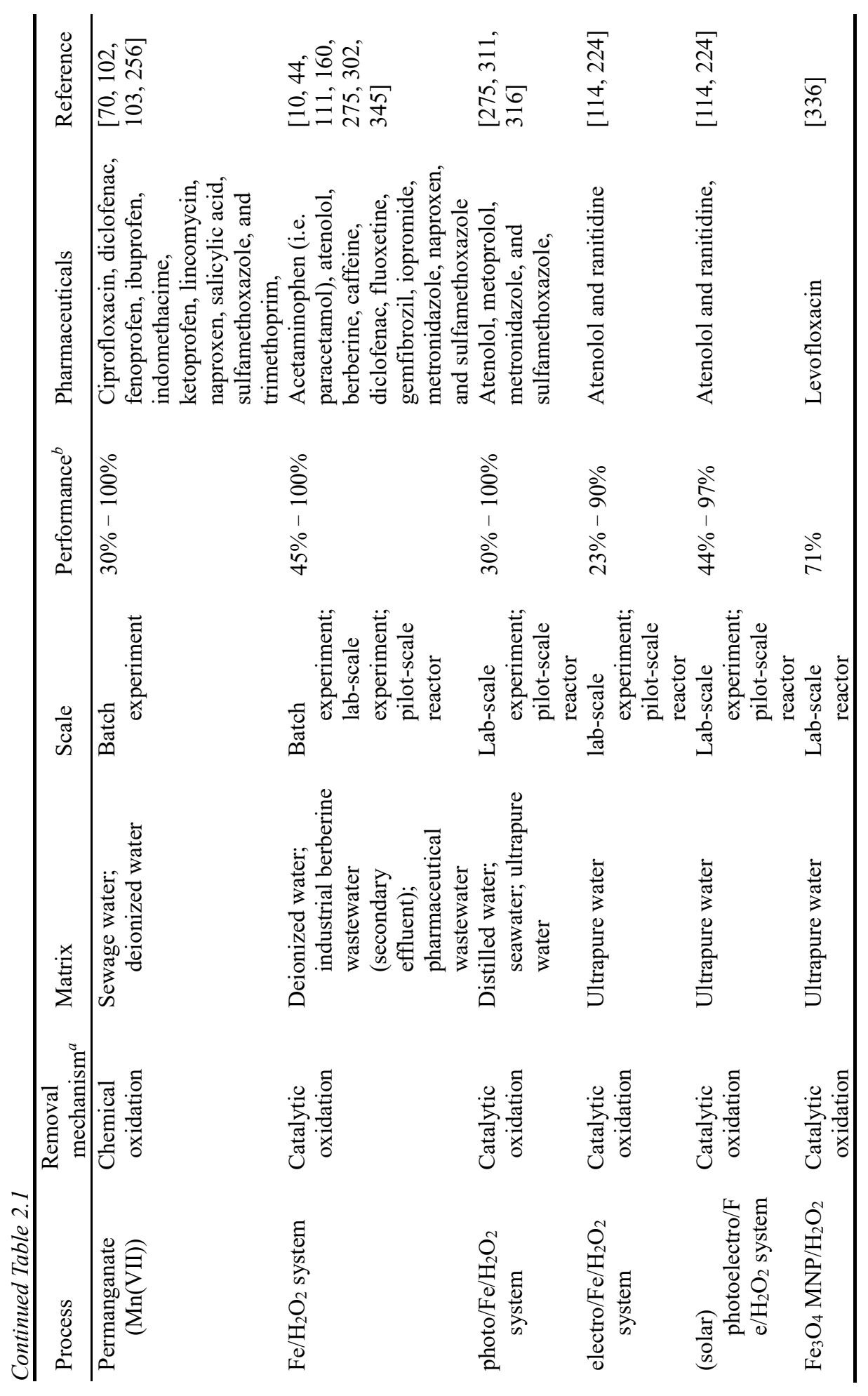




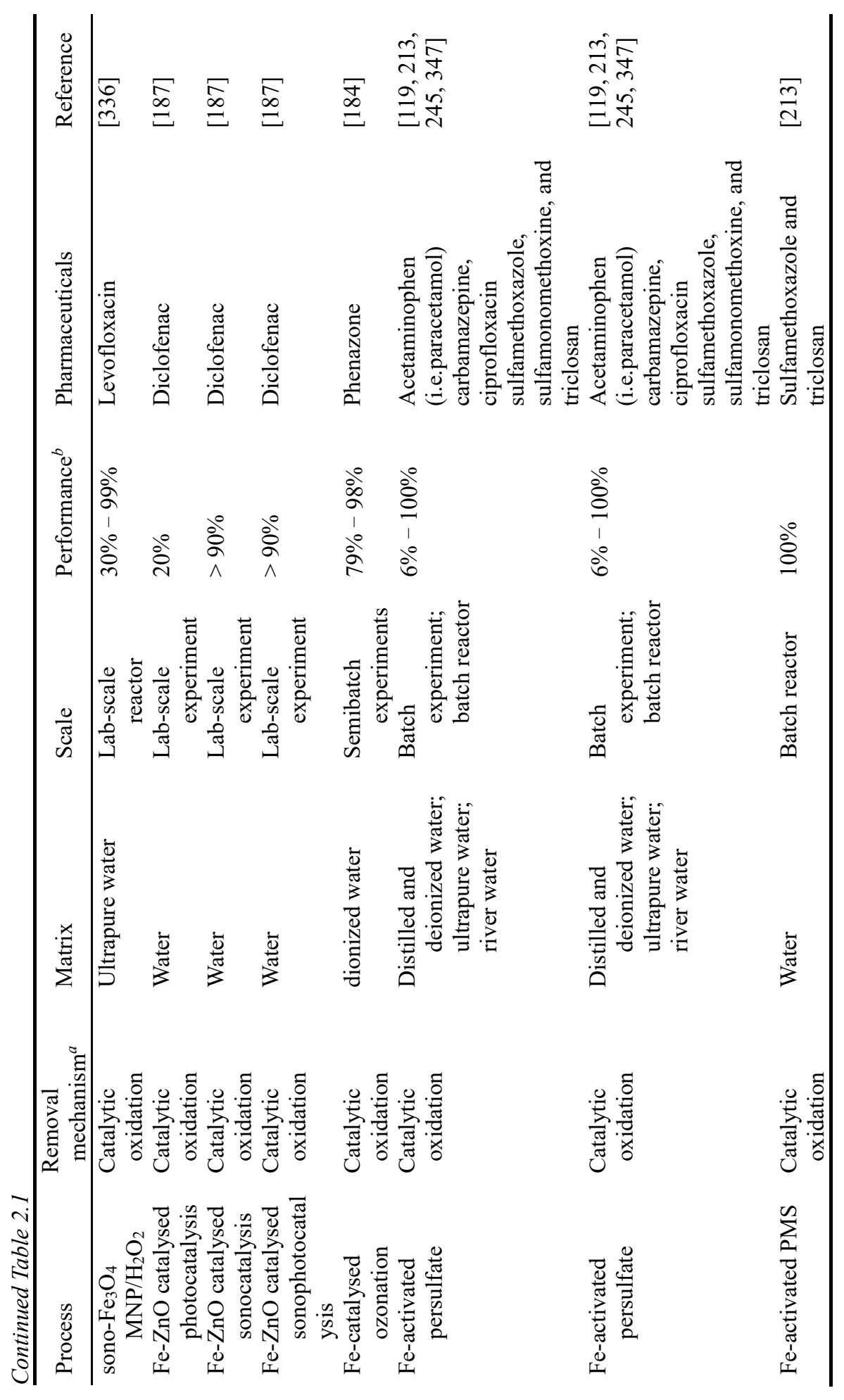




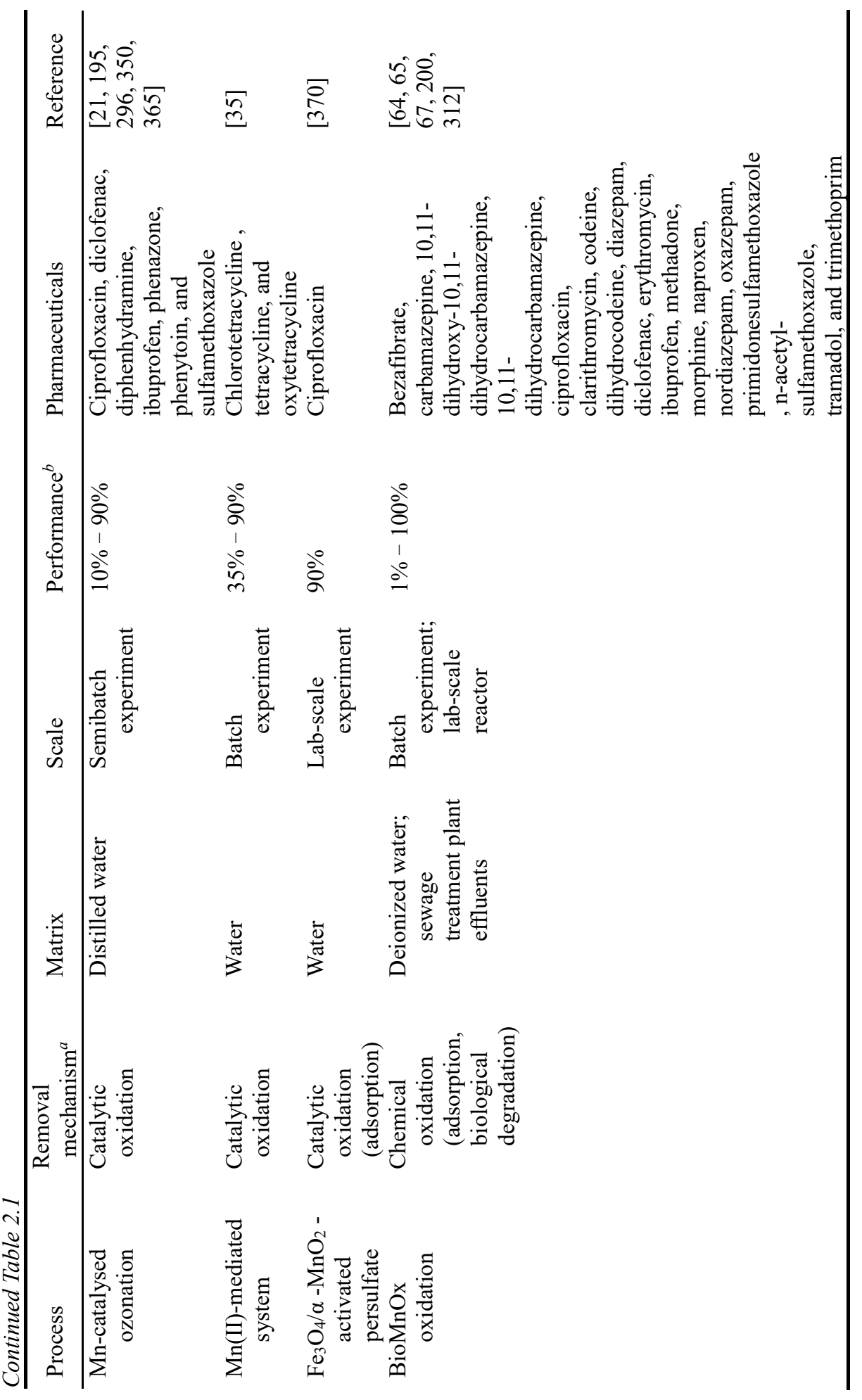




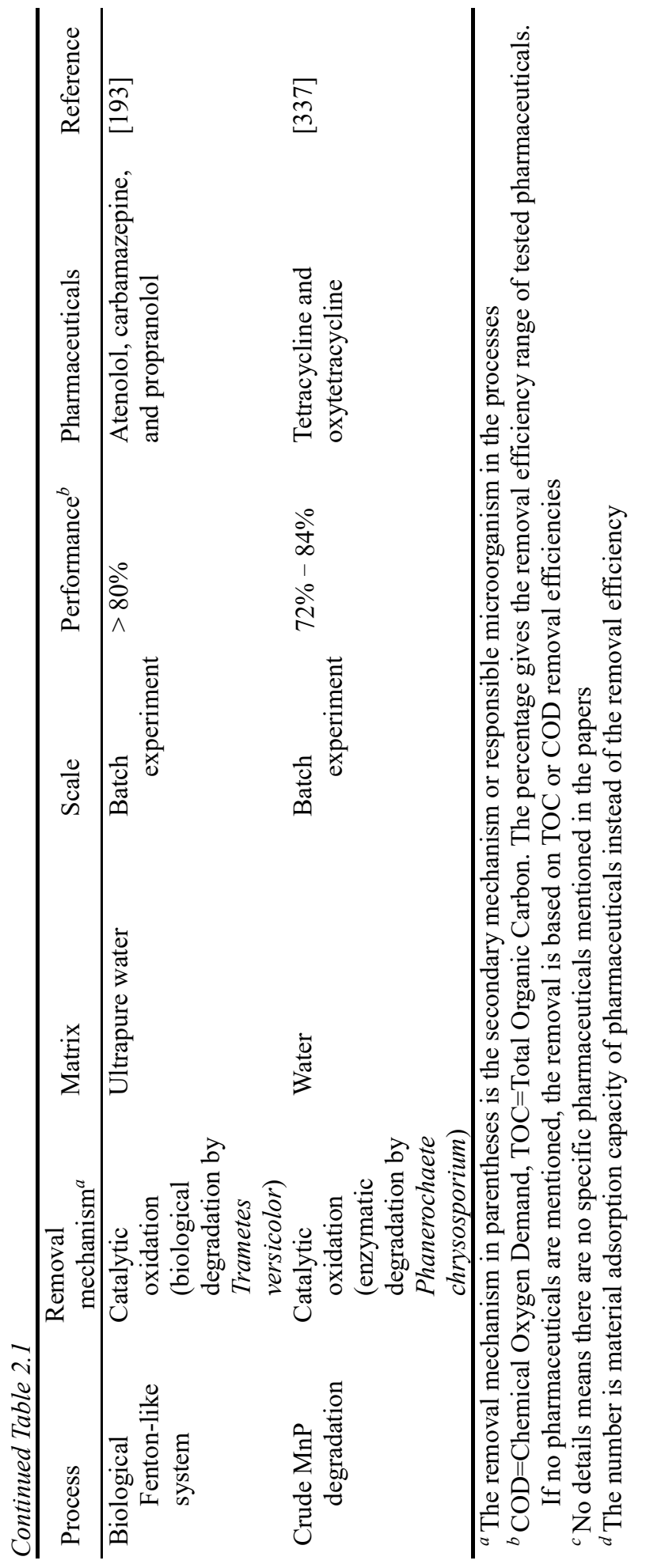




\subsection{Evaluation and discussion}

$\mathrm{Mn}$ - and Fe-based water treatment technologies have the potential to play important roles in pharmaceutical removal processes. However, there are some challenges to the direct application of available water technologies for the removal of pharmaceuticals. The four main challenges, including advantages and challenges, will be explained in detail in the section 2.3.1 2.3.4.

First of all, most described technologies are nonspecific, meaning that they can remove various pharmaceuticals as well as other pollutants. While this versatility can be an advantage, it can also lead to more consumption of reagents in order to also remove pharmaceuticals. Secondly, the high removal efficiency obtained with $\mathrm{Mn}$ - or Fe-based technologies require specific reaction conditions, which may result in more consumption of energy or chemicals. Finally, some Mn- or Fe-based technologies can oxidize the pharmaceuticals into by-products or intermediates. While these intermediates may be more biodegradable than the parent pharmaceutical, in some cases, these daughter compounds are either toxic or recalcitrant to further removal. Finally, the crystal structures and morphologies will also affect pharmaceutical removal performance. Additionally, using these Mnand Fe-based technologies will introduce Mn- or Fe-compounds into the environment. In general, the presence of Fe or $\mathrm{Mn}$ in the environment is safe. However, some compounds used in Mn- or Fe-based technologies such as nZVI or persulfate can be toxic to the native microorganisms.

In the following section, we will evaluate the positive and negative aspects of using the currently available Mn- or Fe-based technologies for pharmaceutical removal, highlighting the challenges of application but also the potential of these technologies. 


\subsubsection{Nonspecificity}

Many physico-chemical, chemical, and biologically related pharmaceutical removal processes with $\mathrm{Fe}$ or $\mathrm{Mn}$ are nonspecific. This improves the robustness and versatility of the technology, as most of these processes can remove various pharmaceuticals (Table 2.1). For example, $\mathrm{Fe} / \mathrm{H}_{2} \mathrm{O}_{2} /$ system is suitable for removing compounds with a range of chemical properties, including antibiotics, analgesics, beta-blockers, and lipid-lowering drugs. However, this versatility means that pharmaceuticals will be removed together with other organic and inorganic pollutants. For instance, bioMnOx is used to remove pharmaceuticals, and also heavy metals, such as $\mathrm{Pb}$ and $\mathrm{As}{ }^{[97]}$. This nonspecificity towards pharmaceuticals can reduce the removal efficiency, as other pollutants will be removed together with pharmaceuticals, thus competing for the available $\mathrm{Mn}$ or Fe. For example, organic compounds and colloids can compete for the surface of amorphous $\mathrm{MnO}_{2}$, leading to lower removal of carbamazepine ${ }^{[93]}$. Even with selective oxidation processes like ferrate and permanganate oxidation, they will not only attack pharmaceuticals containing electron-rich organic moieties, but also aliphatic and aromatic organic compounds [77, 305], phosphate ${ }^{[155]}$, and taste and odor compounds ${ }^{[287]}$. Thus, other compounds in the matrix compete with the pharmaceuticals for Mn or Fe. While this can achieve the goal of removing both common pollutants and pharmaceuticals, the nonspecificity of the process will increase the reagent consumption for removal of a certain amount of pharmaceuticals. 


\subsubsection{Treatment conditions}

There are a variety of robust technologies that can achieve high pharmaceutical removal efficiencies. However, efficient and reliable removal can only be obtained under specific treatment conditions. Almost all pharmaceuticals can be completely removed by all AOPs, including SRAOPs (Table 2.1). In addition, direct chemical oxidation (e.g. Fe(III), $\mathrm{Mn}(\mathrm{IV})$, ferrate, and permanganate oxidation) and chemical reduction (ZVI and nZVI reduction) result in more than $90 \%$ removal of pharmaceuticals. In order to achieve optimal removal, chemical treatments usually require acidic conditions $(\mathrm{pH}<6)$. The sterilized condition for pure culture cultivation is used in biologically related pharmaceutical removal process. BioMnOx used for pharmaceutical removal can be produced by $P$. putida MnB6 (BCCM/LMG 2322), which grows in synthetic medium [64, 65, 67, 200]. Similarly, the biological Fenton-like system with the white-rot fungi $T$. versicolor ${ }^{[192]}$ requires an acidic medium $(\mathrm{pH}=4.5)$ for the cultivation of this fungi $[43,86,192,193]$. Thus, specific cultivation equipment and sterile conditions are needed, and this might limit further application of these technologies in pharmaceutical removal technologies.

\subsubsection{Intermediates and by-products}

In most pharmaceutical removal processes with $\mathrm{Fe}$ or $\mathrm{Mn}$, incomplete mineralization may occur. For example, only $30 \%-40 \%$ mineralization is obtained in electro/ $\mathrm{Fe} / \mathrm{H}_{2} \mathrm{O}_{2}$ system processes ${ }^{[114,224]}$. The presence and accumulation of by-products can be advantageous for further downstream treatment. For example, processes like $\mathrm{Fe} / \mathrm{H}_{2} \mathrm{O}_{2} /$ system will result in partial oxidation of compounds, thus improving the biodegradability of the pharmaceuticals in wastewater $\left[10,{ }^{302}\right]$. A previous study using $\mathrm{Fe} / \mathrm{H}_{2} \mathrm{O}_{2}$ /system as pretreatment shows improved BOD/COD ratios from 0.25 to 0.50 following chemical oxidation, indicating improved biodegradability ${ }^{[10]}$. Thus, combining chemical oxidation of the pharmaceutical with biological treatment of the by-products can result in 
complete mineralization. Similarly, after ferrate treatment, biodegradation of water containing beta-blockers improves from nonbiodegradable to $14 \%$ $-70 \%$ biodegradation ${ }^{[338]}$.

While improved biodegradability can be observed, some by-products will be similarly or even more toxic or recalcitrant as their parent compounds, especially by-products from the oxidation process. In a previous study, the toxicity of atenolol's intermediates from photo/ $\mathrm{Fe} / \mathrm{H}_{2} \mathrm{O}_{2}$ system process is higher than the parent compound [316]. Moreover, sulfamethoxazole removal from wastewater by solar photo $/ \mathrm{Fe} / \mathrm{H}_{2} \mathrm{O}_{2}$ system increases the toxicity of the wastewater from 16 to $86 \%$, as assessed by Vibrio fischeri bioassays [311]. Another important product in these pharmaceutical removal processes is $\mathrm{Mn}$ (II) or Fe(II). Even though they are less threat to human health, they can have a negative effect on the taste, appearance, and staining of water. These results indicate that (1) these treatment technologies must go beyond merely considering removal of the parent pharmaceutical, and (2) many treatment technologies will require a downstream step to ensure complete removal of all toxic compounds.

\subsubsection{Effects of Fe or Mn compounds}

$\mathrm{Mn}$ or Fe compounds exist in different crystal structures and morphologies, and this can lead to different pharmaceutical removal performance. For example, the oxidation efficiency of naproxen with $\alpha$ $\mathrm{MnO}_{2}$ nanomaterials follows the order of commercial particles $<$ nanorods $<$ flower-like nanostructures $<$ nanoparticles ${ }^{[368]}$. Similarly, comparing different types of iron particles for pharmaceutical removal, ZVI has a faster rate for removal of ampicillin than $\mathrm{nZVI}{ }^{[76]}$.

In general, $\mathrm{Mn}$ or Fe compounds in pharmaceutical removal processes are safe to human or ecosystem. For example, nanomaterials like nZVI and MNPs are promising materials for pharmaceutical removal, but they are also potentially toxic to the environment. Previous studies show that nZVI results in ecotoxicity to organisms in both fresh and marine water ${ }^{[134,235]}$. 
Daphnia magna survival exposed to $\mathrm{nZVI}\left(\mathrm{Fe} \geq 5 \mathrm{mg} \cdot \mathrm{L}^{-1}\right)$ drops within 96 $\mathrm{h}^{[134]}$. In addition, $\mathrm{nZVI}$ is also potentially toxic to nerve cells, animal cells, and human cells $[42,137,235]$. One possible explanation is the physical disruption of cell membranes by nZVI. It can also enhance the biocide effect of $\mathrm{Fe}^{[154]}$. Toxicity to microorganisms is also observed with other Mn- or Fe-containing nanoparticles ${ }^{[16]}$. Other compounds used in $\mathrm{Mn}$ - and Febased technologies like peroxymonosulfate are also harmful to human ${ }^{[22]}$.

\subsection{Outlooks}

The challenges and limitations of current $\mathrm{Mn}$ - or Fe--based pharmaceutical technologies discussed above require either further optimizing current technologies or developing new technologies (Figure 2.4). These new technologies have many of the treatment advantages mentioned in section 2.2.3, including nonspecificity, high removal efficiency, and/or potentially biodegradability improvements. These promising technologies require less specific treatment conditions and/or the products will be less toxic, thus addressing some of the challenges mentioned in section 2.2.3.

\subsubsection{Fe- or Mn-enhanced processes}

There are some existing technologies for pharmaceutical removal which could be further enhanced through the addition of Mn and Fe. After improvement or enhancement, these technologies are likely to more efficiently remove pharmaceuticals. 


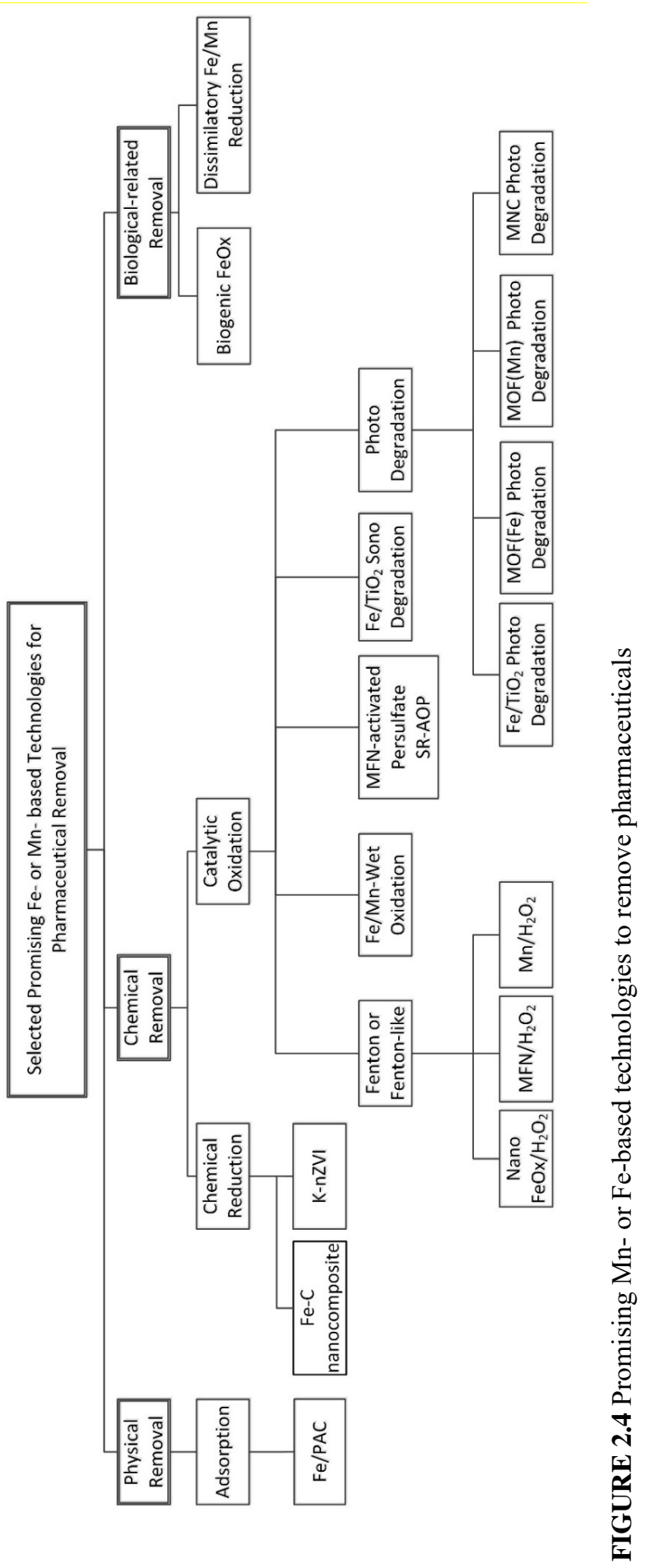


Powdered activated carbon (PAC) adsorption is a physico-chemical removal process for pharmaceuticals ${ }^{[166,191]}$ and other pollutants ${ }^{[73,98,244]}$. Studies show that addition of Fe species can improve the performance of PAC adsorption ${ }^{[89,231]}$. Research investigating the removal of bisphenol A and natural organic matter shows that the adsorption capacities were in the following sequence: bare PAC $<$ hematite/PAC $<$ magnetite/PAC $<$ ferrihydrite/PAC ${ }^{[231]}$. These results show that adding Fe species can improve the adsorption of compounds onto PAC, which is a known physicochemical process for pharmaceutical removal. While the adsorption on $\mathrm{Fe} / \mathrm{PAC}$ is a nonspecific pharmaceutical removal process, this physiochemical technique does not result in toxic products formation.

AOPs such as photo degradation and sono degradation can be accelerated by catalysts. Fe can work as a doping agent for catalysts such as $\mathrm{TiO}_{2}$ in catalytic photo degradation and sono degradation. In catalytic photo degradation, Fe-doped catalyst can improve the removal of volatile organic compounds acetone and benzyl alcohol ${ }^{[286,373]}$. Similarly, sono degradation catalysed by Fe-doped $\mathrm{TiO}_{2}$ shows notably higher removal of the dyes Blue 4 dye and azo fuchsine than undoped $\mathrm{TiO}_{2}{ }^{[117,329]}$.

Wet oxidation is the oxidation of organic and inorganic substances in an aqueous solution or suspension by means of oxygen or air at $200^{\circ} \mathrm{C}-$ $320^{\circ} \mathrm{C}$ and $2-20 \mathrm{MPa}$ either with or without ${ }^{[139,142,157,378]}$. Wet oxidation includes wet air oxidation and wet peroxide oxidation and is used as a pretreatment technology for pharmaceutical wastewater [99, 201, 357, 371]. Results show that $\mathrm{Mn}$ and $\mathrm{Fe}$ (together with $\mathrm{Ce}, \mathrm{Pt}$ or $\mathrm{C}$ ) can catalyse wet oxidation for phenolic compounds removal ${ }^{[40,71,251,264]}$. AOPs can form $\mathrm{OH}^{*}$ and other active oxygen species which are efficient and nonspecific in pharmaceutical removal processes. In previous studies, $\mathrm{Mn}$ is used as a catalyst in supercritical water oxidation to treat pharmaceutical laboratory wastewater ${ }^{[259]}$. In addition, results show wet oxidation can significantly improve the biodegradability of pharmaceutical wastewater from pharmaceutical industry ${ }^{[82,230,357]}$. For example, the ratio of $\mathrm{BOD}_{5} / \mathrm{COD}$ in 
pharmaceutical wastewater increases from 0.1 to 0.75 by catalytic wet air oxidation at $220^{\circ} \mathrm{C}^{[357]}$.

\subsubsection{Advanced Mn or Fe compounds}

Advanced Mn or Fe compounds such as Fe-organic framework, nZVI, and bioMnOx are used to remove pharmaceuticals. These $\mathrm{Fe}$ or $\mathrm{Mn}$ compounds will be synthesized by combining with other materials as well as developing new generation processes. These advanced $\mathrm{Fe}$ or $\mathrm{Mn}$ compounds may lead to better pharmaceutical removal.

Some advanced $\mathrm{Mn}$ or Fe compounds are used as catalysts in AOPs (Fenton, photo degradation, and SR-AOPs), which are currently employed to remove pharmaceuticals. Nano particulate $\mathrm{Fe}$-oxides (nano $\mathrm{FeOx}$ ) is a newly synthetic Fe compound which can catalyse Fenton's reaction ${ }^{[355,356]}$. Results show that higher concentrations of nano $\mathrm{FeOx}$ leads to a higher reaction rate ${ }^{[355,356]}$. Moreover, nano $\mathrm{FeOx}$ can improve the removal of pollutants via adsorption because of the large specific surface area of these nanoparticles ${ }^{[355,356]}$. Metal-organic framework containing Fe or Mn is used as a catalyst in photo degradation with both visible and UV irradiation ${ }^{[326]}$. Another new synthetic AOPs catalyst are ferrite nanoparticles $\left(\mathrm{M}_{\mathrm{x}} \mathrm{Fe}_{3-\mathrm{x}} \mathrm{O}_{4}\right.$ nanoparticles, $\mathrm{M}=\mathrm{Mn}, \mathrm{Fe}, \mathrm{Co}$, etc.). For example, $\mathrm{MnFe}_{2} \mathrm{O}_{4}(\mathrm{MFN})$ can catalyse photo degradation or Fenton's reactions. Over 90\% removal of dye compounds was obtained ${ }^{[190]}$. MFN can also activate PMS, which is used to remove pollutants via SR-AOPs ${ }^{[353]}$. In this removal process, adsorption is an important mechanism ${ }^{[333]}$. Incorporation of $\mathrm{M}_{\mathrm{x}} \mathrm{Fe}_{3-\mathrm{x}} \mathrm{O}_{4}$ to metal oxides or carbon is also promising in pharmaceutical removal. For example, $\mathrm{Fe}_{3} \mathrm{O}_{4-}$ $\mathrm{Cr}_{2} \mathrm{O}_{3}$ magnetic nanocomposite (MNC) is used to catalyse photo degradation. This MNC shows efficient removal of 4-chlorophenol under UV irradiation, good magnetic separation for recovery, and recyclability [281] Kaolinite-supported nZVI (k-nZVI) is recently synthesized ${ }^{[36,315]}$. It is proven that $\mathrm{nZVI}$ can- remove pharmaceuticals through adsorption and chemical reduction ${ }^{[76,277]}$, and it can catalyse Fenton-like processes to 
remove pharmaceuticals. In addition, kaolinite alone can remove the pharmaceutical metoprolol by adsorption together with talc ${ }^{[165]}$. Thus, this newly synthesized k-nZVI is a promising reagent for pharmaceutical removal.

Biologically produced $\mathrm{MnOx}$ have been shown to remove pharmaceuticals. Similar to bioMnOx, Fe oxides can also be generated by microbial activity, resulting in bioFeOx ${ }^{[97]}$. Their potential to remove pollutants has been observed. The large surface area of bioFeOx leads to the adsorption of heavy metals as well as potential adsorption of pharmaceuticals ${ }^{[64,97]}$. In addition, bioFeOx is effective in dehalogenation reactions of organic pollutants, including chlorinated solvents, pesticides and freons ${ }^{[97,141]}$. For pharmaceuticals containing halogens like diclofenac, applicability of dehalogenation by bioFeOx should be investigated.

\subsubsection{Other promising processes}

Some novel processes with $\mathrm{Mn}$ or Fe compounds are also promising in pharmaceutical removal. These processes should be explored to determine their application for pharmaceutical removal. Due to the similar properties between Mn and Fe (Figure 2.1), Mn can work as a catalyst in Fenton's

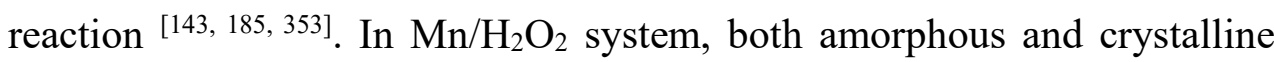
$\mathrm{Mn}(\mathrm{IV})$ compounds are used as catalysts to remove carbon tetrachloride, with removal efficiencies of $\sim 90 \%$ at $\mathrm{pH} 6^{[334]}$. $\mathrm{OH}^{*}$ is generated in $\mathrm{Mn} / \mathrm{H}_{2} \mathrm{O}_{2}$ system and it is applicable to remove pharmaceuticals. Moreover, the $\mathrm{OH}^{*}$ is generated at nearly neutral conditions ( $\mathrm{pH} 6$ ), instead of the acidic conditions at $\mathrm{pH} 3$ that are needed for $\mathrm{Fe} / \mathrm{H}_{2} \mathrm{O}_{2}$ system ${ }^{[238]}$. Consequently, $\mathrm{Mn} / \mathrm{H}_{2} \mathrm{O}_{2}$ will be more cost-efficient for pharmaceutical removal in practice.

Dissimilatory $\mathrm{Mn}$ or $\mathrm{Fe}$ reduction is demonstrated as a process to remove organic pollutants $[33,175,179,261]$. In this process, dissimilatory $\mathrm{Fe}$ reducing bacteria (DIRB) such as Geobacter metallireducens, metabolically degrade organic matter while respiring on Fe(III) or Mn(IV). Dissimilatory $\mathrm{Mn}(\mathrm{IV})$ or $\mathrm{Fe}(\mathrm{III})$ reduction has been applied for the removal of 
monoaromatic compounds, such as benzene, toluene, ethylbenzene and xylene isomers (BTEX) $[4,115,153,175,323]$. A previous study shows the complete removal of BTEX with $\mathrm{Fe}(\mathrm{III})$ at a rate of $0.19 \mu \mathrm{mol} \cdot \mathrm{L}^{-1} \cdot \mathrm{d}^{-1}{ }^{[323]}$. Dissimilatory iron reduction has been shown for a variety of soluble and insoluble $\mathrm{Fe}(\mathrm{III})$ forms, indicating the versatility of this process ${ }^{[176,177]}$. We assume that biological processes which can remove phenolic or aromatic compounds might have the potential to remove pharmaceuticals, as many pharmaceuticals contain at least one aromatic ring. Thus, dissimilatory $\mathrm{Fe}$ reduction was potential to remove pharmaceuticals.

$\mathrm{Mn}(\mathrm{IV})$ has similar characteristics and an even higher standard redox potential compared to $\mathrm{Fe}(\mathrm{III})$. In addition, $\mathrm{Mn}(\mathrm{IV})$ can be used as an alternative electron acceptor by some DIRB ${ }^{[175]}$. Together with Mn(IV)reducing bacteria, the process is employed to remove aromatic compounds, e.g. BTEX ${ }^{[53,323]}$. Results show that complete biodegradation of BTEX ${ }^{[323]}$ and $>60 \%$ naphthalene is mineralized to $\mathrm{CO}_{2}$ with $\mathrm{Mn}(\mathrm{IV})$ as the terminal electron acceptor ${ }^{[153]}$.

The mentioned dissimilatory $\mathrm{Mn}$ or Fe reduction requires a neutral $\mathrm{pH}$ and anaerobic conditions, so there are no needs to adjust the $\mathrm{pH}$ or add large amounts of oxygen. These prerequisites make it an attractive, sustainable and low-cost technology. This biological removal process will remove not only pharmaceuticals but also other organic materials. If given enough time, bacteria will degrade and eventually completely mineralize the pharmaceuticals. Products of the process, Mn(II) or Fe(II), can be oxidized into $\mathrm{Mn}(\mathrm{IV})$ or $\mathrm{Fe}(\mathrm{III})$, thus be recycled and reused for the removal process. 


\subsection{Conclusions}

Mn- or Fe-based technologies are capable of removing pharmaceuticals in water systems. Removing pharmaceuticals decrease the possibility of developing antibiotic-resistant gene or antibiotic-resistant bacteria. Furthermore, the AOPs using Mn or Fe compounds can also remove antibiotic-resistant gene and antibiotic-resistant bacteria [204, 285]. These technologies are efficient for a wide variety of pharmaceuticals, as well as other pollutants under favourable conditions. As discussed in this review, the removal mechanism involved physico-chemical, chemical, and biologically-related processes. So far, current Mn- or Fe-based technologies to remove pharmaceuticals focus on chemical removal. The $\mathrm{Mn}$ or $\mathrm{Fe}$ compounds are generally safe to the human and environment, but there are still some of them like nZVI can be toxic. Even when these technologies partially remove pharmaceuticals, their by-products can be more biodegradable than the parent compounds. These challenges require further attention to optimize these technologies. We have also discussed that $\mathrm{Fe}$ - or Mn-based technologies look promising in pharmaceutical removal processes and are worth studying, for example, based on combined technologies and/or biological processes. Especially biological processes are interesting, due to their mild operational conditions and environmentalfriendly characteristics.

The combination of current and potential Fe- or Mn-based processes is therefore promising to develop novel technologies for the removal of pharmaceuticals from (waste)water. Furthermore, all these Mn- or Fe-based technologies are also valuable for removal both conventional pollutants and micropollutants. 


\section{ACKNOWLEDGEMENT}

The authors thank Dr. Thomas ter Laak (KWR Watercycle Research Institute, the Netherlands), Justine van Enennaam and Thomas Wagner (both from Wageningen University) for valuable discussions. Funding is supported by China Scholarship Council (CSC, File No.201308610161) and Wageningen University, the Netherlands. 



\section{Chapter 3}

\section{Anaerobic biodegradation of pharmaceutical compounds coupled to dissimilatory manganese (IV) or iron (III) reduction}

A modified version of this chapter is in preparation for publication as

Liu, W.; Sutton, N. B.; Rijnaarts, H. H. M.; Langenhoff, A. A. M., Anaerobic biodegradation of pharmaceutical compounds coupled to dissimilatory manganese (IV) or iron (III) reduction. 


\section{ABSTRACT}

Pharmaceutical compounds in water are regarded as emerging contaminants due to their adverse effects on aquatic ecological systems. Anaerobic pharmaceutical biodegradation coupled to dissimilatory manganese (Mn(IV))- or iron (Fe (III))- (hydr)oxides reduction is a potentially efficient but relatively unexplored process to remove these pharmaceuticals from water. In this study, batch experiments were carried out using different types of $\mathrm{Mn}(\mathrm{IV})$ and $\mathrm{Fe}(\mathrm{III})$ species with a microbial inoculum adapted to pharmaceutical biodegradation with $15 \mathrm{mM}$ chemically synthesized Mn(IV) and $10 \mathrm{mg} \cdot \mathrm{L}^{-1}$ metoprolol. Results show an anaerobic degradation of $26 \%$ for caffeine and $52 \%$ for naproxen with $\mathrm{Mn}(\mathrm{IV})$ as a terminal electron acceptor and insignificant biodegradation for other pharmaceuticals tested. Reduction of Mn(IV) from Mn-rich sludge from a drinking water treatment plant is coupled to anaerobic biodegradation of metoprolol and propranolol, resulting in removal efficiencies of $96 \%$ and $31 \%$, respectively. The results indicate that adsorption contributes to the pharmaceutical removal during the first 10 days of incubation, while biodegradation is the main removal mechanism in the whole period. Fe(III) can also be used as electron acceptor in anaerobic pharmaceutical biodegradation. More than half of the added metoprolol is degraded with both chemically synthesized Fe(III) and $\mathrm{Fe}$ (III)-citrate as terminal electron acceptors. However, such a process did not occur when using $\mathrm{Fe}$ (III) in the form of Fe-rich sludge from drinking water treatment processes or Fe(III)-based sorbents. This study indicates that anaerobic pharmaceutical biodegradation coupled to dissimilatory $\mathrm{Mn}(\mathrm{IV})$ or Fe(III) reduction is possible, which is promising for application to cleaning wastewater treatment plant effluents.

KEYWORDS: anaerobic conditions; biodegradation; $\mathrm{Mn}(\mathrm{IV})$ or $\mathrm{Fe}(\mathrm{III})$ reduction; pharmaceuticals 


\subsection{Introduction}

In the last decades, there is concern about pharmaceutical chemicals in water due to the increased consumption of these compounds and improvements in the detection of these compounds. These chemicals are observed in surface water, groundwater, wastewater, and even drinking water in the range from $\mathrm{ng} \cdot \mathrm{L}^{-1}$ to $\mu \mathrm{g} \cdot \mathrm{L}^{-1}\left[{ }^{[6,164]}\right.$. Previous studies have shown that pharmaceuticals have adverse effects. For example, propranolol could be harmful to aquatic organisms ${ }^{[197]}$. Consequently, pharmaceuticals as emerging contaminants are unwanted even at low level concentrations, and compounds like diclofenac or clarithromycin have been classified as a priority substances in water quality watch lists ${ }^{[20,60]}$.

Conventional wastewater treatment facilities insufficiently remove pharmaceuticals such as diclofenac, carbamazepine, and $\beta$-blockers. The removal efficiency is generally less than $50 \%{ }^{[330]}$. To eliminate these pharmaceuticals from water, technologies such as advanced oxidation processes, activated carbon adsorption, and membrane filtration are applied. For example, complete removal of the pharmaceuticals propranolol and diclofenac as well as $75 \%$ carbamazepine removal can be achieved in catalytic photodegradation ${ }^{[95,354]}$. However, some intermediates from these advanced technologies can be more toxic than their parent compounds, which is undesired ${ }^{[223]}$. Furthermore, the high energy consumption will increase the ecological footprint and potential cost in construction and operation, making these technologies less attractive ${ }^{[151]}$.

Biodegradation can be a less energy consuming way to efficiently remove pharmaceuticals, and different redox conditions can be applied in biodegradation $[71,74,151]$. Under aerobic conditions, biodegradation of ibuprofen and diclofenac can achieve $75-100 \%$ removal ${ }^{[151]}$. Under nitrate-reducing conditions, biodegradation is efficient for $\beta$-blockers like atenolol and propranolol ${ }^{[268]}$. Under sulphate-reducing conditions, over $50 \%$ atenolol can be biodegraded within one week ${ }^{[13]}$. Under methanogenic 
conditions, more than $80 \%$ of pharmaceuticals such as diclofenac were found to be biodegraded ${ }^{[262]}$. However, alternative electron acceptors such as $\mathrm{Mn}(\mathrm{IV})$ - or $\mathrm{Fe}(\mathrm{III})$ are less studied compared to the other redox conditions.

Anaerobic biodegradation under $\mathrm{Mn}(\mathrm{IV})$ - or $\mathrm{Fe}(\mathrm{III})$-reducing conditions is also known as dissimilatory $\mathrm{Mn}(\mathrm{IV})$ or $\mathrm{Fe}(\mathrm{III})$ reduction. During the process, $\mathrm{Mn}(\mathrm{IV})$ - or Fe(III)- (hydr)oxides are used as terminal electron acceptor in the anaerobic biodegradation of organic compounds ${ }^{[175]}$. Previous studies show that anaerobic biodegradation with $\mathrm{Mn}(\mathrm{IV})$ as terminal electron acceptor can efficiently remove aromatic compounds such as benzene, toluene, and poly aromatics: for example, naphthalene is mineralized to $\mathrm{CO}_{2}$ and water for more than $60 \%{ }^{[153]}$. To date, anaerobic degradation of naproxen and atenolol under Mn(IV)- or Fe(III)-reducing conditions is described [13, 268]. These results indicate that anaerobic biodegradation coupled to dissimilatory $\mathrm{Mn}(\mathrm{IV})$ or $\mathrm{Fe}(\mathrm{III})$ reduction can remove pharmaceuticals as a wastewater treatment technology. During this anaerobic pharmaceutical biodegradation, $\mathrm{Mn}(\mathrm{IV})$ and $\mathrm{Fe}(\mathrm{III})$ are consumed as terminal electron acceptor.

In addition to pharmaceutical removal efficiency, the influence of $\mathrm{Mn}(\mathrm{IV})$ or Fe(III) from different sources are important for application. Chemically synthesized Mn(IV) or Fe(III) (labelled as Mn(IV) chem-synthesis and $\mathrm{Fe}(\mathrm{III})_{\text {chem-synthesis }}$ ) as well as the $\mathrm{Mn}$ (IV) or $\mathrm{Fe}(\mathrm{III})$ from natural source are commonly used, and reported in literature ${ }^{[153,175]}$. Compared to these compounds, $\mathrm{Mn}(\mathrm{IV})$ or $\mathrm{Fe}(\mathrm{III})$ produced during the drinking water treatment (labelled as $\mathrm{Mn}(\mathrm{IV})_{\text {DWTP }}$ and $\mathrm{Fe}(\mathrm{III})_{\text {DWTP }}$ ) could be a more desirable source. Mn(IV) DwTP and Fe(III)DwTP are waste streams from the drinking water treatment plants ${ }^{[135]}$. Thus, these materials could be a cheap alternative for $\mathrm{Mn}(\mathrm{IV})_{\text {chem-synthesis }}$ and $\mathrm{Fe}(\mathrm{III})_{\text {chem-synthesis. For example, }}$ $\mathrm{Fe}(\mathrm{III})_{\text {DWTP }}$ usually consist of $\mathrm{FeOOH}$, which is a suitable electron acceptor in anaerobic biodegradation processes ${ }^{[175,220]}$. In addition, different types of $\mathrm{Mn}(\mathrm{IV})$ or $\mathrm{Fe}(\mathrm{III})$ can serve as electron acceptor during anaerobic biodegradation of organic compounds ${ }^{[175]}$. To the best of our knowledge, 
there are no studies reported directly using Mn(IV)DWTP or Fe(III)DWTP in dissimilatory metal reduction, nor using it coupled to the removal of pharmaceuticals with these $\mathrm{Mn}$ (IV) or Fe(III) species as electron acceptor.

In this study, we tested the anaerobic biodegradation of pharmaceuticals with different types of $\mathrm{Mn}(\mathrm{IV})$ or Fe(III). Since anaerobic biodegradation of aromatic compounds with $\mathrm{Mn}(\mathrm{IV})$ or $\mathrm{Fe}(\mathrm{III})$ as electron acceptor has been observed, the process is also expected to be effective in removal of aromatic pharmaceuticals. The results presented provide information on anaerobic pharmaceutical biodegradation coupled to dissimilatory $\mathrm{Mn}(\mathrm{IV})$ or $\mathrm{Fe}(\mathrm{III})$ reduction and that contributes to understanding the fate and transfer of pharmaceuticals in the environment, where $\mathrm{Mn}(\mathrm{IV})$ or $\mathrm{Fe}(\mathrm{III})$ are ubiquitous, and which opens new ways towards application in waste water treatment.

\subsection{Methods and materials}

\subsubsection{Chemicals}

Anaerobic water was prepared as previously described by boiling either ultrapure water $(18.2 \mathrm{M} \Omega \cdot \mathrm{cm}, \mathrm{TOC}=18 \mathrm{ppb}$, Millipore, USA) or demineralized water (demiwater) for $5 \mathrm{~min}$, followed by cooling down to room temperature under a gentle $\mathrm{N}_{2}$ flow ${ }^{[172]}$. The anaerobic water was stored in closed glass bottles at room temperature. All the solutions in this study were prepared with anaerobic water unless specified.

Six pharmaceuticals were purchased from Sigma-Aldrich or MP Biomedicals including caffeine, carbamazepine, ibuprofen, metoprolol, naproxen, and propranolol. The chemical structure and properties of these compounds have been described previously ${ }^{[172]}$. A stock solution of the pharmaceutical mixture was prepared with anaerobic ultrapure water, at a concentration of $20 \mathrm{mg} \cdot \mathrm{L}^{-1}$ for each pharmaceutical. Stock of metoprolol and propranolol $\left(1 \mathrm{~g} \cdot \mathrm{L}^{-1}\right)$ were prepared separately with anaerobic ultrapure water. 
Other chemicals were purchased from Sigma-Aldrich. For solid chemicals, the purity was greater than $98 \%$ while the liquids had a purity at HPLC or UPLC quality.

\subsubsection{Preparation of Mn(IV) or Fe(III)}

Different types of $\mathrm{Mn}(\mathrm{IV})$ and $\mathrm{Fe}(\mathrm{III})$ were used in this study (Table

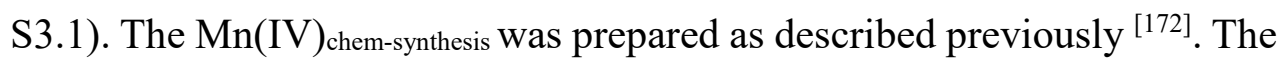
$\mathrm{Mn}(\mathrm{IV}$ )DWTP (Figure S3.1(a)) originated from drinking water production plant 'Noordbargeres' in Emmen, kindly provided by Water Laboratorium Noord (WLN, the Netherlands) ${ }^{[23]}$.

Soluble Fe(III)-citrate was dissolved with boiled demiwater. After cooling down under $\mathrm{N}_{2}$ flush to room temperature, the $\mathrm{pH}$ of $\mathrm{Fe}(\mathrm{III})$-citrate was adjusted to $\mathrm{pH} 7$ with $1 \mathrm{~N} \mathrm{NaOH}$ and diluted to $40 \mathrm{mM}$. The Fe(III)citrate solution was stored in a closed glass bottle and covered with aluminium foil to avoid photodegradation.

$\mathrm{Fe}(\mathrm{III})_{\text {chem-synthesis }}$ was prepared based on the method described previously ${ }^{[153]}$. In brief, $0.4 \mathrm{M} \mathrm{FeCl}_{3}$ was neutralized with $1 \mathrm{~N} \mathrm{NaOH}$ until $\mathrm{pH}$ 7. Thereafter, Fe(III) $)_{\text {chem-synthesis }}$ was washed and stored as $\mathrm{Mn}(\mathrm{IV})_{\text {chem- }}$ synthesis. Fe(III)DwTP was obtained from Evides Waterbedrijf (the Netherlands, Figure S3.1(b)). These Fe(III)DWTP granules are a mixture of Fe(III) from different drinking water treatment plants and then pelletized. Two types of Fe(III)-based sorbents, Fe(III) FerroSorp®Plus $_{\text {and }} \mathrm{Fe}(\mathrm{III})_{\text {FerroSorp®RW, were both }}$ obtained from $\mathrm{HeGo}$ Biotec $\mathrm{GmbH}$ in granular form (Germany, Figure S3.1(b)). 


\subsubsection{Experimental setup}

(1) Inoculum

Inoculum used in the experiments with $\mathrm{Mn}(\mathrm{IV}), \mathrm{Fe}(\mathrm{III})_{\text {chem-synthesis }}$ and $\mathrm{Fe}$ (III)-citrate consisted of a mixture of anaerobic sediments in the effluent channel of wastewater treatment plants in the Netherlands (Text S3.1). This sediment mixture was adapted with $10 \mathrm{mg} \cdot \mathrm{L}^{-1}$ metoprolol and $15 \mathrm{mM}$ $\mathrm{Mn}(\mathrm{IV})_{\text {chem-synthesis }}$ over 800 days in cultivation medium described previously (Table S3.2) ${ }^{[178]}$. In the experiments with Fe(III) ${ }_{\text {chem-synthesis, the mixture }}$ samples were taken out after 100 day incubation. These samples were used as a new inoculum for the experiments with $\mathrm{Fe}(\mathrm{III})_{\text {DWTP }}, \mathrm{Fe}(\mathrm{III})_{\text {FerroSorp } \circledast \text { Plus }}$

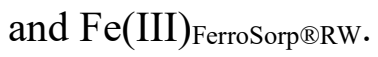

(2) Experimental preparation

All experiments were performed in the same medium, as previously described ${ }^{[178]}$. The medium was prepared under anaerobic conditions in an anaerobic glovebox. In the experiment with $\mathrm{Mn}(\mathrm{IV}), 0.02 \%$ yeast extract was added to the medium, in order to provide sufficient nutrient compounds but in the experiments with $\mathrm{Fe}(\mathrm{III})$, no yeast extract is in the medium.

The experiments with $\mathrm{Mn}(\mathrm{IV})_{\text {chem-synthesis }}$ were carried out in duplicate in $250 \mathrm{~mL}$ bottles, filled with $100 \mathrm{~mL}$ anaerobic medium. The experimental bottles were prepared in the anaerobic glovebox. A selected amount of $\mathrm{Mn}(\mathrm{IV})_{\text {chem-synthesis }}$ was distributed to the bottles, achieving a final concentration of $15 \mathrm{mM} \mathrm{Mn}(\mathrm{IV})$. The stock solution of pharmaceutical mixture was added to reach a final concentration of $10 \mathrm{mg} \cdot \mathrm{L}^{-1}$ for each pharmaceutical. $10 \mathrm{~mL}$ inoculum mixture was transferred to the experimental bottles. 
The experiments with Mn(IV)DwTP (granule and grinded powder) were performed in duplicate in $120 \mathrm{~mL}$ bottles, filled with $50 \mathrm{~mL}$ medium inside an anaerobic glovebox. About $4 \mathrm{~g}$ dry $\mathrm{Mn}(\mathrm{IV})_{\text {DwTP }}$ was added into the bottles, resulting in a final concentration of $15 \mathrm{Mm} \mathrm{Mn(IV).} \mathrm{Only}$ metoprolol and propranolol were tested to minimalize the potential influence of pharmaceuticals on inoculum. $0.5 \mathrm{~mL}$ metoprolol stock solution and $0.5 \mathrm{~mL}$ propranolol stock solution were added to the bottles. The final concentration for each pharmaceutical was $10 \mathrm{mg} \cdot \mathrm{L}^{-1} .5 \mathrm{~mL}$ inoculum mixture was transferred to the experimental bottles.

$\mathrm{Fe}(\mathrm{III})$ is hypothesised as an alternative electron acceptor of $\mathrm{Mn}(\mathrm{IV})$ in anaerobic pharmaceutical biodegradation. With $\mathrm{Fe}(\mathrm{III})_{\text {chem-synthesis, the }}$ experiments were repeating the adaption of the inoculum but in the process, $40 \mathrm{mM} \mathrm{Fe}(\mathrm{III})_{\text {chem-synthesis }}$ was used instead of $15 \mathrm{mM} \mathrm{Mn}(\mathrm{IV})_{\text {chem-synthesis. }}$ The experiments with Fe(III)-citrate were also the same but the $40 \mathrm{mM} \mathrm{Fe}(\mathrm{III})$ citrate solution replaced the anaerobic water during the medium preparation. Only $1 \mathrm{~mL}$ metoprolol stock solution was added to reach a final concentration of $10 \mathrm{mg} \cdot \mathrm{L}^{-1}$.

The experiments with $\mathrm{Fe}(\mathrm{III})_{\text {DWTP }}, \mathrm{Fe}(\mathrm{III})_{\text {FerroSorp®Plus }}$ and

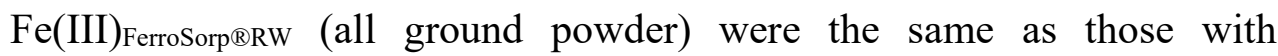
$\mathrm{Mn}(\mathrm{IV})_{\text {DWTP }}$ in a $120 \mathrm{~mL}$ bottles in duplicate. The final concentration of $\mathrm{Fe}(\mathrm{III})$ in these experiments was $40 \mathrm{mM}$. Only metoprolol was added into the experiments at a final concentration of $10 \mathrm{mg} \cdot \mathrm{L}^{-1}$.

When the bottles were ready, all the bottles were closed with butylrubber stoppers and taken out of the glovebox. The bottles were sealed with aluminium crimp caps, and the headspace was exchanged to $\mathrm{N}_{2} / \mathrm{CO}_{2}$ $(80 \% / 20 \%)$. All experiments were conducted at $30^{\circ} \mathrm{C}$ in the dark without shaking. Abiotic controls were prepared similarly, with additional aliquots of $\mathrm{HgCl}_{2}\left(0.1 \mathrm{gHg} \cdot \mathrm{L}^{-1}\right)$ and $\mathrm{NaN}_{3}(0.3 \mathrm{mM})$ to inhibit biotic activity. 


\subsubsection{Sample preparation and analysis}

Liquid samples for pharmaceutical analysis were taken every 3 weeks. After sampling, the samples were centrifuged for $10 \mathrm{~min}$ at $10000 \mathrm{rpm}$. The supernatant was diluted and transferred to amber vials. All the samples were stored at $-20^{\circ} \mathrm{C}$ before analysis. Pharmaceutical analysis was performed by an ultra-performance liquid chromatography with a diode array detector (UPLC, ultimate 3000, Thermo, USA), as previously described ${ }^{[95]}$.

The samples for $\mathrm{pH}$ were taken at the beginning and at the end of the experiments, and were analysed immediately with a $\mathrm{pH}$-meter (MeterLab PHM210, Radiometer Analytical).

The samples for morphologies of the $\mathrm{Mn}$ (IV) and Fe(III) were prepared by grinding if the raw materials were granular. The morphology was analysed by an X-ray powder diffraction (XRD, Bruker D8 advance).

Samples for $\mathrm{Mn}$ content in $\mathrm{Mn}(\mathrm{IV})_{\text {DWTP }}$ were reduced by $0.5 \mathrm{mM}$ $\mathrm{NH}_{2} \mathrm{OH} \cdot \mathrm{HCl}\left(1 \mathrm{~mL} \cdot \mathrm{mg}^{-1}\right.$ sample). The samples for $\mathrm{Mn}(\mathrm{II})$ measurement were also taken at the end of the experiments. The samples were centrifuged at $10000 \mathrm{rpm}$ for $10 \mathrm{~min}$. The supernatant was collected and stored at $-4^{\circ} \mathrm{C}$ before analysis. The $\mathrm{Mn}$ content and $\mathrm{Mn}$ (II) were both measured at wavelength $257.610 \mathrm{~nm}$ by an inductively coupled plasma optical emission spectrometry (ICP-OES,VISTA-MPX CCD Simultaneous, VARIAN co.).

Samples for $\mathrm{Fe}$ analysis were prepared by a modified $\mathrm{HCl}$ extraction method ${ }^{[52]}$. Briefly, $0.5 \mathrm{~mL}$ samples were mixed with $0.5 \mathrm{~mL} 1 \mathrm{M} \mathrm{HCl}$ to fix $\mathrm{Fe}(\mathrm{II})$. Thereafter, $\mathrm{Fe}$ (II) was analyzed directly by colourmetric methods (Hach Dr. Lange Kit 340). The samples were analysed immediately. The Fe

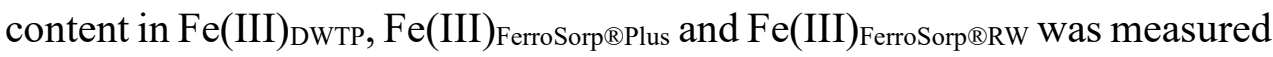
by the same ICP-OES at the wavelength $238.204 \mathrm{~nm}$, while the Fe(II) generated during the experiments was measured using a Hach Dr. Lange Kit (LCK 340). 


\subsection{Results and discussion}

\subsubsection{X-ray diffraction of Mn(IV) and Fe(III)}

First, the Mn(IV) and Fe(III) were characterized by X-ray diffraction (XRD), to identify the morphologies of these compounds and to assess if they are able to be used in dissimilatory $\mathrm{Mn}(\mathrm{IV})$ or $\mathrm{Fe}(\mathrm{III})$ reduction. The XRD pattern shows that the Mn(IV) chem-synthesis is amorphous with two small but broad XRD peaks, which is similar as previously described by others

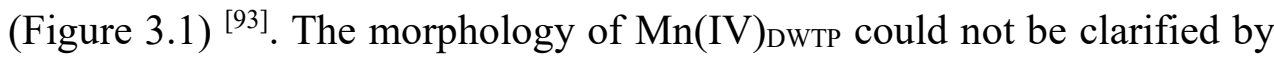
an XRD analysis. Since $\mathrm{Mn}(\mathrm{IV})_{\text {DwTP }}$ is $\mathrm{MnO}_{2}$-coated sand, the XRD pattern highly match the pattern of quartz (Figure 3.1 (a), Figure S3.2(a)).

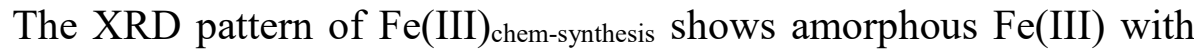
two small but broad XRD peaks, which is a similar pattern as $\mathrm{Fe}(\mathrm{OH})_{3}$ (Figure 3.1(b), Figure S3.2(b)). The XRD patterns of Fe(III) DwTP, $\mathrm{Fe}(\mathrm{III})_{\text {FerroSorp } \circledast \text { Plus }}$ and $\mathrm{Fe}(\mathrm{III})_{\text {FerroSorp®RW }}$ are all partially similar to those of $\mathrm{Fe}_{2} \mathrm{O}_{3}$ and $\mathrm{Fe}_{3} \mathrm{O}_{4}$, indicating a semi-crystalline morphology. The morphology of $\mathrm{Fe}(\mathrm{III})_{\text {DWTP }}$ is closest to an amorphous one, and $\mathrm{Fe}(\mathrm{III})_{\text {FerroSorp®RW }}$ is closer to a crystalline morphology.

Based on the literature, the amorphous $\mathrm{Mn}(\mathrm{IV})$ and $\mathrm{Fe}(\mathrm{III})$ are commonly used $\mathrm{Mn}$ and Fe species in dissimilatory $\mathrm{Mn}(\mathrm{IV})$ or $\mathrm{Fe}(\mathrm{III})$ reduction, and different types of $\mathrm{Mn}(\mathrm{IV})$ and $\mathrm{Fe}(\mathrm{III})$ such as crystalline hematite, goethite, akaganeite, and magnetite, are also suitable for the process $^{[175,177]}$. Therefore, the amorphous and semi-crystalline Mn(IV) and $\mathrm{Fe}(\mathrm{III})$ in this study are expected to remove pharmaceuticals coupled to the dissimilatory $\mathrm{Mn}(\mathrm{IV})$ or $\mathrm{Fe}(\mathrm{III})$ reduction. 

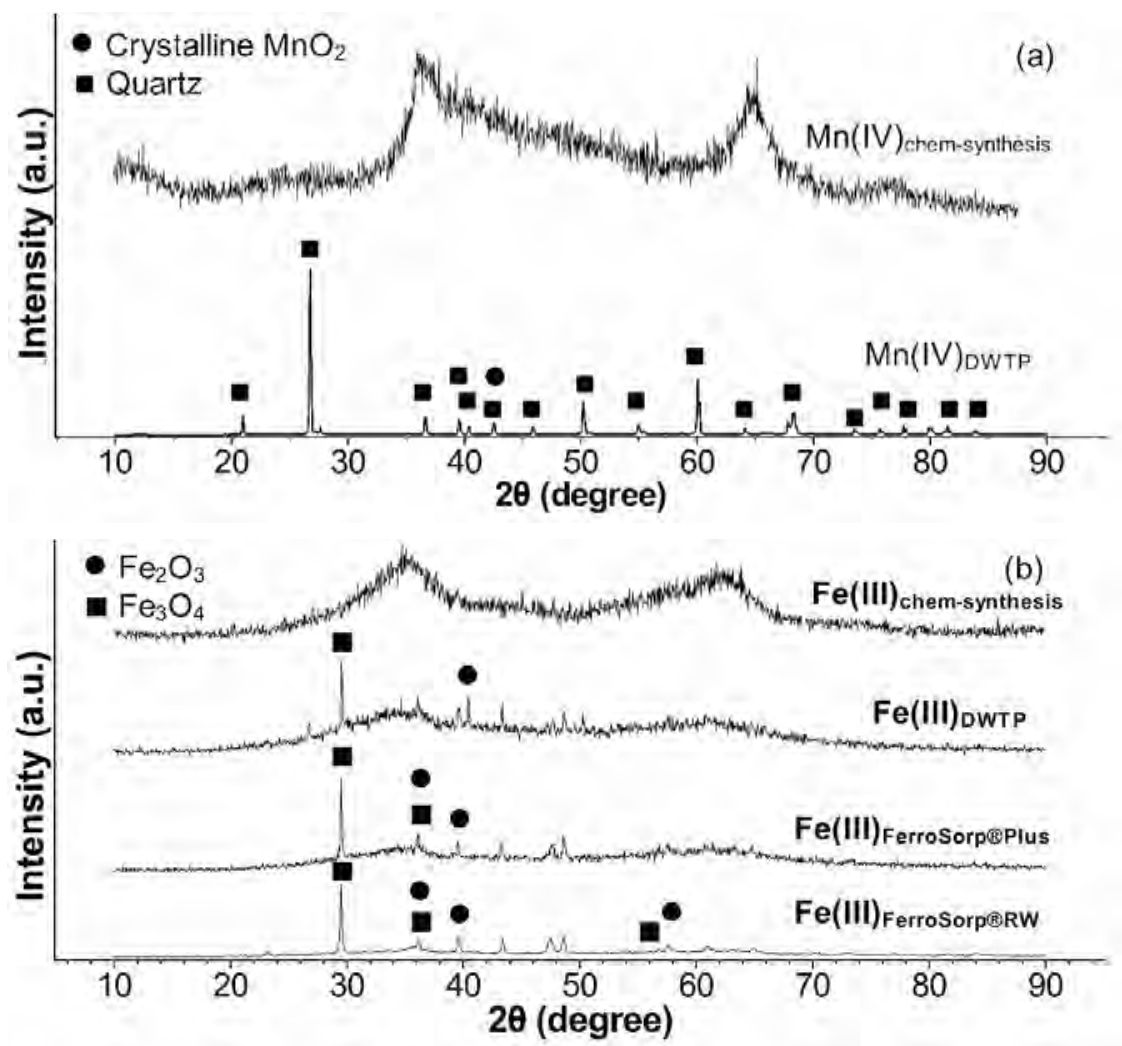

FIGURE 3.1 XRD patterns of different types of (a) chemically synthesised Mn(IV) $\left(\mathrm{Mn}(\mathrm{IV})_{\text {chem-synthesis }}\right)$ and $\mathrm{Mn}(\mathrm{IV})$ from a drinking water treatment plant (Mn(IV) $)_{\text {DWTP }}$; and (b) chemically synthesised $\mathrm{Fe}$ (III) ( $\mathrm{Fe}$ (III) chem-synthesis), $_{\text {, }}$ (III) from a drinking water treatment plant (Fe(III) $)_{\text {DWTP }}$ ), and two Fe(III)-based sorbents Fe(III)FerroSorp®Plus and Fe(III)FerroSorp®RW

\subsubsection{Anaerobic biodegradation of pharmaceuticals with $\operatorname{Mn}(\mathrm{IV})$}

(1) Chemically synthesized Mn(IV)

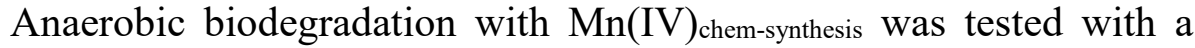
mixture of six commonly used pharmaceuticals. Our results show that the anaerobic biodegradation is effective within 40 days (Figure 3.2). In this period, $26 \%$ of the applied caffeine, and $52 \%$ of the dosed naproxen is removed. Carbamazepine and propranolol are removed within 42 days at lower levels, namely $12 \%$ and $16 \%$, respectively. No removal is observed for ibuprofen and metoprolol. During the anaerobic biodegradation of 
pharmaceuticals, $5.4 \mathrm{mM} \mathrm{Mn}(\mathrm{IV})$ is reduced (Table 3.1), indicating that the $\mathrm{Mn}(\mathrm{IV})$ is the electron acceptor in the anaerobic biodegradation. In the abiotic controls, no degradation of pharmaceuticals is observed (Figure 3.2), further indicating that the observed degradation is linked to $\mathrm{Mn}(\mathrm{IV})$ reduction.

Based on previous studies, anaerobic biodegradation of pharmaceuticals coupled to dissimilatory $\mathrm{Mn}(\mathrm{IV})$ reduction may occur via two pathways ${ }^{[175]}$. First of all, the pharmaceuticals could be hydrolysed or fermented by different bacteria to easier degradable components, such as sugars, amino acids, long chain fatty acid, and/or simpler aromatic intermediates ${ }^{[175,196]}$. These components can be further converted to fermented acids and hydrogen and then consumed by bacteria. In addition, the pharmaceuticals, as well as the potential aromatic intermediates, can also be oxidised directly by bacteria like Geobacter matallereducens. $\mathrm{Mn}(\mathrm{IV})$ reduction in this process provides energy for these bacteria ${ }^{[175]}$.

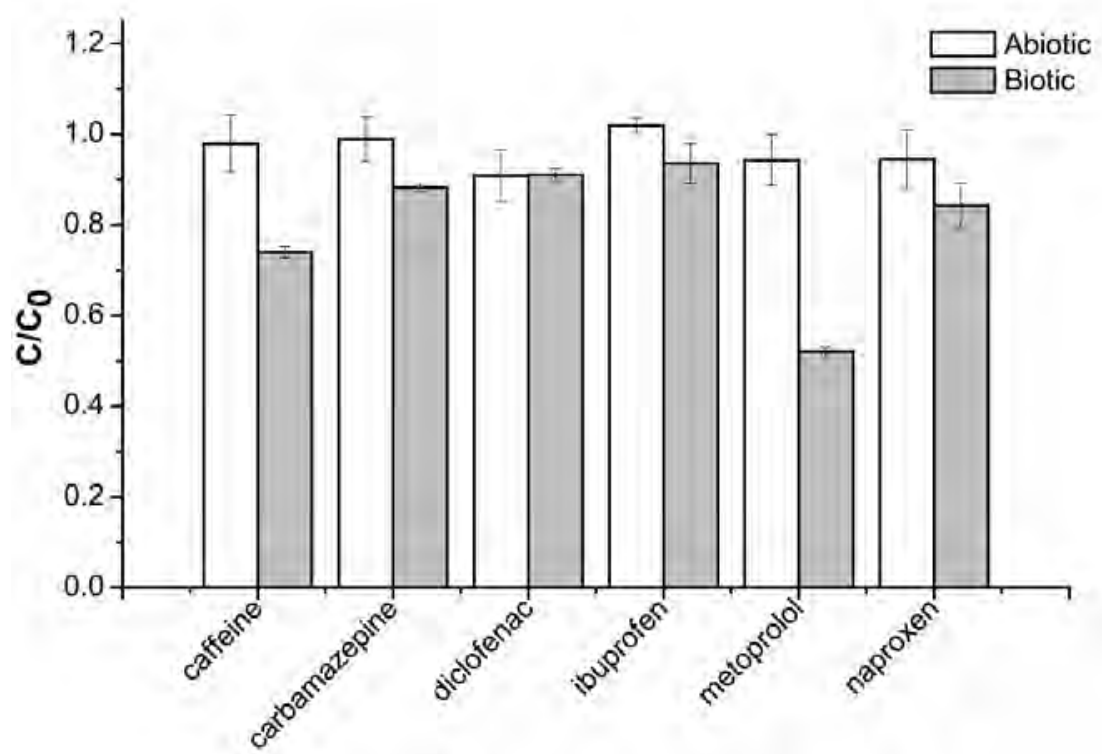

FIGURE 3.2 Biodegradation of pharmaceuticals with chemically synthesized $\mathrm{Mn}(\mathrm{IV})$ oxides after 42 days incubation. Experimental conditions: $\left[\mathrm{MnO}_{2}\right]_{0}=15 \mathrm{mM}$, [pharmaceutical $]_{0}=10$ $\mathrm{mg} \cdot \mathrm{L}^{-1}, \mathrm{pH} 6.5-7.5, \mathrm{~T}=30^{\circ} \mathrm{C}$. Error bars are the difference between duplicate 
(2) $\mathrm{Mn}(\mathrm{IV})$ from drinking water treatment plants

$\mathrm{Mn}(\mathrm{IV})_{\mathrm{DWTP}}$, both as granules and ground powder, is tested whether it is suitable to be used in anaerobic pharmaceutical biodegradation coupled to dissimilatory $\mathrm{Mn}(\mathrm{IV})$ reduction. Results show that $\mathrm{Mn}(\mathrm{IV})$ DwTP granules can remove these two $\beta$-blockers via biodegradation. In the first 10 days, the two pharmaceuticals are removed with Mn(IV)DWTP from the medium in both biotic experiments and abiotic controls (Figure 3.3). Thereafter, no removal of metoprolol is observed in biotic experiments between day 10 and day 35 , while $72 \%$ is removed in the later 37 days incubation between day 35 and day 72. The removal of propranolol in biotic experiments is less pronounced, and resulted in a final removal of $31 \%$ after 72 days of incubation. However, the removal of propranolol is $52 \%$ in the first 10 days incubation. During the anaerobic biodegradation with metoprolol and propranolol, $4.9 \mathrm{mM} \mathrm{Mn}(\mathrm{IV})$ is reduced (Table 3.1). The abiotic controls remained stable after 10 days of incubation, with max. 15\% metoprolol removal, and $9 \%$ propranolol removal. No removal of metoprolol or propranolol is observed in the presence of $\mathrm{Mn}(\mathrm{IV})$ DWTP powder, $(<5 \%$ removal, data not shown).

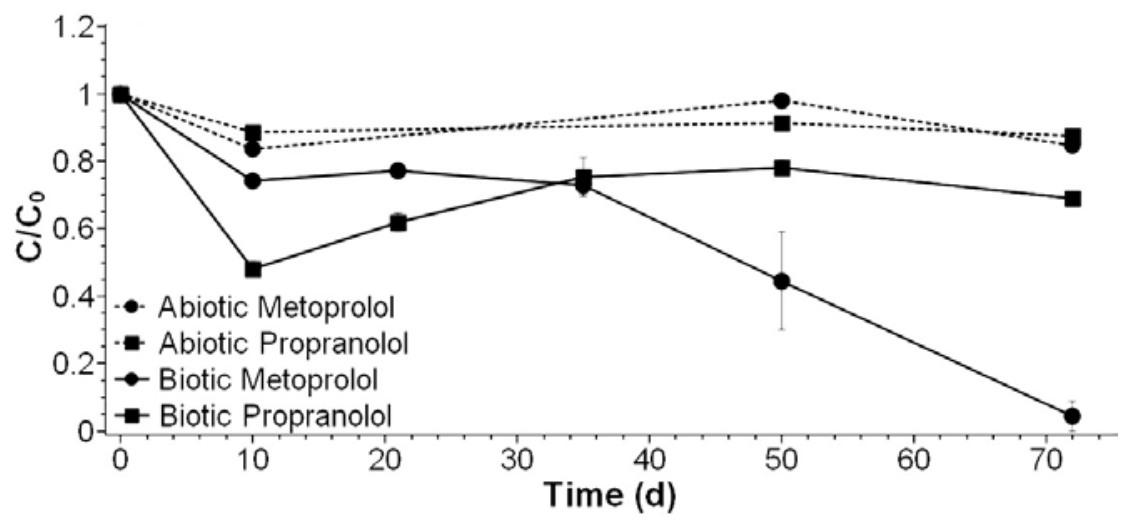

FIGURE 3.3 Biodegradation of metoprolol (•) and propranolol ( $\bullet$ ) with Mn(IV) oxides from drinking water treatment plants $\left(\mathrm{Mn}(\mathrm{IV})_{\mathrm{DWTP}}\right)$. Experimental conditions: $\left[\mathrm{MnO}_{2}\right]_{0}=15$ $\mathrm{mM}$, [pharmaceutical $]_{0}=10 \mathrm{mg} \cdot \mathrm{L}^{-1}, \mathrm{pH} 6.5-7.5, \mathrm{~T}=30^{\circ} \mathrm{C}$. Error bars are the difference between duplicate 
The differences between biotic groups and abiotic controls of both propranolol and metoprolol clearly show that the removal of these two pharmaceuticals is via biodegradation. In addition, adsorption is also responsible for the removal of the two pharmaceuticals with Mn(IV)DwTP. In the first 10 days, removal of two pharmaceuticals is observed in both abiotic controls and biotic experiments, but the removal in biotic experiments is higher. These findings shows that the biodegradation of pharmaceuticals is the main removal mechanisms, but that adsorption also contributes. After, adsorption reached equilibrium biodegradation becomes the dominant removal process. The removal of propranolol shows that the adsorption of this pharmaceuticals onto $\mathrm{MnO}_{2}$ could be reversible, leading to the decrease of removal from $52 \%$ to $31 \%$ after 10 days incubation. In addition, metoprolol biodegradation consumes $\mathrm{Mn}(\mathrm{IV})_{\text {DWTP }}$ during the removal process, probably releasing the propranolol that is adsorbed onto $\mathrm{Mn}(\mathrm{IV})$. The $\mathrm{Mn}(\mathrm{IV})$ reduced in this experiments is also higher than expected due to the presence of yeast extract.

\subsubsection{Anaerobic biodegradation of metoprolol with Fe(III)}

(1) Chemically synthesized Fe(III) and Fe(III)-citrate

$\mathrm{Fe}(\mathrm{III})$ is hypothesised as a suitable electron acceptor for anaerobic biodegradation of pharmaceuticals, because it has been reported that the bacteria involved can use both $\mathrm{Mn}(\mathrm{IV})$ and Fe(III) ${ }^{[175]}$. We used both insoluble $\mathrm{Fe}(\mathrm{III})_{\text {chem-synthesis }}$ and soluble $\mathrm{Fe}(\mathrm{III})$-citrate to test the anaerobic biodegradation of metoprolol coupled to dissimilatory Fe(III) redcution. Our results show that $\mathrm{Fe}(\mathrm{III})$ is an alternative electron acceptor for dissimilatory $\mathrm{Mn}(\mathrm{IV})$ reduction, which can be coupled to biodegradation of metoprolol (Figure 3.4). Within 162 days, 57\% metoprolol is degraded with $\mathrm{Fe}(\mathrm{III})_{\text {chem-synthesis }}$ and about $52 \%$ with $\mathrm{Fe}$ (III)-citrate. Based on the theoretical calculation, when $1 \mathrm{mM}$ metoprolol is totally mineralized, 85 $\mathrm{mM} \mathrm{Fe}(\mathrm{III})$ is reduced (Text S3.2, Table S3.3). During the anaerobic metoprolol biodegradation with $\mathrm{Fe}(\mathrm{III}), 1.8 \mathrm{mM} \mathrm{Fe}(\mathrm{III})$ was reduced when 
$\mathrm{Fe}(\mathrm{III})_{\text {chem-synthesis }}$ is applied, and $8.8 \mathrm{mM} \mathrm{Fe(III)} \mathrm{is} \mathrm{reduced} \mathrm{when} \mathrm{Fe}(\mathrm{III})-$ citrate is applied.

Insignificant removal of metoprolol was found in the abiotic controls $(<5 \%)$. This shows that the removal of metoprolol with two different types of Fe(III) occurs through biodegradation and both can be used by our inoculum that was adapted to Mn(IV). Previous studies have reported that some bacteria can use both $\mathrm{Mn}(\mathrm{IV})$ and $\mathrm{Fe}(\mathrm{III})$ as electron acceptor ${ }^{[175,177]}$. Therefore, the inoculum adapted to $\mathrm{Mn}(\mathrm{IV})$ is also active with $\mathrm{Fe}(\mathrm{III})$, indicating that $\mathrm{Mn}(\mathrm{IV})$ and $\mathrm{Fe}(\mathrm{III})$ are exchangeable in application.

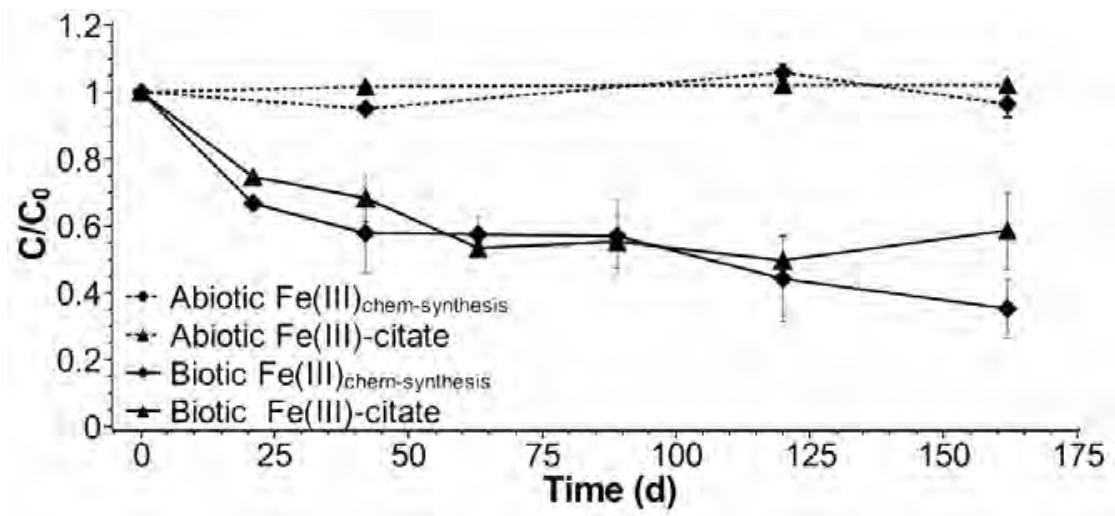

FIGURE 3.4 Biodegradation of metoprolol with chemically produced Fe(III) hydroxides $\left(\mathrm{Fe}(\mathrm{III})_{\text {chem-synthesis }}\right)(\diamond)$ and $\mathrm{Fe}(\mathrm{III})$-citrate $(\boldsymbol{\Delta})$. Experimental conditions: $[\mathrm{Fe}(\mathrm{III})]_{0}=40 \mathrm{mM}$, $[\text { metoprolol }]_{0}=10 \mathrm{mg} \cdot \mathrm{L}^{-1}, \mathrm{pH} 6.5-7.5, \mathrm{~T}=30^{\circ} \mathrm{C}$. Error bars are the difference between duplicate

In this study, the use of soluble Fe(III)-citrate is expected to result in more removal than insoluble $\mathrm{Fe}(\mathrm{III})_{\text {chem-synthesis, }}$, because the soluble form is more accessible to bacteria. However, our results show no obvious difference between the soluble and insoluble Fe(III). Previous studies reveal that bacteria can directly transfer electrons from organic compounds to insoluble $\mathrm{Fe}(\mathrm{III})$ during dissimilatory $\mathrm{Fe}(\mathrm{III})$ reduction, without the formation of compounds that serve either as chelator or as the electron shuttle ${ }^{[175]}$. As a result, the solubility of Fe(III) then does not influence its use by bacteria. In addition, Fe(III)-citrate contains an additional carbon source, citrate, which is an easier degradable organic compound than 
metoprolol. Results show that Fe(III) reduction during metoprolol biodegradation with $\mathrm{Fe}(\mathrm{III})$-citrate is much higher than stoichiometrically needed for the degraded amount of metoprolol (Table 3.1). Based on the theoretical calculation, to remove $52 \%$ metoprolol from $10 \mathrm{mg} \cdot \mathrm{L}^{-1}$ requires $1.2 \mathrm{mM} \mathrm{Fe}(\mathrm{III})$. If the citrate is also taken into account and assuming it is totally removed, the Fe(III) required is increased to $721.2 \mathrm{mM}$. The higher $\mathrm{Fe}(\mathrm{III})$ consumption indicates that citrate is also used as electron donor in the reduction of $\mathrm{Fe}(\mathrm{III})$. Citrate will outcompete metoprolol for $\mathrm{Fe}(\mathrm{III})$, leading to less $\mathrm{Fe}(\mathrm{III})$ available for biodegradation of metoprolol.

Even though the metoprolol removal with two Fe(III) is similar, the different intermediates formed in the processes are different (Figure S3.3). This indicates that the metoprolol biodegradation with two Fe(III) may be through different pathway. The reason could be that citrate also participates in the biodegradation of metoprolol, and/or that bacteria use soluble Fe(III) and insoluble $\mathrm{Fe}(\mathrm{III})$ in different ways.

(2) Other Fe(III) types

Inoculum obtained from the experiments with $\mathrm{Fe}(\mathrm{III})_{\text {chem-synthesis }}$ was tested for its ability to use other insoluble Fe(III) types to remove metoprolol, such as $\mathrm{Fe}$ (III) from drinking water treatment plants or commercial Fe(III) compounds. In this study, Fe(III) from drinking water treatment plants (labelled as Fe(III)DwTP) and two commercial Fe(III)-based sorbents are selected because they are cheap, widely available, and theoretically suitable for bacteria in dissimilatory $\mathrm{Fe}(\mathrm{III})$ reduction. These Fe(III) compounds can be a good source for electron acceptors in anaerobic biodegradation of pharmaceuticals with Fe(III). Results show that in both biotic experiments and abiotic controls, the anaerobic metoprolol degradation is less than $10 \%$ after 62 days incubation, indicating no significant removal of metoprolol (Figure 3.5). 
The insignificant removal of metoprolol with these three types of Fe(III) might be due to their semi-crystalline form instead of having an amorphous nature. Previous studies show that reduction rate using crystalline Fe(III) in dissimilatory $\mathrm{Fe}(\mathrm{III})$ reduction is much slower compared to amorphous $\mathrm{Fe}(\mathrm{III}){ }^{[175]}$. In addition, the microbial inoculum is adapted to amorphous $\mathrm{Fe}(\mathrm{III})$, indicating that it could be less active with semi-crystalline Fe(III). As a results, no anaerobic metoprolol degradation via dissimilatory Fe(III) reduction is observed with these widely available Fe (III) forms.

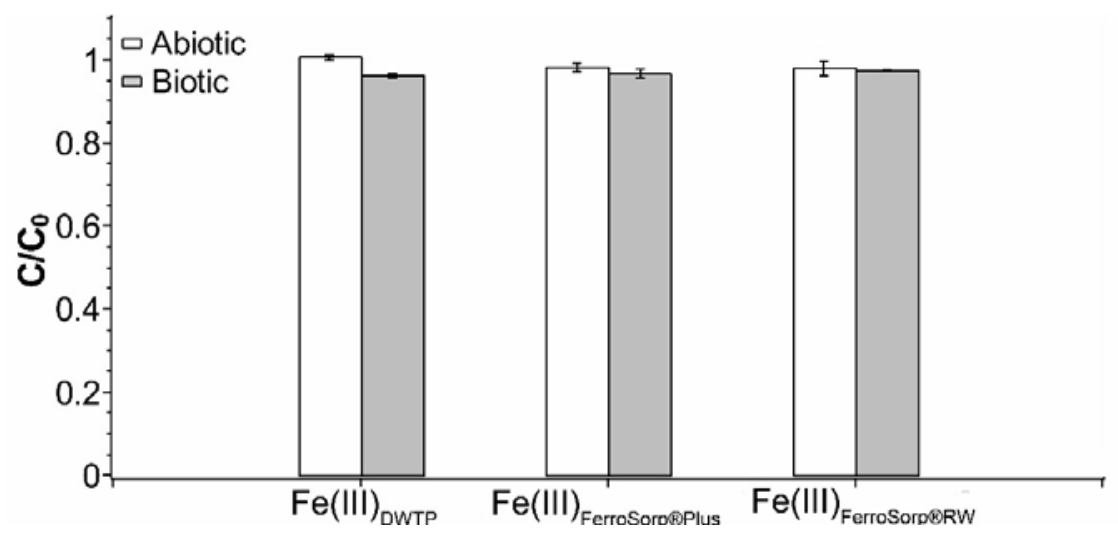

FIGURE 3.5 Degradation of metoprolol with Fe(III) from drinking water treatment plants (labelled as Fe(III)DwTP) and two Fe(III)-based sorbents, FerroSorp ${ }^{\mathbb{B}}$ Plus (labelled as

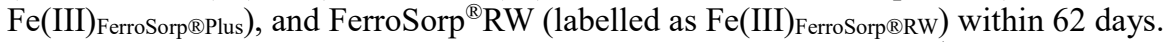
Experimental conditions: $[\mathrm{Fe}(\mathrm{III})]_{0}=40 \mathrm{mM},[\text { metoprolol }]_{0}=10 \mathrm{mg} \cdot \mathrm{L}^{-1}, \mathrm{pH} 6.5-7.5, \mathrm{~T}=30^{\circ} \mathrm{C}$. Error bars are the difference between duplicate

\subsection{Conclusion}

Our study shows that anaerobic biodegradation coupled to dissimilatory $\mathrm{Mn}(\mathrm{IV})$ or $\mathrm{Fe}(\mathrm{III})$ reduction is promising to remove pharmaceuticals. Results show that dissimilatory Mn reduction with $\mathrm{Mn}(\mathrm{IV})_{\text {chem-synthesis }}$ can remove $26 \%$ caffeine and 52\% naproxen within 42 days. Based on previous studies, both naproxen and caffeine can be efficiently removed under anaerobic conditions while the other selected pharmaceuticals are resistant to biodegradation. Mn(IV)DwTP granule can also be used to remove metoprolol and propranolol. After 72 days, an almost 
complete removal of metoprolol, and $31 \%$ propranolol is obtained. The differences between the biotic groups and abiotic controls clearly show that biodegradation of two pharmaceuticals is important.

$\mathrm{Fe}(\mathrm{III})$ can also be used as electron acceptor during anaerobic metoprolol biodegradation. Through anaerobic biodegradation, 57\% metoprolol is removed with $\mathrm{Fe}(\mathrm{III})_{\text {chem-synthesis }}$ and $52 \%$ with $\mathrm{Fe}(\mathrm{III})$-citrate. Anaerobic metoprolol biodegradation with Fe(III)DWTP, Fe(III)FerroSorp®Plus,

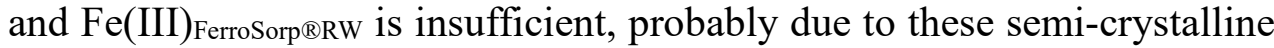
form instead of amorphous Fe(III).

Yeast extract, citrate and other (metal complexing) organic components are electron-donor substrates that compete with pharmaceuticals for iron or manganese reduction, and may thereby inhibit de dissimilatory removal of pharmaceuticals. Care should be taken of competing organic substrates during removal of pharmaceuticals from waste water treatment plant effluents.

In summary, anaerobic biodegradation coupled to dissimilatory Mn(IV) or $\mathrm{Fe}(\mathrm{III})$ reduction can be used for pharmaceutical removal. This pharmaceutical removal process is effective with different types of Mn(IV) and Fe(III), including some widely available Mn (IV) and Fe (III) forms such as $\mathrm{Mn}(\mathrm{IV})$ present in sludge waste originating from drinking water treatment plants. This study contributes to providing fundamental insight for a more sustainable pharmaceutical removal technology in wastewater treatment processes, as well as to understanding biotransformation of pharmaceuticals in the environment. 


\section{ACKNOWLEDGEMENT}

The study is finical supported by China Scholarship Council (File No. 201308610161) and Wageningen University \& Research. The authors appreciate the help from Laura Piai (WUR) and Peter van der Maas (WLN) for the experimental materials and additional information. The authors also appreciate the help from Hans Beijleveld, Livio Carlucci, Ilse Gerrits, Jean Slangen, and Vinnie de Wilde for assistance in analysis, and Marijn van Son for the work with $\mathrm{Mn}(\mathrm{IV})$ oxides from drinking water treatment plants. 


\section{Chapter 4}

\section{Anaerobic conditions are favourable for abiotic diclofenac removal from water with manganese oxides}

A modified version of this chapter is submitted as

Liu, W.; Sutton, N. B.; Rijnaarts, H. H. M.; Langenhoff, A. A. M., Anoxic conditions are favourable for abiotic diclofenac removal from water with manganese oxides. 


\section{ABSTRACT}

This is the first study published addressing pharmaceutical removal under anaerobic conditions with $\mathrm{MnO}_{2}$. This study compares the abiotic removal of seven pharmaceuticals with reactive $\mathrm{MnO}_{2}$ particles in the presence oxygen (aerobic conditions) and in the absence of oxygen (anaerobic conditions). Due to the novelty of pharmaceutical removal under anaerobic conditions, the influence of phosphate buffer, $\mathrm{pH}$, and $\mathrm{MnO}_{2}$ morphologies are also examined. Results show that over $90 \%$ of diclofenac are removed under anaerobic conditions. Additionally, we found that: (1) anaerobic conditions promote diclofenac removal with $\mathrm{MnO}_{2}$; (2) phosphate buffer affects the pharmaceutical removal efficiencies; (3) higher pharmaceutical removal is obtained at acidic $\mathrm{pH}$ compared to neutral or alkaline conditions; and (4) amorphous $\mathrm{MnO}_{2}$ removes pharmaceuticals better than crystalline $\mathrm{MnO}_{2}$. The pharmaceutical molecular structure and properties, $\mathrm{MnO}_{2}$ properties especially reactive sites of the $\mathrm{MnO}_{2}$ surface, are important for degradation kinetics. This study provides a fundamental basis towards understanding pharmaceutical degradation with $\mathrm{MnO}_{2}$ under anaerobic conditions, and development of a cost-effective, sustainable technology for removal of pharmaceuticals from water.

KEYWORDS: manganese oxides; abiotic pharmaceutical removal; in the absence of $\mathrm{O}_{2} ; \mathrm{pH}$ effects; $\mathrm{MnO}_{2}$ morphologies; $\mathrm{MnO}_{2}$ reactivity mechanism 


\subsection{Introduction}

Discharging pharmaceuticals into the water cycle threatens the aquatic environment and drinking water resources. Already at low levels $\left(\mathrm{ng} \cdot \mathrm{L}^{-1}-\right.$ $\left.\mu \mathrm{g} \cdot \mathrm{L}^{-1}\right)^{[280,303]}$, pharmaceuticals can be toxic to aquatic organisms ${ }^{[78,149]}$. As a result, pharmaceuticals discharged to water systems are seen as a priority concern of environmental regulators, and the European Union has added one of them, diclofenac, to the "Watchlist" ${ }^{[60]}$.

Pharmaceutical removal in conventional wastewater treatment is poor, due to the low biodegradability and limited sorption properties of many pharmaceuticals [319]. Advanced technologies such as ozonation or photodegradation successfully remove selected pharmaceuticals from water and wastewater ${ }^{[17,95]}$. However, these technologies require more energy inputs and operational costs, in addition to often high construction and maintenance costs, and unknown environmental effects of formed intermediate compounds.

A promising alternative method may be based on using manganese oxides $\left(\mathrm{MnO}_{2}\right)$ to remove pharmaceuticals from water. $\mathrm{MnO}_{2}$ is a common oxidant in soil, sediment, and marine environments which include local environments with either presence of oxygen (aerobic conditions) or absence of oxygen (anaerobic conditions) ${ }^{[146,276,359]}$. Most studies using $\mathrm{MnO}_{2}$ to remove pharmaceuticals and other micropollutants are conducted under aerobic conditions ${ }^{[248]}$. Previous studies also show that pharmaceutical removal with $\mathrm{MnO}_{2}$ is more effective under acidic conditions ${ }^{[248]}$. Little is known about the abiotic removal of pharmaceuticals under anaerobic conditions with $\mathrm{MnO}_{2}$. Furthermore, the effect of oxygen on pharmaceutical removal is inconsistent in different studies. For example, oxygen can accelerate sulfamethazine oxidation by participation in the formation of intermediates ${ }^{[69]}$, while for levofloxacin removal rates under aerobic and anaerobic conditions are indifferent ${ }^{[163]}$. Therefore, more studies are required to address pharmaceutical removal with $\mathrm{MnO}_{2}$ under 
both aerobic and anaerobic conditions, and to improve the understanding of the removal mechanisms. From an application perspective, water treatment technologies commonly include aerobic and anaerobic steps. Investigating pharmaceutical removal under anaerobic conditions with $\mathrm{MnO}_{2}$ may extend the application of this technology. Additionally, applying anaerobic conditions can reduce the construction and operation cost of maintaining aerobic conditions in water treatment systems.

Phosphate, $\mathrm{pH}$, and $\mathrm{MnO}_{2}$ morphologies are known to affect the removal of organic compounds with $\mathrm{MnO}_{2}{ }^{[69,276,352]}$. For example, various $\mathrm{MnO}_{2}$ morphologies have been tested to remove pharmaceuticals and other organic compounds, with amorphous $\mathrm{MnO}_{2}$ (birnessite) as most effective and most used ${ }^{[248]}$. However, little is known about how these parameters affect the removal process under anaerobic conditions.

In this study, a series of batch experiments with pharmaceuticals were conducted under aerobic and anaerobic conditions simulating the conditions encountered in nature as well as in wastewater treatment facilities. Seven widely used pharmaceuticals were selected and tested in the experiments. The effects of oxygen, phosphate, $\mathrm{pH}$, and $\mathrm{MnO}_{2}$ morphologies were studied to better understand the degradation processes involved and to optimize these towards the application of technology using reactive $\mathrm{MnO}_{2}$ for pharmaceutical removal. 


\subsection{Methods and materials}

\subsubsection{Chemicals}

Caffeine, carbamazepine, diclofenac, metoprolol, naproxen, and propranolol were purchased from Sigma-Aldrich while ibuprofen was purchased from MP Biomedicals (detailed information in Table S4.1). Other chemicals were purchased from Sigma-Aldrich at 98\% purity (for solids), or at HPLC or UPLC quality (for solvents). Pharmaceutical stocks were prepared with ultrapure water $(18.2 \mathrm{M} \Omega \cdot \mathrm{cm}, \mathrm{TOC}=18 \mathrm{ppb}$, Millipore, USA) and stored in amber glass bottles at $-20^{\circ} \mathrm{C}$. Other solutions were prepared with demineralised water (demiwater). Details are described in Text S4.1.

\subsection{2 $\mathrm{MnO}_{2}$ preparation}

Amorphous $\mathrm{MnO}_{2}$ was obtained by freshly synthesizing prior to experiments as described ${ }^{[152]}$. Briefly, equal amounts of $\mathrm{MnCl}_{2}$ and $\mathrm{KMnO}_{4}$ were mixed, $\mathrm{pH}$ was adjusted to $\sim 10$ with $\mathrm{NaOH}$, and $\mathrm{MnO}_{2}$ was washed by centrifugation (Text S4.2). Amorphous $\mathrm{MnO}_{2}$ was used in all experiments unless specification. Crystalline $\mathrm{MnO}_{2}$ was purchased from Sigma-Aldrich (Figure S4.1, S4.2).

\subsubsection{Batch experiments}

Glass bottles $(125 \mathrm{~mL})$ were filled with $50 \mathrm{~mL} \mathrm{MnO}_{2}$ suspension (7 $\mathrm{mM})$ in demiwater. Aerobic experiments were prepared at atmospheric oxygen level. Experiments under anaerobic conditions were prepared in the anaerobic glovebox with anaerobic water and closed with a rubber stopper and aluminum cap before taking them out of the anaerobic glovebox. Outside the glovebox, the headspace was exchanged with $100 \% \mathrm{~N}_{2}$. All the experimental bottles were closed with rubber stoppers, crimped with aluminum caps, wrapped in aluminum foil to prevent photodegradation and incubated without shaking at $30^{\circ} \mathrm{C}$. 
Experiments were started by spiking bottles to achieve the final pharmaceutical concentration of $1 \mathrm{mg} \cdot \mathrm{L}^{-1}$. Aliquots were collected, and reactions were quenched immediately for analysis by centrifugation (10000 rpm for $10 \mathrm{~min}$ ). Blank experiments without $\mathrm{MnO}_{2}$ were prepared and conducted simultaneously with each batch of experiments. Sample collection and preparation before analysis are detailed described in supplementary materials (Text S4.3).

Experiments in $50 \mathrm{mM}$ phosphate buffer with only diclofenac were conducted to compare the process under aerobic and anaerobic conditions. In addition, effects of $\mathrm{pH}$ and $\mathrm{MnO}_{2}$ morphologies under anaerobic conditions were investigated with phosphate buffer solutions at $\mathrm{pH} 4-5$ (4.5), $\mathrm{pH} 7.0$, and $\mathrm{pH} 8-9$ (8.5) (Text S4.1).

\subsubsection{Analysis}

The pharmaceutical analysis was conducted as described previously using an ultra-performance liquid chromatography with a diode array detector (UPLC, ultimate 3000, Thermo, USA) ${ }^{[95]}$. $\mathrm{pH}$ was determined by a pH meter (PHM210, MeterLab, Radiometer analytical). The $\mathrm{Mn}^{2+}$ analysis was conducted by an inductively coupled plasma spectrometer with optical emission spectroscopy (ICP-OES). $\mathrm{MnO}_{2}$ morphologies were characterized by X-ray diffraction. The $\mathrm{MnO}_{2}$ before and after the reaction with diclofenac and metoprolol was characterized via a Fournier-Transform Infra-Red spectrometer (FTIR, Bruker TENSOR 27). Details are described in supplementary materials (Text S4.3). 


\subsection{Results and discussion}

\subsubsection{Pharmaceutical removal under aerobic versus anaerobic conditions}

In the absence of $\mathrm{MnO}_{2}$, no removal is observed for all seven pharmaceuticals within 24 hours under both aerobic and anaerobic conditions in all experiments (Table S4.2). In the presence of $\mathrm{MnO}_{2}$, metoprolol, propranolol, and diclofenac are removed within 24 hours in both demiwater (Figure 4.1(a) and (b)) and phosphate buffer (Figure 4.1(c)), while no removal is observed for the other four pharmaceuticals (Figure S4.3). Furthermore, the results show that anaerobic conditions promote the removal of diclofenac, while higher removal is observed under aerobic conditions for metoprolol and propranolol. Diclofenac removal efficiencies of $78 \%$ under anaerobic conditions and $59 \%$ under aerobic conditions were observed after 24 hours incubating a solution of mixed pharmaceuticals in demineralized water (Figure 4.1(a)). However, only 33\% metoprolol was removed under anaerobic conditions compared to $69 \%$ under aerobic conditions. Similarly, 51\% propranolol was removed under anaerobic conditions compared to $84 \%$ under aerobic conditions. Diclofenac degradation in a mixture together with other six pharmaceuticals (Figure 4.1(a) was found to be lower than in a demiwater system which only diclofenac was present. Under anaerobic conditions, 92\% diclofenac is removed with $\mathrm{MnO}_{2}$. While under aerobic conditions, 69\% diclofenac removal is observed (Figure 4.1(b)). 


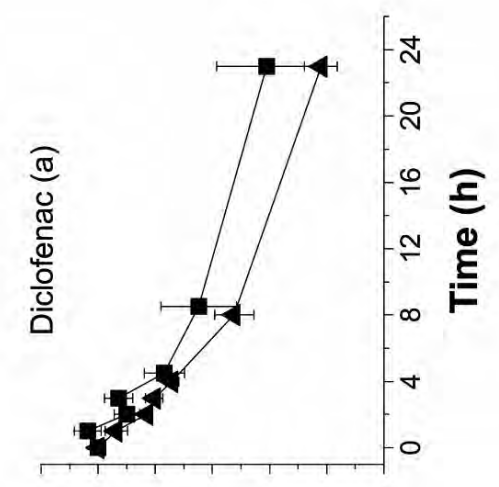

氙 $\frac{\sum}{\stackrel{\Xi}{\Xi}}$

芯施

응 응

$>$ 풀

힐

表家

密宁苛

흥. 을

อิ:
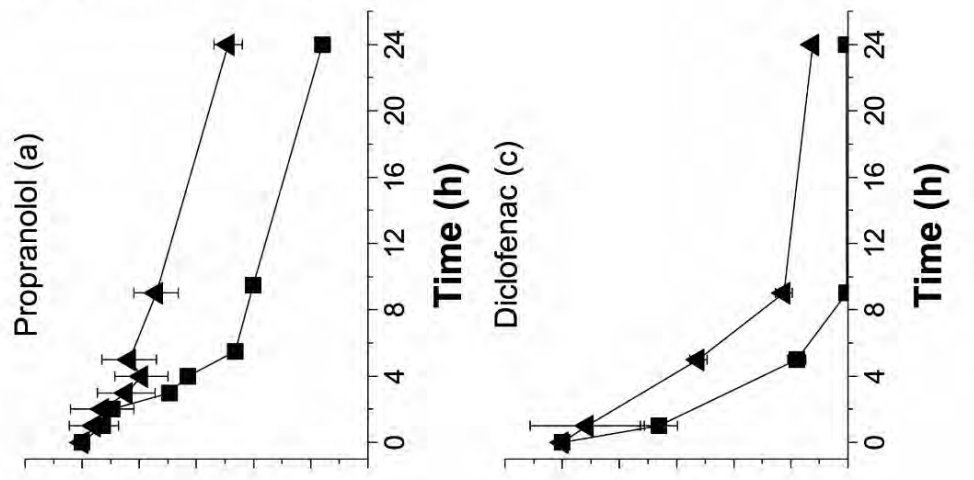

要.

छ

త⿹

흥

을

돈

严迅

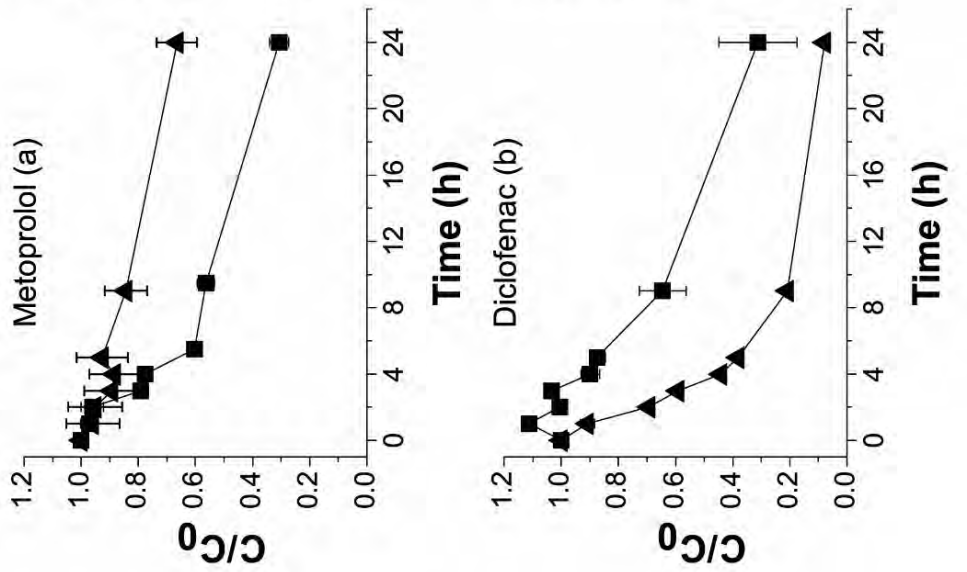

훙

के

ह 흉

돈

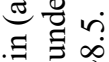

을 ?

$\sum \equiv$

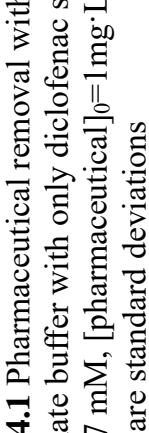

$\checkmark$ 政

된 की

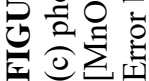


TABLE 4.1 Initial removal rate $\left(r_{o b s, ~ i n i t}, \mathrm{mg} \cdot \mathrm{L}^{-1} \cdot \mathrm{h}^{-1}, R^{2}=0.80-0.97\right)$ and initial removal rate constant $\left(k_{\text {obs, init }}, \mathrm{h}^{-1}, R^{2=} 0.85-0.99\right)$ of pharmaceutical removal with $\mathrm{MnO}_{2}$ based on pseudofirst-order in first 5 hours

\begin{tabular}{|c|c|c|c|c|c|c|c|}
\hline \multirow{2}{*}{$\begin{array}{l}\text { Experimental } \\
\text { solution }\end{array}$} & \multirow[t]{2}{*}{ Matrix } & \multirow[t]{2}{*}{$\mathrm{pH}$} & \multirow[t]{2}{*}{ Compound } & \multicolumn{2}{|c|}{$\begin{array}{c}r_{o b s, \text { init }} \\
\left(10^{-2} \mathrm{mg} \cdot \mathrm{L}^{-1} \cdot \mathrm{h}^{-1}\right)\end{array}$} & \multicolumn{2}{|c|}{$\begin{array}{c}k_{\text {obs, init }} \\
\left(10^{-2} \mathrm{~h}^{-1}\right)\end{array}$} \\
\hline & & & & Aerobic & Anaerobic & Aerobic & Anaerobic \\
\hline \multirow{3}{*}{$\begin{array}{l}\text { Mixture of } \\
\text { seven } \\
\text { pharmaceutical }\end{array}$} & \multirow{3}{*}{ Demiwater } & \multirow{3}{*}{$\sim 8.5$} & Metropolol & 7.39 & $2.98^{a}$ & 9.21 & 3.18 \\
\hline & & & Propranolol & 10.10 & 4.02 & 14.18 & 4.48 \\
\hline & & & Diclofenac & 5.33 & 6.48 & 5.96 & 7.49 \\
\hline $\begin{array}{l}\text { Only diclofenac } \\
\text { present in } \\
\text { solution }\end{array}$ & Demiwater & $\sim 8.5$ & Diclofenac $^{b}$ & 4.70 & 9.06 & 5.56 & 18.13 \\
\hline $\begin{array}{l}\text { Only diclofenac } \\
\text { present in } \\
\text { solution }\end{array}$ & $\begin{array}{l}50 \mathrm{mM} \\
\mathrm{PO}_{4}{ }^{3-} \\
\text { buffer }\end{array}$ & $\sim 7.0$ & Diclofenac $^{b}$ & 10.48 & 8.73 & 57.32 & 16.60 \\
\hline
\end{tabular}

Our results show that anaerobic conditions promote (are favourable for) diclofenac removal with $\mathrm{MnO}_{2}$. In contrast, previous studies show either no effect or lower removal efficiencies under anaerobic conditions ${ }^{[14,69,361]}$. This unique result directs our further studies on the mechanism of pharmaceutical removal under anaerobic conditions with $\mathrm{MnO}_{2}$. In order to eliminate the effects of $\mathrm{pH}$ and ionic strength on pharmaceutical removal with $\mathrm{MnO}_{2}{ }^{[69,108]}$, we control $\mathrm{pH}(\sim 7)$ with $50 \mathrm{mM}$ phosphate buffer and maintain the ionic strength $(0.1 \mathrm{M})$ with $\mathrm{NaCl}$. In further experiments with phosphate buffer, $90 \%$ of diclofenac is removed under anaerobic conditions while nearly complete degradation of diclofenac is observed under aerobic conditions (Figure 4.1 (c)).

TABLE 4.2 Diclofenac removal efficiency under anaerobic conditions at different $\mathrm{pH}$ conditions with two $\mathrm{MnO}_{2}$ morphologies after 48 hours. Experimental conditions: $\left[\mathrm{MnO}_{2}\right]_{0}=7$ $\mathrm{mM},[\text { diclofenac }]_{0}=1 \mathrm{mg} \cdot \mathrm{L}^{-1}$, [ionic strength] $=0.1 \mathrm{M}$

\begin{tabular}{llll}
\hline $\mathrm{MnO}_{2}$ morphologies & $\sim \mathrm{pH} 4.5$ & $\sim \mathrm{pH} 7.0$ & $\sim \mathrm{pH} 8.5$ \\
\hline Amorphous $\mathrm{MnO}_{2}$ & $100 \%$ & $100 \%$ & $71 \%$ \\
Crystalline $\mathrm{MnO}_{2}$ & $21 \%$ & Not detected & Not detected \\
\hline
\end{tabular}

A pseudo-first-order model with initial incubation period was applied to analyze the removal kinetics (Table 4.1), as performed in previous studies under aerobic conditions ${ }^{[125,359,361]}$. Comparison of the initial removal rate 
$\left(r_{o b s,}\right.$ init $)$ and the initial removal rate constant $\left(k_{o b s, ~ i n i t}\right)$ of different pharmaceuticals shows that oxygen affects pharmaceutical removal with $\mathrm{MnO}_{2}$. In demiwater with the pharmaceutical mixture and with only diclofenac, diclofenac removal is accelerated under anaerobic conditions; metoprolol and propranolol removal rates are lower under anaerobic conditions. Furthermore, diclofenac was removed at the highest rate when dissolved as a sole compound in aerobic phosphate buffer containing $\mathrm{MnO}_{2}$.

\subsubsection{Influence of $\mathrm{pH}$ and $\mathrm{MnO}_{2}$ morphologies on diclofenac removal}

Pharmaceutical removal with $\mathrm{MnO}_{2}$ is affected by $\mathrm{pH}$. Previous studies show that $\mathrm{MnO}_{2}$ morphologies also influence pharmaceutical removal ${ }^{[276]}$. However, our novel observation of diclofenac removal under anaerobic conditions with $\mathrm{MnO}_{2}$ indicate that the removal mechanisms of pharmaceuticals with $\mathrm{MnO}_{2}$ under anaerobic conditions might be different from removal under aerobic conditions. Therefore, it is important to investigate the effect of $\mathrm{pH}$ and $\mathrm{MnO}_{2}$ morphologies on diclofenac removal to understand the removal mechanism. We investigate the effect of $\mathrm{pH}$ and $\mathrm{MnO}_{2}$ morphologies using both amorphous $\mathrm{MnO}_{2}$ and crystalline $\mathrm{MnO}_{2}$ under anaerobic conditions at $\mathrm{pH} \sim 4.5, \mathrm{pH} \sim 7.0$, and at $\mathrm{pH} \sim 8.5$ established with a $50 \mathrm{mM}$ phosphate buffer.

Diclofenac removal efficiencies with $\mathrm{MnO}_{2}$ under anaerobic conditions are inversely related to $\mathrm{pH}$ (Table 4.2). Within 48 hours, diclofenac removal under anaerobic conditions varies from $100 \%$ at around $\mathrm{pH} \sim 4.5$ and $\mathrm{pH} \sim 7.0$, to $70 \%$ at $\mathrm{pH} \sim 8.5$ with amorphous $\mathrm{MnO}_{2}$. In contrast, diclofenac removal is notably lower with crystalline $\mathrm{MnO}_{2}$. Only $21 \%$ of diclofenac is removed with crystalline $\mathrm{MnO}_{2}$ at $\mathrm{pH} \sim 4.5$. In the experiments carried out at $\mathrm{pH} \sim 7.0$ and $\mathrm{pH} \sim 8.5$, no removal is with crystalline $\mathrm{MnO}_{2}$.

\subsubsection{Discussion}

Under aerobic conditions, pharmaceutical removal can be accelerated 
by oxygen ${ }^{[69]}$. However, this fails to explain why anaerobic conditions promote diclofenac removal when oxygen is not present to participate in the removal process (Text S4.4, Figure S4.4). There are different intermediates formed under aerobic and anaerobic conditions during diclofenac removal with $\mathrm{MnO}_{2}$ (Text S4.4, Figure S4.4). These intermediates have different adsorption affinities for the reactive sites on the $\mathrm{MnO}_{2}$ surface, which is possibly the key to explaining the differences between aerobic and anaerobic conditions. Based on the results, two factors appear to influence the efficiency of pharmaceutical removal and are elaborated below: (1) pharmaceutical molecular structure and chemical properties, and (2) the $\mathrm{MnO}_{2}$ properties.

\subsubsection{Pharmaceutical molecular structure and chemical properties}

The molecular structure and chemical properties of pharmaceuticals are important in organic compound removal with $\mathrm{MnO}_{2}$. Previous studies show that oxidation with $\mathrm{MnO}_{2}$ in the presence of oxygen involves cleavage of the $\mathrm{C}-\mathrm{N}$ bond of the organic compound. Metoprolol and propranolol have $\mathrm{C}-\mathrm{N}$ bonds, in which the $\mathrm{N}$ atom is bound to an alkyl group. These compounds are similar to those tested in previous studies (Table S4.1, S4.3) in which aerobic conditions promote the removal. This $\mathrm{C}-\mathrm{N}$ bond cleavage can result in the formation of radicals in the presence of oxygen [14, 69]. Oxidation of diclofenac involves hydroxylation and decarboxylation instead of C-N cleavage ${ }^{[108]}$, which is a different mechanism than that of metoprolol and propranolol. This shows that the removal mechanism is closely related to pharmaceutical molecular structure and chemical properties. 
The pharmaceutical's properties are also affected by $\mathrm{pH}$. Due to the low $\mathrm{pKa}$ of diclofenac $(\mathrm{pKa}=4.15)$, lower $\mathrm{pH}$ results in a less negatively charged compound. This leads to less electrostatic repulsion between diclofenac and $\mathrm{MnO}_{2}$, which is also negatively charged. As compared to the other two compounds, diclofenac has a higher affinity to adsorb at low $\mathrm{pH}$ onto $\mathrm{MnO}_{2}$ surface and therefore has a more favourable first step in removal with $\mathrm{MnO}_{2}$.

\subsubsection{2 $\mathrm{MnO}_{2}$ properties.}

The properties of $\mathrm{MnO}_{2}$ are affected by $\mathrm{pH}$ as well. At acidic $\mathrm{pH}, \mathrm{MnO}_{2}$ is also less negatively charged due to its isoelectric point, resulting in less electrostatic repulsion and better adsorption of organic compounds. In addition, the $\mathrm{MnO}_{2}$ redox potential increases from $0.76 \mathrm{~V}$ at $\mathrm{pH} 8.0$, to about $0.99 \mathrm{~V}$ at $\mathrm{pH} 4.0{ }^{[167]}$. Thus, the degradation reaction is energetically more favorable at lower $\mathrm{pH}$. Both factors may lead to faster degradation, as shown in our study (Table 4.2). $\mathrm{pH}$ used in this experiment is at neutral $\mathrm{pH}$, which was found unfavourable for oxidation of pharmaceuticals in previous studies ${ }^{[32,93,346]}$. In addition, there are less protons at the low redox potential of $\mathrm{MnO}_{2}$ at higher $\mathrm{pH}$, which is crucial for the electron transfer from $\mathrm{Mn}(\mathrm{IV})$ to $\mathrm{Mn}(\mathrm{II})$. As a result, no removal of caffeine, carbamazepine, ibuprofen, and naproxen was observed in this study, while the removal efficiency of metoprolol and propranolol is low under both aerobic and anaerobic conditions. 
(a) In demiwater

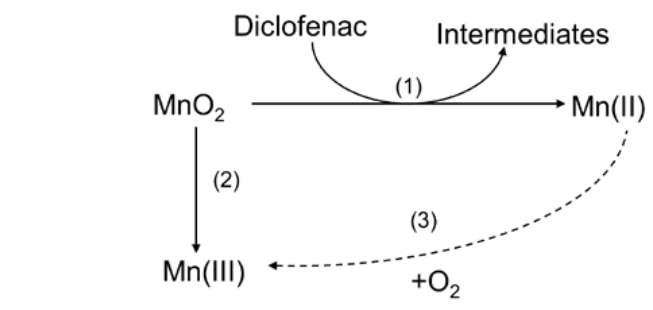

(b) In phosphate buffer

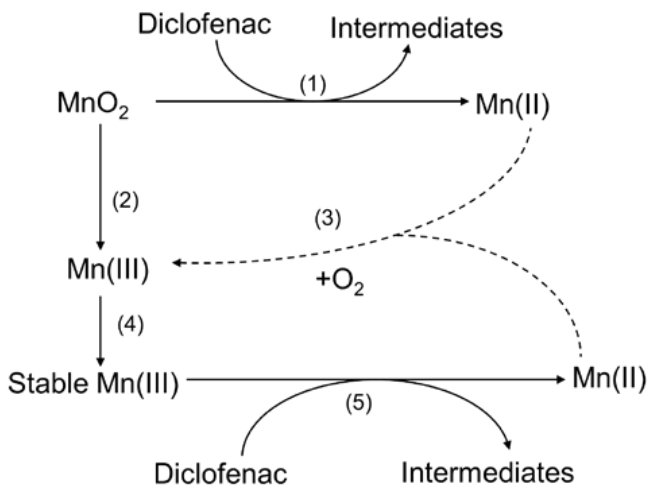

FIGURE 4.2 The effects of phosphate on diclofenac removal with $\mathrm{MnO}_{2}$ under aerobic and anaerobic conditions. Solid lines are processes under both aerobic and anaerobic conditions; dashed lines are the processes only under aerobic conditions. (1) $\mathrm{MnO}_{2}$ removes diclofenac via oxidation and produces $\mathrm{Mn}(\mathrm{II})^{[65,108]}$; (2) $\mathrm{Mn}(\mathrm{III})$ comes from $\mathrm{MnO}_{2}$ synthesis process [248]; (3) $\mathrm{Mn}$ (II) is oxidised to $\mathrm{Mn}$ (III) by $\mathrm{O}_{2}$; (4) $\mathrm{Mn}$ (III) from $\mathrm{MnO}_{2}$ was stabilized by $\mathrm{Mn}_{3}\left(\mathrm{PO}_{4}\right)_{2}$ formed via Eq. ${ }^{[127]}$; (5) Mn(III) oxidises diclofenac and produces $\mathrm{Mn}(\mathrm{II})$

Different $\mathrm{MnO}_{2}$ morphologies have different properties affecting diclofenac removal. In our research, diclofenac removal is better with amorphous $\mathrm{MnO}_{2}$ than with crystalline $\mathrm{MnO}_{2}$, which is in line with previously reported findings ${ }^{[248,276,313]}$. Amorphous $\mathrm{MnO}_{2}$ particles are usually smaller than crystalline particles. Thus the amorphous $\mathrm{MnO}_{2}$ particles have the larger surface area, which increases pharmaceutical removal. Unfortunately, due to the analytical limits, size analysis of amorphous $\mathrm{MnO}_{2}$ appeared technically not feasible (Text S4.5, Figure S4.5). In addition, amorphous $\mathrm{MnO}_{2}$ contains small amounts of $\mathrm{Mn}$ (III) which can increase $\mathrm{MnO}_{2}$ reactivity and oxidizing ability ${ }^{[248]}$, thus promoting pharmaceutical removal even further. 
In the presence of phosphate, diclofenac removal with $\mathrm{MnO}_{2}$ is better under aerobic conditions than that under anaerobic conditions. Using $\mathrm{O}_{2}$ to oxidize $\mathrm{Mn}(\mathrm{II})$ to $\mathrm{Mn}(\mathrm{III})$ is a thermodynamically favorable reaction. In the presence of phosphate buffer, phosphate can form $\mathrm{Mn}_{3}\left(\mathrm{PO}_{4}\right)_{2}$ with $\mathrm{Mn}$ (II) from diclofenac oxidation (Equation 4.1) ${ }^{[127]}$.

$$
3 \mathrm{Mn}^{2+}+2 \mathrm{PO}_{4}^{3-} \rightarrow \mathrm{Mn}_{3}\left(\mathrm{PO}_{4}\right)_{2}
$$

Computations show that the chemical structure of $\mathrm{Mn}_{3}\left(\mathrm{PO}_{4}\right)_{2}$ can stabilize $\mathrm{Mn}$ (III) and thereby facilitate $\mathrm{Mn}$ (II) oxidation to $\mathrm{Mn}(\mathrm{III})$ under aerobic conditions ${ }^{[127]}$. The $\mathrm{Mn}^{2+}$ analysis shows that the presence of higher $\mathrm{Mn}$ (II) concentrations in phosphate buffer than in demiwater, which we explain as a result of larger amounts of $\mathrm{Mn}$ (III) formed under aerobic conditions. More $\mathrm{Mn}(\mathrm{III})$ is likely the reason that more diclofenac is removed than under anaerobic conditions, as we observed (Figure 4.1) and mechanistically present in Figure 4.2.

\subsubsection{Reactive sites on $\mathrm{MnO}_{2}$ surface}

The adsorption of organic molecules onto a reactive metal oxide surface is found to be the key parameter dictating removal of many organic compounds, and specifically to the reactive sites on $\mathrm{MnO}_{2}$ surface ${ }^{[93,346,362]}$. Our results with the mixed pharmaceutical solution in the demiwater show competition for reactive sites between diclofenac and the other different pharmaceuticals. This is evidenced by the lower diclofenac removal in the presence of other pharmaceuticals (Figure 4.1(a), (b)). 
Based on our FTIR results, there was no obvious disappearance of reactive sites during diclofenac removal with $\mathrm{MnO}_{2}$ under both aerobic and anaerobic conditions (TEXT S4.6, Figure S4.6), possibly due to a relatively high concentration of $\mathrm{MnO}_{2}$ in the experiment. However, it is clearly that the FTIR spectrums are different between the $\mathrm{MnO}_{2}$ before and after reacting with diclofenac, especially under anaerobic conditions. This indicates that the intermediates from diclofenac change the $\mathrm{MnO}_{2}$. This change may contribute to the better diclofenac removal with $\mathrm{MnO}_{2}$ under anaerobic conditions.

In phosphate buffer, phosphate can reduce the diclofenac removal by being adsorbed onto the $\mathrm{MnO}_{2}$ surface and competing with DFC for the reactive sites of $\mathrm{MnO}_{2}{ }^{[352]}$. Consequently, although the lower $\mathrm{pH}$ in phosphate buffer should promote diclofenac removal $(\mathrm{pH} 7$ in buffer versus $\mathrm{pH} 8-9$ in demiwater), diclofenac removal is better in demiwater because $\mathrm{MnO}_{2}$ reactive sites are not blocked by phosphate (Table 4.1). However, similar removal efficiencies and kinetics in demiwater and phosphate buffer under anaerobic conditions are observed (Figure 4.1). This indicates there is a mechanism promoting diclofenac removal in phosphate buffer, which competes with the inhibition by phosphate adsorbing and occupying the reactive sites on $\mathrm{MnO}_{2}$ surface. From previous studies, it is known that $\mathrm{Mn}(\mathrm{II})$ can occupy reactive sites on $\mathrm{MnO}_{2}$ surface and then inhibit pharmaceutical removal ${ }^{[93,346]}$. Our removal results in phosphate buffer show that 1.54 $\mu \mathrm{M} \mathrm{Mn}{ }^{2+}$ was generated under aerobic conditions while $2.16 \mu \mathrm{M}$ was generated under anaerobic conditions. Less $\mathrm{Mn}(\mathrm{II})$ under aerobic conditions resulted in possibly less formation of $\mathrm{Mn}_{3}\left(\mathrm{PO}_{4}\right)_{2}$ via Eq.1, which presumably lead to more available reactive sites for diclofenac removal. Under anaerobic conditions, the balance of these promoting and inhibiting effects by adsorbing phosphate leads to similar diclofenac removal in demiwater and phosphate buffer. 


\subsection{Conclusion}

In conclusion, this study addresses the gap of understanding pharmaceutical removal in the absence of oxygen (anaerobic conditions) with $\mathrm{MnO}_{2}$. Anaerobic conditions show higher diclofenac removal compared to aerobic conditions in demiwater. In phosphate buffer, aerobic conditions resulted in about $10 \%$ more diclofenac removal. $\mathrm{pH}$ and $\mathrm{MnO}_{2}$ morphologies influence the removal process and its efficiency. Our results in both demiwater and phosphate buffer suggest that the process is promising in treating water and wastewater containing pharmaceuticals. The results show that amorphous $\mathrm{MnO}_{2}$ is the most suitable material for further research and application, and the most optimal and applicable conditions are at neutral $\mathrm{pH}$ in anaerobic systems. By using a more favourable $\mathrm{pH}$ (acidic $\mathrm{pH}$ ), the removal of all the pharmaceuticals can be expected under anaerobic conditions. To our knowledge, this is the first study discussing pharmaceutical removal with $\mathrm{MnO}_{2}$ under anaerobic conditions. Using anaerobic conditions is less energy-consuming compared to aerobic conditions (aeration), and Mn can be regenerated and recycled via a biological or chemical process $[126,301]$. Overall, this study makes a contribution to (1) understanding pharmaceutical removal in the absence of oxygen; (2) improving the knowledge of pharmaceutical removal mechanisms with $\mathrm{MnO}_{2}$; and (3) providing fundamental insight into a $\mathrm{MnO}_{2}$-based process which may lead to a more sustainable technology for pharmaceutical removal. 


\section{ACKNOWLEDGEMENT}

The work was supported by China Scholarship Council (File No.201308610161) and Wageningen University \& Research. The authors appreciate the support from Hans Beijleveld, Jan Kubiak, Ilse Gerrits, and Jean Slangen and their help with the chemical analyses. Special thanks go to Sidiharam Pujari for the FTIR analysis and Harry Baptist for the freezedrying procedure. 



\section{Chapter 5}

\section{Application of manganese oxides under anaerobic conditions to remove diclofenac from water}

A modified version of this chapter is submitted as

Liu, W.; Langenhoff, A. A. M.; Sutton, N. B.; Rijnaarts, H. H. M., Application of manganese oxides under anoxic conditions to remove diclofenac from water. 


\section{ABSTRACT}

This study investigates diclofenac (DFC) removal with manganese oxides $\left(\mathrm{MnO}_{2}\right)$ under anaerobic conditions (absence of oxygen). DFC removal is quantified in terms of efficiency and observed initial kinetics $\left(k_{\mathrm{obs}}\right.$, init $)$ to investigate the effects of temperature, $\mathrm{MnO}_{2}$ amount, and co-solutes. Overall, DFC removal and $k_{\text {obs, init }}$ both increase upon changing temperature from 10 to $30^{\circ} \mathrm{C}$ and both decrease after further increasing temperature to $40^{\circ} \mathrm{C}$. Increasing the amount of $\mathrm{MnO}_{2}$ relative to diclofenac improve degradation, as this provides more reactive surface sites for DFC conversions. However, increasing the molar ratio of $\mathrm{MnO}_{2}$ and $\mathrm{DFC}$ from 2200:1 to 8900:1 does not further increase diclofenac removal. The presence of metal ions inhibits DFC removal, possibly because the ions adsorb onto the reactive sites at the $\mathrm{MnO}_{2}$ surface and compete with DFC. Phosphate has a diverse effect on diclofenac degradation: low concentrations inhibit and high concentrations promote removal. The presence of humic acids significantly promotes diclofenac removal, which is probably caused by quickly absorbing DFC and attaching to $\mathrm{MnO}_{2}$ surface. Also, humic acids can bind the $\mathrm{Mn}^{2+}$ produced during the DFC removal. These findings are a first step towards further developing pharmaceutical removal technology using $\mathrm{MnO}_{2}$ under anaerobic conditions.

KEYWORDS: manganese oxides; abiotic pharmaceutical removal; anaerobic condition; temperature; $\mathrm{MnO}_{2}$ amount; co-solutes 


\subsection{Introduction}

Diclofenac ([2-(2,6-Dichloroanilino)phenyl]acetic acid, DFC) is a commonly used pharmaceutical known to have the highest acute toxicity to wildlife among the non-steroidal anti-inflammatory drugs ${ }^{[174,279]}$. In Europe, the mean DFC consumption is around $1300 \mu \mathrm{g} \cdot$ capita $^{-1} \cdot \mathrm{d}^{-1}[128]$. As a result, DFC has been detected in surface water, groundwater, and even in drinking water in the range of $0-1000 \mathrm{ng} \cdot \mathrm{L}^{-1}{ }^{[304]}$. Due to its toxic effects to the environment and ecosystem, the European Union (EU) has added DFC into the "Watchlist" [60]. The European Community suggests DFC concentration for the environmental quality threshold for good water quality a value of $100 \mathrm{ng} \cdot \mathrm{L}^{-1}$ (annual average) ${ }^{[56]}$. Various technologies can remove DFC, such as advanced oxidation processes like photo-degradation, or algae treatment systems, but these technologies often either produce toxic intermediates or are too costly $[49,170,174]$.

Using manganese oxide $\left(\mathrm{MnO}_{2}\right)$ to remove pharmaceuticals can achieve high removal efficiencies and may produce less and lower amounts

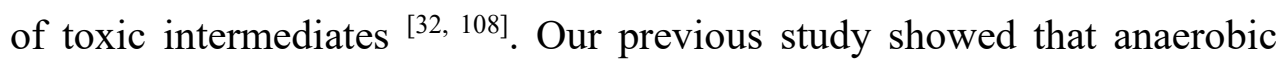
conditions (absence of oxygen) are favorable for DFC removal with $\mathrm{MnO}_{2}$, opening the way to a new cost-efficient and sustainable pharmaceutical removal process based on applying $\mathrm{MnO}_{2}$ under anaerobic conditions, not yet studied by others ${ }^{[172]}$. In order to develop this process into an applicable technology, a number of operational parameters were studied, namely temperature, the amount of $\mathrm{MnO}_{2}$, and the presence of co-solutes (metal ions, phosphate, humic acid). 
Reactions between $\mathrm{MnO}_{2}$ and organic compounds are endothermic, and therefore increasing temperature can accelerate the rates of the removal processes ${ }^{[32,260]}$. However, observed initial rate constant of oxytetracycline removal with $\mathrm{MnO}_{2}$ under aerobic conditions is reported to be lower at $40^{\circ} \mathrm{C}$ than at 5 to $30^{\circ} \mathrm{C}{ }^{[260]}$. These contradicting results to theory and the lack of investigations under anaerobic conditions lead to the necessity of further investigating temperature effects. From an application perspective, the results will partially determine the applicability of $\mathrm{MnO}_{2}$ technologies in different seasons and climates.

Another important parameter in the application is the amount of $\mathrm{MnO}_{2}$, which can be expressed as the molar ratio between the pharmaceutical(s) and $\mathrm{MnO}_{2}$. Previous studies show that increasing the ratio between $\mathrm{MnO}_{2}$ and chlortetracycline in the range of 4:1 to $32: 1$ leads to faster removal ${ }^{[32]}$. However, no significant change is observed in triclosan, carbadox, and ciprofloxacin removal with $\mathrm{MnO}_{2}$ when the ratio changes from 10:1 to 300:1 ${ }^{[359]}$. In addition, the ratios studied previously are usually low while they can be much higher in application due to the low concentration of pharmaceuticals. From an application perspective, optimizing $\mathrm{MnO}_{2}$ amount can decrease operation costs, by applying minimum amounts of $\mathrm{MnO}_{2}$ at maximum DFC removal.

Co-solutes in water including metal ions, anions (like phosphate), and organic compounds are commonly observed. The EU allows $3.57 \mu \mathrm{M}$ iron and $0.91 \mu \mathrm{M}$ manganese in drinking water ${ }^{[59]}$. In urban wastewater effluent, the phosphate concentration should be $<2 \mathrm{mg} P \cdot \mathrm{L}^{-1}$ while the organic compounds (expressed as Chemical Oxidation Demand, COD) are allowed at $125 \mathrm{mg} \cdot \mathrm{L}^{-1}$ based on EU regulation ${ }^{[58]}$. All these co-solutes can affect pharmaceutical removal with $\mathrm{MnO}_{2}$ in WWTP effluents under aerobic conditions. Previous studies under aerobic conditions showed that pharmaceutical removal could be inhibited by metal ions and phosphate $\left(\mathrm{PO}_{4}{ }^{3-}\right)^{[32,167]}$ while humic acid representing organic matters can both promote and inhibit this process ${ }^{[132,167]}$. However, none of these parameters 
are investigated under anaerobic conditions. In this study, four metal ions $\left(\mathrm{Mn}^{2+}, \mathrm{Ca}^{2+}, \mathrm{Mg}^{2+}\right.$, and $\left.\mathrm{Fe}^{3+}\right), \mathrm{PO}_{4}^{3-}$, and different concentrations of humic acid are selected to investigate the effects of co-solutes on the application of $\mathrm{MnO}_{2}$ under anaerobic to remove DFC.

In this study, we investigate the efficiencies and reaction kinetics of DFC removal from water by $\mathrm{MnO}_{2}$ under anaerobic conditions. The effects of temperature, $\mathrm{MnO}_{2}$ amount, and co-solutes were investigated to evaluate the application potential and optimal conditions. Removal mechanisms under anaerobic conditions are affected by the pharmaceutical chemical structure and properties of both pharmaceuticals and $\mathrm{MnO}_{2}{ }^{[69,172]}$. The results provide the basis for developing a new treatment technology for removal of trace organic contaminants from WWTP effluent.

\subsection{Materials and methods}

\subsubsection{Chemicals}

Diclofenac sodium salt (DFC) was purchased from Sigma-Aldrich (Table 5.1). Other chemical reagents used in the experiments were purchased from either Sigma-Aldrich or Merck KGaA (Germany). All the chemicals had $>97 \%$ purity. The liquid used in these experiments was at either high performance liquid chromatographic grade or ultra-performance liquid chromatographic grade. Millipore water purification system was used to prepare ultrapure water $(18.3 \mathrm{M} \Omega \cdot \mathrm{cm}, \mathrm{TOC}=18 \mathrm{ppb})$. Anaerobic water was prepared by boiling demineralized water (demiwater) for 5 min and cooling under $\mathrm{N}_{2}$-flow to the room temperature. All solutions were prepared with anaerobic water unless specified otherwise. DFC stock solution was prepared in ultrapure water to reach a final concentration of $157 \mu \mathrm{M}$ in a 50$\mathrm{mL}$ amber glass bottle. This stock was stored at $-20^{\circ} \mathrm{C}$ to avoid potential decomposition. Humic acid (HA) was purchased from Sigma-Aldrich (product No. 53680). HA stock solution was prepared at a final concentration of $1000 \mathrm{mg} \cdot \mathrm{L}^{-1}$ in anaerobic water with $1-3$ drops of $1 \mathrm{M}$ 
$\mathrm{NaOH}$. This stock was stored in a $50 \mathrm{~mL}$ glass bottle at $4^{\circ} \mathrm{C}$ to avoid decomposition.

TABLE 5.1 Chemical structure and properties of diclofenac sodium (DFC) ${ }^{a}$

\begin{tabular}{|l|l|l|}
\hline & CAS No. & $15307-79-6$ \\
\hline \multirow{2}{*}{ Empirical Formula } & $\mathrm{C}_{14} \mathrm{H}_{10} \mathrm{Cl}_{2} \mathrm{NNaO}_{2}$ \\
\hline & Molecular Weight & $318.13 \mathrm{~g} \cdot \mathrm{mol}^{-1}$ \\
\hline PKa & 4.15 \\
\hline & logK & 1.13 \\
\hline & Solubility in water & $50 \mathrm{mg} \cdot \mathrm{mL}^{-1}$ \\
\hline
\end{tabular}

${ }^{a}$ The data are collected from Sigma-Aldrich and literature ${ }^{[308]}$

\subsubsection{Synthesis of manganese oxides}

Manganese oxides $\left(\mathrm{MnO}_{2}\right)$ were freshly synthesized by a modified method as previously described ${ }^{[172]}$. In brief, equal volumes of $0.4 \mathrm{M} \mathrm{MnCl}_{2}$ and $0.4 \mathrm{M} \mathrm{KMnO}_{4}$ were mixed and adjusted to $\mathrm{pH} 10$ with $1 \mathrm{M} \mathrm{NaOH}$. The $\mathrm{MnO}_{2}$ was washed six times with anaerobic demiwater via centrifugation (15 min at $5000 \mathrm{rpm}$ ) and decanting. $\mathrm{MnO}_{2}$ was stored at $4^{\circ} \mathrm{C}$ as a suspension with $\mathrm{N}_{2}$ headspace and diluted to an appropriate concentration before using.

\subsubsection{Experimental setup}

Batch experiments were prepared under anaerobic conditions in 125 $\mathrm{mL}$ glass bottles. All bottles were sealed with rubber stoppers and aluminum crimp-caps, settled at $30^{\circ} \mathrm{C}$ without shaking, and covered with aluminum foil to avoid photodecomposition. The $\mathrm{pH}$ was maintained at 7 for all experiments with a $10 \mathrm{mM}$ MOPS (4-morpholinepropanesulfonic acid) buffer solution. Sodium chloride $(\mathrm{NaCl})$ was added to adjust the ionic strength $(I=0.01 \mathrm{M})$. The final concentration of $\mathrm{MnO}_{2}$ in the bottle was $7 \mathrm{mM}$. The $50 \mathrm{ml}$ buffer containing $\mathrm{NaCl}$ was added into the experimental bottles. The headspace of all bottles was exchanged with $\mathrm{N}_{2}$ to keep the system anaerobic. 
The experiments were started by adding $0.25-1 \mathrm{~mL}$ DFC stock solution $(157 \mu \mathrm{M})$ into the experimental bottles. All the experiments were carried out in triplicate and lasted for 33 hours in most cases. $1.2 \mathrm{~mL}$ mixture samples were taken regularly during the experimental period. The samples were centrifuged immediately at $10000 \mathrm{rpm}$ for $10 \mathrm{~min}$. The supernatant was collected and stored at $-20^{\circ} \mathrm{C}$ until analysis. Sorption of DFC onto $\mathrm{MnO}_{2}$ were not taken into account because it is insignificant based on previous studies ${ }^{[65,172]}$, but it is still an important removal mechanism.

Control experiments without $\mathrm{MnO}_{2}$ were prepared and conducted simultaneously with each batch of reactions. The effect of temperature was investigated by conducting the experiments at $10,20,30$, or $40^{\circ} \mathrm{C}$. The effect of $\mathrm{MnO}_{2}$ amount was investigated by applying different molar ratio between $\mathrm{MnO}_{2}$ and $\mathrm{DFC}$ from 480:1 to $8900: 1$ at $20^{\circ} \mathrm{C}$. The effect of co-solutes was investigated at $30^{\circ} \mathrm{C}$ with different concentrations of metal ions $\left(\mathrm{Mn}^{2+}, \mathrm{Ca}^{2+}\right.$, $\mathrm{Mg}^{2+}, \mathrm{Fe}^{3+}$ at 0.1 and $\left.0.1 \mathrm{mM}\right)$, the anion $\left(\mathrm{PO}_{4}{ }^{3-}\right.$ at $0.5,1$, and $\left.116 \mathrm{mgP} \cdot \mathrm{L}^{-1}\right)$, and dissolved organic compound (HA at 5, 10, 15, and $25 \mathrm{mg} \cdot \mathrm{L}^{-1}$ ). In the experiments with HA, DFC was added before adding HA. Samples were taken before and after adding $\mathrm{HA}$ at the beginning of the experiments.

\subsubsection{Analysis}

DFC was measured by ultra-performance liquid chromatography with a diode array detector (Ultimate 3000 , Thermo co. Ltd.). $10 \mu \mathrm{L}$ of samples were automatically injected into a CSH phenyl-Hexyl column $(1.7 \mu \mathrm{m}, 130$ $\AA, 2.1 \times 150 \mathrm{~mm}$, Waters co., USA). The details of analytical methods and setting of the machine were described previously ${ }^{[95,172]}$.

Phosphate concentration was analyzed by colorimetric method using cuvettes from Hach Lange (LCK 349). All metal ions were analyzed by an inductively coupled plasma atomic emission spectroscopy (ICP-OES, Perkin Elmer Instruments, USA). $\mathrm{pH}$ was determined by a $\mathrm{pH}$ meter (PHM210, MeterLab, Radiometer Analytical). 


\subsubsection{Kinetics study}

In literature, different models have been used to describe organic compound removal with $\mathrm{MnO}_{2}$ : pseudo-first-order model, pseudo-firstorder model with data from the first several hours of the experiments, pseudo-second-order model, and mechanism-based kinetics models [32, 260, 359]. The pseudo-first-order kinetic model has been used to evaluate the reaction kinetics of micropollutants and other organic compounds with $\mathrm{MnO}_{2}{ }^{[125]}$. However, in experimental results deviation from this model after a certain reaction time was also reported. To better predict long-term kinetics of organic compound removal with $\mathrm{MnO}_{2}$, the pseudo-second-order model was used ${ }^{[32]}$. The pseudo-second-order model usually gave a better fit during the long period. The mechanism-based model was proposed to fit data obtained in long-term experiments. Rubert and Pedersen ${ }^{[260]}$ developed the mechanism-based kinetics model to better describe oxytetracycline removal with $\mathrm{MnO}_{2}$. Similarly, Zhang, Chen and Huang [359] described another kinetic model based on the removal mechanism to describe antibacterial agent removal with $\mathrm{MnO}_{2}$. In this study, all four models were validated with the results obtained at $30^{\circ} \mathrm{C}$ with $7 \mathrm{mM} \mathrm{MnO}_{2}, 3.14 \mu \mathrm{M} \mathrm{DFC}$, and no co-solutes. 


\subsection{Results and discussion}

\subsubsection{Kinetic results}

Our results show that diclofenac (DFC) can be removed by applying $\mathrm{MnO}_{2}$ under anaerobic conditions. The pseudo-first-order model fits the data poorly $\left(R^{2}=0.84\right)$ while the other three models fit the data better and are useful for evaluating our kinetic studies $\left(R^{2}=0.96-0.99\right)$ (Text S5.1, Table $\mathrm{S} 5.1$, Figure S5.1,). The results show that anaerobic $\mathrm{MnO}_{2}$ mediated DFC removal follows a two-stage kinetic process under all experimental conditions. Most DFC conversion is obtained in the first 9 hours (following the pseudo-first-order reaction) and only about $10 \%$ DFC removal is obtained in the subsequent 24 hours (from $\mathrm{t}=9 \mathrm{~h}$ to $\mathrm{t}=33 \mathrm{~h}$, following the pseudo-zero-order reaction). Therefore, the pseudo-first-order model with data from the first 9 hours was used to calculate the observed removal rate constants $\left(k_{\text {obs,init }}\right)$ (Table 5.2). Without $\mathrm{MnO}_{2}$, no DFC removal is observed (Text S5.2, Table S5.2, Figure S5.2).

\subsubsection{Effect of temperature}

Results show that the application of manganese oxides $\left(\mathrm{MnO}_{2}\right)$ to remove diclofenac (DFC) under anaerobic conditions is generally an endothermic process (Table 5.2, Figure 5.1). DFC removal increases from

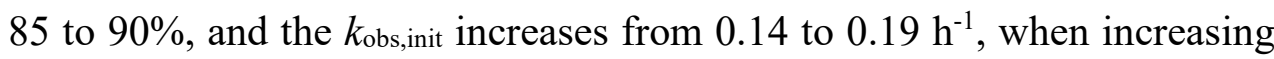
the temperature from 10 to $30^{\circ} \mathrm{C}$. However, when the temperature is further increased to $40^{\circ} \mathrm{C}$, both removal and $k_{\text {obs, init }}$ drop dramatically to respectively $38 \%$ and $0.04 \mathrm{~h}^{-1}$ (Figure 5.1, Table 5.2). When the temperature is subsequently reduced from 40 to $20^{\circ} \mathrm{C}$, only a slight increase in total removal is observed and $k_{\text {obs, init }}$ remained low. 
At $40^{\circ} \mathrm{C}, \mathrm{MnO}_{2}$ particle aggregation is observed (Figure $\mathrm{S} 3(\mathrm{a}-\mathrm{d}$ ), Figure S5.4). To investigate whether this aggregation plays a role in the unexpected drop of DFC removal at $40^{\circ} \mathrm{C}$, an additional experiment was performed (Figure 5.1, dashed line). The experiment was started at $40^{\circ} \mathrm{C}$, but the temperature was changed to $20^{\circ} \mathrm{C} t=9 \mathrm{~h}$. The temperature of the bottles dropped to $20^{\circ} \mathrm{C}$ within 1 hour. Results show that only $22 \%$ DFC is removed from $\mathrm{t}=9 \mathrm{~h}$ to $\mathrm{t}=33 \mathrm{~h}$, which is lower than the $48 \%$ DFC removed in this time period if the experiment is started at $20^{\circ} \mathrm{C}$. The results show that the process is irreversible.

Aggregation of $\mathrm{MnO}_{2}$ particles was observed at $40^{\circ} \mathrm{C}$ which can decrease the amount and availability of reactive surface sites on $\mathrm{MnO}_{2}$ for DFC removal. This may be a reason for the reduced DFC removal at high temperature. The aggregation may be caused by two processes: Ostwald ripening and/or aging. Ostwald ripening, also called coarsening or competitive growth, occurs in the suspension where large particles grow at the cost of small particles ${ }^{[246]}$. Amorphous particles (or small crystals) dissolve and re-precipitate on the largest crystals initially present. As a result, the amorphous particles or small crystals grow to relatively large crystals ${ }^{[229]}$. Ostwald ripening is promoted by elevated temperature, as demonstrated in previous studies ${ }^{[188,284]}$. The aging process is the physical change of minerals over time. Aggregation of $\mathrm{MnO}_{2}$ is observed to be a fast process at $40^{\circ} \mathrm{C}$ (hours - days), and a slow process at $20^{\circ} \mathrm{C}$ ( 6 months, the duration of our experiments, Text S5.3, Figure S5.3 (e, f)). This indicates that $\mathrm{MnO}_{2}$ aging process is accelerated when changing the temperature to $40^{\circ} \mathrm{C}$, which quickly changes $\mathrm{MnO}_{2}$ morphology irreversibly ${ }^{[293]}$. As a result, active $\mathrm{MnO}_{2}$ precipitates into a more stable form, leading to less DFC removal ${ }^{[208]}$, and the reactivity cannot be restored when changing again to lower temperatures, i.e. $20^{\circ} \mathrm{C}$ (Figure 5.1, dashed line). Overall, the aggregation of $\mathrm{MnO}_{2}$ particles leads to less DFC removal. 


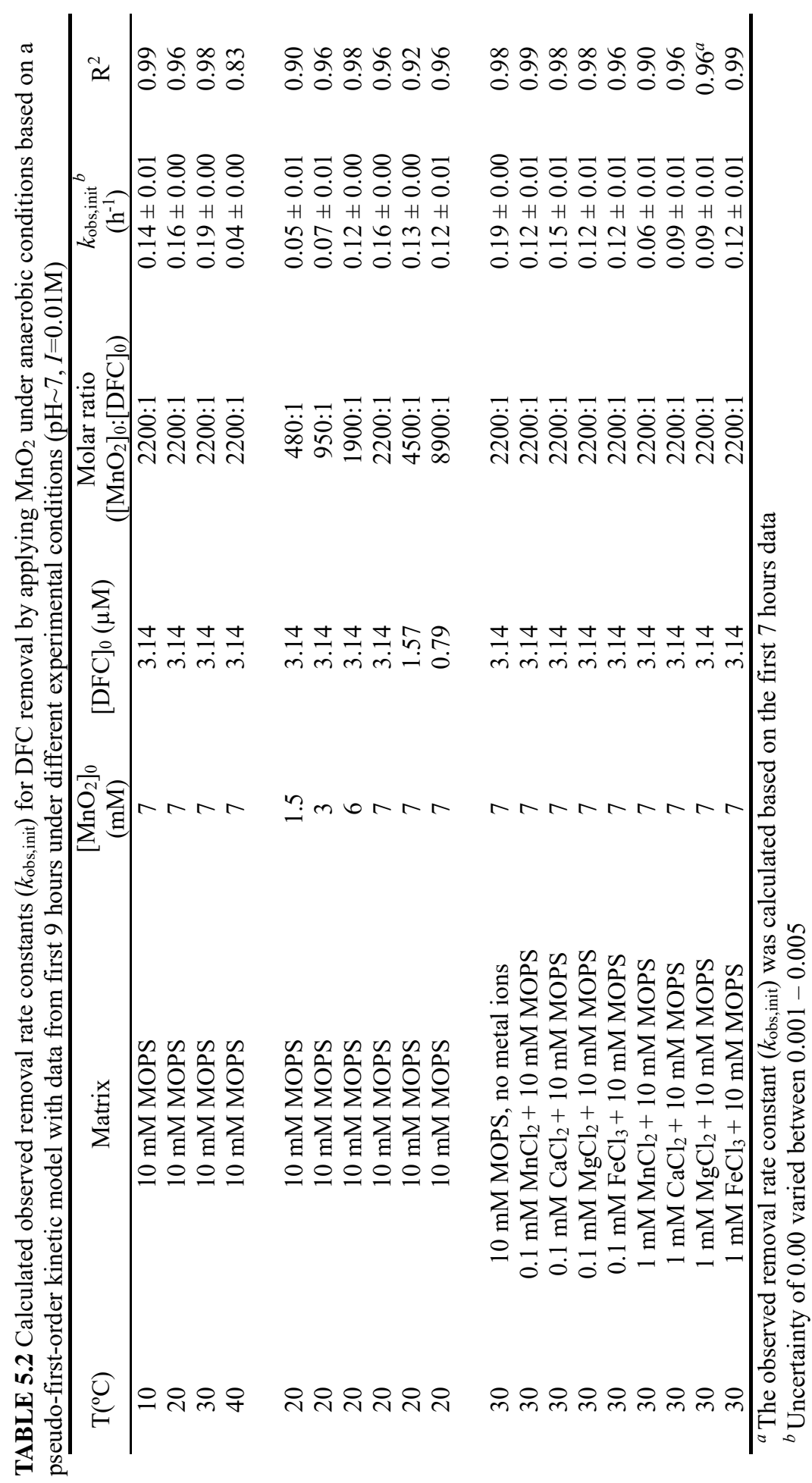




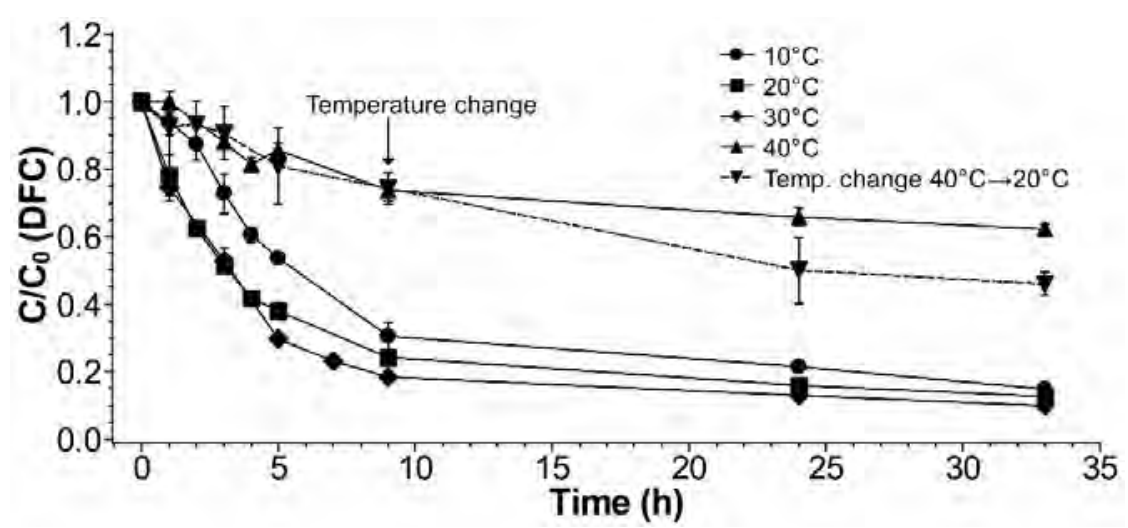

FIGURE 5.1 DFC removal by applying $\mathrm{MnO}_{2}$ under anaerobic conditions at different temperatures. The solid lines represent the experiments maintained at one temperature while the dashed line represents the experiment in which the temperature changed. Experimental conditions: $\left[\mathrm{MnO}_{2}\right]_{0}=7 \mathrm{mM},[\mathrm{DFC}]_{0}=3.14 \mu \mathrm{M}, \mathrm{pH} \sim 7, I=0.01 \mathrm{M}$. Error bars are standard deviations of triplicate experiments

\subsubsection{Effect of $\mathrm{MnO}_{2}$ amount}

The amount of $\mathrm{MnO}_{2}$, expressed as the molar ratio between $\mathrm{MnO}_{2}$ and DFC, determines the efficiency of DFC removal under anaerobic conditions. Results show that a higher molar ratio between $\mathrm{MnO}_{2}$ and $\mathrm{DFC}$ leads to higher and faster removal (Table 5.2, Figure 5.2). DFC removal decreases from $52 \%$ at a molar ratio of $\mathrm{MnO}_{2}$ :DFC of $480: 1$ to $87 \%$ at a molar ratio of 2200:1, while the $k_{\text {obs,init }}$ increases from 0.05 to $0.16 \mathrm{~h}^{-1}$. Further increasing the amount of $\mathrm{MnO}_{2}$ to $\mathrm{DFC} / \mathrm{MnO}_{2}$ changes from 2200:1 to $8900: 1$, both the removal efficiency and $k_{\text {obs,init }}$ are slightly decreased and the $k_{\text {obs,init }}$ values levels off to $0.13 \mathrm{~h}^{-1}$. 


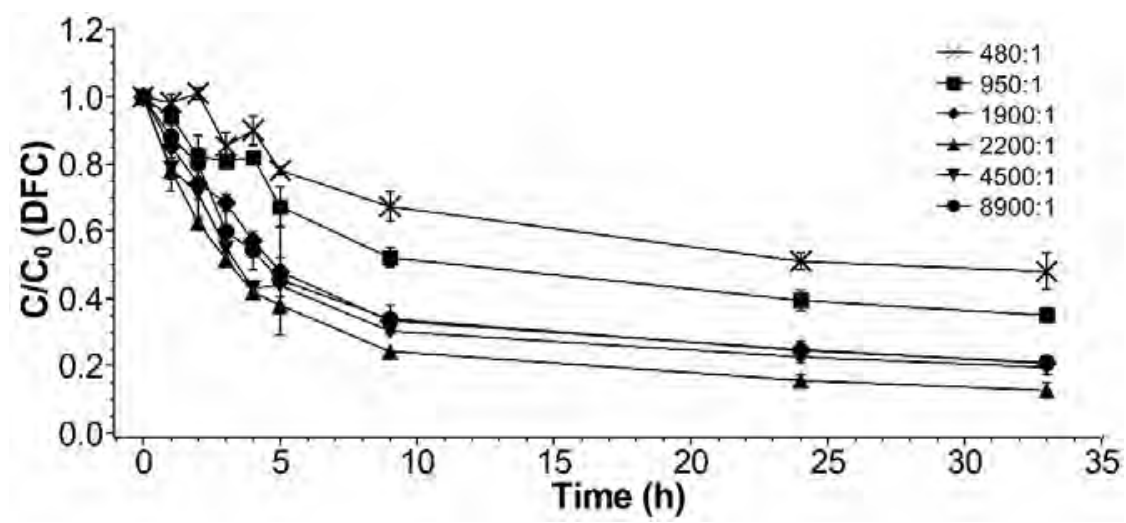

FIGURE 5.2 DFC removal by applying different amounts of $\mathrm{MnO}_{2}$ (molar ratio $\left.[\mathrm{DFC}]_{0} /\left[\mathrm{MnO}_{2}\right]_{0}\right)$ under anaerobic conditions. Experimental conditions: $20^{\circ} \mathrm{C}, \mathrm{pH} \sim 7, I=0.01$ M. Error bars are the standard deviation of triplicate experiments

When the $\mathrm{MnO}_{2}$ particles are applied in a reactor for treating WWTP effluent, the amount of $\mathrm{MnO}_{2}$ is in the $\mathrm{mM}$ range while the concentrations of DFC and other pharmaceuticals are extremely low, in the $\mathrm{nM}$ to $\mu \mathrm{M}$ range. Therefore, high ratios between $\mathrm{MnO}_{2}$ and DFC were used in this study to mimic those reactor conditions. Results show that increasing the amount of $\mathrm{MnO}_{2}$ improves pharmaceutical removal with $\mathrm{MnO}_{2}$. Increasing the amount of $\mathrm{MnO}_{2}$ provides relatively more reactive surface sites. As a result, DFC can better attach to the $\mathrm{MnO}_{2}$ surface, the first step in its removal. After adsorprion, the DFC is removed via chemical oxidation. During this process, increasing surface reactive sites will not improve the oxidation of DFC. In addition, due to the properties of pharmaceuticals and $\mathrm{MnO}_{2}$, adsorption will not be improved by simply increasing the reactive surfaces sites because of increasing $\mathrm{MnO}_{2}$ amount. As a result, both the removal and $k_{\text {obs,init }}$ are stable when the $\mathrm{MnO}_{2}$ : DFC changes from 2200:1 to 8900:1. 


\subsubsection{Effect of metal ions}

Under anaerobic conditions, inhibition of DFC removal is observed in the presence of four metal ions at two different concentrations (Table 5.2, Figure 5.3). In the absence of metal ions, after 33 hours, $90 \%$ of the DFC is removed. In the presence of $0.1 \mathrm{mM} \mathrm{Mn}^{2+}, \mathrm{Ca}^{2+}, \mathrm{Mg}^{2+}$, or $\mathrm{Fe}^{3+}, 80-84 \%$ of DFC is removed. Results also show that $\mathrm{Ca}^{2+}$ has the least inhibition on DFC removal, with a decrease in $k_{\mathrm{obs} \text {,init }}$ from 0.19 to $0.15 \mathrm{~h}^{-1}$. For the other metal ions, $k_{\mathrm{obs} \text {,init }}$ decreases to about $0.12 \mathrm{~h}^{-1}$. Increasing the concentration of metal ions to $1 \mathrm{mM}$ results in further inhibition effects in the order of "metal free" $<\mathrm{Fe}^{3+}<\mathrm{Ca}^{2+} \approx \mathrm{Mg}^{2+}<\mathrm{Mn}^{2+}$. Only $58 \%$ of DFC is removed in the presence of $\mathrm{Mn}^{2+}$, followed by $77 \%$ with $\mathrm{Mg}^{2+}$ and $74 \%$ with $\mathrm{Ca}^{2+}$. The least inhibitory effect is observed in the presence of $\mathrm{Fe}^{3+}$ with about $88 \%$ of DFC removed, which is close to the removal (90\%) in the absence of metals. The inhibition in the kinetics follows the same order as the removal efficiency, namely "metal free" $<\mathrm{Fe}^{3+}<\mathrm{Ca}^{2+} \approx \mathrm{Mg}^{2+}<\mathrm{Mn}^{2+}$ (Table 5.2).

The inhibitory effect of metal ions is most likely due to competition by ions with $\mathrm{DFC}$ for reactive surface sites on $\mathrm{MnO}_{2}$. Since the $\mathrm{pH}$ characterizing the point-of-zero-charge of $\mathrm{MnO}_{2}$ (birnessite) is 0.97 [299], $\mathrm{MnO}_{2}$ is negatively charged at neutral $\mathrm{pH}$. Similarly, DFC is also negatively charged $(\mathrm{pKa}=4.15)$ under the experimental conditions. Therefore, the positively charged metal ions are more easily adsorbed onto $\mathrm{MnO}_{2}$ surface via electrostatic interactions than DFC via forming complex, resulting in fewer reactive surface sites available for DFC removal. The adsorption of metal ions onto $\mathrm{MnO}_{2}$ is related to the radius of hydrated ions ${ }^{[83]}$. At low concentration $(0.1 \mathrm{mM})$, abundant reactive sites for DFC removal are present, even though some reactive surface sites are used by metal ions. Therefore, there is little difference between metal ions and their inhibition of DFC removal. However, at a higher concentration $(1 \mathrm{mM})$, the inhibition effect of metal ions follows the order of $\mathrm{Mn}^{2+}>\mathrm{Ca}^{2+} \approx \mathrm{Mg}^{2+}>\mathrm{Fe}^{3+}$. This order is roughly the same as the adsorption affinity described previously ${ }^{[209]}$. 
The least inhibition of $\mathrm{Fe}^{3+}$ is probably because the radius of $\mathrm{Fe}^{3+}(0.064 \mathrm{~nm})$ is the smallest among the four metal ions $\left(\mathrm{Mn}^{2+}: 0.080 \mathrm{~nm}, \mathrm{Ca}^{2+}: 0.103 \mathrm{~nm}\right.$, $\left.\mathrm{Mg}^{2+}: 0.070 \mathrm{~nm}\right)$. It is reported that the decreasing ionic radius will decrease adsorption affinity ${ }^{[269]}$. In addition, even though $\mathrm{Fe}^{3+}$ was added as ion into the bottle, some of them will precipitate at $\mathrm{pH} 7$ in the experiments, which also decreases the inhibition effect of Fe.
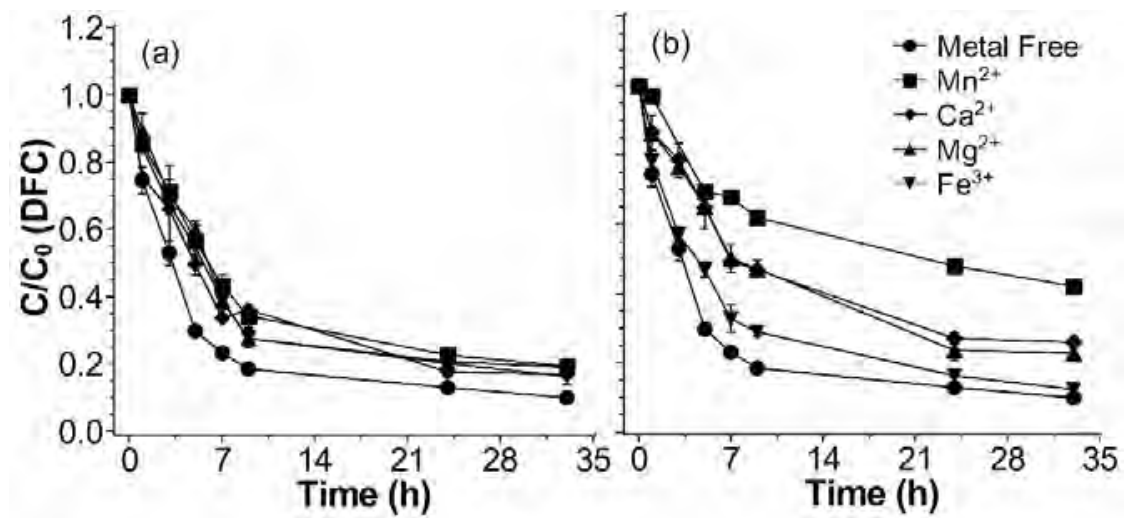

FIGURE 5.3 DFC removal by applying $\mathrm{MnO}_{2}$ under anaerobic conditions in the presence of different metal ions at (a) $0.1 \mathrm{mM}$; and (b) $1 \mathrm{mM}$. Experimental conditions: $\left[\mathrm{MnO}_{2}\right]_{0}=7 \mathrm{mM}$; $[\mathrm{DFC}]_{0}=3.14 \mu \mathrm{M}, 30^{\circ} \mathrm{C}, \mathrm{pH} \sim 7, I=0.01 \mathrm{M}$. Error bars are standard deviations of triplicate experiments

\subsubsection{Effect of phosphate}

Phosphate $\left(\mathrm{PO}_{4}{ }^{3-}\right)$ is a common pollutant in wastewater which affects the removal of micropollutants including pharmaceuticals and other organic compounds with $\mathrm{MnO}_{2}{ }^{[32,85,248]}$. Of the studies carried out under aerobic conditions, a limited number of studies have looked into the effects of $\mathrm{PO}_{4}{ }^{3-}$, and no studies are reported for anaerobic conditions ${ }^{[32,248]}$. Therefore, we investigated the effects of phosphate $\left(\mathrm{PO}_{4}{ }^{3-}\right)$ on the application of $\mathrm{MnO}_{2}$ under anaerobic conditions to remove DFC (Table 5.3). At low $\mathrm{PO}_{4}{ }^{3-}$ concentration $\left(<1 \mathrm{mg} \mathrm{P} \cdot \mathrm{L}^{-1}\right)$, DFC removal decreases from $76 \%$ with no $\mathrm{PO}_{4}{ }^{3-}$ to $46 \%$ at $0.5 \mathrm{mg} \mathrm{P} \cdot \mathrm{L}^{-1}$. When the $\mathrm{PO}_{4}{ }^{3-}$ concentration further increases to $1 \mathrm{mg}$ P. $\mathrm{L}^{-1}$, DFC removal increases slightly to $54 \%$. Complete DFC removal is obtained when the concentration is $116 \mathrm{mg} \mathrm{P} \cdot \mathrm{L}^{-1}$. 
TABLE 5.3 DFC removal by applying $\mathrm{MnO}_{2}$ under anaerobic conditions in presence of phosphate at different concentrations after 33 hours. Experimental conditions: $\mathrm{T}=30^{\circ} \mathrm{C}$, $\left[\mathrm{MnO}_{2}\right]_{0}=7 \mathrm{mM} ;[\mathrm{DFC}]_{0}=3.14 \mu \mathrm{M}, \mathrm{pH} \sim 7, I=0.1 \mathrm{M}$

\begin{tabular}{cc}
\hline $\mathrm{PO}_{4}{ }^{3-}\left(\mathrm{mg} \mathrm{P} \cdot \mathrm{L}^{-1}\right)$ & DFC Removal \\
\hline 0 & $76 \%$ \\
0.5 & $46 \%$ \\
1 & $54 \%$ \\
116 & $100 \%$ \\
\hline
\end{tabular}

$\mathrm{PO}_{4}{ }^{3-}$ can adsorb onto the $\mathrm{MnO}_{2}$ surface, which decreases the reactive surface sites for DFC removal ${ }^{[228]}$. On the other hand, $\mathrm{PO}_{4}{ }^{3-}$ can decrease the inhibition effects of $\mathrm{Mn}^{2+}$ generated from $\mathrm{DFC}$ removal by forming $\mathrm{Mn}_{3}\left(\mathrm{PO}_{4}\right)_{2}{ }^{[127]}$. This mitigates inhibition of DFC removal by $\mathrm{Mn}^{2+}$, leading to higher conversion efficiencies at higher $\mathrm{PO}_{4}{ }^{3-}$ levels. In addition, the structure of $\mathrm{Mn}_{3}\left(\mathrm{PO}_{4}\right)_{2}$ can help in $\mathrm{Mn}$ (III) stabilization. As $\mathrm{Mn}$ (III) is a more active oxidant than $\mathrm{Mn}(\mathrm{IV})$, stabilization of $\mathrm{Mn}(\mathrm{III})$ by $\mathrm{PO}_{4}{ }^{3-}$ also results in enhanced DFC removal. When the $\mathrm{PO}_{4}{ }^{3-}$ concentration is low, the inhibition effect of $\mathrm{PO}_{4}{ }^{3}$ on DFC removal is dominant, resulting in lower DFC removal efficiencies. However, increasing $\mathrm{PO}_{4}{ }^{3-}$ concentration leads to a decreasing inhibition effect of $\mathrm{Mn}^{2+}$ and even a stimulation effect due to $\mathrm{Mn}(\mathrm{III})$ stabilization resulting in more DFC removal.

\subsubsection{Effect of humic acid}

Humic acid (HA), chosen as a representative of organic matter, significantly promotes DFC removal under anaerobic conditions (Table 5.4). Based on the fast DFC removal observed in the presence of humic acid (HA) in a pre-test (data are not shown), initial DFC concentration was increased to $5.57 \mu \mathrm{M}$. Even when concentration of $\mathrm{HA}$ is only $5 \mathrm{mg} \cdot \mathrm{L}^{-1}, 80 \% \mathrm{DFC}$ is removed within 1 hour. When HA concentration increases from $10 \mathrm{mg} \cdot \mathrm{L}^{-1}$ to $20 \mathrm{mg} \cdot \mathrm{L}^{-1}$, DFC removal increases from 87 to $96 \%$ within 1 hour. 
TABLE 5.4 DFC removal by applying $\mathrm{MnO}_{2}$ under anaerobic conditions at different humic acid (HA) concentrations. Experimental conditions: $\left[\mathrm{MnO}_{2}\right]_{0}=7 \mathrm{mM}$; $[\mathrm{DFC}]_{0}=5.57 \mu \mathrm{M}$, $30{ }^{\circ} \mathrm{C}, \mathrm{pH} \sim 7, I=0.01 \mathrm{M}$

\begin{tabular}{ccccc}
\hline $\mathrm{HA}\left(\mathrm{mg} \cdot \mathrm{L}^{-1}\right)$ & $\mathrm{t}=0 \mathrm{~h}$, no HA & $\mathrm{t}=0 \mathrm{~h}$, with HA & $\mathrm{t}=0.5 \mathrm{~h}$ & $\mathrm{t}=1 \mathrm{~h}$ \\
\hline $0^{a}$ & $0 \%$ & $0 \%$ & $\mathrm{n} . \mathrm{a} .^{b}$ & $25 \%$ \\
5 & $0 \%$ & $33 \%$ & $71 \%$ & $80 \%$ \\
10 & $0 \%$ & $19 \%$ & $76 \%$ & $87 \%$ \\
15 & $0 \%$ & $48 \%$ & $90 \%$ & $95 \%$ \\
20 & $0 \%$ & $75 \%$ & $91 \%$ & $96 \%$ \\
\hline
\end{tabular}

${ }^{a}[\mathrm{DFC}]_{0}=3.14 \mu \mathrm{M}$

${ }^{b}$ n.a. $=$ not analysed

In this study, DFC removal is promoted in the presence of HA. Under aerobic conditions, it is reported that HA can form a complex with $\mathrm{Mn}^{2+}$ produced from $\mathrm{MnO}_{2}$ during DFC removal ${ }^{[248]}$. Thus the strong binding ability of HA leads to more attractive sorption/complexation sites for $\mathrm{Mn}^{2+}$ than $\mathrm{MnO}_{2}$ reactive sites, thus reducing blockage of the reactive surface site by $\mathrm{Mn}^{2+}$. As a result, more sites are made available for DFC removal in the presence of HA.

\subsubsection{Application potential}

Applying $\mathrm{MnO}_{2}$ under anaerobic conditions to remove DFC is a promising and efficient process. This study presents basic boundary conditions for application, providing the first step towards transferring this process from the lab into a feasible technology. Based on the results, the optimal conditions of applying $\mathrm{MnO}_{2}$ under anaerobic conditions to remove DFC will be neutral $\mathrm{pH}$, moderate temperature $\left(10-30^{\circ} \mathrm{C}\right), \mathrm{MnO}_{2}: \mathrm{DFC}$ ratio $\geq 2200: 1$, no metal ions, that may be compensated by the presence of organic matter (humic acids), and no or very high concentration of $\mathrm{PO}_{4}{ }^{3-}$, namely $\geq 116 \mathrm{mg} P \cdot \mathrm{L}^{-1}$.

Experiments varying the temperatures show that DFC removal efficiency is high and stable in the range $10-30^{\circ} \mathrm{C}$. In most temperate and subtropical climate areas, the water or wastewater temperature is within this range all the year round. Therefore, no extra heating or temperature-control systems are necessary, leading to less cost in construction and operation. 
Supplying $\mathrm{MnO}_{2}$ during this process is another potential cost for operation. As mentioned in this paper, amount of $\mathrm{MnO}_{2}$ needed in the application can be high under both aerobic and anaerobic conditions due to the low pharmaceutical concentrations and possible reactor form (like bed filter). In this study, results provide information on optimizing $\mathrm{MnO}_{2}$ dosage based on pharmaceutical removal. These results show that the application of $\mathrm{MnO}_{2}$ at a certain amount is possible to maintain the high pharmaceutical removal efficiency for a long time.

We studied the effects of typical co-solutes to assess the application of this process both in drinking water treatment and in wastewater treatment processes. The four selected metal ions are all ubiquitously present in the aquatic environment, especially in drinking water. The two concentrations tested in this study are at a similar level in drinking water based on World Health Organization ${ }^{[340,341]}$ and $\mathrm{EU}{ }^{[59]}$. In addition, $\mathrm{Mn}^{2+}$ will be produced in the process, and this has the strongest inhibition effect among the four metal ions. Therefore, incorporation of metal removal processes and pharmaceutical removal with $\mathrm{MnO}_{2}$ will be a wise option in application.

Both $\mathrm{PO}_{4}{ }^{3-}$ and organic compounds, like $\mathrm{HA}$, are commonly observed co-solutes in wastewater. The diverse effects of $\mathrm{PO}_{4}{ }^{3-}$ on DFC removal indicate that the $\mathrm{PO}_{4}{ }^{3-}$ should be taken into account in design and operation of full application technologies. HA can promote DFC removal. In addition, the HA can bind the metals including $\mathrm{Mg}, \mathrm{Ca}$, and $\mathrm{Mn}$. This reduces the inhibition of metal ions on pharmaceutical removal with $\mathrm{MnO}_{2}$. As a result, the application of manganese oxides under anaerobic conditions as a tertiary treatment has advantages in the application. The organic matter remaining after wastewater treatment processes contain often high levels of HA and may, therefore, promote DFC removal. 


\subsection{Conclusion}

The application of manganese oxides $\left(\mathrm{MnO}_{2}\right)$ under anaerobic conditions to remove diclofenac (DFC) is effective. Compared to pharmaceutical removal technologies under aerobic conditions, anaerobic conditions do not require aeration systems to ensure oxygen supply. This decreases the costs of construction and operation. The results indicate that the optimal control of the $\mathrm{MnO}_{2}$ properties, especially the $\mathrm{MnO}_{2}$ reactive surface sites, are important in DFC removal under anaerobic conditions. Based on the experimental results, the optimal operational conditions are neutral $\mathrm{pH}$, moderate temperature $\left(10-30^{\circ} \mathrm{C}\right), \mathrm{MnO}_{2} / \mathrm{DFC}$ ratio in the range 2200:1 - 8900:1, no metal ions, no or high concentration of $\mathrm{PO}_{4}{ }^{3-}$, and in the presence of humic acids. This study is the first step towards translating the process into the application. Results show the diverse effects of temperature, $\mathrm{MnO}_{2}$ dosage, and phosphate on the DFC removal efficiency and the observed initial reaction rate constant $\left(k_{\mathrm{obs}, \text { init }}\right)$. While there is obvious inhibition by metal ions, the significant promotion of humic acid to DFC removal may be used to compensate for this inhibitory effect, including mitigating the inhibitory effect of $\mathrm{Mn}^{2+}$ formed during the process. In addition, $\mathrm{Mn}^{2+}$ produced in this process can be oxidized back to $\mathrm{MnO}_{2}$ using permanganate, manganese oxidizing bacteria, or other oxidation processes. The agents, used in the re-oxidation of $\mathrm{Mn}^{2+}$ to $\mathrm{MnO}_{2}$, can also remove Pharmaceuticals [67, 101]. The cycling of Mn decreases the concentration of $\mathrm{Mn}^{2+}$ in the effluent and recovers valuable manganese for reuse.

In summary, anaerobic $\mathrm{MnO}_{2}$ mediated removal of pharmaceuticals from water is a potentially interesting, sustainable and promising technology. Therefore we plan to extend our future research to pharmaceuticals other than DFC, and to develop the technology further to scaling up and application. 


\section{ACKNOWLEDGEMENT}

This work is finical supported by China Scholarship Council (CSC, File No. 201308610161), and Wageningen University \& Research. The authors thank Menghan Sun and Lydia Senanu for assistance with the experiments and Hans Beijleveld, Livio Carlucci, Ilse Gerrits, and Jean Slangen for their help in analysis, and colleagues at our department for their valuable suggestions. 


\section{Chapter 6}

\section{Biological regeneration of manganese (IV) using oxygen and iron (III) using nitrate for anaerobic metal oxide mediated removal of pharmaceuticals from water}

A modified version of this chapter is in preparation for publication as Liu, W.; Langenhoff, A. A. M.; Sutton, N. B.; Rijnaarts, H. H. M., Biological regeneration of manganese (IV) using oxygen and iron (III) using nitrate for anaerobic metal oxide-mediated removal of pharmaceuticals from water. 


\section{ABSTRACT}

Application of manganese (IV) (Mn(IV)) and iron (III) (Fe(III)) (hydr)oxides in removing pharmaceuticals from water is attractive for their capacity in degrading these chemicals, and their potential regeneration. Pharmaceutical degradation under anaerobic conditions is energetically most favorable. Thus, regeneration of the Mn(IV) or Fe(III) should also be produced under these conditions, or with a minimum oxygen dosage. In the study presented here, batch experiments were carried out to investigate this in-process production of $\mathrm{Mn}$ (IV) and Fe(III) from $\mathrm{Mn}$ (II) and Fe(II), as well as the removal of pharmaceuticals coupled to the biological $\mathrm{Mn}(\mathrm{IV})$ and $\mathrm{Fe}$ (III) regeneration. Results show that biological production of (reoxidation to) $\mathrm{Mn}(\mathrm{IV})$ can be achieved under oxygen-limiting conditions. The biological production of $\mathrm{Fe}(\mathrm{III})$ can be achieved with nitrate under anaerobic conditions. Both biologically produced $\mathrm{Mn}(\mathrm{IV})$ and $\mathrm{Fe}(\mathrm{III})$ are amorphous. Pharmaceutical biodegradation during the regeneration is tested, as well as the abiotic removal of pharmaceuticals with different types of $\mathrm{Mn}(\mathrm{IV})$ or $\mathrm{Fe}(\mathrm{III})$. Biodegradation of pharmaceuticals with $\mathrm{Mn}(\mathrm{II})$ oxidizing bacteria resulted in an insignificant removal of the selected pharmaceuticals. Using Mn(IV) produced from drinking water treatment plants achieves a removal of $23 \%$ of metoprolol and $44 \%$ of propranolol, similar to the removal with chemically synthesized Mn(IV). When Fe(III) was produced with the help of nitrate, pharmaceutical biodegradation is insignificant. Anaerobic abiotic pharmaceutical tests showed that about 31 - $43 \%$ of propranolol is removed when using Fe(III) originating from drinking water treatment plants, which is higher than with either biologically or chemically synthesized Fe(III). In addition, one of the commercially available Fe(III)-based sorbent tested, Fe(III)FerroSorp®RW, can also remove propranolol. This study indicates that the biological regeneration of $\mathrm{Mn}(\mathrm{IV})$ and $\mathrm{Fe}(\mathrm{III})$, from their reduced species produced in an anaerobic pharmaceutical degradation set up, is feasible. Mn(IV) and $\mathrm{Fe}(\mathrm{III})$ produced and obtained from different processes can be used for this. 
KEYWORDS: biological production; $\mathrm{Mn}(\mathrm{IV})$ and Fe(III) (hydr)oxides; abiotic removal; pharmaceuticals; biodegradation; anaerobic condition; nitrate 



\subsection{Introduction}

Pharmaceutical compounds have been identified as important emerging environmental water contaminants in the last decades. Pharmaceuticals are detected not only in wastewater but also in groundwater, surface water, and even in drinking water ${ }^{[79]}$. The continuous discharge of these compounds to the water originating from industrial emissions and human consumption could lead to potential risks for ecosystems such as extended reproductive periods of aquatic organisms, and also for human health $[79,148]$. Therefore, the presence of pharmaceuticals in aquatic environments is unwanted, even at the low concentrations currently encountered $\left(\mathrm{ng} \cdot \mathrm{L}^{-1} \text { to } \mu \mathrm{g} \cdot \mathrm{L}^{-1}\right)^{[6]}$.

Conventional wastewater treatment processes are insufficient in removing pharmaceuticals such as carbamazepine, diclofenac, or metoprolol ${ }^{[46]}$, so many advanced technologies such as photocatalysis are applied ${ }^{[95,354]}$. Such methods usually require aerobic conditions (presence of oxygen), leading to high energy consumption for aeration or oxygen generation. Manganese (Mn)- or iron (Fe)- based technologies, especially those applying $\mathrm{Mn}(\mathrm{IV})$ - or $\mathrm{Fe}(\mathrm{III})$-(hydr)oxides, successfully remove various pharmaceuticals via both abiotic and biotic processes under anaerobic conditions (without oxygen) ${ }^{[170]}$. Previous research showed that anaerobic abiotic diclofenac removal with $\mathrm{MnO}_{2}$ is more efficient than under aerobic conditions ${ }^{[172]}$. The anaerobic biodegradation can also efficiently remove pharmaceuticals including naproxen with $\mathrm{Mn}(\mathrm{IV})$ or $\mathrm{Fe}(\mathrm{III})^{[171,268]}$. Furthermore, the anaerobic conditions are more sustainable because they require less energy input for operations like aeration.

An additional outstanding advantage is that $\mathrm{Mn}(\mathrm{IV})$ and $\mathrm{Fe}(\mathrm{III})$ can be regenerated after use, decreasing waste sludge outputs and increasing the sustainability in potential upscaled application. As anaerobic pharmaceutical degradation is foreseen, $\mathrm{Mn}(\mathrm{IV})$ or $\mathrm{Fe}(\mathrm{III})$ production under anaerobic conditions is most attractive, allowing these metals to be re-used 
directly in the process. Both chemical and biological methods can be used to regenerate $\mathrm{Mn}(\mathrm{IV})$ and $\mathrm{Fe}(\mathrm{III})$ from the $\mathrm{Mn}$ (II) and $\mathrm{Fe}(\mathrm{II})$ released during pharmaceutical degradation. Chemical production is achieved through direct oxidation using oxygen $\left(\mathrm{O}_{2}\right)$ or a strong oxidant such as chlorine, chlorine dioxide, ozone or $\mathrm{KMnO}_{4}{ }^{[135]}$. For example, chemically produced $\mathrm{Mn}(\mathrm{IV})$ can be obtained via the oxidation of $\mathrm{MnCl}_{2}$ with $\mathrm{KMnO}_{4}{ }^{[65]}$. $\mathrm{Fe}$ (II) can also be directly oxidized in the presence of $\mathrm{O}_{2}$.

The chemical synthesis of Mn(IV) or Fe(III) usually uses strong oxidants and these oxidants can also produce unwanted by-products during the synthesis. The biological production, however, can be cleaner with no or fewer by-products. Since pharmaceutical removal with $\mathrm{Mn}$ (IV) or Fe(III) is more attractive under anaerobic conditions, the regeneration of $\mathrm{Mn}(\mathrm{IV})$ and $\mathrm{Fe}(\mathrm{III})$ should be preferentially also under anaerobic conditions. However, the high redox potential of $\mathrm{Mn}(\mathrm{IV})(+1.23 \mathrm{~V})$ indicates that biological $\mathrm{Mn}(\mathrm{IV})$ production can only occur in the presence of $\mathrm{O}_{2}{ }^{[301]}$. To limit the $\mathrm{O}_{2}$ transfer to the anaerobic step of biological $\mathrm{Mn}(\mathrm{IV})$ production and pharmaceutical removal, minimal $\mathrm{O}_{2}$-dosage need to be applied. $\mathrm{Fe}$ (III) can be produced by microorganisms under anaerobic conditions using $\mathrm{NO}_{3}^{-}$ as electron acceptor ${ }^{[292,366]}$. In addition, biological $\mathrm{Fe}(\mathrm{III})$ production has the potential to remove pharmaceuticals via abiotic processes and/or biotic processes. Previous studies reported complete removal of atenolol and 70\% removal of propranolol with $\mathrm{NO}_{3}{ }^{-}$via biological degradation ${ }^{[13,268]}$.

In addition to regeneration, $\mathrm{Mn}(\mathrm{IV})$ or $\mathrm{Fe}(\mathrm{III})$ can be obtained from commercial sources or from various waste streams in the water sector. This results in other properties of the two metal oxide species, which may lead to more or less effective pharmaceutical degradation. Biologically produced

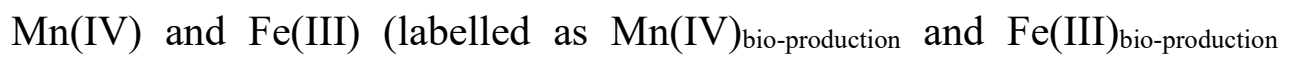
throughout) have a larger specific surface area and higher binding energy than chemically synthesized $\mathrm{Mn}$ (IV) and Fe(III) (labelled here as

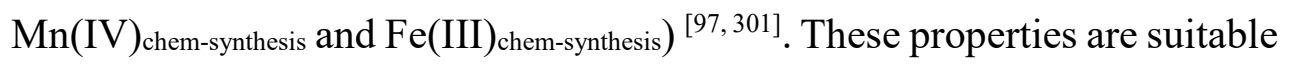
for abiotic removal of pollutants such as pharmaceuticals or heavy metal. A 
previous study showed that the removal of diclofenac with $\mathrm{Mn}(\mathrm{IV})_{\text {bio-production }}$ at neutral $\mathrm{pH}$ is 10 -fold faster compared to $\mathrm{Mn}(\mathrm{IV})_{\text {chem-synthesis }}{ }^{[65]}$. Another source of $\mathrm{Mn}(\mathrm{IV})$ and $\mathrm{Fe}(\mathrm{III})$ is waste from drinking water treatment plants. $\mathrm{Mn}(\mathrm{IV})$ or Fe(III) produced during drinking water treatment (Mn(IV)DWTP and $\left.\mathrm{Fe}(\mathrm{III})_{\text {DWTP }}\right)$ are usually produced via chemical or biological processes, or the combination of these two processes ${ }^{[135,144]}$. Thus, Mn(IV) DwTP and $\mathrm{Fe}(\mathrm{III})_{\text {DWTP }}$ likely have different properties than $\mathrm{Mn}(\mathrm{IV})$ or $\mathrm{Fe}(\mathrm{III})$ produced solely via defined chemical or biological processes. Little is known about applying these types of $\mathrm{Mn}(\mathrm{IV})$ or $\mathrm{Fe}(\mathrm{III})$ oxide species to remove of pharmaceuticals under anaerobic conditions.

This paper aims to (1) investigate biological regeneration of $\mathrm{Mn}(\mathrm{IV})$ under $\mathrm{O}_{2}$-limiting conditions from $\mathrm{Mn}$ (II) formed during pharmaceutical degradation or drinking water production; (2) investigate biological regeneration of $\mathrm{Fe}(\mathrm{III})$ by applying $\mathrm{NO}_{3}{ }^{-}$under anaerobic conditions from $\mathrm{Fe}$ (II) formed during anaerobic pharmaceutical degradation or drinking water production; (3) investigate biodegradation of pharmaceuticals during these metal oxide regeneration steps; and (4) compare the abiotic removal of pharmaceuticals under anaerobic conditions with different $\mathrm{Mn}(\mathrm{IV})$ and Fe(III) metal oxide species. The results together contribute to an understanding of essential aspects of $\mathrm{Mn}$ and $\mathrm{Fe}$ regeneration and recycling during metal oxide mediated pharmaceutical removal from water. This brings future application of such a technology into view.

\subsection{Methods and materials}

\subsubsection{Chemicals}

Anaerobic water was used in most of the experiments unless specified. Anaerobic water was prepared by boiling ultrapure water or demineralized water (demiwater) for $5 \mathrm{~min}$ and cooled to room temperature by flushing with $\mathrm{N}_{2}$. Ultrapure water was collected from a Millipore system (18.2 $\mathrm{M} \Omega \cdot \mathrm{cm}, \mathrm{TOC}=18 \mathrm{ppb}, \mathrm{USA})$. 
Seven commonly used pharmaceuticals are tested in this study, including caffeine, carbamazepine, diclofenac, ibuprofen, metoprolol, naproxen, and propranolol, were purchased either from Sigma-Aldrich or from MP Biomedicals, as previously described ${ }^{[172]}$.The stock solution of pharmaceutical mixture $\left(20 \mathrm{mg} \cdot \mathrm{L}^{-1} \mathrm{each}\right)$ was prepared with ultrapure water. All other chemicals were purchased from Sigma-Aldrich at purity $>98 \%$ for solids and at HPLC or UPLC quality for liquids.

The Mn(IV) and Fe(III) involved in this study are the same materials used in a previous study (Table 6.1) ${ }^{[171]}$. Mn(IV) bio-production was collected during the experiments and prepared as described ${ }^{[65]}$. In short, $\mathrm{Mn}(\mathrm{IV})_{\text {bio- }}$ production was centrifugation at 7,000 g for $15 \mathrm{~min}$, and then was washed several times through centrifugation and resuspended with $10 \mathrm{mM}$ anaerobic phosphate buffer $\left(\mathrm{Na}_{2} \mathrm{HPO}_{4} / \mathrm{KH}_{2} \mathrm{PO}_{4}\right.$, Sørensen buffer). $\mathrm{Mn}(\mathrm{IV})_{\text {chem-synthesis }}$ was prepared the same as previously described ${ }^{[172]}$. $\mathrm{Mn}(\mathrm{IV}$ )DWTP was kindly provided by Water Laboratorium Noord (WLN, the Netherlands), originally from drinking water production plant 'Noordbargeres' in Emmen. The Mn(IV)DwTP was dried under $\mathrm{N}_{2}$ flushing.

Fe(III)bio-production was collected and prepared by washing the same as $\mathrm{Mn}(\mathrm{IV})_{\text {bio-production }}$ by centrifugation and resuspended with $10 \mathrm{mM}$ anaerobic phosphate buffer $\left(\mathrm{Na}_{2} \mathrm{HPO}_{4} / \mathrm{KH}_{2} \mathrm{PO}_{4} \text {, Sørensen buffer). Fe(III) }\right)_{\text {chem-synthesis }}$ was prepared based on a previous study ${ }^{[153]}$. Briefly, the $0.4 \mathrm{M} \mathrm{FeCl}_{3}$ was neutralized with $1 \mathrm{~N} \mathrm{NaOH}$ until $\mathrm{pH}$ 7. Then, the $\mathrm{Fe}(\mathrm{III})_{\text {chem-synthesis }}$ was washed in the same way as Mn(IV) chem-synthesis. Fe(III) DwTP was kindly provided by Evides Waterbedrijf (the Netherlands). Two Fe(III)-based sorbents, FerroSorp ${ }^{\circledR}$ Plus and FerroSorp ${ }^{\circledR}$ RW was obtained from HeGo Biotec GmbH. 


\subsubsection{Experimental setup}

\subsubsection{Biological production of $\mathrm{Mn}(\mathrm{IV})$}

(1) Inoculum

The Mn(II)-oxidizing bacteria was kindly provided by Utrecht University. The pre-cultivation of the bacteria was carried out in $150 \mathrm{~mL}$ flasks with $50 \mathrm{~mL}$ fresh Luria-Bertani (LB) medium at $30{ }^{\circ} \mathrm{C}$ on a shaker (200 rpm) ${ }^{[295]}$. LB medium was freshly prepared before experiments consisted of (per liter of demiwater) $10 \mathrm{~g}$ tryptone, $10 \mathrm{~g} \mathrm{NaCl}$, and $5 \mathrm{~g}$ yeast extract ${ }^{[295]}$. The $\mathrm{pH}$ of the medium was adjusted to 7.0 with $10 \mathrm{~N} \mathrm{NaOH}$. The medium was sterilized by autoclaving at $120^{\circ} \mathrm{C}$ for $20 \mathrm{~min}$ prior to use. When the $\mathrm{OD}_{600}$ reached around 1.0, the bacterial culture was ready for use in our experiments.

(2) Batch experiments

The batch experiments to produce $\mathrm{Mn}(\mathrm{IV})_{\text {bio-production }}$ were carried out in triplicate in $125 \mathrm{~mL}$ glass bottles containing $30 \mathrm{~mL}$ sterilized anaerobic LB medium. The preparation of the medium and the batch bottles was carried out in an anaerobic glovebox. Bottles were closed with butyl-rubber stoppers and then taken out of the glovebox. Thereafter, bottles were sealed with aluminum crimp caps. The headspace was exchanged with the $\mathrm{N}_{2} / \mathrm{O}_{2}$ gas mixture to 1.2 bar. The total $\mathrm{O}_{2}$ amount, including gaseous $\mathrm{O}_{2}$ and dissolved $\mathrm{O}_{2}$, was expressed in the percentage in headspace, that is $0.3 \%$

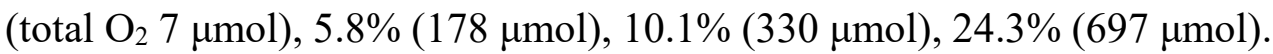
The calculation process was described in Text S6.1. 
The bottles were sterilized by autoclaving at $120^{\circ} \mathrm{C}$ for $15 \mathrm{~min}$. Bottles with cotton stoppers were carried as a positive control (no $\mathrm{O}_{2}$ limitation). Blank controls without bacteria were taken along as well. Filter-sterilized $\mathrm{MnCl}_{2}$ stock ( $9 \mathrm{mM}$ ) was added to the bottles to reach a final concentration of $0.3 \mathrm{mM} \mathrm{Mn}$ (II) ( $\sim 9 \mu \mathrm{mol} \mathrm{Mn})$. The experiments were started by adding $0.3 \mathrm{~mL}$ pre-cultivated $\mathrm{Mn}(\mathrm{II})$-oxidizing bacteria. All bottles were incubated at $30{ }^{\circ} \mathrm{C}$ on a shaker $(200 \mathrm{rpm})$. Liquid samples were collected regularly for analysis of bacteria and $\mathrm{Mn}(\mathrm{II})$.

(3) Sample preparation

The samples for bacteria growth were taken and measured immediately without treatment. Liquid samples for Mn(II) analysis were centrifuged at $10,000 \mathrm{rpm}$ for $10 \mathrm{~min}$. Then, the supernatant was collected and analyzed immediately based on standard methods ${ }^{[252]}$.

\subsubsection{Biological production of Fe(III)}

(1) Inoculum

The inoculum was kindly provided by Wageningen University \& Research, the Netherlands. The inoculum consisted of the pre-incubated activated sludge of WWTP Bennekom, the Netherlands in the presence of $48.5 \mathrm{mg} \cdot \mathrm{L}^{-1} \mathrm{Fe}(\mathrm{II})$ and $10.1 \mathrm{mg} \cdot \mathrm{L}^{-1} \mathrm{NO}_{3}{ }^{-}$.

(2) Batch experiments

The batch experiments to produce Fe(III) bio-production were carried out in triplicate in $125 \mathrm{~mL}$ bottles with $100 \mathrm{~mL}$ medium (Table S6.1). Sufficient $\mathrm{NO}_{3}^{-}, 3 \mathrm{mM}$, was used to biologically produce $\mathrm{Fe}(\mathrm{III})$. The $\mathrm{pH}$ of the medium was maintained at $\mathrm{pH} 7.5$. The preparation of the medium and batch bottles was carried out in the anaerobic glovebox. The bottles were closed with butyl-rubber stoppers, taken out of the anaerobic glovebox and sealed with aluminum crimp caps. The headspace of the bottles was exchanged with the $\mathrm{N}_{2} / \mathrm{CO}_{2}$ gas mixture to achieve $80 \% \mathrm{~N}_{2}$ and $20 \% \mathrm{CO}_{2}(\mathrm{v} / \mathrm{v})$ and brought to 1.2 bar. The experiments were started by adding $10 \mathrm{~mL}$ inoculum to all the 
bottles. Abiotic controls were prepared with $3 \mathrm{mM} \mathrm{NO}_{3}{ }^{-}$along with the experiments without inoculum. The experiments were conducted in the dark at $30^{\circ} \mathrm{C}$, shaking at $120 \mathrm{rpm}$. Concentrations of $\mathrm{NO}_{3}{ }^{-}$and $\mathrm{Fe}$ were analyzed at the beginning and at the end of the experiments.

(3) Sample preparation

Samples for $\mathrm{NO}_{3}{ }^{-}$measurement were prepared exactly the same as those for pharmaceuticals. The samples for $\mathrm{NO}_{3}{ }^{-}$were stored at $4{ }^{\circ} \mathrm{C}$ and analyzed within one month.

Samples for $\mathrm{Fe}$ analysis were prepared by a modified $\mathrm{HCl}$ extraction method ${ }^{[52]}$. Briefly, $0.5 \mathrm{~mL}$ samples were mixed with $0.5 \mathrm{~mL} 1 \mathrm{M} \mathrm{HCl}$ to fix $\mathrm{Fe}(\mathrm{II})$. Thereafter, Fe(II) was analyzed directly by colorimetric methods (Hach Dr. Lange Kit 340). The total Fe was analyzed by the same procedure, with the exception that $1 \mathrm{~mL} 0.5 \mathrm{M} \mathrm{NH}_{2} \mathrm{OH} \cdot \mathrm{HCl}$ was added before analysis. The samples were stored at $4{ }^{\circ} \mathrm{C}$ before analysis. 


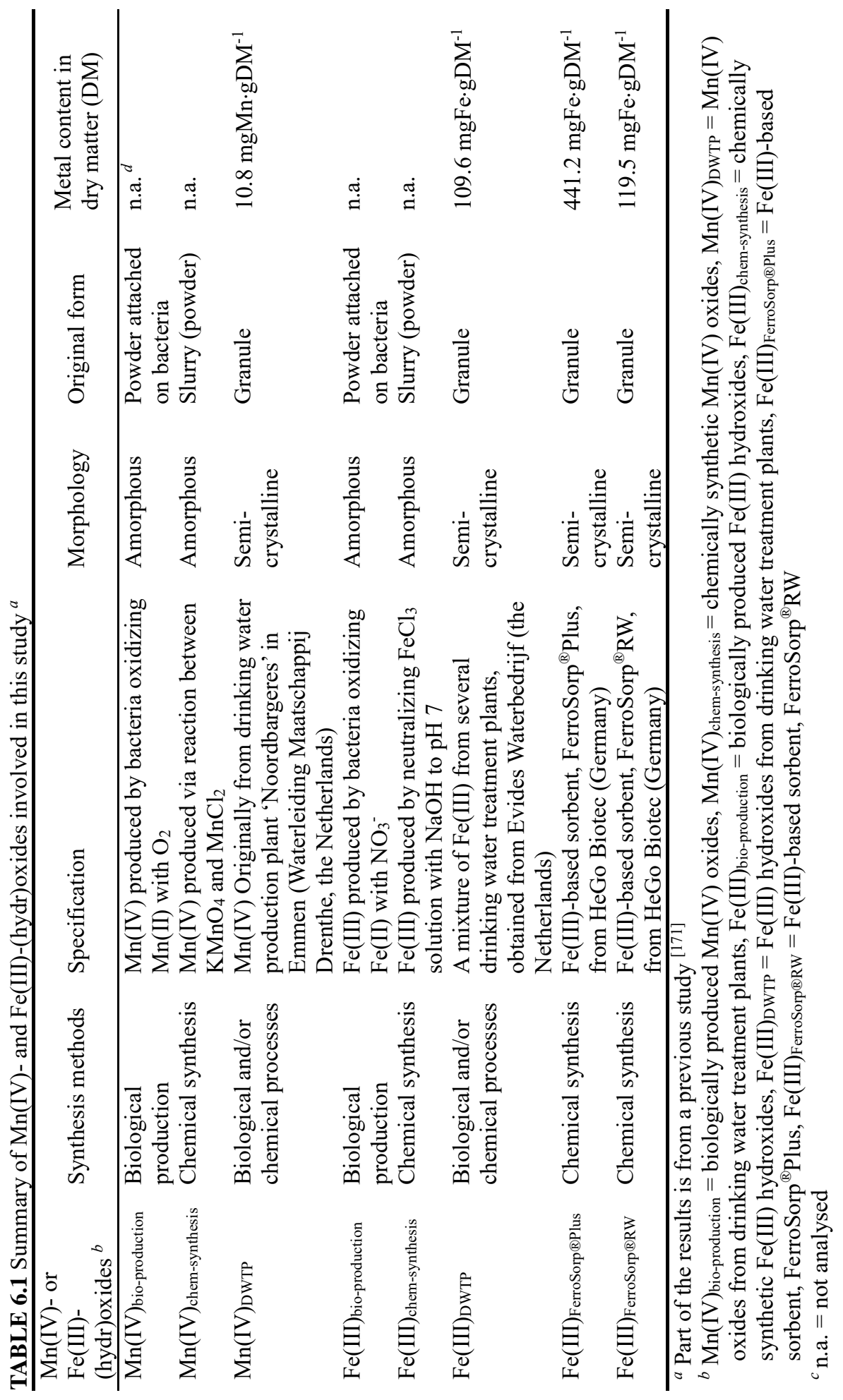




\subsubsection{Pharmaceutical removal}

(1) Biodegradation during biological Mn(IV) production

Biodegradation of pharmaceuticals was carried out by the same method as biological $\mathrm{Mn}(\mathrm{IV})$ production process in and add filter-sterilized stock of pharmaceutical mixture $\left(20 \mathrm{mg} \cdot \mathrm{L}^{-1}\right)$ at a final concentration $0.5 \mathrm{mg} \cdot \mathrm{L}^{-1}$.

The samples for pharmaceutical measurement were centrifuged at $10,000 \mathrm{rpm}$ for $10 \mathrm{~min}$ immediately after taken. The supernatant was collected and pre-treated by solid phase extraction (SPE) as described previously ${ }^{[339]}$. The recovery rate of SPE is $85-115 \%$. Thereafter, the samples were stored in amber vials at $-20^{\circ} \mathrm{C}$ before analysis.

(2) Abiotic removal with different Mn(IV)

The batch experiments on the abiotic removal of pharmaceuticals were carried out in duplicate under anaerobic conditions. Batch experiments were similar to previous studies ${ }^{[169,172]}$, and the $\mathrm{pH}$ of solutions was maintained by $10 \mathrm{mM}$ phosphate buffer which is also used to prepare $\mathrm{Mn}(\mathrm{IV})_{\text {bio-production. }}$ Final concentrations in the batches were $7 \mathrm{mM} \mathrm{Mn}(\mathrm{IV})_{\text {bio-production. The }}$ experiments were initiated by adding $1.25 \mathrm{~mL}$ stock of pharmaceutical mixture into the experimental bottles, resulting in a final concentration of $0.5 \mathrm{mg} \cdot \mathrm{L}^{-1}$. Samples were taken regularly to analyze the concentration of pharmaceuticals.

Since the Mn(IV) DWTP is produced main via biological process but the chemical process is also possibly involved ${ }^{[307]}$, it can have different properties from $\mathrm{Mn}(\mathrm{IV})_{\text {chem-synthesis }}$ or $\mathrm{Mn}(\mathrm{IV})_{\text {bio-production. Therefore, the }}$ abiotic removal of pharmaceuticals under anaerobic conditions with this $\mathrm{Mn}(\mathrm{IV})_{\text {DwTP }}$ (granules and ground powder) was also tested. 
The samples for pharmaceutical measurement were centrifuged at $10,000 \mathrm{rpm}$ for $10 \mathrm{~min}$ immediately after taken. The supernatant was collected and stored in amber vials at $-20{ }^{\circ} \mathrm{C}$ before analysis. Parallel samples were taken to investigate the contribution of adsorption to the removal. $0.5 \mathrm{~mL}$ samples were taken, and then $1 \mathrm{~mL}$ reducing agent $(0.5 \mathrm{mM}$ $\mathrm{NH}_{2} \mathrm{OH} \cdot \mathrm{HCl}$ ) were added immediately. Then, the mixture was centrifuged at $10,000 \mathrm{rpm}$ for $10 \mathrm{~min}$. The supernatant was collected and stored in amber vials at $-20{ }^{\circ} \mathrm{C}$ before analysis. The presence of $\mathrm{NH}_{2} \mathrm{OH} \cdot \mathrm{HCl}$ has no effects on the analysis of pharmaceuticals.

(3) Biodegradation during biological Fe(III) production

Pharmaceutical biodegradation during biological Fe(III) production was also tested. The experiments were carried out the same as biological $\mathrm{Fe}$ (III) production. Before adding the inoculum, the pharmaceutical mixture was added to batch bottles at a final concentration of each pharmaceutical at $1 \mathrm{mg} \cdot \mathrm{L}^{-1}$. Samples were taken every 30 days for analyzing the concentrations of pharmaceuticals, $\mathrm{NO}_{3}{ }^{-}$and $\mathrm{Fe}$.

The samples for pharmaceutical measurement were prepared as those in experiments on biodegradation during biological $\mathrm{Mn}(\mathrm{IV})$ production.

(4) Abiotic removal with different Fe(III)

Abiotic removal of pharmaceuticals with different types of Fe(III) was carried out the same as with $\mathrm{Mn}(\mathrm{IV})$. The final concentration of $\mathrm{Fe}(\mathrm{III})$ is $0.4 \mathrm{mM}$, and that of pharmaceutical is $0.5 \mathrm{mg} \cdot \mathrm{L}^{-1}$. Sample preparation was the same as those in biodegradation of pharmaceuticals during biological $\mathrm{Mn}(\mathrm{IV})$ production. 


\subsubsection{Analysis}

The Mn analysis including total $\mathrm{Mn}$ and $\mathrm{Mn}$ (II) was performed by an inductively coupled plasma optical emission spectrometry (VISTA-MPX CCD Simultaneous, VARIAN co.) equipped with an megapixel (MPX) detector at wavelength $257.610 \mathrm{~nm}$.

$\mathrm{Fe}$ analysis including total $\mathrm{Fe}$ or Fe(II) was performed by Hach Dr. Lange Kit (LCK 340). $\mathrm{NO}_{3}{ }^{-}$concentrations were measured by a Hach Dr. Lange Kit (LCK 320, 321). Morphologies of Mn bio-production $_{\text {and }} \mathrm{Fe}_{\text {bio-production }}$ were analyzed by an X-ray powder diffraction (XRD, Bruker D8 advance, Bruker, Germany). The pharmaceutical analysis was performed by an ultraperformance liquid chromatography with a diode array detector (UPLC, ultimate 3000 , Thermo, USA), as previously described ${ }^{[95]}$.

\subsection{Results and discussion}

\subsubsection{Biological regeneration}

(1) Biological $\mathrm{Mn}(\mathrm{IV})$ production under $\mathrm{O}_{2}$-limiting conditions

The biological production of $\mathrm{Mn}(\mathrm{IV})$ under $\mathrm{O}_{2}$-limiting conditions occurs under all $\mathrm{O}_{2}$ concentrations (Figure 6.1). The initial $\mathrm{O}_{2}$ amount varies from 178 to $700 \mu \mathrm{mol}$, and similar amounts of $\mathrm{Mn}(\mathrm{IV})_{\text {bio-production are }}$ produced during the first 24 hours $(p>0.05)$. During the period from 24 to 48 hours, no further $\mathrm{Mn}(\mathrm{IV})_{\text {bio-production }}$ production is observed, that resulting in a total $\mathrm{Mn}(\mathrm{IV})_{\text {bio-production }}$ production of $0.7 \mu \mathrm{mol}$. In the group without $\mathrm{O}_{2}$ limitation (positive control group), the $\mathrm{Mn}(\mathrm{IV})_{\text {bio-production }}$ after 24 hours and 48 hours is much higher than in the $\mathrm{O}_{2}$-limiting groups. These results indicate that the amount of $\mathrm{O}_{2}$ limits biological Mn production. $\mathrm{Mn}(\mathrm{II})$ oxidizing bacteria are aerobic bacteria, and this limited initial amount of $\mathrm{O}_{2}$ will affect bacterial activity. A certain level of $\mathrm{O}_{2}$ is necessary for their growth and biological processes. Therefore, a certain amount of $\mathrm{O}_{2}$ must be present during biological production of $\mathrm{Mn}$, despite the inhibition of the biological $\mathrm{Mn}(\mathrm{IV})$ production. 


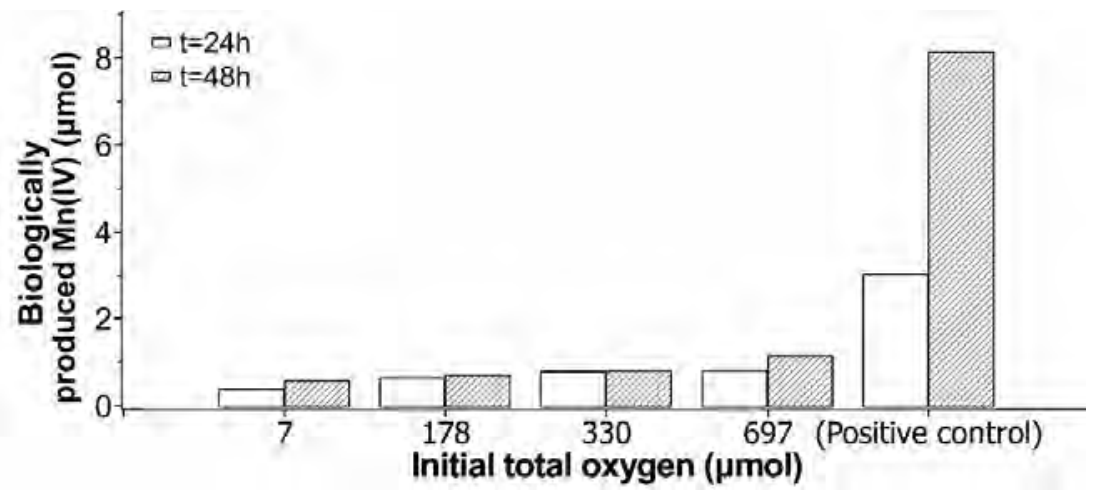

FIGURE 6.1 Biologically produced $\mathrm{Mn}$ (IV) oxides from $\mathrm{Mn}$ (II) under $\mathrm{O}_{2}$-limiting conditions after 24 and 48 hours

(2) Biological $\mathrm{Fe}(\mathrm{III})$ production with $\mathrm{NO}_{3}{ }^{-}$under anaerobic conditions

During the biological production of $\mathrm{Fe}(\mathrm{III}), 0.8 \mathrm{mM}$ sodium acetate was added to promote the growth of the bacteria and biological production of $\mathrm{Fe}(\mathrm{III})$. The $3 \mathrm{mM} \mathrm{NO}_{3}{ }^{-}$is used in this experiment to make sure that $\mathrm{NO}_{3}{ }^{-}$ is not the limiting factor. During the process, $0.61 \mathrm{mM} \mathrm{Fe}(\mathrm{III})$ biologically produced coincided with $0.59 \mathrm{mM} \mathrm{NO}_{3}{ }^{-}$consumption (Table 6.2). The molar ratio of $\mathrm{Fe}(\mathrm{III})_{\text {bio-production }}$ and consumed $\mathrm{NO}_{3}{ }^{-}$in our study is around 1:1, while the ideal ratio is 5:1 (Equation 6.1) ${ }^{[215]}$. There are a number of processes that could contribute to additional nitrate consumption.

$$
10 \mathrm{Fe}(\mathrm{II})+2 \mathrm{NO}_{3}^{-}+28 \mathrm{H}_{2} \mathrm{O} \rightarrow 10 \mathrm{Fe}(\mathrm{OH})_{3}+\mathrm{N}_{2}+18 \mathrm{H}^{+}
$$

Since the redox pairs at $\mathrm{pH} 7$ of during the nitrate reduction are more positive than that of $\mathrm{Fe}(\mathrm{III}) / \mathrm{Fe}(\mathrm{II})$ (Ferrihydrite/ $\mathrm{Fe}^{2+},-100$ to $\left.100 \mathrm{mV}\right)^{[291]}$, they can all oxidise $\mathrm{Fe}(\mathrm{II})$ to $\mathrm{Fe}$ (III), forming different products. For example, when the final product is $\mathrm{NO}_{2}$, the ratio between $\mathrm{Fe}(\mathrm{III})_{\text {bio-production }}$ and $\mathrm{NO}_{3}{ }^{-}$consumption is around 1:1 (Equation 6.2).

$$
\mathrm{Fe}(\mathrm{II})+\mathrm{NO}_{3}^{-}+2 \mathrm{H}^{+} \rightarrow \mathrm{Fe}(\mathrm{OH})_{3}+\mathrm{NO}_{2}+\mathrm{H}_{2} \mathrm{O}
$$


TABLE 6.2 Biological production of $\mathrm{Fe}(\mathrm{III})$ (Fe(III)bio-production) with a different initial concentration of $\mathrm{NO}_{3}^{-}$.

\begin{tabular}{cccc}
\hline $\begin{array}{c}\text { Initial NO}{ }^{-} \\
(\mathrm{mM})\end{array}$ & $\begin{array}{c}\mathrm{Fe}(\mathrm{III}) \\
\text { production } \\
(\mathrm{mM})\end{array}$ & $\begin{array}{c}\mathrm{NO}_{3}{ }^{-} \text {consumption } \\
(\mathrm{mM})\end{array}$ & $\begin{array}{c}\text { Molar ratio } \\
{\left[\mathrm{Fe}(\mathrm{III})_{\text {bio-production }}\right]:} \\
{\left[\mathrm{NO}_{3}{ }^{-}\right]_{\text {consumption }}}\end{array}$ \\
\hline $\begin{array}{c}0.08 \\
(\text { Blank controls })\end{array}$ & $\begin{array}{c}\text { n.d. }^{a} \\
2.8\end{array}$ & 0.02 & n.a. ${ }^{b}$ \\
$\begin{array}{c}2.7 \\
\text { (Abiotic }\end{array}$ & n.d. & 0.59 & $1.04: 1$ \\
controls) & & n.d. & n.a. \\
\hline
\end{tabular}

${ }^{a}$ n.d. $=$ not detected

${ }^{b}$ n.a. $=$ not applicable

In addition, the presence of acetate promotes denitrification under anaerobic conditions: a portion of the nitrate is used to oxidize the acetate. In the process, bacteria will consume the $\mathrm{NO}_{3}{ }^{-}$without producing $\mathrm{Fe}(\mathrm{III})$. Therefore, the observed molar ratio between $\mathrm{Fe}(\mathrm{III})$ bio-production and $\mathrm{NO}_{3}{ }^{-}$ consumption is $1: 1$, less than the theoretical value $5: 1$.

(3) Properties

The properties of the $\mathrm{Mn}(\mathrm{IV})$ and $\mathrm{Fe}(\mathrm{III})$ used in this study are analyzed by X-ray diffraction (XRD). Based on the XRD pattern, $\mathrm{Mn}(\mathrm{IV})_{\text {bio-production is }}$ amorphous (Figure 6.2). The morphology of the two Mn(IV) species produced within this study, $\mathrm{Mn}(\mathrm{IV})$ bio-production and $\mathrm{Mn}(\mathrm{IV})_{\text {chem-synthesis, are }}$ same ${ }^{[171]}$. Similar results are also reported in a previous study ${ }^{[322]}$. Furthermore, materials sourced from DWTP waste are also tested. From a previous study, the ground $\mathrm{Mn}(\mathrm{IV})_{\text {DWTP }}$ powder has peaks which are also observed in crystalline $\mathrm{MnO}_{2}$. This indicates that the $\mathrm{Mn}(\mathrm{IV})_{\text {DwTP }}$ has a semi-crystalline nature (Table 6.1) ${ }^{[171]}$. However, the raw materials of $\mathrm{Mn}(\mathrm{IV})_{\text {DWTP }}$ could be amorphous. During the grinding, the specific area of $\mathrm{Mn}(\mathrm{IV})_{\text {DwTP }}$ powder will increase, but it might also change its morphology

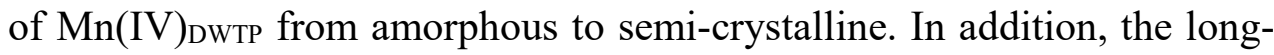
term storage can slowly change the morphology of $\mathrm{Mn}(\mathrm{IV})_{\text {DwTP }}$ via aging processes, for instance changing them from amorphous to crystalline ${ }^{[293]}$. 


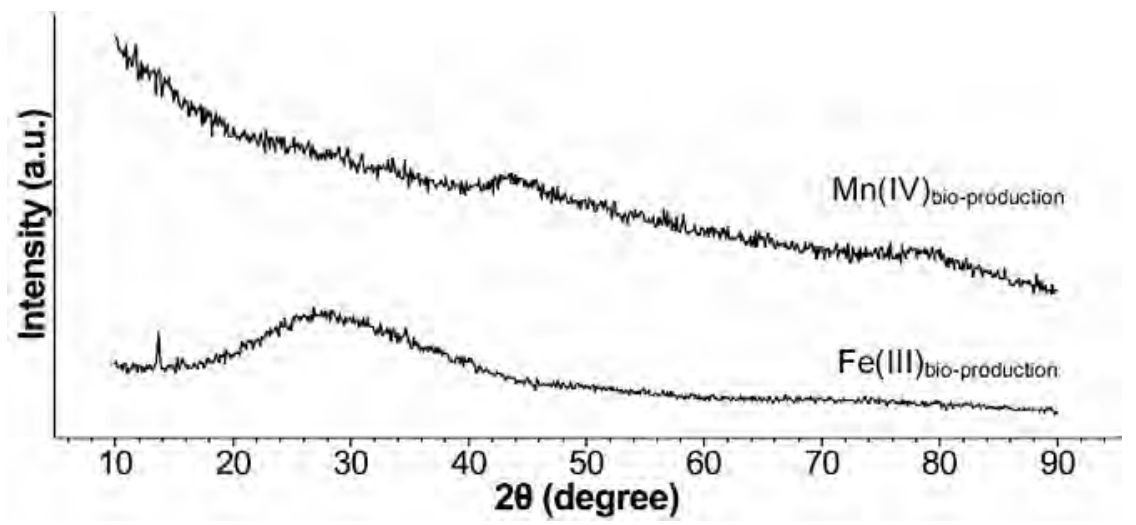

FIGURE 6.2 X-ray diffraction spectrum of biologically produced $\mathrm{Mn}(\mathrm{IV})$ oxides $\left(\mathrm{Mn}(\mathrm{IV})_{\text {bio- }}\right.$ production) and biologically produced $\mathrm{Fe}(\mathrm{III})$ hydroxides (Fe(III)bio-production)

XRD patterns show that $\mathrm{Fe}(\mathrm{III})_{\text {bio-production }}$ is amorphous and similar to that used in our other study (Figure 6.2) ${ }^{[272]}$. The other Fe(III) used in this study are the same as used in a previous study ${ }^{[171]}$. The Fe(III) from drinking water treatment (Fe(III) $)_{\text {DWTP }}$ ), and two Fe(III)-based sorbents are semicrystalline. They are all a mixture of $\mathrm{Fe}_{2} \mathrm{O}_{3}$ and $\mathrm{Fe}_{3} \mathrm{O}_{4}$. Based on the XRD pattern, the $\mathrm{Fe}(\mathrm{III})$ DWTP appears to be the most amorphous among these three materials while the $\mathrm{Fe}(\mathrm{III})_{\text {FerroSorp } \mathbb{R} \mathrm{W}}$ is the most crystalline.

\subsubsection{Removal of pharmaceuticals}

(1) Pharmaceutical removal during biological Mn(IV) production

$\mathrm{Mn}(\mathrm{IV})$ production in this study occurs under oxygen-limiting, but nonetheless aerobic conditions. Pharmaceutical removal during $\mathrm{Mn}(\mathrm{IV})$ production is expected since aerobic biodegradation of pharmaceutical compounds has been reported previously ${ }^{[151]}$. In this study, biodegradation of pharmaceuticals with $\mathrm{Mn}$ (II)-oxidizing bacteria was tested. Results show that there is no significant removal of the selected pharmaceuticals (Table S6.2). Similar studies with Pseudomonas putida MnB6 (a strain of Mn(II)oxidizing bacteria) also show that the removal of diclofenac and other micropollutants is insignificant ${ }^{[67,200]}$. The Mn(II)-oxidizing bacteria used to produce $\mathrm{Mn}(\mathrm{IV})$ is a pure strain specialized in $\mathrm{Mn}(\mathrm{IV})$ oxidation. These bacteria are growing under $\mathrm{O}_{2}$-limiting conditions. Thus, this individual 
strain most likely had neither the degradation capacity nor optimal growth conditions to biodegrade challenging pharmaceutical structures.

(2) Abiotic pharmaceutical removal with Mn(IV)

Batch experiments were carried out to test the abiotic removal of pharmaceuticals with different types of Mn(IV). Due to experimental conditions, we were unable to produce sufficient $\mathrm{Mn}(\mathrm{IV})_{\text {bio-production }}$ for our abiotic removal tests. Therefore, the experiments were carried out with $\mathrm{Mn}(\mathrm{IV})_{\text {DWTP }}$ (granule and ground powder). The experiments on the abiotic removal of pharmaceuticals were carried out in anaerobic water in duplicate. Results show no abiotic anaerobic removal with the Mn(IV)DwTP granule but with ground $\mathrm{Mn}(\mathrm{IV})_{\text {DWTP }}$ powder supported the efficient removal of metoprolol and propranolol (Table 6.3). With ground Mn(IV) $)_{\text {DwTP }}$ powder, removal of metoprolol is $23 \%$ in 24 hours, of which $20 \%$ is removed due to adsorption. Similarly, $44 \%$ propranolol is removed, and $30 \%$ is a result of adsorption.

The experimental conditions are exactly the same as applied in a

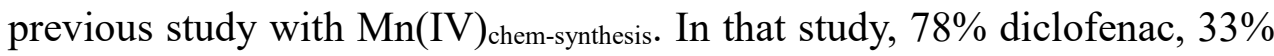
metoprolol and 51\% propranolol are removed under anaerobic conditions with $\mathrm{MnO}_{2}$ in anaerobic water (Table 6.3) ${ }^{[172]}$. In this current study, the removal of metoprolol and propranolol with two different $\mathrm{Mn}(\mathrm{IV})$ types is similar, but no diclofenac removal is observed with Mn(IV)DwTP. No adsorption was observed during the abiotic removal of pharmaceuticals with $\mathrm{Mn}(\mathrm{IV})_{\text {chem-synthesis. }}$ 
TABLE 6.3 Abiotic removal of pharmaceuticals (\%) with Mn(IV) from drinking water treatment plants $\left(\mathrm{Mn}(\mathrm{IV})_{\mathrm{DWTP}}\right)$ and manually synthesized, chemically produced $\mathrm{Mn}(\mathrm{IV})$ $\left(\mathrm{Mn}(\mathrm{IV})_{\text {chem-synthesis }}\right)$ under anaerobic conditions

\begin{tabular}{llll}
\hline & $\operatorname{Mn}(\mathrm{IV})_{\text {DWTP }}$ granule $^{a}$ & $\mathrm{Mn}(\mathrm{IV})_{\text {DWTP }_{\text {powder }}}{ }^{a}$ & $\operatorname{Mn}(\mathrm{IV})_{\text {chem-synthesis }^{b}}$ \\
\hline Diclofenac & $3( \pm 2)$ & $-4( \pm 0)$ & $78( \pm 6)$ \\
Metoprolol & $5( \pm 3)$ & $23( \pm 2)$ & $33( \pm 7)$ \\
Propranolol & $9( \pm 3)$ & $44( \pm 3)$ & $51( \pm 5)$ \\
\hline
\end{tabular}

${ }^{a}$ Data between brackets show the difference between the duplicates

${ }^{b}$ Data are from a previous study of the same group ${ }^{[172]}$. The data in the bracket is the standard deviation of the triplicate

Our research on anaerobic abiotic removal of diclofenac with Mn(IV) shows that the amorphous $\mathrm{Mn}(\mathrm{IV})$ is better than crystalline $\mathrm{Mn}(\mathrm{IV}){ }^{[172]}$. Based on the XRD pattern, the Mn(IV)DwTP powder can be defined as semicrystalline. Therefore, it appears to be less effective in anaerobic abiotic pharmaceutical removal. In addition, even though both $\mathrm{Mn}(\mathrm{IV})$ DwTP granule and $\mathrm{Mn}(\mathrm{IV})_{\text {DwTP }}$ powder are semi-crystalline, the Mn(IV)DwTP powder has a larger specific area and potentially has more reactive surface and sites. Previous studies indicated that more reactive surface sites of $\mathrm{Mn}(\mathrm{IV})$ generally lead to more removal of pharmaceuticals ${ }^{[172,248]}$. This may explain the better performance by the ground Mn(IV) DWTP $_{\text {powder than }} \mathrm{Mn}(\mathrm{IV})_{\text {DWTP }}$ granule in pharmaceutical removal.

The reason why $\mathrm{Mn}(\mathrm{IV})_{\text {DwTP }}$ powder is only effective to remove two $\beta$-blockers but is inactive towards converting other pharmaceuticals could not yet be revealed. We hypothesize that there may be a relation with the molecular properties of the pharmaceuticals. The two $\beta$-blockers have quite a similar chemical structure, the aromatic ring, the oxygen molecule connected to the aromatic ring, and a long-chain structure. In addition, they have a similar pKa value (metoprolol 9.5, propranolol 9.42) ${ }^{[172]}$. During the abiotic removal, the compounds are firstly adsorbed onto $\mathrm{MnO}_{2}$ surface or forming a complex ${ }^{[172]}$. The adsorption capacity is related to the chemical structure and properties. Thus, the two pharmaceuticals are better removed than others. 
(3) Pharmaceutical removal during biological Fe(III) production

The pharmaceutical removal units in application will also transfer pharmaceuticals to the biological Fe(III) regeneration unit. Since organic compounds like acetate present in the media can lead to dentrification, the pharmaceuticals are likely to function in the same way, affecting biological $\mathrm{Fe}$ (III) production under anaerobic conditions. In addition, based on the literature, the degradation of pharmaceuticals in the presence of $\mathrm{Fe}(\mathrm{II})$ and $\mathrm{NO}_{3}{ }^{-}$could occur via (1) biodegradation with $\mathrm{NO}_{3}{ }^{-},(2)$ abiotic removal with $\mathrm{Fe}(\mathrm{II})$, or (3) abiotic removal with $\mathrm{Fe}(\mathrm{III})$ bio-production ${ }^{[206,268,327]}$. In this study, we aimed to better illuminate the removal processes by carrying out experiments without $\mathrm{Fe}(\mathrm{II})$ or $\mathrm{NO}_{3}{ }^{-}$to see the role of these compounds in pharmaceutical removal during the biological Fe(III) production step.

Results show that biological production of Fe(III) occurs in the presence of pharmaceuticals, but the removal of pharmaceuticals is inefficient during the production. During the experiments, $0.17 \mathrm{mM}$ $\mathrm{Fe}(\mathrm{III})_{\text {bio-production }}$ is produced and $0.14 \mathrm{mM} \mathrm{NO}_{3}{ }^{-}$is consumed, a similar ratio of 1:1 to that is observed with acetate instead of pharmaceuticals (Table 6.4). But the biological production of Fe(III) is inhibited by the presence of pharmaceuticals. Both $\mathrm{Fe}(\mathrm{III})_{\text {bio-production }}$ production and $\mathrm{NO}_{3}{ }^{-}$consumption is much less than the experiments with acetate without pharmaceuticals. Without $\mathrm{Fe}(\mathrm{II}), 0.24 \mathrm{mM} \mathrm{NO}_{3}{ }^{-}$is consumed with pharmaceuticals as the electron donor, indicating that there is also a denitrification process consuming pharmaceuticals. No Fe(III) bio-production is produced in the experimental groups with only $\mathrm{NO}_{3}{ }^{-}$or with only $\mathrm{Fe}(\mathrm{II})$ (Table 6.4). 
TABLE 6.4 Biological production of $\mathrm{Fe}(\mathrm{III})$ with $\mathrm{NO}_{3}{ }^{-}$coupled to the biodegradation of pharmaceuticals

\begin{tabular}{ccc}
\hline Experimental group & $\mathrm{NO}_{3}{ }^{-}$consumption $(\mathrm{mM})$ & $\begin{array}{c}\mathrm{Fe}(\mathrm{III}) \text { production } \\
(\mathrm{mM})\end{array}$ \\
\hline $\mathrm{Fe}(\mathrm{II})+\mathrm{NO}_{3}{ }^{-}$ & 0.14 & 0.17 \\
$\mathrm{Fe}(\mathrm{II})$ & n.a. $^{a}$ & n.d. ${ }^{b}$ \\
$\mathrm{NO}_{3}{ }^{-}$ & 0.24 & n.a. \\
\hline
\end{tabular}

${ }^{a}$ n.a. $=$ not analysed

${ }^{b}$ n.d. $=$ not detected

The degradation of pharmaceuticals is tested during the biological production of $\mathrm{Fe}(\mathrm{III})$ in the presence of $\mathrm{Fe}(\mathrm{II})$ and $\mathrm{NO}_{3}^{-}$. Results show that the removal of pharmaceuticals is inefficient (Figure 6.3). During the biological $\mathrm{Fe}$ (III) production, about 20\% diclofenac, $17 \%$ ibuprofen and $24 \%$ naproxen are removed, and the removal of caffeine, carbamazepine, and metoprolol is less than $10 \%$. A slightly higher removal is seen in the experimental groups with only $\mathrm{NO}_{3}{ }^{-}$, e.g. with a removal of $34 \%$ for carbamazepine, $40 \%$ for diclofenac, $31 \%$ for metoprolol, and $26 \%$ for naproxen. Removal of pharmaceuticals with only Fe(II) is insignificant ( $<$ $15 \%$ ). The abiotic controls were carried out without inoculum. Results show that the removal of six pharmaceuticals in all abiotic controls is negligible (Figure S6.1, Text S6.2).

Results show that biological Fe(III) production has no significant promoting effects on pharmaceutical removal. Pharmaceutical removal efficiency during biological Fe(III) production is similar, or even less than that with only $\mathrm{NO}_{3}{ }^{-}$. In previous studies, the biodegradation of six selected pharmaceuticals is inefficient with $\mathrm{NO}_{3}{ }^{-[268,339]}$, similar to the results in this study. In addition, the results indicate that in our experiments $\mathrm{Fe}(\mathrm{II})$ is a more reactive electron donor for denitrification than the pharmaceutical compounds tested. 


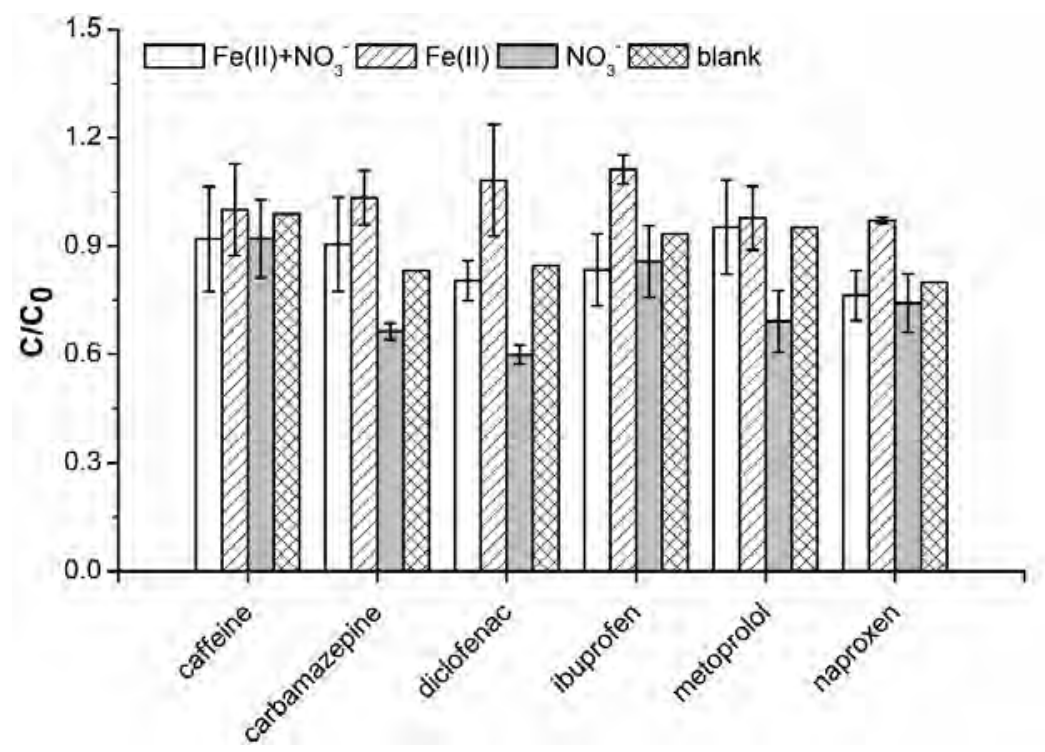

FIGURE 6.3 Biodegradation of pharmaceuticals during the experiments of biological production of $\mathrm{Fe}(\mathrm{III})$ within 150 days. Experimental conditions: $[\mathrm{Fe}(\mathrm{II})]_{0}=1.2 \mathrm{mM},\left[\mathrm{NO}_{3}{ }^{-}\right]_{0}=$ $0.4 \mathrm{mM}$, [pharmaceutical $]_{0}=1 \mathrm{mg} \cdot \mathrm{L}^{-1}, \mathrm{~T}=30^{\circ} \mathrm{C}, \mathrm{pH}=7$, shaking speed $120 \mathrm{rpm}$. Error bars stand for the standard deviation

Biodegradation of some pharmaceuticals with $\mathrm{NO}_{3}{ }^{-}$has been observed previously ${ }^{[13,268]}$. However, removal of pharmaceuticals like metoprolol is reported to be inefficient ${ }^{[268,339]}$. In our study, the biodegradation of all six pharmaceuticals with $\mathrm{NO}_{3}{ }^{-}$is low $(<40 \%)$. Therefore, the bacteria appear to preferentially oxidize $\mathrm{Fe}(\mathrm{II})$ instead of pharmaceuticals, using $\mathrm{NO}_{3}{ }^{-}$as the electron acceptor. In addition, the Fe(III)bio-production usually attaches on the surface of bacteria ${ }^{[237]}$, which may be of influence on their removal performance in processes.

Previous studies reported that Fe(II) could also remove

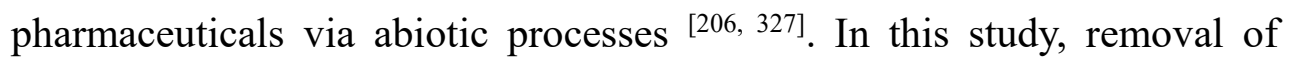
pharmaceuticals with $\mathrm{Fe}$ (II) was found to be insignificant. Other authors revealed that removal of antibiotic pharmaceuticals with $\mathrm{Fe}(\mathrm{II})$ requires the presence of both $\mathrm{Fe}(\mathrm{II})$ and Fe(III) (goethite) ${ }^{[55,206]}$. The amorphous $\mathrm{Fe}(\mathrm{III})_{\text {bio-production }}$ produced in this process is different from highly crystalline goethite ${ }^{[377]}$. As a result, $\mathrm{Fe}(\mathrm{II})$ appears to have no contribution to the degradation of pharmaceuticals. 
In summary, the biological production of $\mathrm{Fe}(\mathrm{III})$ from $\mathrm{Fe}(\mathrm{II})$ in the presence nitrate and pharmaceuticals can be successfully conducted, but the removal of pharmaceuticals during the process is inefficient and has no additional contribution to the anaerobic Fe(III) mediated pharmaceutical removal. These results also show that nitrate dosage should be controlled to prevent nitrate concentrations in the pharmaceutical degrading process step.

(4) Abiotic removal with Fe(III)

Abiotic removal of pharmaceuticals with Fe(III) compounds is also investigated in this study. Removal by $\mathrm{Fe}(\mathrm{III})_{\text {bio-production }}$ is expected via adsorption since it has a large specific surface area ${ }^{[97]}$. Fe(III)DwTP is usually produced via chemical processes with $\mathrm{O}_{2}$ (aeration) while biological processes are also observed under conditions where substantial organic matter is present $[135,144]$. The production process leads to potentially different $\mathrm{Fe}$ (III) compounds and thus different pharmaceutical removal from

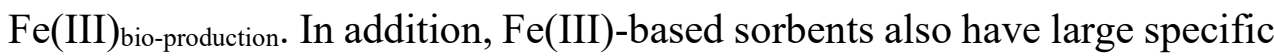
surface area. Similar to Fe(III) bio-production, these sorbents may also be suitable to remove pharmaceuticals via adsorption. Thus, we investigate commercially available Fe(III)FerroSorp®Plus, and Fe(III)FerroSorp®RW.

The abiotic removal of pharmaceuticals under anaerobic conditions with different $\mathrm{Fe}(\mathrm{III})$ are tested. Both granule and ground powder of these $\mathrm{Fe}$ (III) are used to select the best materials for the future reactor development. Results show that $31 \%$ propranolol is removed within 5 days under anaerobic conditions with Fe(III) DwTP powder (Table 6.5). Furthermore, $20 \%$ of propranolol is removed with Fe(III) FerroSorp®RW powder. Like the results with powder, only propranolol is removed for $45 \%$ under anaerobic condition with $\mathrm{Fe}(\mathrm{III})_{\text {DWTP }}$ granule and for $24 \%$ using $\mathrm{Fe}(\mathrm{III})_{\text {FerroSorp®RW }}$ granule. This removal efficiency with the granules is higher than that with the same Fe(III) powder. Adsorption of pharmaceuticals is not observed with Fe(III) $)_{\text {DwTP }}$ powder and $\mathrm{Fe}(\mathrm{III})_{\text {FerroSorp®RW }}$ powder during the removal. 
TABLE 6.5 Abiotic removal of propranolol under anaerobic conditions with different Fe(III) powder within 5 days. Experimental conditions: $[\mathrm{Fe}(\mathrm{III})]_{0}=20 \mathrm{mM}$. Pharmaceutical $]_{0}=0.5$ $\mathrm{mg} \cdot \mathrm{L}^{-1}$, phosphate buffer $\mathrm{pH}=7, \mathrm{~T}=30^{\circ} \mathrm{C}^{a}$

\begin{tabular}{|c|c|c|c|}
\hline Fe(III) (hydr)oxides & $\begin{array}{c}\text { Removal } \\
\text { efficiency }(\%)^{b}\end{array}$ & Fe(III) (hydr)oxides & $\begin{array}{c}\text { Removal } \\
\text { efficiency }(\%)^{b}\end{array}$ \\
\hline $\mathrm{Fe}(\mathrm{III})_{\text {DWTP }}$ granule & $43( \pm 2)$ & $\mathrm{Fe}(\mathrm{III})_{\text {FerroSorp }}{ } \mathrm{RW}$ granule & $25( \pm 2)$ \\
\hline Fe(III) DwTP powder & $31( \pm 1)$ & $\mathrm{Fe}(\mathrm{III})_{\text {FerroSorp®RW }}$ powder & $21( \pm 1)$ \\
\hline
\end{tabular}

No removal is observed with other types of Fe(III) or without Fe(III) (Figure S6.2, S6.3, Table S6.3). Pharmaceutical removal under anaerobic conditions with $\mathrm{Fe}(\mathrm{III})$ bio-production was found to be insignificant. Adsorption is not observed at high levels, while is a critical step during the reactive removal [61, 327, 328]: after adsorption onto Fe(III) through molecular complexation at the oxide surface, pharmaceuticals are chemically converted. The previous study shows that phosphate ions can be adsorbed onto $\mathrm{Fe}(\mathrm{III})_{\text {bio-production }}{ }^{[250]}$, blocking pharmaceuticals to reach the sorption sites. In this study, phosphate is used as a buffer to maintain the $\mathrm{pH} \sim 7$. As

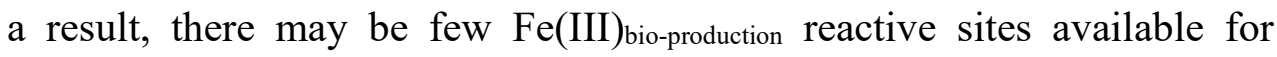
pharmaceutical adsorption and subsequent conversion, leading to the insufficient removal of pharmaceuticals.

Morphologies of Fe(III) may lead to the higher removal efficiency of propranolol with Fe(III)DWTP than with Fe(III)FerroSorp®RW. The Fe(III)DWTP is more amorphous than $\mathrm{Fe}(\mathrm{III})_{\text {FerroSorp } ® \mathrm{RW}}$. However, pharmaceutical removal with amorphous $\mathrm{Fe}(\mathrm{III})_{\text {chem-synthesis }}$ is also inefficient. In addition, grinding the granule is expected to increase the specific surface area of Fe(III), potentially increasing the adsorption capacity and number of reactive sites per weight of Fe(III) oxide, and also increasing the corresponding abiotic removal. However, this study shows that abiotic pharmaceutical removal with $\mathrm{Fe}$ (III) granule is similar, even better than with powder. A detailed investigation is required to understand the abiotic pharmaceutical removal with different types of Fe(III) oxides under anaerobic conditions. 
In this study, only anaerobic abiotic removal of propranolol with $\mathrm{Fe}(\mathrm{III})$ is observed. Base on the previous study, the pharmaceutical removal mechanisms with $\mathrm{Fe}(\mathrm{III})$ is similar to that with $\mathrm{Mn}(\mathrm{IV})^{[61]}$. Therefore, the removal of diclofenac, propranolol, and metoprolol is expected. Since the oxidant power of $\mathrm{Fe}(\mathrm{III})$ is weaker than $\mathrm{Mn}(\mathrm{IV})$, it is reasonable that pharmaceutical removal with $\mathrm{Fe}(\mathrm{III})$ is less efficient than that with $\mathrm{Mn}(\mathrm{IV})$, and that a less more extensive range of pharmaceuticals can be removed with $\mathrm{Fe}(\mathrm{III})$ than with $\mathrm{Mn}(\mathrm{IV})$. As a result, the only removal of propranolol is observed with $\mathrm{Fe}(\mathrm{III})$, that appears to have more suitable properties for the anaerobic abiotic removal of pharmaceuticals with $\mathrm{Fe}(\mathrm{III})$ than other pharmaceuticals. It is essential in future studies to reveal favourable properties present in the suit of pharmaceuticals to react with $\mathrm{Fe}(\mathrm{III})$.

\subsection{Conclusion}

This study aimed at investigating biological regeneration of manganese(IV) by oxygen and iron (III) by nitrate in support of the anaerobic metal oxide-mediated removal of pharmaceuticals from water.

Results of this study show that the biological production of amorphous $\mathrm{Mn}(\mathrm{IV})$ occurs under $\mathrm{O}_{2}$-limiting conditions, despite the limited growth of the associated bacteria. There is no removal of pharmaceuticals mediated by $\mathrm{Mn}(\mathrm{II})$-oxidizing bacteria. In the abiotic removal of pharmaceuticals with $\mathrm{Mn}(\mathrm{IV})$ under anaerobic conditions, ground Mn(IV)DwTP powder can remove pharmaceuticals like metoprolol and propranolol.

Under anaerobic conditions, amorphous $\mathrm{Fe}(\mathrm{III})_{\text {bio-production }}$ is formed under nitrate-reducing conditions. The biological production of Fe(III) is obtained with and without pharmaceuticals. However, pharmaceuticals appear to inhibit Fe(III) production. During production of Fe(III)bio-production, the degradation of pharmaceuticals is negligible. Abiotic removal with $\mathrm{Fe}$ (III) is only observed with propranolol. Based on the abiotic removal of

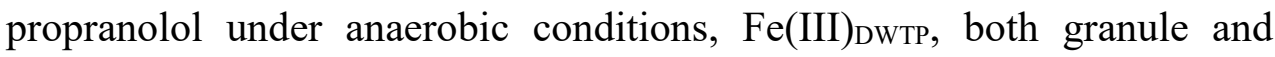
ground powder, has the best performance, followed by the Fe(III)FerroSorp®RW. 
In conclusion, biological regeneration of $\mathrm{Mn}(\mathrm{IV})$ and $\mathrm{Fe}(\mathrm{III})$ is feasible with dosage of limited amounts of $\mathrm{O}_{2}$ or nitrate not changing the anaerobic conditions needed for pharmaceutical degradation. Mn(IV) DWTP and Fe(III)DWTP show potential for abiotic anaerobic removal of propranolol. The abiotic anaerobic removal of metoprolol is also achieved with

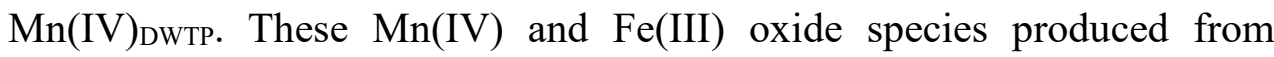
biological, chemical or biological-chemical (like in drinking water treatment) procedures could be used to remove pharmaceuticals under anaerobic conditions. The results of this study indicate that biological processes can be used to produce or regenerate $\mathrm{Mn}(\mathrm{IV})$ and $\mathrm{Fe}(\mathrm{III})$. The proof of principle is given but scaling up towards a complete recycling of $\mathrm{Mn}$ or $\mathrm{Fe}$ in continuously operated reactor configurations is the next challenge for future research oriented at further development of this technology.

\section{ACKNOWLEDGEMENT}

The work was supported by China Scholarship Council (File No.201308610161) and Wageningen University \& Research (WUR). The authors appreciate the help from Laura Piai (WUR), Yvonne Mos (WUR), Peter van der Maas (Water Laboratorium Noord), and Margot Koster (Utrecht University), for the experimental materials and the information. The authors appreciate the support from Hans Beijleveld, Livio Carlucci, Ilse Gerrits, and Vinnie de Wilde for their help with the chemical analyses, and Yiyuan Dong for collecting part of results in experiments on the biological production of $\mathrm{Mn}(\mathrm{IV})$ and $\mathrm{Fe}(\mathrm{III})$. 



\section{Chapter 7}

General Discussion: Towards a sustainable technology for removing pharmaceuticals from water using metal oxides 


\subsection{Introduction}

Concerns for the adverse effects of pharmaceutical compounds in water results in a societal demand for control and removal of these compounds. In this dissertation, anaerobic manganese (Mn)- or iron (Fe)mediated pharmaceutical degradation is proposed as a treatment technology to remove these compounds from water. A series of experiments are designed and setup to study these processes, in which pharmaceuticals are converted via abiotic removal or biological degradation while in most cases, the $\mathrm{Mn}(\mathrm{IV})$ or $\mathrm{Fe}(\mathrm{III})$ is reduced to $\mathrm{Mn}$ (II) or $\mathrm{Fe}(\mathrm{II})$. Thereafter, these reduced metal ions can be re-oxidized via biological or chemical processes, and transferred back to the pharmaceutical removal processes for reuse (Figure 1.2). Since the $\mathrm{Mn}$ and Fe are abundant in the environment and are important to the transformation pathway of organic compounds, including contaminants, studying the anaerobic Mn- or Fe- mediated pharmaceutical degradation also contributes to understanding the fate of pharmaceuticals in the environments.

This dissertation focuses on the principals and application of anaerobic degradation of pharmaceuticals in $\mathrm{Mn}$ (IV)- or Fe(III)-mediated system. Investigations have been carried out on the pharmaceutical removal efficiency, different types of $\mathrm{Mn}(\mathrm{IV})$ and $\mathrm{Fe}(\mathrm{III})$, environmental and operational conditions, as well as removal mechanisms. Biological regeneration of $\mathrm{Mn}(\mathrm{IV})$ and $\mathrm{Fe}(\mathrm{III})$ are tested, as well as the potential biodegradation of pharmaceuticals coupled to the regeneration. The outcomes are a step towards translating the results from this study into an affordable, environmentally friendly technology to remove pharmaceuticals during water treatment, and to improve and optimize pharmaceutical removal technologies. This technology can be used in wastewater treatment plants and in drinking water treatment plants (Figure 7.1), preventing the presence and accumulation of pharmaceuticals in the aquatic environment and soil, therefore reducing of potential long-term effects of 
pharmaceuticals on human's health ${ }^{[156]}$.

The results of these studies are obtained through batch experiments under ideal conditions which can be different from the environmental and operational conditions in application. To apply in practice, these results need to be critically reviewed, and the influence of the actual situation on the pharmaceutical removal during the water treatment processes need to be taken into account. In this chapter, removal mechanisms and the removal efficiencies are summarized and compared. Finally, the gaps between the lab-scale experimental results and the potential full-scale treatment performance are emphasized, and the future research perspectives to cross these gaps are proposed.

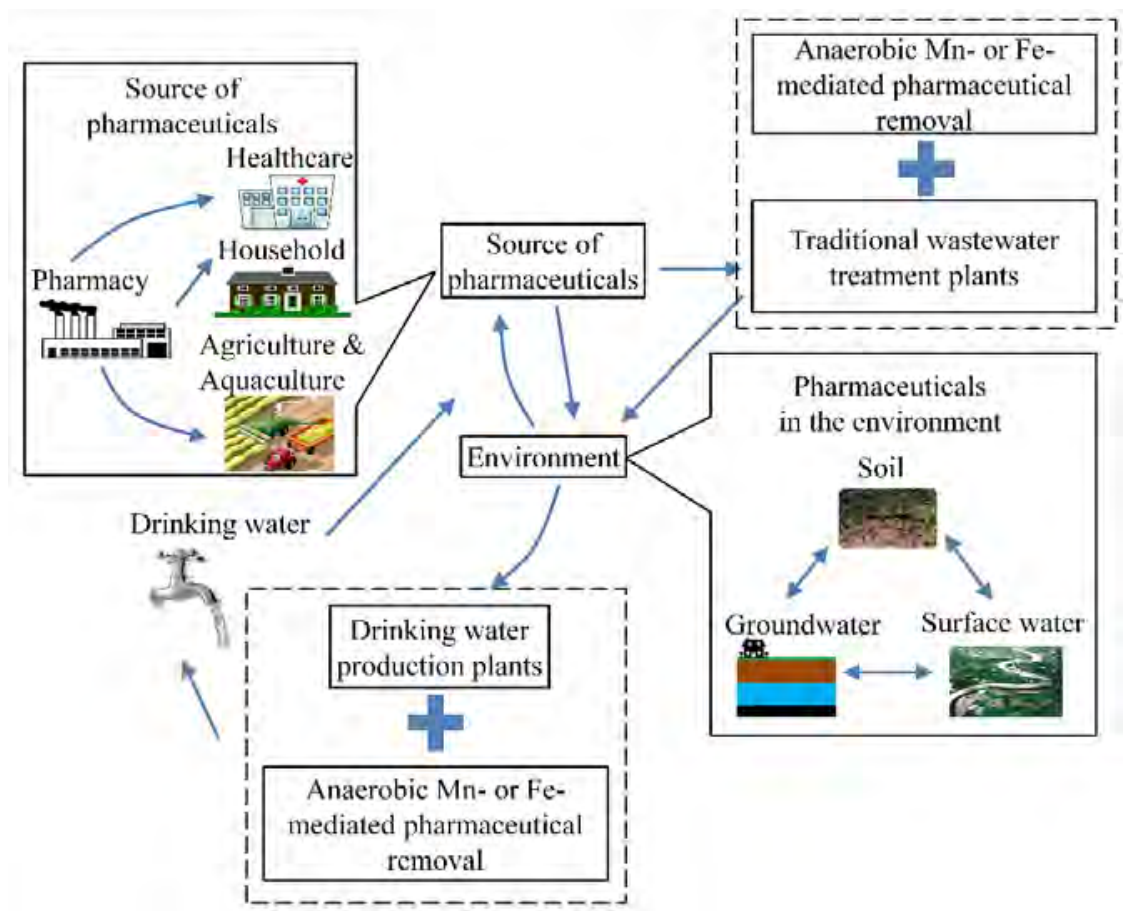

FIGURE 7.1 Source and pathway of pharmaceuticals in the environment controlled by the application of anaerobic Mn- or Fe- mediated pharmaceutical degradation 


\subsection{Outcomes}

\subsubsection{Removal mechanisms}

The main mechanisms of anaerobic pharmaceutical removal in the $\mathrm{Mn}(\mathrm{IV})$ - or $\mathrm{Fe}(\mathrm{III})$-mediated systems include adsorption, chemical oxidation, and biological degradation. Often, these mechanisms act simultaneously in reactors and the natural environment and contribute together to the overall removal of the pharmaceuticals. For example, the anaerobic pharmaceutical removal coupled to dissimilatory $\mathrm{Mn}$ (IV) reduction is mainly through biodegradation but adsorption is still an important process in the chain of interactions occurring leading to biodegradation.

(1) Adsorption

Adsorption is an important step during the pharmaceuticals removal in both abiotic removal and biodegradation of pharmaceuticals. In the anaerobic abiotic removal of pharmaceuticals, the adsorption and the chemical oxidation are involved. The compounds are first adsorbed onto the $\mathrm{Mn}(\mathrm{IV})$ or Fe(III). Thereafter, these pharmaceuticals are oxidized. During the anaerobic abiotic pharmaceutical removal with $\mathrm{Mn}(\mathrm{IV})$, adsorption contributes to over 30\% removal of propranolol (Chapter 6).

Adsorption is also observed in anaerobic biodegradation of pharmaceuticals coupled to dissimilatory Mn(IV) reduction. During the process, about $10 \%$ removal is observed in the first 10 days in the abiotic controls, resulting from the adsorption (Chapter 3). 
(2) Chemical oxidation

Chemical oxidation is the main removal mechanism in anaerobic abiotic pharmaceutical removal with $\mathrm{Mn}$ (IV) or Fe(III). In this thesis, diclofenac, metoprolol, and propranolol are efficiently removed by Mn(IV) through chemical oxidation (Chapter $4-6$ ), and oxidation of propranolol by $\mathrm{Fe}(\mathrm{III})$ is also observed (Chapter 6 ).

Interestingly, even though the chemical oxidation efficiently removes pharmaceuticals in anaerobic abiotic conditions with $\mathrm{Mn}(\mathrm{IV})$ and $\mathrm{Fe}(\mathrm{III})$ (Chapter $4-6$ ), the abiotic controls in anaerobic biodegradation demonstrate insignificant pharmaceutical removal (Chapter 3). This could be due to the different matrix used in these two experiments (Table 7.1). The matrix used in anaerobic abiotic removal experiments is water or a simple buffer system while the anaerobic biodegradation experiments are performed with synthetic cultivation medium. Results in this thesis show that the presence of co-solutes such as metal ions or low concentration of phosphate could occupy the Mn(IV) surface reactive sites via interactions between negatively charged phosphate ions and positively charged oxide surfaces (Chapter 5). As a result, there are less surface reactive sites available for pharmaceuticals and their removal is inhibited. Similarly, the nutrient and trace elements in synthetic medium and the inhibitors in abiotic controls are more likely to block the surface reactive sites. Therefore, the pharmaceutical removal in abiotic controls in anaerobic biodegradation with $\mathrm{Mn}(\mathrm{IV})$ or $\mathrm{Fe}(\mathrm{III})$ is insignificant.

Similarly, the microbial inoculum in biodegradation studies could also influence the availability of the reactive sites, by bacterial adhesion using (generally negatively charged) cell surface polymers that adsorb on the positively charged metal oxide surfaces ${ }^{[253,254]}$. This could be of effect in both biotic experimental groups and in abiotic controls with sterilized biomass. Based on previous study, the bacteria are expected to attach on the solid $\mathrm{Mn}(\mathrm{IV})$ or $\mathrm{Fe}(\mathrm{III})$ to transfer the electrons ${ }^{[175]}$. Therefore, the 
pharmaceuticals are not able to directly contact to the Mn(IV), leading to insignificant removal of pharmaceuticals via chemical oxidation in abiotic controls, as well as via adsorption.

\section{(3) Biological degradation}

Biological degradation is another important removal mechanism described in this dissertation. The anaerobic biodegradation with $\mathrm{Mn}(\mathrm{IV})$ can remove caffeine, naproxen, metoprolol, and propranolol (Chapter 3). The anaerobic biodegradation with $\mathrm{Fe}(\mathrm{III})$ has been tested with metoprolol, and is found to be over $50 \%$ (Chapter 3). The biodegradation of pharmaceuticals is also tested coupled to the biological production of $\mathrm{Mn}(\mathrm{IV})$ and $\mathrm{Fe}(\mathrm{III})$. No removal is obtained with $\mathrm{Mn}$ (II)-oxidizing bacteria. The pharmaceutical removal efficiency during the biological production of $\mathrm{Fe}(\mathrm{III})$ is less than $20 \%$ (Chapter 6).

TABLE 7.1 Critical experimental parameters investigated and presented in this dissertation

\begin{tabular}{|c|c|c|c|c|}
\hline \multirow[b]{2}{*}{ Conditions } & \multicolumn{2}{|c|}{$\begin{array}{l}\text { Anaerobic pharmaceutical } \\
\text { biodegradation }\end{array}$} & \multicolumn{2}{|c|}{$\begin{array}{l}\text { Anaerobic abiotic pharmaceutical } \\
\text { removal }\end{array}$} \\
\hline & $\begin{array}{l}\text { Biodegradation } \\
\text { with Mn(IV) } \\
\text { (Chapter 3) }\end{array}$ & $\begin{array}{l}\text { Biodegradation } \\
\text { with Fe(III) } \\
\text { (Chapter 3) } \\
\end{array}$ & $\begin{array}{l}\text { Abiotic removal } \\
\text { with } \mathrm{Mn}(\mathrm{IV}) \\
\text { (Chapter } 4-6)\end{array}$ & $\begin{array}{l}\text { Abiotic removal } \\
\text { with Fe(III) } \\
\text { (Chapter 6) }\end{array}$ \\
\hline $\mathrm{T}\left({ }^{\circ} \mathrm{C}\right)$ & 30 & 35 & $10-30$ & 30 \\
\hline $\mathrm{pH}$ & $\sim 7$ & $\sim 7$ & $4 \sim 9$ & $\sim 7$ \\
\hline $\begin{array}{l}\text { Redox } \\
\text { conditions }\end{array}$ & $\begin{array}{l}\mathrm{Mn}(\mathrm{IV})- \\
\text { reducing }\end{array}$ & $\begin{array}{l}\mathrm{Fe}(\mathrm{III})- \\
\text { reducing }\end{array}$ & Anaerobic & Anaerobic \\
\hline Matrix & $\begin{array}{l}\text { Synthetic } \\
\text { medium }\end{array}$ & $\begin{array}{l}\text { Synthetic } \\
\text { medium }\end{array}$ & $\begin{array}{l}\text { Demineralized } \\
\text { water, } 10 \mathrm{mM} \\
\text { MOPS buffer + } \\
10 \mathrm{mM} \mathrm{NaCl}\end{array}$ & $\begin{array}{l}10 \mathrm{mM} \\
\text { phosphate } \\
\text { buffer }+10 \mathrm{mM} \\
\mathrm{NaCl}\end{array}$ \\
\hline $\begin{array}{l}\text { Initial } \\
\text { pharmaceutical } \\
\left(\mathrm{mg} \cdot \mathrm{L}^{-1}\right)\end{array}$ & 10 & $1-10$ & $0.25-1$ & 0.5 \\
\hline $\begin{array}{l}\text { Experimental } \\
\text { period }(d)\end{array}$ & $40-70$ & $60-160$ & $1-1.4$ & 5 \\
\hline $\begin{array}{l}\text { Other } \\
\text { conditions }\end{array}$ & Dark and static & Dark and static & Dark and static & Dark and static \\
\hline
\end{tabular}




\subsubsection{Comparison of processes}

In this thesis research, anaerobic pharmaceutical degradation is studied with $\mathrm{Mn}(\mathrm{IV})$ and $\mathrm{Fe}(\mathrm{III})$, and abiotic and biotic processes are considered and compared which one holds the most promise for successful application. When reviewing the literature on current Mn- or Fe-related pharmaceutical removal technologies, a framework is proposed and used (Chapter 2). Based on that, the anaerobic pharmaceutical degradation in Mn- or Fe-mediated systems are evaluated in the following aspects:

\section{(1) Process performance}

The primary objective of this dissertation research is to develop a mechanistic understanding and assessment on potential technologies to remove the pharmaceuticals from water using metal oxides. Therefore, important criteria are the extent and the rate of removal of different pharmaceuticals. The removal rate is for most experiments calculated for experimental time frames where the pharmaceutical removal is stable. However, in some experiments this is not possible, leading to samples taken at the beginning and at the end of the experiments, leading to rate calculations with a relatively high uncertainty range. Nevertheless these data are useful as first rough estimates.

\section{(2) Condition}

In addition to pharmaceutical removal, the environmental and operational conditions, such as $\mathrm{pH}$, temperature, or presence of co-solutes, are found to affect the removal efficiency of pharmaceuticals in different processes, as well as the matrix or cultivation medium. The processes are better if they are effective under conditions which are similar or close to natural conditions, because these processes are required less cost and energy to maintain a special operational conditions. 
(3) Sustainability

In the process evaluation and comparison, the sustainability of the pharmaceutical removal processes should be taken into account. In sustainability, the energy consumption of the process, and the effects of the products on environment are important factors, and the newly proposed and current water treatment processes can be compared on these aspects.

(4) Metal oxide types.

Various forms of Mn- or Fe- (hydr)oxides are the main materials consumed during the removal processes studied. The proper type of metal oxide is critical in application to achieve high enough removal efficiency. In addition, the costs and availability of the metal oxides must be considered. In case the $\mathrm{Mn}$ or Fe species can be used that are e.g. waste by-products such as $\mathrm{Mn}$ or Fe containing sludge produced at drinking water treatment plants. These could be favourable materials to be used in the application.

\subsubsection{Process performance}

The process performance is mainly evaluated by the extent and rate of removal of pharmaceuticals. The results indicated that the anaerobic Mn- or Fe-mediated removal is effective for different pharmaceuticals (Table 7.2). In general, the pharmaceutical removal rate in the anaerobic biodegradation is slower than that for abiotic removal but both of them can achieve removal efficiency over $90 \%$ of certain specific pharmaceuticals (Chapter $3-6$ ).

The pharmaceutical removal technology can be applied as a tertiary treatment in wastewater treatment processes to protect the surface water and groundwater from pollution by these compounds. Also, it can be used to protect drinking water as a pre-treatment treatment unit. The pharmaceuticals, which are recalcitrant in conventional water treatment plants are the target compounds of pharmaceutical removal units. Based on literature, the seven pharmaceuticals selected in this dissertation can be classified into two groups; poorly removable pharmaceuticals $(<45 \%)$, and highly removable pharmaceuticals ( $>60 \%$ ) (Table 7.2). Among the poorly 
removable pharmaceuticals found in this study, carbamazepine, diclofenac, metoprolol, and propranolol can be listed. These compounds are also generally found to pass standard wastewater treatment plants, and are thus more likely to enter a tertiary pharmaceutical removal unit when placed in water treatment plants. Highly removable pharmaceuticals include caffeine, ibuprofen, and naproxen. Although degradable in WWTP, these compounds are also generally found in WWTP effluent due to their relatively high concentrations in the influent. For example, removal of ibuprofen in wastewater treatment plants (WWTPs) is around $72-100 \%$, but the maximum concentration of ibuprofen in WWTP effluent can be $95 \mu \mathrm{g} \cdot \mathrm{L}^{-1}$, much higher than other investigated pharmaceuticals in this thesis (Table 1.1). In addition, concentrations of ibuprofen observed in WWTPs effluents are found to be up to 60 times higher than the lowest predicted no effect concentrations (Table 1.1, Table 7.2). Therefore, tertiary treatment well degradable compounds like ibuprofen is also required.

The pharmaceutical removal by using metal oxides as assessed in this work varied greatly based on the pharmaceutical studied and experimental setups. Removal of carbamazepine is not observed in any of the experiments conducted in this study (Chapter $3-6$ ). Complete removal of diclofenac at removal rate of $24.3 \mathrm{mg} \cdot \mathrm{L}^{-1} \cdot \mathrm{d}^{-1}$ is obtained in the anaerobic abiotic removal process using $\mathrm{Mn}(\mathrm{IV})$ (Chapter 5), whereas only 20\% is removed when biodegradation is coupled to $\mathrm{Fe}(\mathrm{III})$ production at a rate of $0.0015 \mathrm{mg}$ pharmaceutical $\cdot \mathrm{L}^{-1} \cdot \mathrm{d}^{-1}$ (Chapter 6$)$. The fastest removal of metoprolol $(0.36$ mg pharmaceutical $\cdot \mathrm{L}^{-1} \cdot \mathrm{d}^{-1}$ achieving $33 \%$ removal, Chapter 4 \& 6) is obtained in anaerobic abiotic removal with $\mathrm{Mn}(\mathrm{IV})$, followed by the anaerobic pharmaceutical biodegradation with $\mathrm{Mn}(\mathrm{IV}) \quad(0.17 \mathrm{mg}$ pharmaceutical $\cdot \mathrm{L}^{-1} \cdot \mathrm{d}^{-1}$ and $96 \%$, Chapter 3 ). In the anaerobic pharmaceutical biodegradation with $\mathrm{Fe}(\mathrm{III}), 57 \%$ metoprolol is removed at $0.05 \mathrm{mg} \cdot \mathrm{L}^{-1} \cdot \mathrm{d}^{-1}$ (Chapter 3). In propranolol removal, anaerobic abiotic pharmaceutical removal with $\mathrm{Mn}(\mathrm{IV})$ is the most efficient process $(51 \%$ at $0.53 \mathrm{mg} \cdot \mathrm{L}^{-1} \cdot \mathrm{d}^{-1}$, Chapter $4 \& 6$ ), while the removal rate of anaerobic 
pharmaceutical biodegradation with $\mathrm{Mn}(\mathrm{IV})$, and the anaerobic abiotic pharmaceutical removal with $\mathrm{Fe}(\mathrm{III})$ is the same $\left(0.04 \mathrm{mg} \cdot \mathrm{L}^{-1} \cdot \mathrm{d}^{-1}\right.$, Chapter $3 \& 6$ ). For ibuprofen, only $17 \%$ is biologically degraded coupled to Fe(III) production at an extremely slow removal rate, namely $0.60 \times 10^{-3} \mathrm{mg} \cdot \mathrm{L}^{-1} \cdot \mathrm{d}^{-1}$ (Chapter 6).

\subsubsection{Condition}

In addition to pharmaceutical removal, the conditions are found to affect the removal efficiency of pharmaceuticals, which is very relevant for the future reactor design and operation. The environmental and operational conditions applied in this thesis are quite similar to those in current water treatment technologies (Table 7.1).

The environmental conditions in both anaerobic biodegradation and abiotic removal of pharmaceuticals in $\mathrm{Mn}$ - or Fe-mediated systems are the same as natural conditions, namely at $10-40{ }^{\circ} \mathrm{C}, \mathrm{pH} \sim 7$. These conditions are also widely used in wastewater and drinking water treatment processes such as upflow anaerobic sludge blanket reactor, or a slow sand filter ${ }^{[3,363]}$.

The specific operational conditions vary for different pharmaceutical removal processes. In the anaerobic pharmaceutical biodegradation with $\mathrm{Mn}(\mathrm{IV})$ or $\mathrm{Fe}(\mathrm{III})$, the operational parameters require further optimization and adaptation. First of all, the concentrations of pharmaceuticals in the studies in this thesis $\left(1-10 \mathrm{mg} \cdot \mathrm{L}^{-1}\right.$, Chapter $\left.3 \& 6\right)$ are much higher than that in the wastewater $\left(\mathrm{ng} \cdot \mathrm{L}^{-1}-\mu \mathrm{g} \cdot \mathrm{L}^{-1}\right)$. Thus, in the experiments in this study, pharmaceuticals can act as the only carbon and energy source supporting growth of bacteria involved in the biodegradation, giving these a selective pressure benefit. If these biological processes are applicable at lower level of concentrations of pharmaceuticals requires further study. In addition, the time needed for biodegradation of pharmaceuticals as found in our experimental work ( $40-160$ days, Chapter $3 \& 6)$ is much longer than the retention time generally considered acceptable for tertiary treatments (maximum $10-30$ days) ${ }^{[290]}$. When the influent is stable, longer 
retention times for pharmaceutical biodegradation will lead to a larger reactor, and higher cost of construction and operation. Due to the different properties of the pharmaceuticals, the time needed in biodegradation could also be different.

In the anaerobic abiotic pharmaceutical removal with $\mathrm{Mn}(\mathrm{IV})$ or $\mathrm{Fe}(\mathrm{III})$, the required operational conditions are quite similar to the slow sand filter ${ }^{[3]}$. For example, the abiotic anaerobic pharmaceutical removal with Mn(IV) usually takes $1-1.5$ days with the most efficient removal during the first $0.2-0.3$ days ( $5-7$ hours). Generally the retention time of a slow sand filter is $0.2-0.5$ days ( $5-13$ hours). This is long enough to efficiently remove pharmaceuticals using these $\mathrm{Mn}(\mathrm{IV})$ and $\mathrm{Fe}(\mathrm{III})$ mediated processes. In addition, a typically constructed slow sand filter consists of a layer of fine sand supported by gravel. Those can be replaced by fine $\mathrm{Mn}(\mathrm{IV})$ particles supported by $\mathrm{Mn}(\mathrm{IV})$ granules, giving higher reative surface areas per unit of volume, thus reducing the filter size are allowing higher loading capacities.

The (liquid) matrix in which the pharmaceuticals are removed is also important. In the anaerobic biodegradation, the matrix is the synthetic medium containing nutrient compounds, trace elements, and vitamin solutions (Chapter $3 \& 6$ ). In the abiotic removal, however, the matrix is much simpler, namely demineralized water or phosphate buffer (Chapter 4 - 6). The presence of co-solutes is found to inhibit the anaerobic abiotic pharmaceutical removal. For example, the removal of diclofenac is observed in anaerobic abiotic removal with $\mathrm{Mn}(\mathrm{IV})$ but not in the abiotic controls of anaerobic biodegradation with Mn(IV) (Chapter $3-5$ ). Thus, the anaerobic biodegradation of pharmaceuticals with $\mathrm{Mn}$ (IV) or Fe(III) is more suitable in wastewater treatment effluents because wastewater can supply the nutrient compounds for the bacterial activity. On the other hand, the anaerobic abiotic removal with $\mathrm{Mn}(\mathrm{IV})$ or $\mathrm{Fe}(\mathrm{III})$ is more suitable in drinking water treatment plants because the matrix is much simpler. 


\subsubsection{Sustainability}

In general, the anaerobic pharmaceutical degradation with $\mathrm{Mn}(\mathrm{IV})$ or $\mathrm{Fe}(\mathrm{III})$ is a potential sustainable pharmaceutical removal technology. Firstly, pharmaceutical removal is achieved under anaerobic conditions, requiring no aeration or other high energy consumption input. For another thing, the main products in pharmaceutical removal, $\mathrm{Mn}$ (II) or Fe(II), can be recycled and reused (Chapter 6). This further reduces the $\mathrm{Mn}$ (II) or Fe(II) enter the effluent of this technology. In addition, the Mn(IV) or Fe(III) from drinking water treatment plants (DWTPs) can be used as an alternative metal oxide source (Chapter $3 \& 6$ ). These $\mathrm{Mn}$ or Fe species are -thus far- waste byproducts in drinking water production, and which by application in water treatment for removing pharmaceuticals become a valuable product. Therefore, the anaerobic pharmaceutical removal with $\mathrm{Mn}$ or Fe can be considered sustainable.

However, the other products from anaerobic Mn(IV)- or Fe(III)mediated pharmaceutical removal, such as pharmaceutical intermediates, might affect the ecosystem, human health, and the current water treatment chain. Previous studies indicate that some transformation intermediates from pharmaceuticals could be more toxic than their parent compounds ${ }^{[309]}$. Since the toxicity assessment is not included in this dissertation, it is impossible to determine if the intermediates are more toxic when they are formed in the anaerobic pharmaceutical biodegradation or in anaerobic abiotic pharmaceutical removal. 
In the anaerobic biodegradation of pharmaceuticals, the growth of bacteria results in waste biomass. The waste biomass should be treated, for example, via anaerobic digestion. However, the biomass from pharmaceutical removal contains $\mathrm{Mn}$ or Fe, both of which will affect the anaerobic digestion. Previous studies show $\mathrm{Mn}$ or Fe can promote the production of butyric acid during the fermentation process ${ }^{[173]}$. The Fe(III) can also affect the removal and recovery of phosphate in anaerobic sludge digestion ${ }^{[37,288]}$. Adsorption of phosphate onto $\mathrm{MnO}_{2}$ has also been reported previously ${ }^{[227,228]}$. In addition, the anaerobic biodegradation with $\mathrm{Fe}(\mathrm{III})$ is also efficient in nitrogen (ammonia) removal ${ }^{[232,372]}$.

In drinking water treatment processes, the pharmaceutical removal units are expected before sand filtration. The Mn(II) and Fe(II) generated during the anaerobic pharmaceutical degradation will enter the DWTPs. However, the $\mathrm{Mn}$ (II) and $\mathrm{Fe}(\mathrm{II})$ are also target compounds for drinking water production $[135,307]$. Therefore, anaerobic metal-mediated pharmaceutical degradation will increase the loading of Mn and Fe removal in DWTPs. When anaerobic pharmaceutical biodegradation is applied, the loading in disinfection units in DWTPs will also be increased.

In summary, the anaerobic pharmaceutical degradation with $\mathrm{Mn}(\mathrm{IV})$ or $\mathrm{Fe}(\mathrm{III})$ is generally a sustainable process but the environmental influence of this pharmaceutical removal technology should be considered in follow-up studies. On one side, the toxic effects of pharmaceutical intermediates produced in this process require further assessment. On the other side, influence of applying this process in the current water treatment chain should be taken into account. Compared to the influence on wastewater treatment processes and in drinking water production, the anaerobic pharmaceutical degradation with $\mathrm{Mn}$ or Fe has less negative effects as a post-treatment unit in WWTPs. 


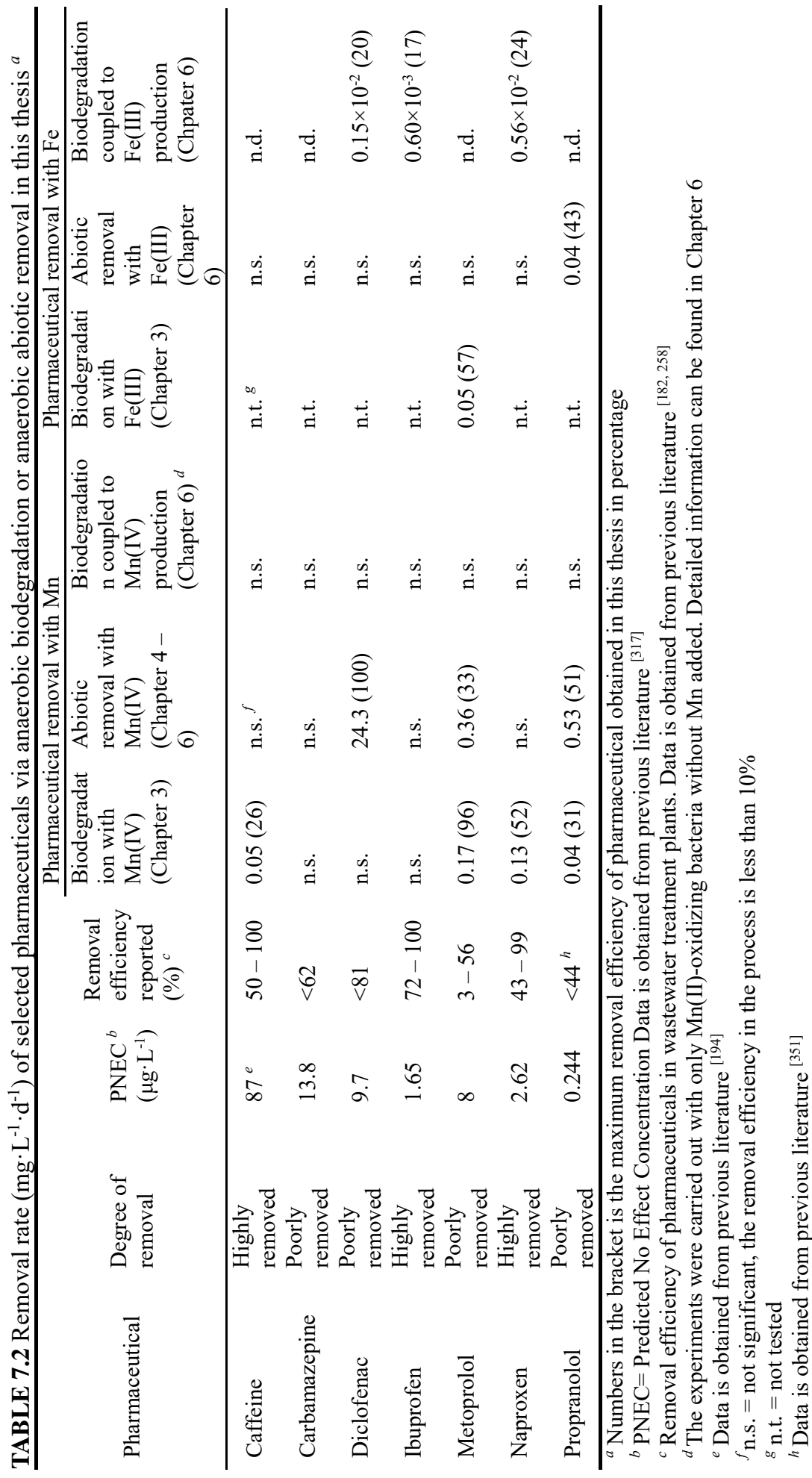




\subsubsection{Metal oxide types}

The $\mathrm{Mn}$ and $\mathrm{Fe}$ species are important consumable materials during the pharmaceutical removal. In this dissertation, $\mathrm{Mn}$ and $\mathrm{Fe}$ species from different sources and synthesis methods are tested (Table 7.3). The removal efficiency of pharmaceuticals with different $\mathrm{Mn}$ or $\mathrm{Fe}$ species in both biological degradation and abiotic removal are summarised in Table 7.4.

The results indicate that amorphous chemically synthesized Mn(IV) is the most suitable material in both anaerobic pharmaceutical biodegradation and anaerobic abiotic pharmaceutical removal (Chapter3 - 6). It can be used for the removal of caffeine, diclofenac, naproxen, metoprolol and propranolol. Also the $\mathrm{Mn}(\mathrm{IV})$ from drinking water treatment plants are suitable for removal of metoprolol and propranolol (Chapter $3 \& 6$ ). The pharmaceutical removal with $\mathrm{Fe}(\mathrm{III})$ is also effective, more pharmaceuticals should be tested (Chapter $3 \& 6$ ).

The reduced $\mathrm{Mn}(\mathrm{II})$ and $\mathrm{Fe}(\mathrm{II})$ species generated during the anaerobic pharmaceutical degradation with $\mathrm{Mn}(\mathrm{IV})$ or $\mathrm{Fe}(\mathrm{III})$ can be re-oxidized and reused in application (Chapter 6). Therefore, the biogenic regenerated $\mathrm{Mn}(\mathrm{IV})$ and $\mathrm{Fe}$ (III) oxides are the most suitable input source in stable removal process. In addition, the $\mathrm{Mn}$ and $\mathrm{Fe}$ removal process in drinking water production can also be regarded as $\mathrm{Mn}$ and Fe cycling. Thus, the $\mathrm{Mn}(\mathrm{IV})$ and $\mathrm{Fe}(\mathrm{III})$ from drinking water treatment plants are also suitable source in pharmaceutical removal. 
TABLE 7.3 $\mathrm{Mn}$ and Fe species tested in different pharmaceutical removal processes in this thesis

\begin{tabular}{|c|c|c|}
\hline $\begin{array}{l}\text { Pharmaceutical } \\
\text { removal processes }\end{array}$ & Mn species & Fe species \\
\hline $\begin{array}{l}\text { Anaerobic } \\
\text { pharmaceutical } \\
\text { biodegradation with } \\
\text { Mn(IV) or Fe(III) } \\
\text { (Chapter 3) }\end{array}$ & $\begin{array}{l}\text { Chemically synthesized } \\
\text { Mn(IV) oxides (self- } \\
\text { synthesized) } \\
\text { - Mn(IV) from drinking } \\
\text { water treatment plants }\end{array}$ & $\begin{array}{l}\text { - } \text { Chemically synthesized } \\
\text { Fe(III) hydroxides (self- } \\
\text { synthesized) } \\
\text { - Fe(III) from drinking water } \\
\text { treatment plants } \\
\text { - Fe(III)-citrate (commercial } \\
\text { products) } \\
\text { - Fe(III)-based sorbents } \\
\text { (commercial products) }\end{array}$ \\
\hline $\begin{array}{l}\text { Anaerobic abiotic } \\
\text { removal with Mn(IV) } \\
\text { or Fe(III) }{ }^{a} \\
\text { (Chapter } 4-6)\end{array}$ & $\begin{array}{l}\text { - Chemically synthesized } \\
\text { Mn(IV) oxides (self- } \\
\text { synthesized) } \\
\text { - Chemically synthesized } \\
\mathrm{MnO}_{2} \text { (commercial } \\
\text { products) } \\
\text { - Mn(IV) from drinking } \\
\text { water treatment plants }\end{array}$ & $\begin{array}{l}\text { - Chemically synthesized } \\
\text { Fe(III) hydroxides (self- } \\
\text { synthesized) } \\
\text { - biogenic Fe(III) hydroxides } \\
\text { - Fe(III) from drinking water } \\
\text { treatment plants } \\
\text { - Fe(III)-based sorbents } \\
\text { (commercial products) }\end{array}$ \\
\hline $\begin{array}{l}\text { Pharmaceutical } \\
\text { biodegradation during } \\
\text { biological Mn(IV) or } \\
\text { Fe(III) production } \\
\text { (Chapter 6) }\end{array}$ & - Not tested $^{b}$ & - $\mathrm{FeCl}_{2}$ \\
\hline \multicolumn{3}{|c|}{$\begin{array}{l}{ }^{a} \text { In the abiotic removal of pharmaceuticals with } \mathrm{Mn}(\mathrm{IV}) \text {, both oxic and anaerobic } \\
\text { conditions were tested while in the removal with Fe(III), only anaerobic conditions } \\
\text { were tested } \\
{ }^{b} \text { The pharmaceutical biodegradation during biological Mn(IV) production was tested } \\
\text { with only Mn(II)-oxidizing bacteria without Mn(II). The detailed information can be } \\
\text { found in Chapter } 6\end{array}$} \\
\hline
\end{tabular}




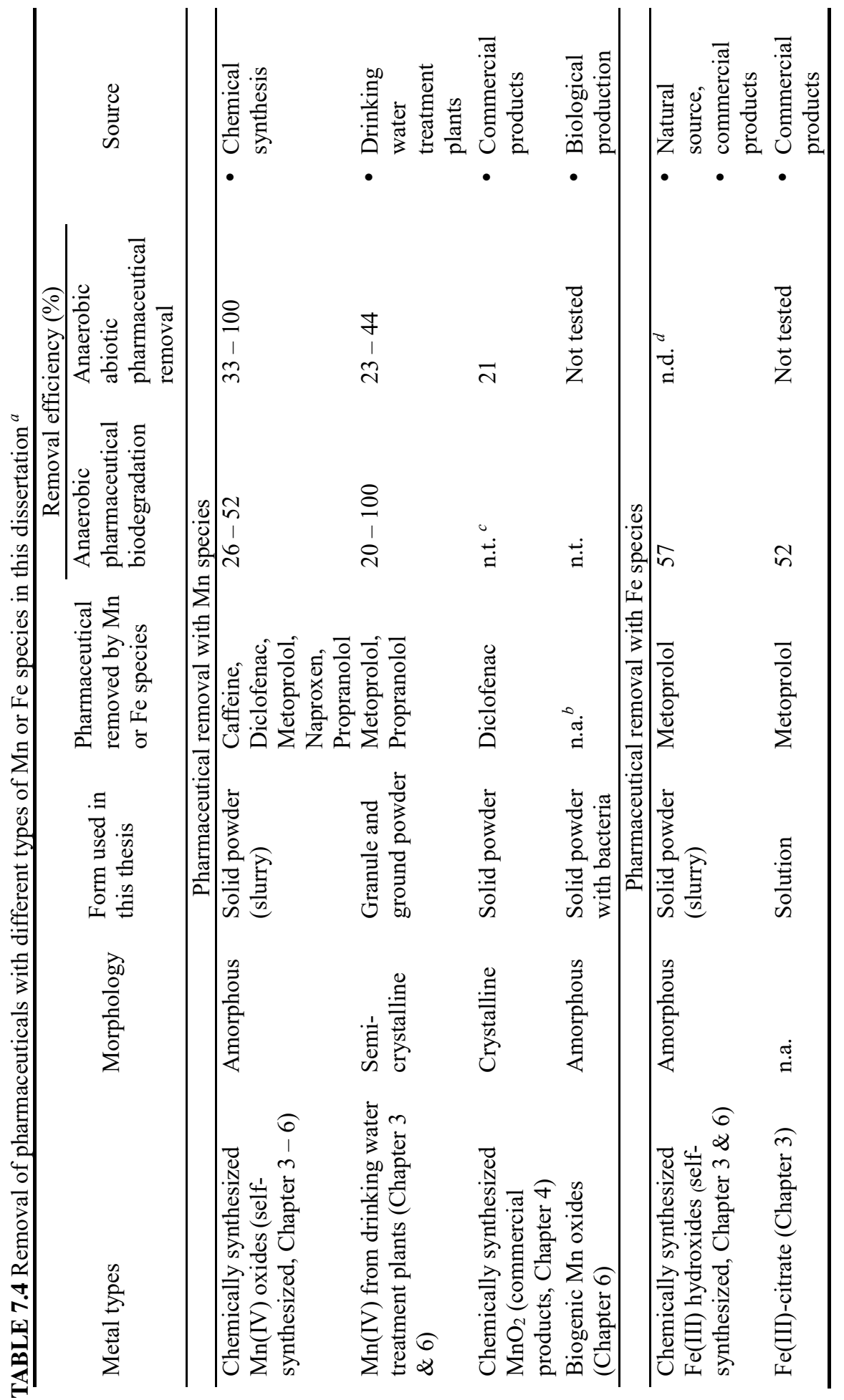




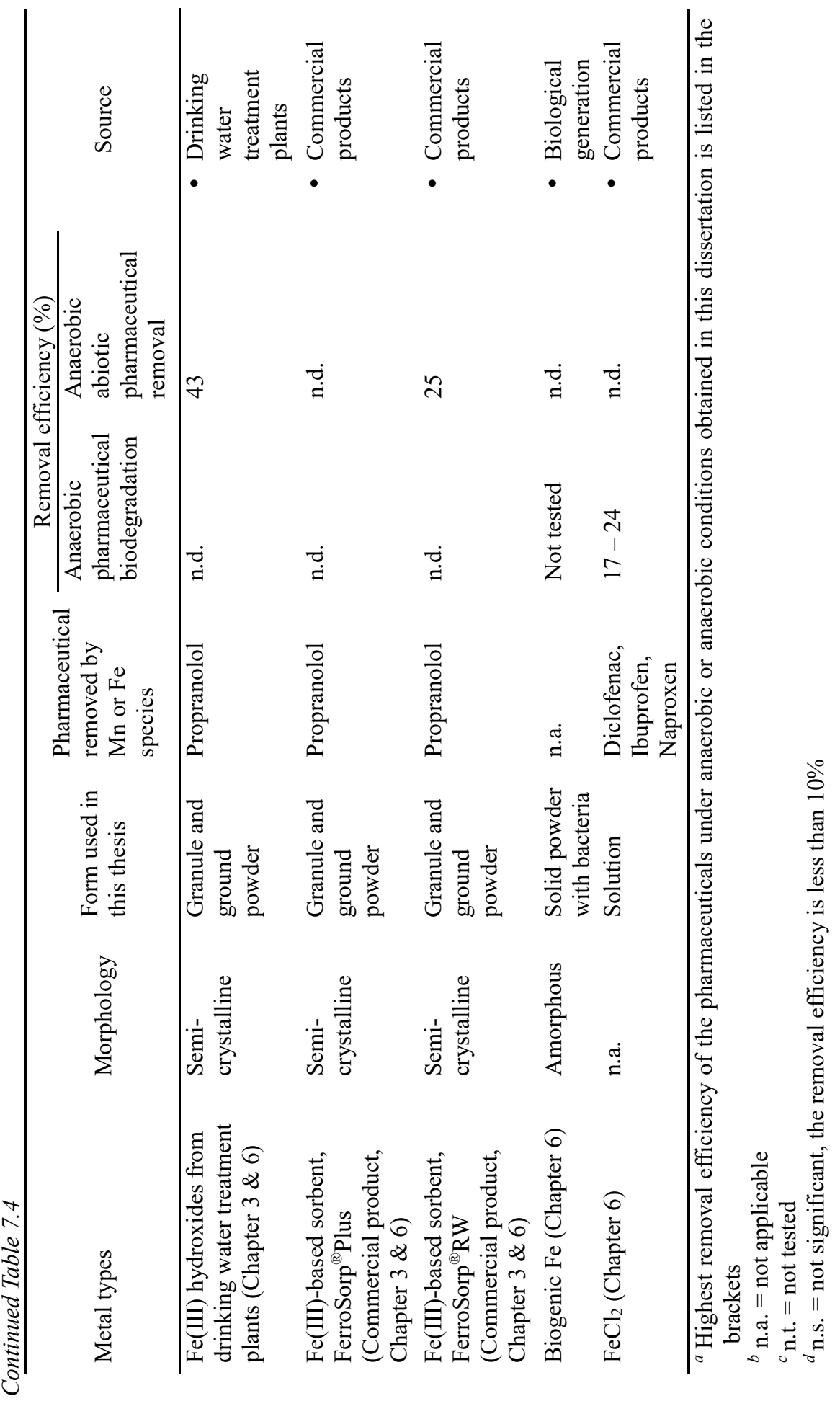




\subsection{Future perspective}

\subsubsection{From lab to application}

The ultimate objective of this study is to develop anaerobic Mn- or Femediated pharmaceutical degradation into an efficient, cost-effective, environmental friendly technology in water treatment. It is still a long process from the batch studies as performed in this thesis research to the full-scale application in the field. For this development, three steps are proposed.

\section{Step 1: Exploring the limits of Mn- and Fe-mediated pharmaceutical removal}

This thesis demonstrates that anaerobic $\mathrm{Mn}$ - or Fe-mediated pharmaceutical degradation in water is possible and it is an indication of relevant treatment conditions. To apply this process in practice, more studies are required. First of all, only seven pharmaceuticals are used in this thesis and only some of them are removed. More pharmaceuticals should be tested to further understand the pathway of pharmaceutical degradation, and to determine wider classes of compounds that can be removed. Can the anaerobic Mn- or Fe-mediated pharmaceutical degradation used as function efficient at actual concentrations? This is another important question to answer. Since the pharmaceutical concentration used in this thesis is in the range of $\mathrm{mg} \cdot \mathrm{L}^{-1}$, which is thousand times higher than that in often observed in waste water effluents $\left(\mathrm{ng} \cdot \mathrm{L}^{-1}-\mu \mathrm{g} \cdot \mathrm{L}^{-1}\right)$, it is essential to test the anaerobic biodegradation and anaerobic abiotic removal of pharmaceuticals at that level through batch experiments.

An advantage of anaerobic $\mathrm{Mn}$ - or Fe-mediated pharmaceutical degradation is the cycling and reuse of $\mathrm{Mn}$ and Fe species. Therefore, future studies on applying the regenerated $\mathrm{Mn}(\mathrm{IV})$ and $\mathrm{Fe}(\mathrm{III})$, namely, biologically produced $\mathrm{Mn}(\mathrm{IV})$ and Fe(III) is necessary. In this thesis, anaerobic abiotic pharmaceutical removal with these biologically produced 
$\mathrm{Mn}(\mathrm{IV})$ and $\mathrm{Fe}$ (III) has been tested, and further investigation on applying them in anaerobic pharmaceutical biodegradation is needed.

The effects of co-solutes on anaerobic abiotic pharmaceutical removal are described in this thesis. However, they can also affect the anaerobic pharmaceutical biodegradation. For example, ammonia in the wastewater can be used by the bacteria to reduce Fe(III) ${ }^{[162,267]}$, thus competing with pharmaceuticals. In addition, the organic matter can promote biodegradation of pharmaceuticals via co-metabolism ${ }^{[92]}$, or inhibit by competing with pharmaceuticals as a carbon source. The effects of organic matter on anaerobic Mn- or Fe-mediated pharmaceutical biodegradation are unknown, and worthwhile studying.

Studying the kinetics of both anaerobic biodegradation and anaerobic abiotic removal will contribute to determining the needed hydraulic retention time (HRT) and/or the solid retention time (SRT). The HRT will ensure that the pharmaceuticals are staying at a shortest time in the reactor achieving the most efficient removal. The SRT will ensure the bacteria and oxidants like $\mathrm{MnO}_{2}$ stay in the reactor long enough to contact with pharmaceuticals and then remove these compounds. Previous studies have shown that both HRT and SRT affect the degradation of pharmaceuticals and other micropollutants in current water treatment technologies ${ }^{[7,22,39,189]}$. These factors highly affect the design of the treatment reactor.

Results from previous studies have shown that the intermediates from pharmaceutical removal technologies can be more toxic than parent compounds ${ }^{[205]}$. Therefore, evaluation of the anaerobic Mn- or Fe-mediated pharmaceutical degradation should continue beyond the removal efficiency of pharmaceutical parent compounds, with a focus on the intermediates. Due to the improvement of analytical methods, it is possible to directly identify the possible intermediates of pharmaceuticals in anaerobic degradation. Furthermore, toxicity and risk assessment can be used as a new tool to evaluate the performance of the technology, which is more 
comprehensive than the simple intermediates identification. In addition, the toxicity assessment could reveal the "cocktail effects" of the intermediates, which is hard to predict based on the intermediates analysis.

In this first step, most suggested studies are application-orientated. Some studies on mechanism and intermediates are also interesting to know, to better understand the pharmaceutical removal process. The results collected in this step can also be used to design a lab-scale reactor and settle the operational parameters.

\section{Step 2: Simulating the pharmaceutical removal in a lab-scale reactor}

Once the potential of Fe- and $\mathrm{Mn}$ - mediated pharmaceutical removal have been further explored, these conditions must be translated into process conditions for application. This thesis envisions that the anaerobic Mn- or Fe-mediated pharmaceutical degradation in water contains two units - a pharmaceutical removal unit, and a metal cycling system (also has potential to remove pharmaceuticals) (Figure 7.2). The results obtained from this dissertation and batch experiments in Step 1, together with data from literature, are sufficient for the design of a lab-scale reactor. For example, the lab-scale reactor can be designed by modifying the bed filter reactors based on the experimental results because bed filter has been used previously to remove pharmaceutical compoundss with $\mathrm{MnO}_{2}$ under aerobic conditions ${ }^{[108,109]}$. Similarly, the sand filter can be used as the Mn(II) or $\mathrm{Fe}(\mathrm{II})$ oxidation unit (metal cycling system), because this reaction has been used in DWTPs to remove (oxidize) $\mathrm{Mn}$ (II) and Fe(II) via both chemical and biological processes ${ }^{[239]}$. The lab-scale reactor can be used to test if the selected operational parameters are suitable for anaerobic $\mathrm{Mn}$ - or Femediated pharmaceutical degradation, such as HRT, SRT, flow rate, etc. In addition, the lab-scale reactor can also be used to simulate and monitor application parameters like loading shock. 
Another focus of this step is the start-up and operational strategy of the pharmaceutical removal reactor applying the anaerobic Mn- or Fe-mediated degradation, especially the bioreactor. In this dissertation, it took approximately 3 years to enrich the active culture from anaerobic sediment (Chapter 3). This is an enormous drawback for the application of the anaerobic pharmaceutical biodegradation with $\mathrm{Mn}(\mathrm{IV})$ or Fe(III). A wise start-up strategy is therefor to develop a pre-adapted inoculum and this should be studied during this step.

Biological techniques like bioaugmentation are also options in procedures for start-up. Results show that bioaugmentation can successfully improve the biodegradation of pharmaceuticals in wastewater treatment processes $[210,214,374]$. By adding adapted inocula which are efficient in anaerobic pharmaceutical biodegradation with $\mathrm{Mn}(\mathrm{IV})$ or $\mathrm{Fe}(\mathrm{III})$, it is expected to shorten the adaption period and improve the pharmaceutical removal.

The lab-scale reactor will help accumulate the experience of starting and operating the reactor in application. Combining with batch experiments, the operational parameters will be optimized to achieve the highest pharmaceutical removal efficiency.

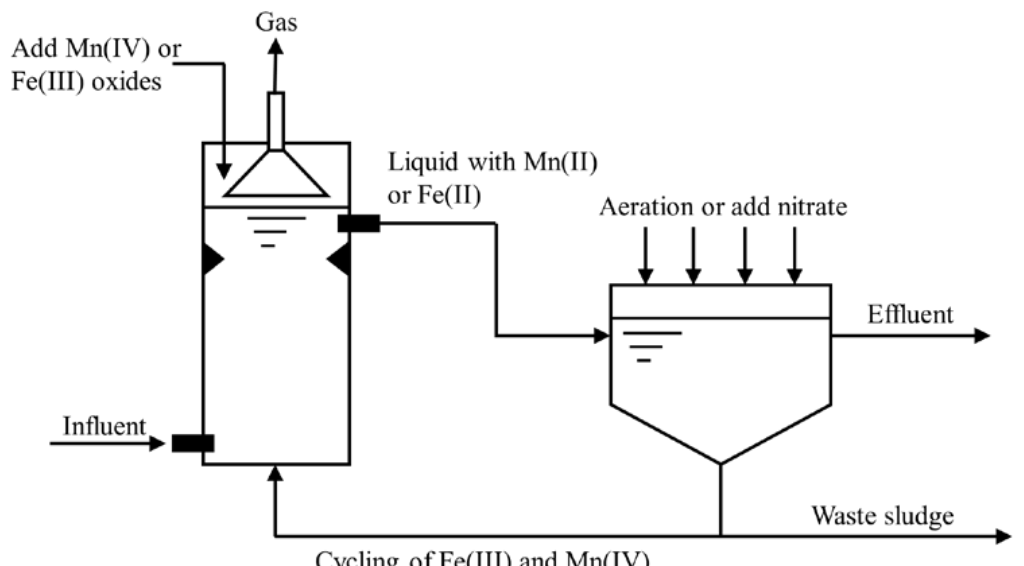

FIGURE 7.2 Proposed water treatment systems applying anaerobic pharmaceutical degradation with $\mathrm{Mn}(\mathrm{IV})$ or $\mathrm{Fe}(\mathrm{III})$ 


\section{Step 3. Translating the pharmaceutical removal to pilot-scale systems before application}

The final step before real scale application is to build a pilot-scale reactor to evaluate the performance with real wastewater or groundwater, to gain operation experience, to monitor the long-term operation, and to further optimize the pharmaceutical removal. After that the anaerobic Mn- or Femediated pharmaceutical degradation is ready as a market applicable technology to remove pharmaceuticals from water.

When there are enough data on the anaerobic Mn- or Fe-mediated pharmaceutical degradation, a mathematic model can be developed to describe the adsorption, chemical oxidation, as well as the biological degradation of pharmaceuticals under anaerobic conditions with Mn or Fe. This model can then be used to estimate or predict the performance of the technology in a given situation. In addition, it will promote the understanding of anaerobic degradation of pharmaceuticals with metals.

\subsubsection{Other perspective}

In addition to research developing the anaerobic Mn- or Fe-mediated pharmaceutical degradation into a technology, there are other research related to the future application.

A simple framework is used to partially evaluate the sustainability of pharmaceutical removal in this thesis. The investigation is missing the environmental influence of the anaerobic pharmaceutical degradation with $\mathrm{Mn}(\mathrm{IV})$ or $\mathrm{Fe}(\mathrm{III})$, such as the ecotoxicity of the (by-)products from the process. Therefore, toxicity assessment, together with pharmaceutical removal, is a good method to evaluate the process, and can be used as an indicator to compare this technology with other technologies. In addition, methods like life-cycle approach (LCA) could be more suitable. The LCA has been applied in water treatment including pharmaceutical removal technologies ${ }^{[249,257]}$. The analysis could provide adequate assessment of 
environmental changes related to the anaerobic degradation of pharmaceuticals with metal, qualification the energy consumption and intermediates emission, and their effects on human's health.

Molecular biology, such as Fluorescent in situ hybridization, and cloning of $16 \mathrm{~S}$ rDNA, have often been used in environmental studies. These techniques are used to described the microbial community and biodiversity in the systems, and can be useful when it is incorporated into design and operation of water treatment processes ${ }^{[266]}$. In the anaerobic biological degradation of pharmaceuticals with $\mathrm{Mn}(\mathrm{IV})$ and $\mathrm{Fe}(\mathrm{III})$, molecular biological methods can be used to describe the microbial community in the process, contributing to better understanding which bacteria degrade the pharmaceuticals, and which genes and enzymes are involved. The structure of the microbial community, together with other conventional operational information, can also be used as an indicator to assess the stability of the system, and to diagnose the problems in operation.

In summary, the anaerobic Mn- or Fe-mediated biological degradation and abiotic removal processes can remove pharmaceuticals. The abiotic removal of pharmaceuticals is effective to remove compounds like diclofenac, metoprolol and propranolol. The anaerobic biodegradation can also remove pharmaceuticals including caffeine, naproxen, metoprolol and propranolol. The long incubation time for activating metal oxide using biomass calls for the further optimization and investigation on this promising pharmaceutical removal process. In general, the anaerobic Mnor Fe-mediated pharmaceutical degradation process offers great potential for developing a sustainable and affordable technology to remove specific pharmaceuticals from water. With further fundamental and applicationoriented research, the anaerobic pharmaceutical degradation with $\mathrm{Mn}$ or Fe will become an attractive technology in both WWTPs and DWTPs to remove pharmaceuticals from water. The process will contribute to the safe reuse of wastewater effluents for sustaining ecosystems and cleaner and safer water cycle. 


\section{Supplementary materials}




\section{Supplementary materials for Chapter 1}

Introduction: Pharmaceuticals in the environment and pharmaceutical removal technology

TABLE S1.1 Abbreviation of countries

\begin{tabular}{cccc}
\hline Abbreviation & Country & Abbreviation & Country \\
\hline BRA & Brazil & JOR & Jordan \\
CAN & Canada & KOR & Republic of Korea \\
CHN & China & SGP & Singapore \\
CRI & Costa Rica & GBR & United Kingdom \\
HRV & Croatia & USA & United States \\
IND & India & VNM & Vietnam \\
JPN & Japan & SER & Yugoslavia \\
\hline
\end{tabular}




\section{Supplementary materials for Chapter 3}

Anaerobic biodegradation of pharmaceutical compounds coupled to dissimilatory manganese (IV) or iron (III) reduction

TEXT S3.1 Adaption of the inoculum

The inoculums used in this study was the mixture anaerobic sediment of effluent channel at different wastewater treatment plants (WWTPs) in the Netherlands, including WWTP Bennekom, WWTP Ede, and WWTP Driebergen. The content of organic matter in the raw mixture is around 11 $\mathrm{mg}$ per $\mathrm{kg}$ dry matter. Before the inoculum showing the capacity of degrading metoprolol biologically with $\mathrm{Mn}(\mathrm{IV})$, it has been cultivated in the presence of $10 \mathrm{mg} \cdot \mathrm{L}^{-1}$ metoprolol and $15 \mathrm{mM}$ chemically produced $\mathrm{Mn}$ (IV) over 800 days.

TEXT S3.2 Theoretical calculation of $\mathrm{Mn}(\mathrm{IV})$ and Fe(III) reduction during anaerobic pharmaceutical biodegradation

The $\mathrm{Mn}(\mathrm{IV})$ and $\mathrm{Fe}(\mathrm{III})$ reduction during the anaerobic pharmaceutical biodegradation is calculated based on the balance of electron transfer. During the calculation, the $\mathrm{O}_{2}$ is used as a bridge. The total electrons provided by complete mineralization of pharmaceuticals is calculated. Then the same amount of electrons should be accepted by $\mathrm{Mn}$ (IV) or Fe(III) reduction. However, the electron transferred during the pharmaceutical oxidation with $\mathrm{Mn}(\mathrm{IV})$ or $\mathrm{Fe}(\mathrm{III})$ is difficult to estimate. The calculation of pharmaceutical mineralization with $\mathrm{O}_{2}$ is estimated based on mass balance (Table S3.3). 


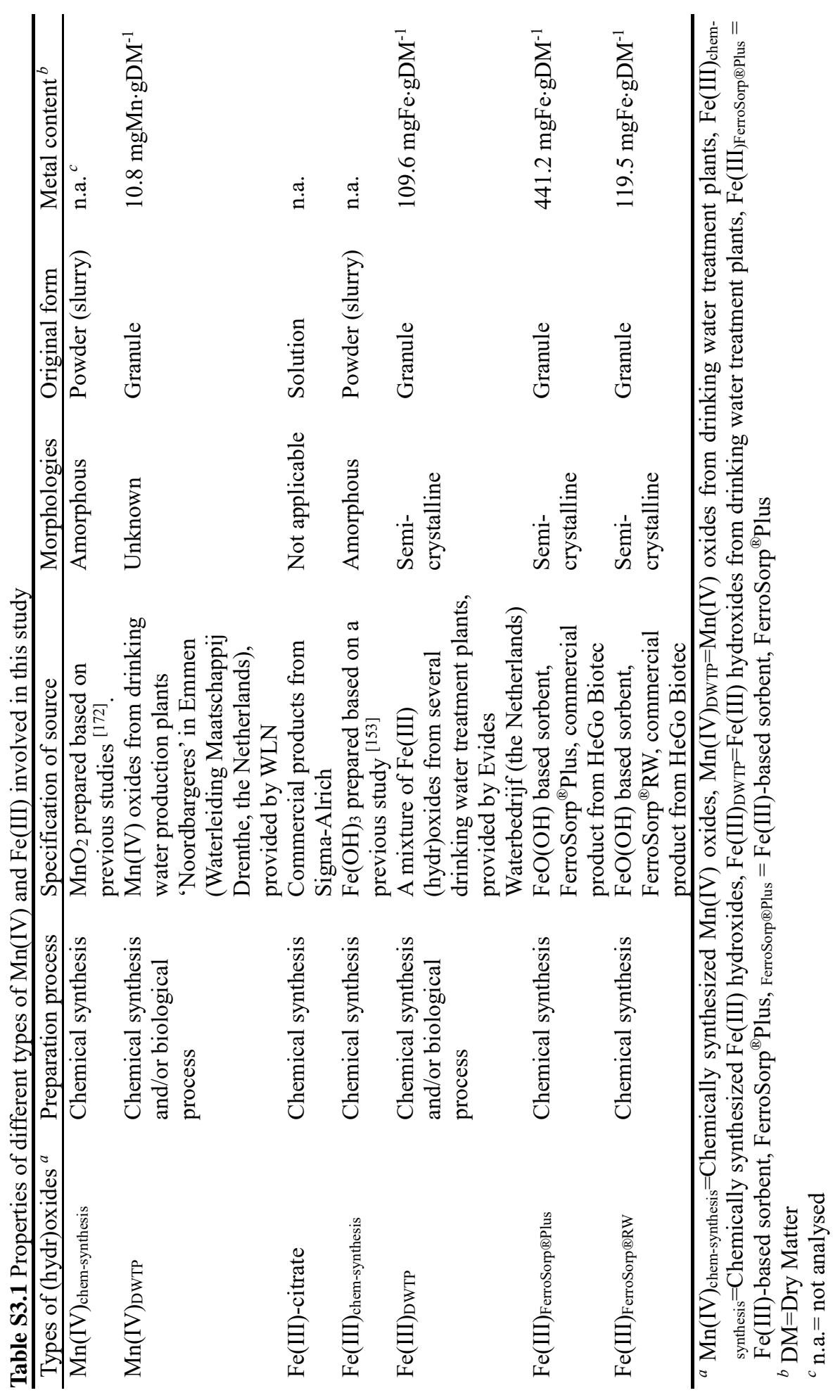


TABLE S3.2 Medium recipe for anaerobic biodegradation of pharmaceuticals with Mn(IV) or Fe(III)

\begin{tabular}{|c|c|c|c|}
\hline Compounds & $\begin{array}{l}\text { Final } \\
\text { concentration } \\
\left(\mu \mathrm{g} \cdot \mathrm{L}^{-1}\right)\end{array}$ & Compounds & $\begin{array}{l}\text { Final } \\
\text { concentration } \\
\left(\mu \mathrm{g} \cdot \mathrm{L}^{-1}\right)\end{array}$ \\
\hline $\mathrm{AlK}\left(\mathrm{SO}_{4}\right)_{2}$ & 0.1 & $\mathrm{NaCl}$ & 10 \\
\hline $\begin{array}{l}\text { Biotin } \\
\text { (Vitamin } \mathrm{H})\end{array}$ & 20 & $\mathrm{NaH}_{2} \mathrm{PO}_{4} \cdot 2 \mathrm{H}_{2} \mathrm{O}$ & $3.75 \mathrm{mM}$ \\
\hline $\mathrm{CaCl}_{2} \cdot 2 \mathrm{H}_{2} \mathrm{O}$ & $0.75 \mathrm{mM}$ & $\mathrm{NaHCO}_{3}$ & $30 \mathrm{mM}$ \\
\hline $\mathrm{CoSO}_{4}$ & 1 & $\mathrm{NH}_{4} \mathrm{Cl}$ & $28.0 \mathrm{mM}$ \\
\hline $\mathrm{CuSO}_{4} \cdot 5 \mathrm{H}_{2} \mathrm{O}$ & 0.1 & $\mathrm{NiCl}_{2} \cdot 6 \mathrm{H}_{2} \mathrm{O}$ & 24 \\
\hline $\begin{array}{l}\text { Cyanocobalamine } \\
\text { (vitamin B12) }\end{array}$ & 1 & Nicotinamide & 50 \\
\hline $\mathrm{FeSO}_{4} \cdot 7 \mathrm{H}_{2} \mathrm{O}$ & 1 & NTA & 15 \\
\hline $\begin{array}{l}\text { Folic acid } \\
\text { (dihydrate) }\end{array}$ & 20 & $\begin{array}{l}\text { p-Aminobenzoic acid } \\
(\mathrm{Na}-\text { salt })\end{array}$ & 50 \\
\hline $\mathrm{H}_{3} \mathrm{BO}_{3}$ & 0.1 & $\begin{array}{l}\text { Pantothenate } \\
(\mathrm{Ca} \text { - salt })\end{array}$ & 55 \\
\hline $\mathrm{KCl}$ & $1.34 \mathrm{mM}$ & $\begin{array}{l}\text { Pyridoxine } \\
\text { (vitamin B6) }\end{array}$ & 100 \\
\hline $\begin{array}{l}\text { Lipoic acid } \\
\text { (thioctic acid) }\end{array}$ & 50 & $\begin{array}{l}\text { Riboflavine } \\
\text { (vitamin B2) }\end{array}$ & 50 \\
\hline $\mathrm{MnSO}_{4} \cdot 2 \mathrm{H}_{2} \mathrm{O}$ & 5 & $\begin{array}{l}\text { Thiamine } \mathrm{HCl} \\
\text { ( vitamin } \mathrm{B} 1 \text { ) }\end{array}$ & 50 \\
\hline $\mathrm{Na}_{2} \mathrm{MoO}_{4}$ & 25 & $\mathrm{ZnSO}_{4}$ & 1 \\
\hline $\mathrm{Na}_{2} \mathrm{~S} \cdot 9 \mathrm{H}_{2} \mathrm{O}$ & $1 \mathrm{mM}$ & Yeast extract & $0.02 \%(\mathrm{w} / \mathrm{w})$ \\
\hline
\end{tabular}

TABLE S3.3 Theoretical calculation of $\mathrm{Mn}(\mathrm{IV})$ and $\mathrm{Fe}(\mathrm{III})$ reduction during anaerobic pharmaceutical degradation (mol/mol pharmaceutical)

\begin{tabular}{|c|c|c|c|c|}
\hline Pharmaceutical & Proposed reaction & $\begin{array}{l}\text { Total } \\
\text { electron } \\
\text { transfer }\end{array}$ & $\begin{array}{l}\mathrm{Mn}(\mathrm{IV}) \\
\text { reduction }\end{array}$ & $\begin{array}{l}\mathrm{Fe}(\mathrm{III}) \\
\text { reduction }\end{array}$ \\
\hline $\begin{array}{l}\text { Caffeine } \\
\left(\mathrm{C}_{8} \mathrm{H}_{10} \mathrm{~N}_{4} \mathrm{O}_{2}\right)\end{array}$ & $\begin{aligned} \mathrm{C}_{8} \mathrm{H}_{10} \mathrm{~N}_{4} \mathrm{O}_{2}+ & 9.5 \mathrm{O}_{2} \\
& \rightarrow 8 \mathrm{CO}_{2}+5 \mathrm{H}_{2} \mathrm{O}+2 \mathrm{~N}_{2}\end{aligned}$ & 38 & 19 & 38 \\
\hline $\begin{array}{l}\text { Carbamazepine } \\
\left(\mathrm{C}_{15} \mathrm{H}_{12} \mathrm{~N}_{2} \mathrm{O}\right)\end{array}$ & $\begin{aligned} \mathrm{C}_{15} \mathrm{H}_{12} \mathrm{~N}_{2} \mathrm{O}+ & 17.5 \mathrm{O}_{2} \\
\rightarrow & 15 \mathrm{CO}_{2}+6 \mathrm{H}_{2} \mathrm{O}+\mathrm{N}_{2}\end{aligned}$ & 70 & 35 & 70 \\
\hline $\begin{array}{l}\text { Ibuprofen } \\
\left(\mathrm{C}_{13} \mathrm{H}_{18} \mathrm{O}_{2}\right)\end{array}$ & $\mathrm{C}_{13} \mathrm{H}_{18} \mathrm{O}_{2}+16.2 \mathrm{O}_{2} \rightarrow 13 \mathrm{CO}_{2}+9 \mathrm{H}_{2} \mathrm{O}$ & 66 & 33 & 66 \\
\hline $\begin{array}{l}\text { Metoprolol } \\
\left(\mathrm{C}_{15} \mathrm{H}_{25} \mathrm{NO}_{3}\right)\end{array}$ & $\begin{aligned} \mathrm{C}_{15} \mathrm{H}_{25} \mathrm{NO}_{3}+ & 21.25 \mathrm{O}_{2} \\
& \rightarrow 15 \mathrm{CO}_{2}+12.5 \mathrm{H}_{2} \mathrm{O} \\
& +0.5 \mathrm{~N}_{2}\end{aligned}$ & 85 & 42.5 & 85 \\
\hline $\begin{array}{l}\text { Naproxen } \\
\left(\mathrm{C}_{14} \mathrm{H}_{14} \mathrm{O}_{3}\right)\end{array}$ & $\mathrm{C}_{14} \mathrm{H}_{14} \mathrm{O}_{3}+16 \mathrm{O}_{2} \rightarrow 14 \mathrm{CO}_{2}+7 \mathrm{H}_{2} \mathrm{O}$ & 64 & 32 & 64 \\
\hline $\begin{array}{l}\text { Propranolol } \\
\left(\mathrm{C}_{16} \mathrm{H}_{21} \mathrm{NO}_{2}\right)\end{array}$ & $\begin{aligned} \mathrm{C}_{16} \mathrm{H}_{21} \mathrm{NO}_{2}+ & 20.25 \mathrm{O}_{2} \\
& \rightarrow 16 \mathrm{CO}_{2}+10.5 \mathrm{H}_{2} \mathrm{O} \\
& +0.5 \mathrm{~N}_{2}\end{aligned}$ & 81 & 40.5 & 81 \\
\hline $\begin{array}{l}\text { Citrate } \\
\left(\mathrm{C}_{6} \mathrm{H}_{8} \mathrm{O}_{7}\right)\end{array}$ & $\mathrm{C}_{6} \mathrm{H}_{8} \mathrm{O}_{7}+4.5 \mathrm{O}_{2} \rightarrow 12 \mathrm{CO}_{2}+8 \mathrm{H}_{2} \mathrm{O}$ & 18 & 9 & 18 \\
\hline
\end{tabular}


(a)

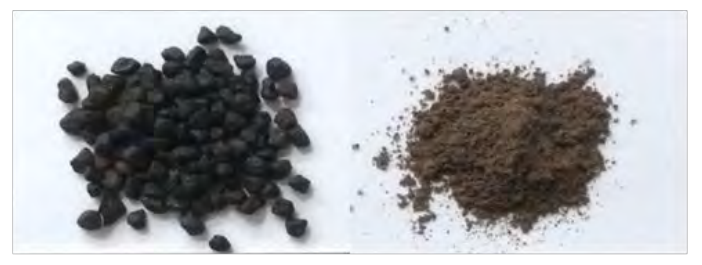

(b)

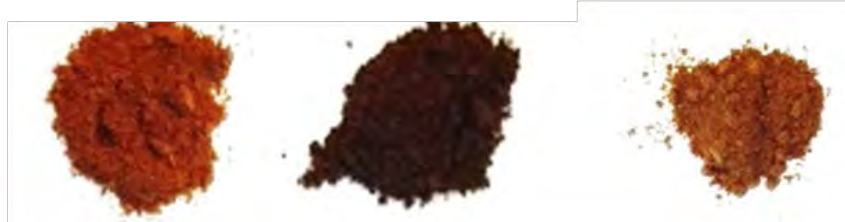

FIGURE S3.1 Image of (a) granule and powder of Mn(IV) from drinking water treatment plants; (b) ground powder of $\mathrm{Fe}$ (III) from drinking water treatment plants, Fe(III)-based sorbent, FerroSorp ${ }^{\circledR}$ Plus, and Fe(III)-based sorbent, FerroSorp ${ }^{\mathbb{R}} \mathrm{RW}$ (from left to right)
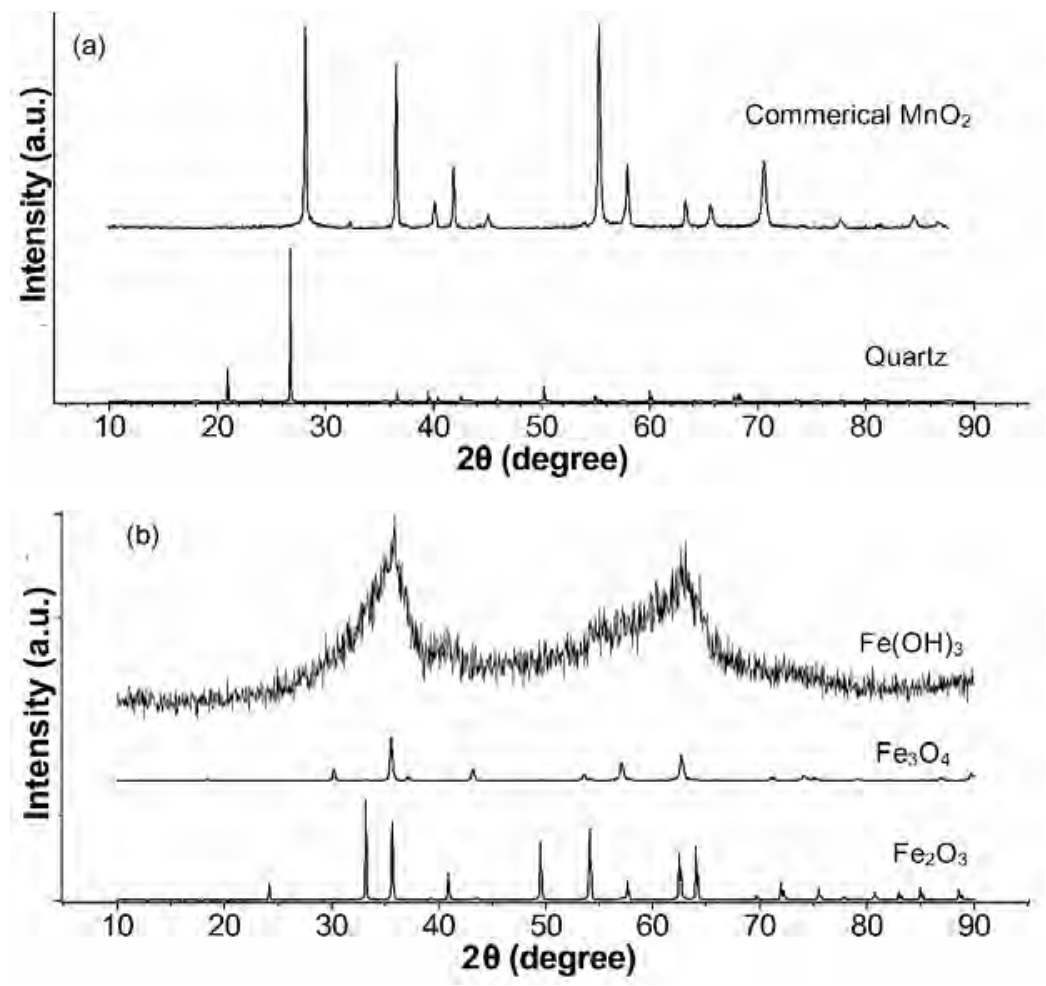

FIGURE S3.2 X-ray diffraction spectrum of reference compounds (a) chemically produced $\mathrm{MnO}_{2}$ (commercial products) and quartz (from RRUFF database R060604); (b) $\mathrm{Fe}(\mathrm{OH})_{3}$, $\mathrm{Fe}_{3} \mathrm{O}_{4}$, and $\mathrm{Fe}_{2} \mathrm{O}_{3}$ 


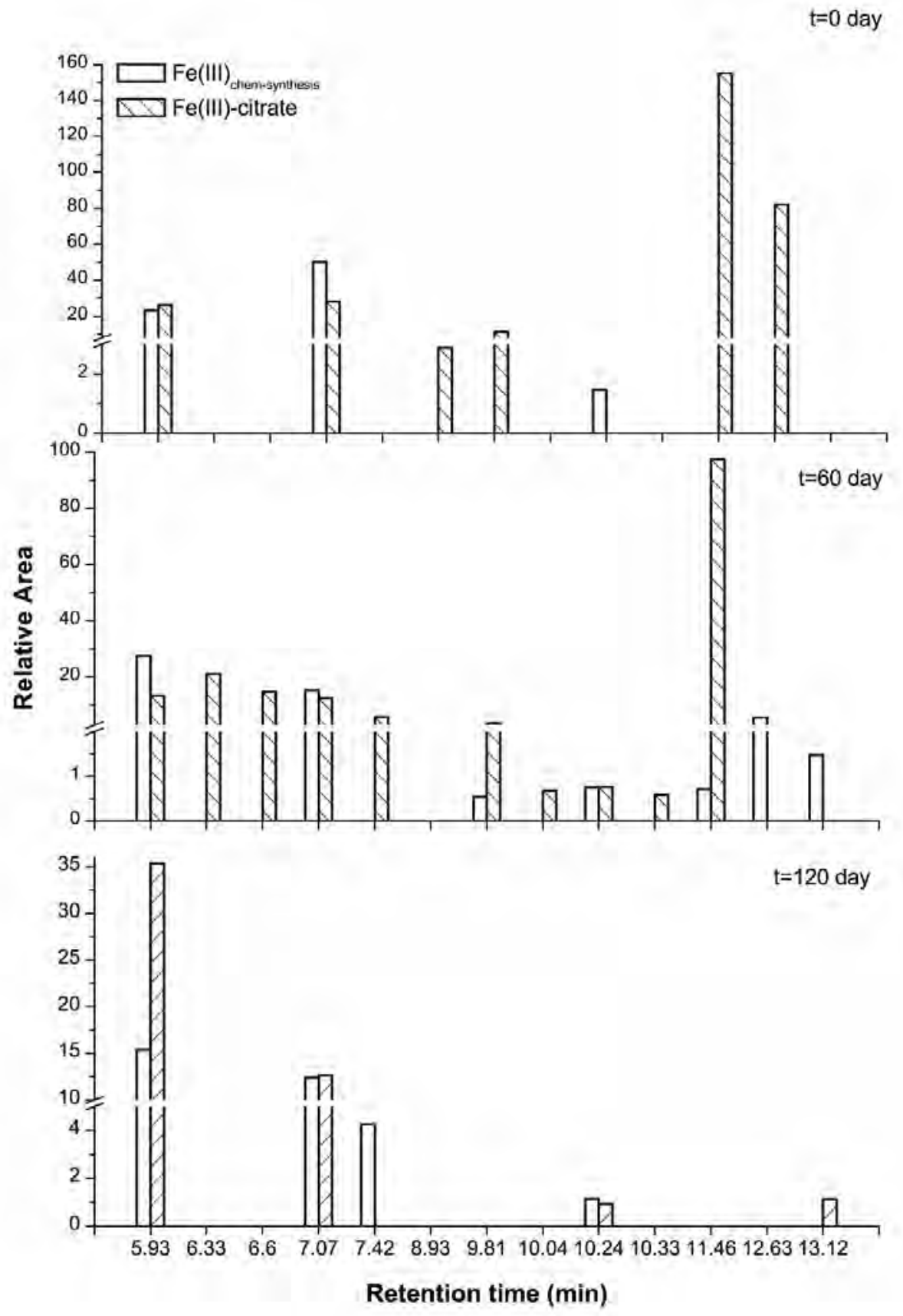

FIGURE S3.3 Presence of potential intermediates from anaerobic metoprolol biodegradation with $\mathrm{Fe}(\mathrm{III})_{\text {chem-synthesis }}$ and $\mathrm{Fe}(\mathrm{III})$-citrate at $\mathrm{t}=0$ day, $\mathrm{t}=60$ day, $\mathrm{t}=120$ day in chromatography. The relative area is the ratio between the area of the potential intermediates and the area of internal standard (fenoprofen) 


\section{Supplementary materials for Chapter 4}

Anaerobic conditions promote abiotic diclofenac removal with manganese oxides

\section{TEXT S4.1 Solution preparation}

\section{(1) Anaerobic water}

The anaerobic water was prepared by boiling the demineralised water for 5 minutes. Then the boiled water was transferred to a glass bottle and bubbled with $\mathrm{N}_{2}$ until it had cooled down to room temperature. The water was then sealed and stored at room temperature.

(2) Pharmaceutical stock

The pharmaceutical stock was included pharmaceutical mixture stock and diclofenac stock. The pharmaceutical mixture stock was prepared by dissolving $20 \mathrm{mg}$ of every seven pharmaceuticals with $1 \mathrm{~L}$ ultrapure water. The final concentration of each pharmaceutical in pharmaceutical mixture stock is about $20 \mathrm{mg} \cdot \mathrm{L}^{-1}$. The diclofenac stock was prepared by dissolving $125 \mathrm{mg}$ diclofenac with $50 \mathrm{~mL}$ ultrapure water. The final diclofenac concentration in diclofenac stock is about $2500 \mathrm{mg} \cdot \mathrm{L}^{-1}$.

(3) Reaction solution

The reaction solution contained $7 \mathrm{mM} \mathrm{MnO} 2,50 \mathrm{mM}$ buffer to maintain constant $\mathrm{pH}$ at 7 , and an appropriate amount of $\mathrm{NaCl}$ to maintain constant ionic strength at $0.1 \mathrm{M}$. The buffer is $\mathrm{H}_{3} \mathrm{PO}_{4} / \mathrm{NaH}_{2} \mathrm{PO}_{4}$ for $\mathrm{pH} \sim 4.5$, $\mathrm{NaH}_{2} \mathrm{PO}_{4} / \mathrm{K}_{2} \mathrm{HPO}_{4}$ for $\mathrm{pH} \sim 7.0$, and $\mathrm{K}_{2} \mathrm{HPO}_{4}$ for $\mathrm{pH} \sim 8.5$. The reaction solution was prepared with both normal demineralised water and anaerobic water. 
TEXT S4.2 $\mathrm{MnO}_{2}$ generation

Both $0.4 \mathrm{mM} \mathrm{MnCl} 2$ and $0.4 \mathrm{mM} \mathrm{KMnO}_{4}$ were prepared with demineralised water. While stirring the $\mathrm{KMnO}_{4}$ solution continuously, equal volume of $\mathrm{MnCl}_{2}$ was added. Then, $\mathrm{NaOH}(1 \mathrm{~N})$ was added into the mixture to bring the $\mathrm{pH}$ to 10 . The $\mathrm{MnO}_{2}$ solid then centrifuged at $5000 \mathrm{rpm}$ for 15 min and then resuspended by anaerobic water. The centrifigation and suspended in anaerobic water were repeated for six times. Suspension of $\mathrm{MnO}_{2}$ in anaerobic water were stored at $4^{\circ} \mathrm{C}$ for the addition to batch experiment.

\section{TEXT S4.3 Analysis}

\section{(1) Pharmaceutical analysis}

$1 \mathrm{~mL}$ samples were collected and centrifuged at $10000 \mathrm{rpm}$ for $10 \mathrm{~min}$. The supernatant then transferred to amber vials. $50 \mu \mathrm{L}$ of internal standard (5mg L $\mathrm{L}^{-1}$ fenoprofen) was added into the sample. The samples were stored at $-20{ }^{\circ} \mathrm{C}$ before analysis.

The pharmaceutical analysis was performed as described ${ }^{[95]}$ by a ultraperformance liquid chromatography (UPLC, ultimate 3000, Thermo, USA) with a diode array detector, and a CSH phenyl-Hexyl column $(1.7 \mu \mathrm{m}, 130$ $\AA, 2.1 \times 150 \mathrm{~mm}$ ). A mixture of water with $0.1 \%$ formic acid (solution A) and acetonitrile with $0.1 \%$ formic acid (solution B) was used as the mobile phase. The analysis started with $100 \%$ solution A for $0.5 \mathrm{~min}$. Then it decreased to $20 \%$ at $13 \mathrm{~min}$. After staying for $3 \mathrm{~min}$, it went back to $100 \%$ at $17 \mathrm{~min}$ and stopped at $22.4 \mathrm{~min}$. The flow rate is $0.3 \mathrm{~mL} / \mathrm{min}$ while the oven is at $40{ }^{\circ} \mathrm{C}$. The injection volume of samples was $10 \mu \mathrm{l}$. The pharmaceutical concentration was calculated based on relative area (area of pharmaceutical/area of internal standard) and the slope of the calibration curve. 
(2) $\mathrm{Mn}(\mathrm{II})$ analysis

The Mn(II) generated during the removal processes was determined by an inductively coupled plasma spectrometer with optical emission spectroscopy (ICP-OES, Vista MPX Simultaneous, Varian Inc. (Part A), USA). Controls with only $\mathrm{MnO}_{2}$ and buffers but without pharmaceuticals showed no $\mathrm{Mn}^{2+}$ produced.

(3) $\mathrm{MnO}_{2}$ morphologies analysis

The two kinds of $\mathrm{MnO}_{2}$ were characterized by X-ray diffraction (XRD, D2 PHASER, Bruker, Germany). The results showed in Figure S1. In addition, microscopes were also used to characterized the $\mathrm{MnO}_{2}$ morphologies (Figure S4.2).

Fournier-Transform Infra-Red spectrometers

The $\mathrm{MnO}_{2}$ solid with diclofenac or metoprolol as described in previously (section 4.2.3) were collected by centrifugation (5000rpm, 15 min) after $24 \mathrm{~h}$ under both oxic and anaerobic conditions in deminerized water. Control sample, bare $\mathrm{MnO}_{2}$ without pharmaceuticals, was also collected based on the same method. The samples were freeze-dried before analysis. All the samples were analyzed by a Fournier-Transform Infra-Red spectrometers (Bruker TENSOR 27). The reference spectrum of untreated diclofenac and metoprolol standard was also acquired in the same analytical condition.

\section{TEXT S4.4 Intermediates}

In the chromatography spectrum, the peaks at different retention time (RT) are representative different intermediates of diclofenac. The diclofenac is observed at $\mathrm{RT}=14.64 \mathrm{~min}$. Due to the practical limits, it is impossible for us to identify the formula or structure of intermediates in diclofenac removal with $\mathrm{MnO}_{2}$. However, the chromatography clearly shows that the intermediates formed under aerobic and anaerobic conditions are different. This may indicate that oxygen contributes to forming the intermediates. 
TEXT S4.5 Size analysis

Size analysis was performed by a laser size analyzer (Mastersizer 2000, Malven, UK). The size of $\mathrm{MnO}_{2}$ particles keep increasing during the analysis process. Therefore, it is impossible to compare the size between amorphous $\mathrm{MnO}_{2}$ and crystalline $\mathrm{MnO}_{2}$. Generally, the amorphous $\mathrm{MnO}_{2}$ is smaller than crystalline $\mathrm{MnO}_{2}$ (Figure S4.2).

TEXT S4.6 FTIR analysis

The bare $\mathrm{MnO}_{2}$ under oxic and anaerobic conditions are the same, therefore, we only use the FTIR spectra of oxic $\mathrm{MnO}_{2}$ in Figure S4.6.The FTIR spectra show the $\mathrm{MnO}_{2}$ changed before and after reacting with diclofenac. The spectra of bare $\mathrm{MnO}_{2}$ is similar to previous study ${ }^{[32]}$. The broad peak at $3380 \mathrm{~cm}^{-1}$ was assigned to the stretching vibration of $-\mathrm{OH}$ group in water and Mn-O-H. The peaks at $1634 \mathrm{~cm}^{-1}$ and $1056 \mathrm{~cm}^{-1}$ were assigned to the bending vibrations of the $-\mathrm{OH}$ in $\mathrm{Mn}-\mathrm{OH}$. These peaks are also the indications of the reactive sites on $\mathrm{MnO}_{2}$ surface. The peak at 428 $\mathrm{cm}^{-1}$ was assigned to the bending vibration of $\mathrm{Mn}-\mathrm{O}{ }^{[32,278]}$.

Due to the extremely huge amount of $\mathrm{MnO}_{2}$ added into the system comparing to diclofenac, the spectra of $\mathrm{MnO}_{2}$ after reacting are still similar to the bare $\mathrm{MnO}_{2}$. However, there are still some peaks appeared between $800-2000 \mathrm{~cm}^{-1}$ showing the $\mathrm{MnO}_{2}$ is changed. Three new peaks at 1379 $\mathrm{cm}^{-1}, 1017 \mathrm{~cm}^{-1}$ and $828 \mathrm{~cm}^{-1}$ were not attributed to the pure diclofenac either (Figure S4.6 (c)). Therefore, they are probably from the intermediates. The peak at $1379 \mathrm{~cm}^{-1}$ is assigned to alkynes, aromatics or $\mathrm{C}=\mathrm{O}$, the peak at $1017 \mathrm{~cm}-1$ is assigned to $\mathrm{C}-\mathrm{O}$ (2-bands) and the peak at $828 \mathrm{~cm}^{-1}$ is assigned to $\mathrm{N}-\mathrm{H}$ wagging ${ }^{[278]}$. 
In addition, the peak shift and peak change were also observed. The peak at $1632 \mathrm{~cm}^{-1}$ decreased after reacting with diclofenac under aerobic condition while it increased under anaerobic conditions. The higher peak probably indicates that the reactive sites are activated and more available for diclofenac. Another peak shift is observed from $1272 \mathrm{~cm}^{-1}$ to $1287 \mathrm{~cm}^{-1}$. The peak also larger. That peak is assigned to alkynes or $\mathrm{NO}_{2}$.

All these peaks showed that under anaerobic conditions, the $\mathrm{MnO}_{2}$ changed more than that under aerobic conditions. The change may be caused by the intermediates. The change of $\mathrm{MnO}_{2}$ under anaerobic conditions can be the reason why anaerobic conditions promote diclofenac removal.

TABLE S4.1 Structure and properties of selected pharmaceuticals in this study

\begin{tabular}{|c|c|c|c|c|}
\hline Pharmaceutical $^{a}$ & CAS No. & Chemical Structure & $\mathrm{pK}_{\mathrm{a}}$ & $\operatorname{LogK}_{\text {ow }}$ \\
\hline $\begin{array}{l}\text { diclofenac } \\
\text { (DFC) }\end{array}$ & $15307-79-6$ & & 4.15 & 4.57 \\
\hline $\begin{array}{l}\text { Caffeine } \\
\text { (CAF) }\end{array}$ & $58-08-2$ & & $\begin{array}{l}10.4 \\
\left(\text { at } 40^{\circ} \mathrm{C} \text { ) }\right.\end{array}$ & -0.07 \\
\hline $\begin{array}{l}\text { Carbamazepine } \\
\text { (CBZ) }\end{array}$ & $298-46-4$ & & 13.9 & 2.45 \\
\hline $\begin{array}{l}\text { Ibuprofen } \\
\text { (IBP) }\end{array}$ & $15687-27-1$ & & 4.91 & 3.97 \\
\hline $\begin{array}{l}\text { Metoprolol } \\
\text { (MET) }\end{array}$ & $56392-17-7$ & & 9.5 & 1.88 \\
\hline $\begin{array}{l}\text { Naproxen } \\
\text { (NAP) }\end{array}$ & $22204-53-1$ & & 4.15 & 3.18 \\
\hline $\begin{array}{l}\text { Propranolol } \\
\text { (PROP) }\end{array}$ & $318-98-9$ & & 9.42 & 3.48 \\
\hline
\end{tabular}

${ }^{a}$ Text in the brackets is the abbreviation of each pharmaceutical 
TABLE S4.2 Pharmaceutical concentration $\left(\mathrm{C} / \mathrm{C}_{0}\right.$ at $\left.\mathrm{t}=24 \mathrm{~h}\right)$ in absence of $\mathrm{MnO}_{2}$ in demineralised water. Experimental conditions: [pharmaceutical $]_{0}=1 \mathrm{mg} \cdot \mathrm{L}^{-1}, \mathrm{pH} \sim 8.5$

\begin{tabular}{ccc}
\hline Compounds & Aerobic conditions & Anaerobic conditions \\
\hline caffeine & 1.02 & 1.02 \\
carbamazepine & 1.01 & 1.01 \\
diclofenac & 1.00 & 1.09 \\
ibuprofen & 1.03 & 1.04 \\
metoprolol & 1.01 & 1.01 \\
naproxen & 1.02 & 1.02 \\
propranolol & 1.01 & 1.02 \\
\hline
\end{tabular}

TABLE S4.3 Structure and properties of glyphosate and sulfamethazine

\begin{tabular}{lllll}
\hline Compound & CAS No. & Chemical Structure & $\mathrm{pK}_{\mathrm{a}}$ & $\mathrm{LogK}_{\mathrm{ow}}$ \\
glyphosate & $1071-83-6$ & & \\
sulfamethazine & $57-68-1$ & &
\end{tabular}

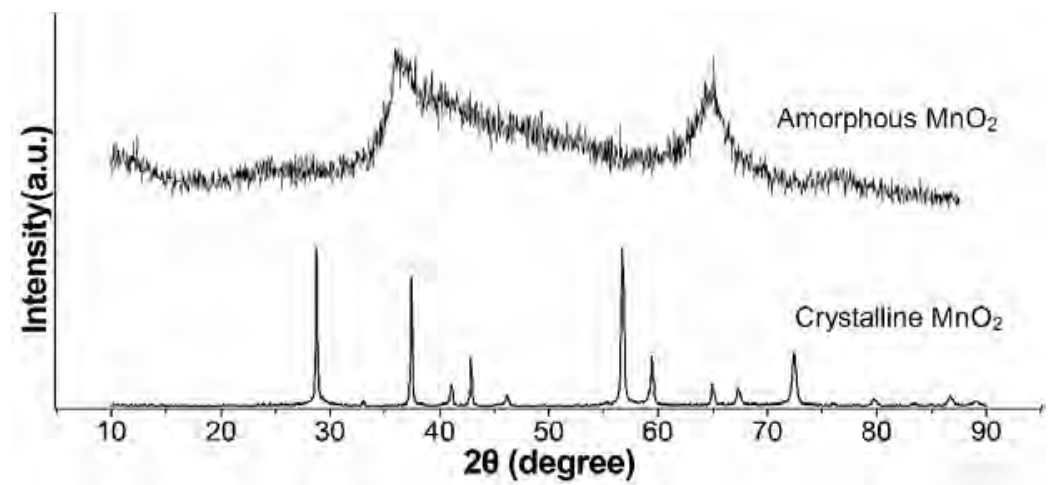

FIGURE S4.1 X-ray diffraction spectrum of amorphous $\mathrm{MnO}_{2}$ and crystalline $\mathrm{MnO}_{2}$ 

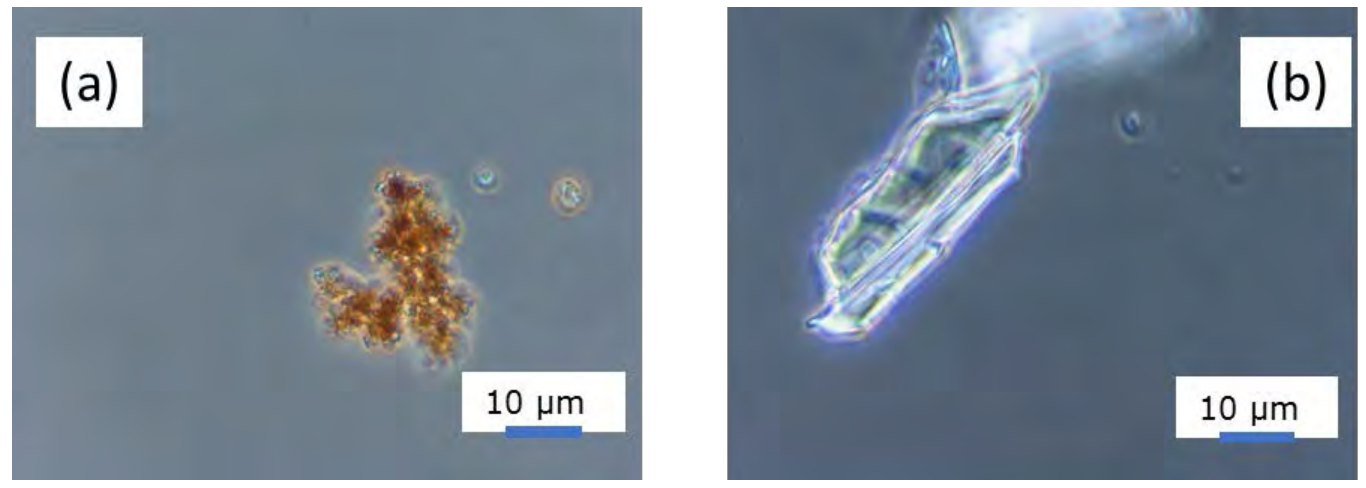

FIGURE S4.2 Microscopy of (a) amorphous $\mathrm{MnO}_{2}$ and (b) crystalline $\mathrm{MnO}_{2}$ at 100 times magnified
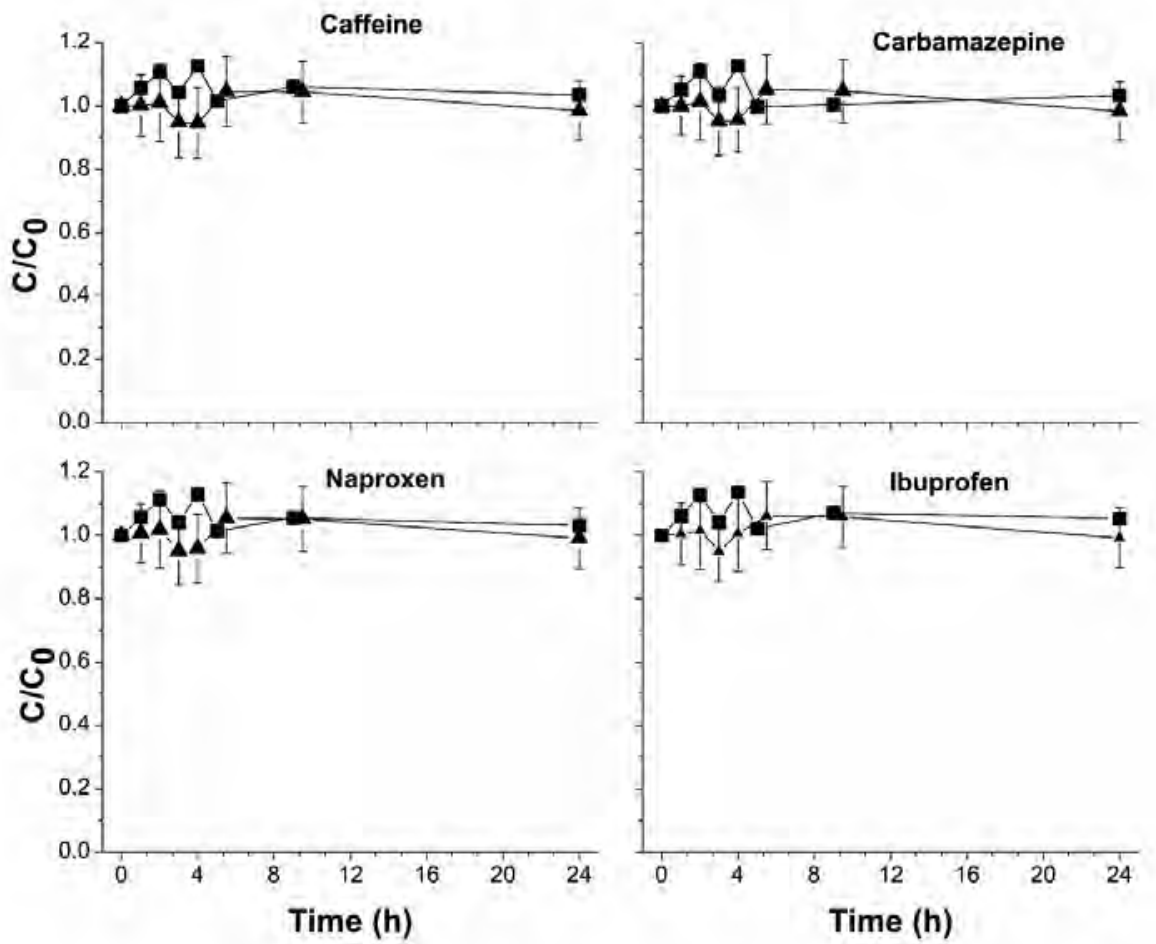

FIGURE S4.3 Pharmaceutical removal with $\mathrm{MnO}_{2}$ in demineralised water with pharmaceutical mixture under aerobic conditions ( $\mathbf{a})$ and anaerobic conditions $(\boldsymbol{\Delta})$. Experimental conditions: $\left[\mathrm{MnO}_{2}\right]_{0}=7 \mathrm{mM}$, [pharmaceutical $]_{0}=1 \mathrm{mg} \cdot \mathrm{L}^{-1}, \mathrm{pH} \sim 8.5$. Error bars are standard deviations 


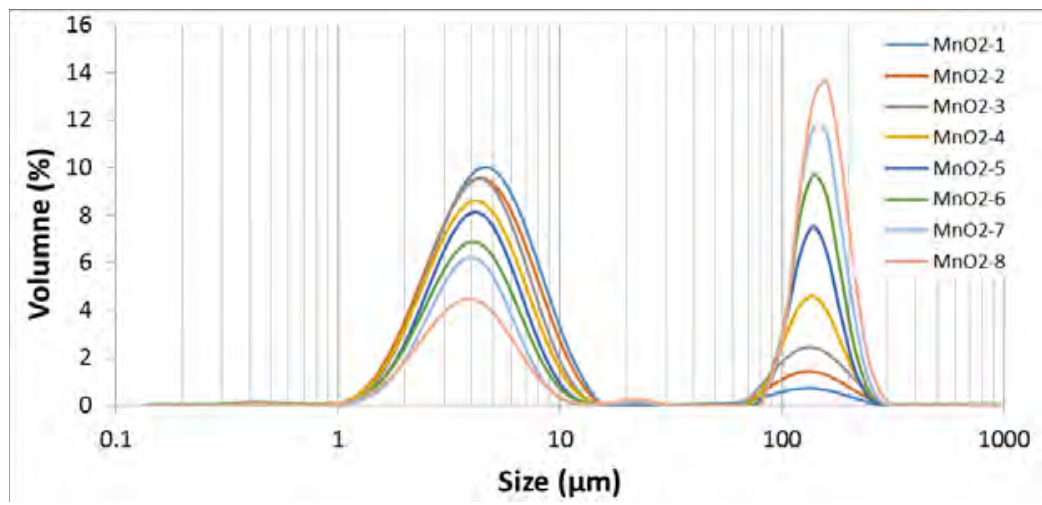

FIGURE S4.5 Size analysis of amorphous $\mathrm{MnO}_{2}$ (eight times analysis in one single run, 40 sec/sample)

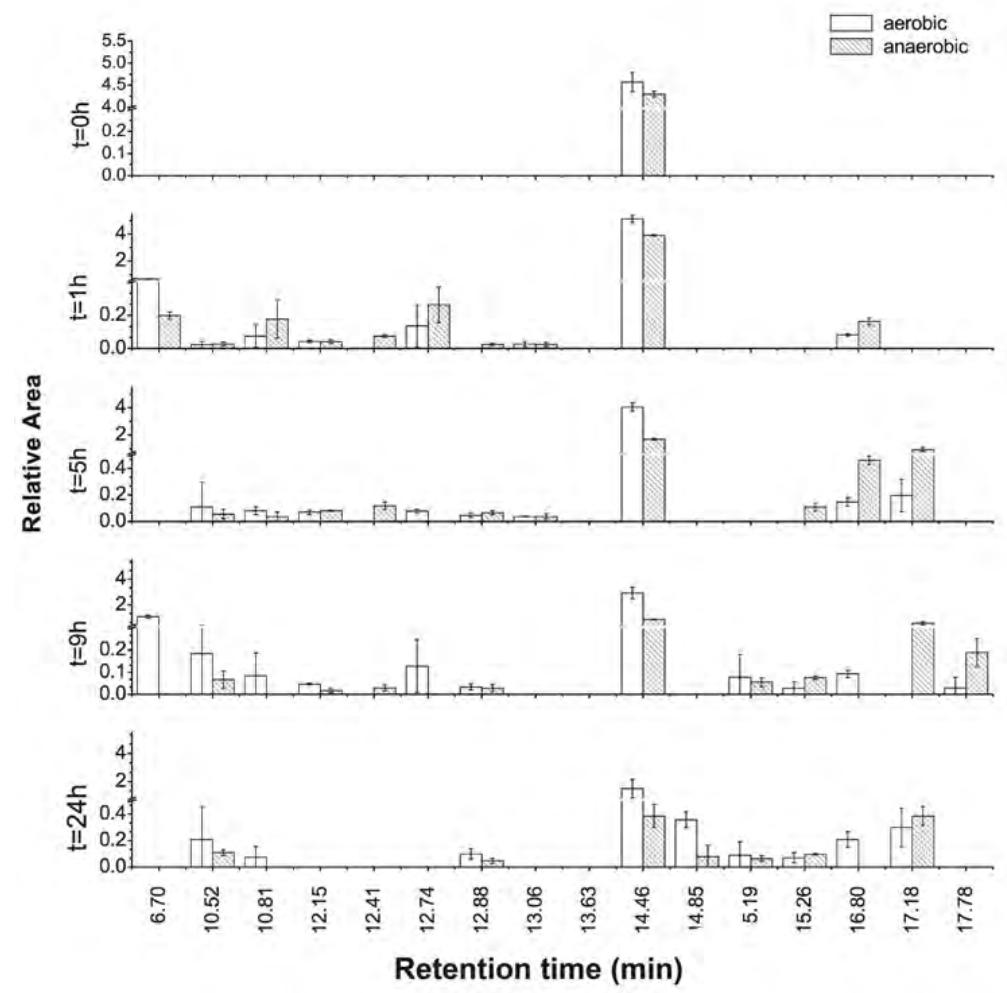

FIGURE S4.4 Presence and variation of intermediates from pharmaceuticals under aerobic and anaerobic conditions at different reaction time point showed in chromatography spectrum in demineralised water system. The relative area was the ratio between the area of the potential intermediates and the area of internal standard (fenoprofen). Error bars are standard deviations 

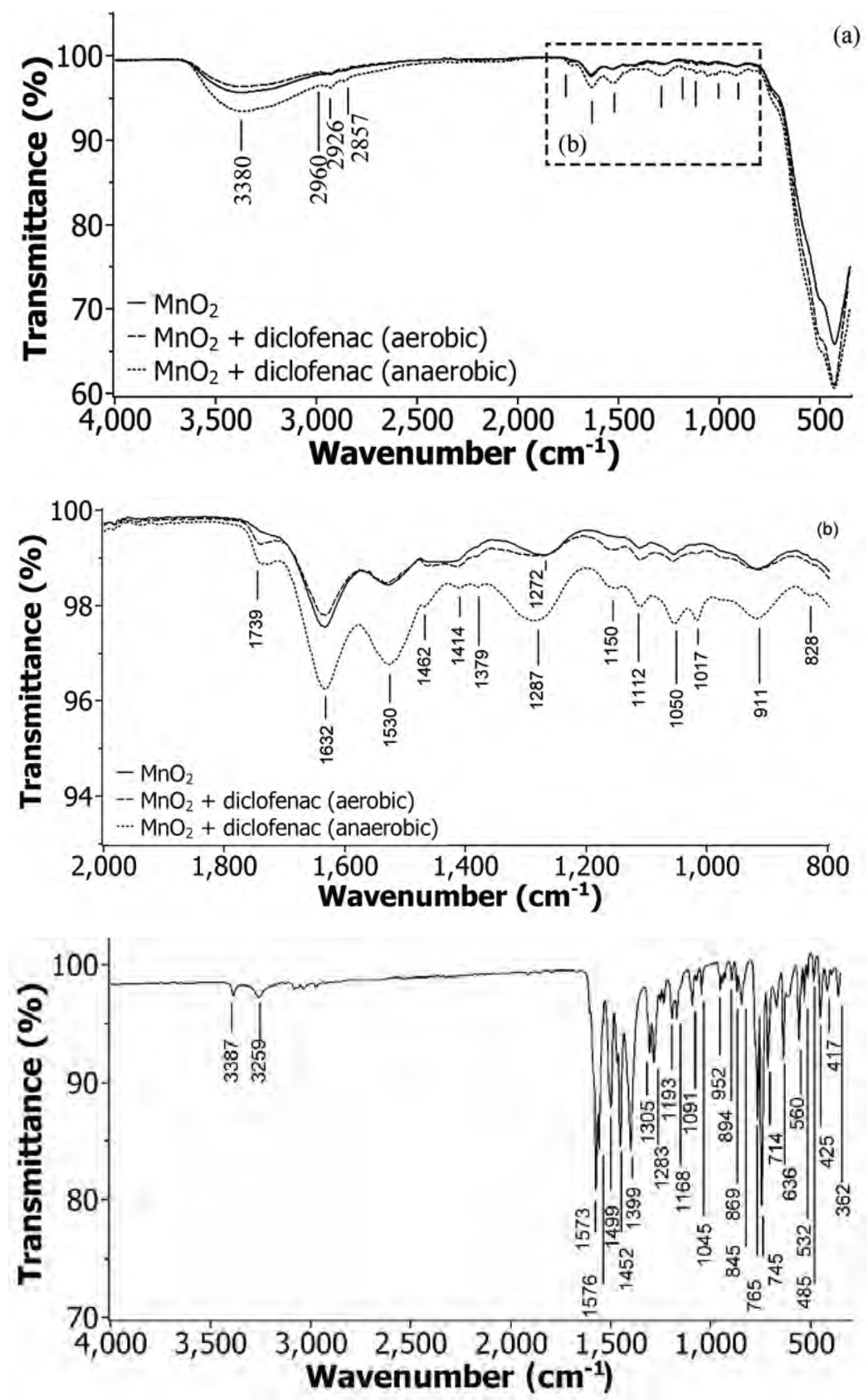

FIGURE S4.6 FTIR spectra of $\mathrm{MnO}_{2}$ before (solid line) and after reacting with diclofenac under aerobic condition (dash line) and anaerobic condition (dot line) at (a) $350-4000 \mathrm{~cm}^{-1}$, and (b) $800-2000 \mathrm{~cm}^{-1}$. The pure diclofenac (c) was diclofenac sodium, used as a reference 


\section{Supplementary Material for Chapter 5}

Application of manganese oxides under anaerobic conditions to remove diclofenac from water

TEXT S5.1 Kinetic model selection

Four kinetics models were used to fit the DFC removal data at $20^{\circ} \mathrm{C}$. Since the DFC removal is an obvious two-stage removal, we used both the all the data and the data from the first 9 hours to fit the pseudo-first-order model. Based on the corresponding $\mathrm{R}^{2}$ values in Figure $\mathrm{S} 1$, pseudo-firstorder model with first 9 hour data, pseudo-second-order model, and mechanism-based model fitted the data similarly in general. The removal kinetics was fitted slightly better to the mechanism-based model than the other two models. All the data in the experiments were used to fit the mechanism-based model (Table S5.1). However, the plateau concentration $\left(C_{\mathrm{e}}\right)$ was not obtained in all experiments, thus will lead to inconsistent transformation trends of DFC removal. Since the other three models have similar performance, the simplest model was selected to fit all the data under different experimental conditions in this paper, which is the pseudo-firstorder model with first 9 hour data.

TEXT S5.2 Results of blank experiments

The experiments without $\mathrm{MnO}_{2}$ were carried out as the blank experiments. The results showed that no DFC was removed without $\mathrm{MnO}_{2}$ (Table S5.2). To investigate the effects of humic acids on DFC removal under anaerobic conditions with $\mathrm{MnO}_{2}$, the experiments without $\mathrm{MnO}_{2}$ as controls were carried out at the lowest and highest HA concentration in this study, that is, $5 \mathrm{mg} \cdot \mathrm{L}^{-1}$ and $20 \mathrm{mg} \cdot \mathrm{L}^{-1}$. The results show that no DFC is removed after 33 hours (Figure S5.2). 


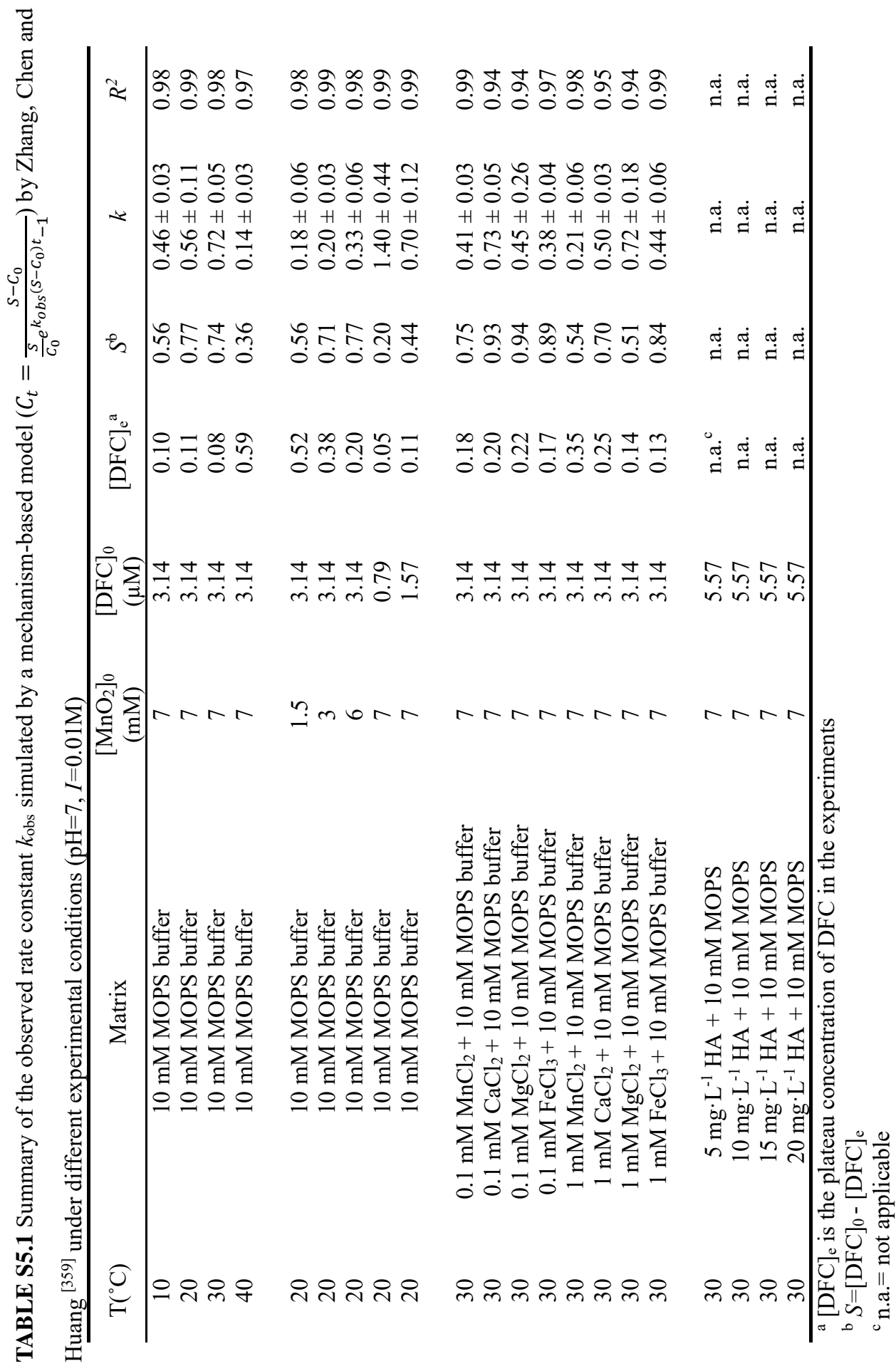


TABLE S5.2 DFC removal under anaerobic conditions without $\mathrm{MnO}_{2}$ under different experimental conditions after 33 hours

\begin{tabular}{|c|c|c|c|c|c|}
\hline $\mathrm{T}\left({ }^{\circ} \mathrm{C}\right)$ & Matrix & $\begin{array}{c}{\left[\mathrm{MnO}_{2}\right]_{0}} \\
(\mathrm{mM})\end{array}$ & $\begin{array}{c}{[\mathrm{DFC}]_{0}} \\
(\mu \mathrm{M})\end{array}$ & $\mathrm{C} / \mathrm{C}_{0}{ }^{a}$ & $\begin{array}{c}\text { Standard } \\
\text { deviation } \\
(\%)\end{array}$ \\
\hline 10 & $10 \mathrm{mM}$ MOPS & 7 & 3.14 & 0.98 & 5.9 \\
\hline 20 & $10 \mathrm{mM}$ MOPS & 7 & 3.14 & 0.94 & 7.2 \\
\hline 30 & $10 \mathrm{mM}$ MOPS & 7 & 3.14 & 1.05 & 1.4 \\
\hline 40 & $10 \mathrm{mM}$ MOPS & 7 & 3.14 & 1.02 & 1.9 \\
\hline 20 & $10 \mathrm{mM}$ MOPS & 1.5 & 3.14 & 1.13 & 9.2 \\
\hline 20 & $10 \mathrm{mM}$ MOPS & 3 & 3.14 & 1.08 & 5.2 \\
\hline 20 & $10 \mathrm{mM}$ MOPS & 6 & 3.14 & 1.08 & 9.6 \\
\hline 20 & $10 \mathrm{mM}$ MOPS & 7 & 3.14 & 0.94 & 7.2 \\
\hline 20 & $10 \mathrm{mM}$ MOPS & 7 & 0.79 & 1.06 & 13.8 \\
\hline 20 & $10 \mathrm{mM}$ MOPS & 7 & 1.57 & 1.01 & 3.4 \\
\hline 30 & $10 \mathrm{mM}$ MOPS, no metal ions & 7 & 3.14 & 1.05 & 1.4 \\
\hline 30 & $0.1 \mathrm{mM} \mathrm{MnCl} \mathrm{M}_{2}+10 \mathrm{mM}$ MOPS & 7 & 3.14 & 1.10 & 1.4 \\
\hline 30 & $0.1 \mathrm{mM} \mathrm{CaCl}_{2}+10 \mathrm{mM}$ MOPS & 7 & 3.14 & 1.00 & 3.8 \\
\hline 30 & $0.1 \mathrm{mM} \mathrm{MgCl}_{2}+10 \mathrm{mM}$ MOPS & 7 & 3.14 & 0.98 & 3.6 \\
\hline 30 & $0.1 \mathrm{mM} \mathrm{FeCl}_{3}+10 \mathrm{mM}$ MOPS & 7 & 3.14 & 0.99 & 3.6 \\
\hline 30 & $1 \mathrm{mM} \mathrm{MnCl}{ }_{2}+10 \mathrm{mM}$ MOPS & 7 & 3.14 & 1.05 & 1.7 \\
\hline 30 & $1 \mathrm{mM} \mathrm{CaCl}_{2}+10 \mathrm{mM}$ MOPS & 7 & 3.14 & 0.98 & 2.2 \\
\hline 30 & $1 \mathrm{mM} \mathrm{MgCl}_{2}+10 \mathrm{mM}$ MOPS & 7 & 3.14 & 1.02 & 2.8 \\
\hline 30 & $1 \mathrm{mM} \mathrm{FeCl}_{3}+10 \mathrm{mM}$ MOPS & 7 & 3.14 & 0.95 & 4.1 \\
\hline 30 & 10 mM MOPS, no HA & 7 & 3.14 & 1.02 & 9.7 \\
\hline 30 & $5 \mathrm{mg} \cdot \mathrm{L}^{-1} \mathrm{HA}+10 \mathrm{mM}$ MOPS & 7 & 5.57 & 1.00 & 4.0 \\
\hline 30 & $20 \mathrm{mg} \cdot \mathrm{L}^{-1} \mathrm{HA}+10 \mathrm{mM}$ MOPS & 7 & 5.57 & 1.02 & 1.2 \\
\hline
\end{tabular}




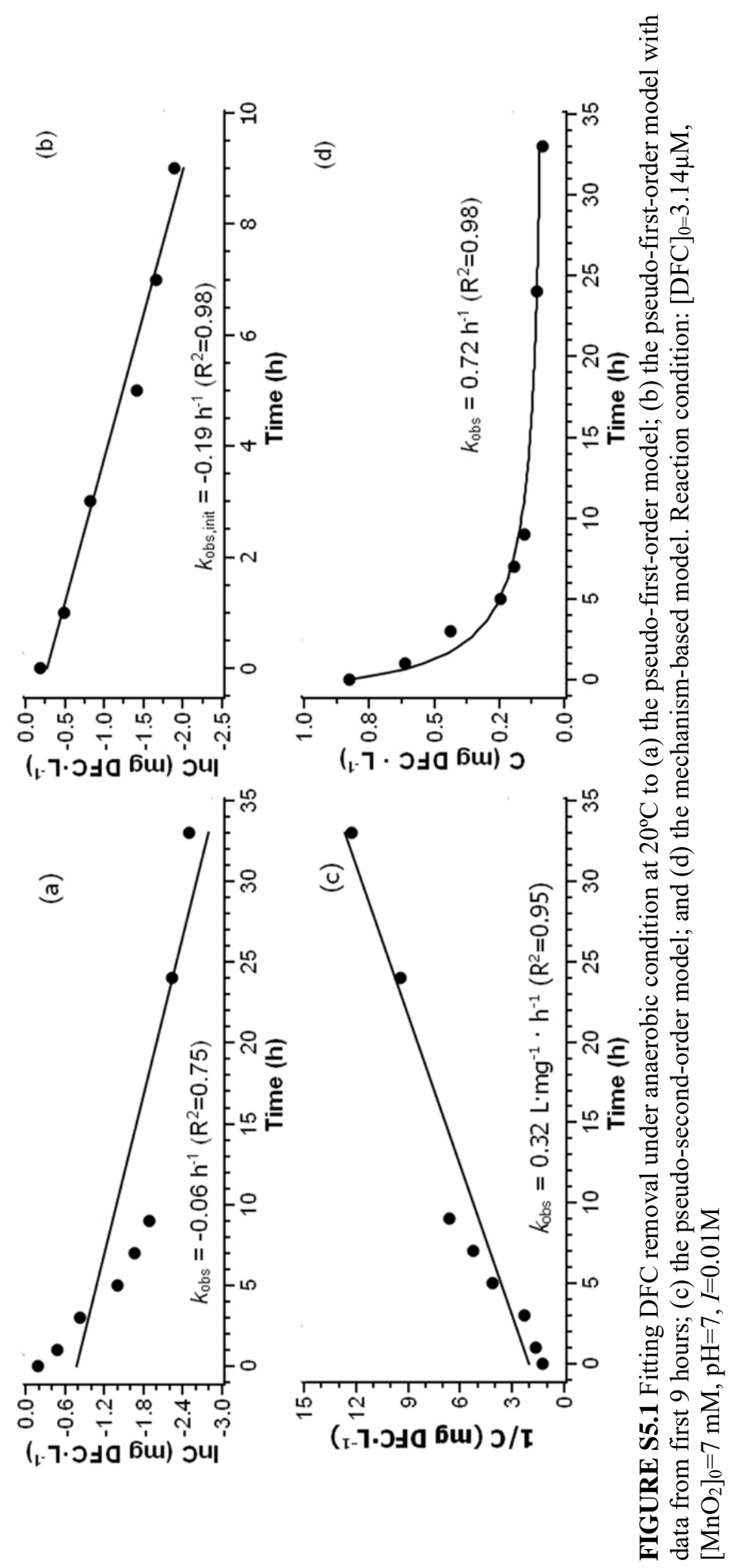


TEXT S5.3 Change of $\mathrm{MnO}_{2}$ particles

Based on the microscopies, it is clear that the $\mathrm{MnO}_{2}$ particle size at $20^{\circ} \mathrm{C}$ is smaller than that at $40^{\circ} \mathrm{C}$ (Figure S5.3 (a) - (d)). In addition, when the $\mathrm{MnO}_{2}$ particles was settled at $20^{\circ} \mathrm{C}$ for a longer time (6 months in this case), the $\mathrm{MnO}_{2}$ particle size was also increased (Figure S5.3(e), (f)). The settlement ability test also supported this indirectly (Figure S5.4).

However, we failed to analyze the change of $\mathrm{MnO}_{2}$ particles due to the practical limits as mentioned previously ${ }^{[172]}$.

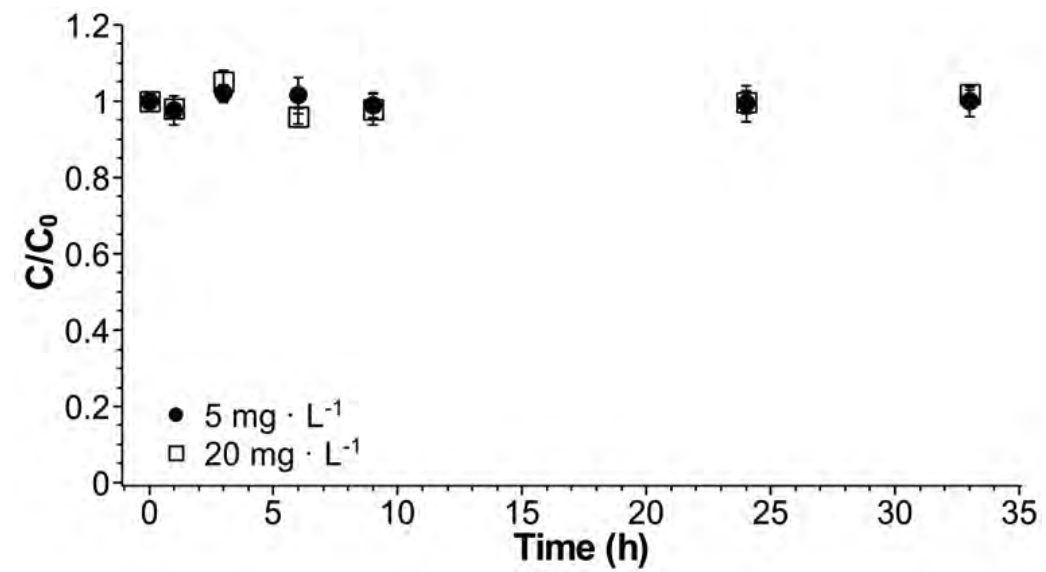

FIGURE S5.2 DFC removal without $\mathrm{MnO}_{2}$ under anaerobic conditions at different $\mathrm{HA}$ concentrations. Experimental conditions: $\left[\mathrm{MnO}_{2}\right]_{0}=7 \mathrm{mM}$; $[\mathrm{DFC}]_{0}=5.57 \mu \mathrm{M}, 30^{\circ} \mathrm{C}, \mathrm{pH} \sim 7$, $I=0.01 \mathrm{M}$. Error bars are standard deviations 


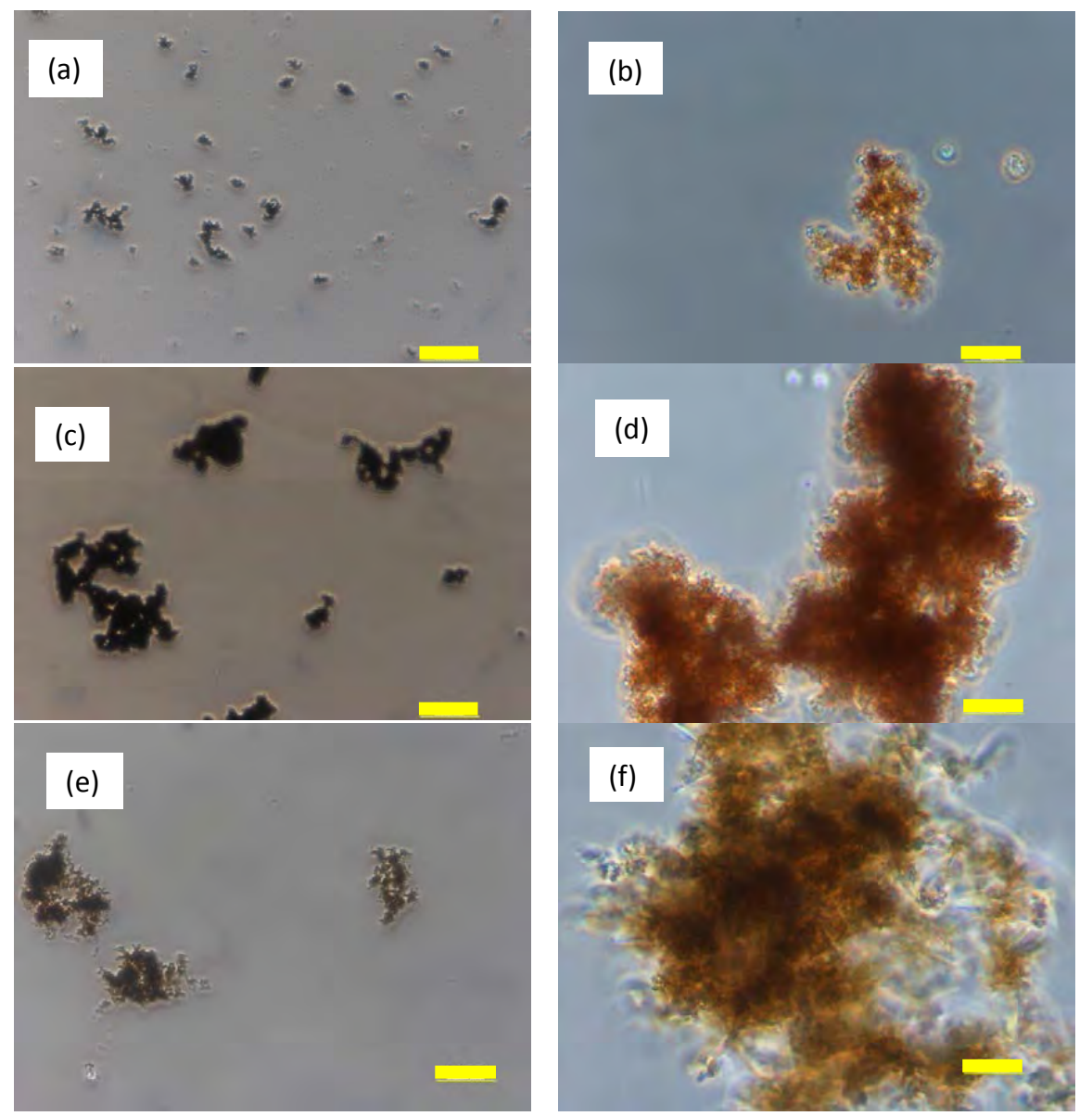

FIGURE S5.3 Microscopy of $\mathrm{MnO}_{2}$ at (a) $20^{\circ} \mathrm{C}, 33$ hours, $\times 10$; (b) $20^{\circ} \mathrm{C}, 33$ hours, $\times 100$; (c) $40^{\circ} \mathrm{C}$, 33 hours, $\times 10$; (b) $40^{\circ} \mathrm{C}, 33$ hours, $\times 100$, (e) $20^{\circ} \mathrm{C}, 6$ months, $\times 10$, (f) $20^{\circ} \mathrm{C}, 6$ months, $\times 100$. Experimental condition: $[\mathrm{DFC}]_{0}=3.14 \mu \mathrm{M},\left[\mathrm{MnO}_{2}\right]_{0}=7 \mathrm{mM}, \mathrm{pH}=7, I=0.01 \mathrm{M}$. The yellow bar -represents $100 \mu \mathrm{m}$ length in (a), (c) and (e) and $10 \mu \mathrm{m}$ in (b), (d) and (f)
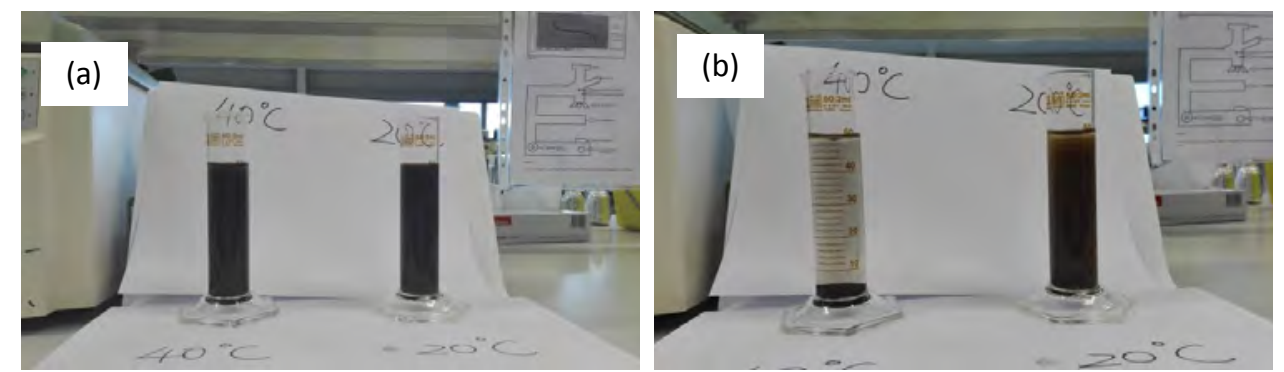

FIGURE S5.4. Settlement ability of $\mathrm{MnO}_{2}$ treated after 33 hours at different temperatures at (a) $\mathrm{t}=0$ min; (b) $\mathrm{t}=30 \mathrm{~min}$ 


\section{Supplementary materials for Chapter 6}

Biological regeneration of manganese (IV) using oxygen and iron (III) using nitrate for anaerobic metal oxide mediated removal of pharmaceuticals from water

Text S6.1 Calculation of total $\mathrm{O}_{2}$ amount

The total $\mathrm{O}_{2}$ amount includes the $\mathrm{O}_{2}$ in the headspace and that dissolved in the medium. The amount $\mathrm{O}_{2}$ in the headspace is calculated according to the ideal gas law (Equation S6.1).

$$
p V=n R T
$$

in which

$p$ is the partial pressure of the gas $\left(\mathrm{O}_{2}\right)$.

$V$ is the volume of the $\mathrm{O}_{2}, 70 \mathrm{~mL}$ in this experiment

$\mathrm{n}$ is the amount of oxygen in mole

$R$ is gas constant, $8.314 \mathrm{~m}^{3} \cdot \mathrm{Pa} \cdot \mathrm{mol}^{-1} \cdot \mathrm{K}^{-1}$

$T$ is the absolute temperature, $303.15 \mathrm{~K}$

The in $\mathrm{O}_{2}$ dissolved is calculated according to Henry's Law (Equation S6.2).

$$
p=K_{H}^{p c} c_{a q}
$$

In which

$p$ is the partial pressure of $\mathrm{O}_{2}$

$K_{H}^{p c}$ is the Henry's Law constant. To simply the calculation, the value is $\mathrm{O}_{2}$ in water at $30^{\circ} \mathrm{C}, 1.18 \times 10^{-3} \mathrm{~mol} \cdot \mathrm{L}^{-1} \cdot \mathrm{atm}^{-1}$

$c_{a q}$ is the molar concentration of dissolved $\mathrm{O}_{2}$ 
TEXT S6.2 Abiotic control results

The abiotic controls show that the degradation of pharmaceutical during the anaerobic biological production of $\mathrm{Fe}(\mathrm{III})$ is insignificant without bacteria. The recovery rate of solid phase extraction (SPE) is $85-115 \%$, so when the removal efficiency is less than $20 \%$, it is hard to conclude if that is removal or that is caused by the SPE and detection deviation. In addition, propranolol was also included in the experiments. However, the recovery with the current SPE methods is poor and various from $10-30 \%$. Therefore, the data is not shown here.

TABLE S6.1 Medium recipe for bioregeneration of Fe(III)

\begin{tabular}{|c|c|c|c|}
\hline Compounds & $\begin{array}{l}\text { Final } \\
\text { concentration } \\
\left(\mathrm{g} \cdot \mathrm{L}^{-1}\right)\end{array}$ & Compounds & $\begin{array}{l}\text { Final } \\
\text { concentration } \\
\left(\mathrm{g} \cdot \mathrm{L}^{-1}\right)\end{array}$ \\
\hline $\mathrm{FeCl}_{2}$ & 0.11 & $\mathrm{NaHCO} 3$ & 2.5 \\
\hline $\mathrm{KCl}$ & 0.10 & $\mathrm{NH}_{4} \mathrm{Cl}$ & 0.15 \\
\hline $\mathrm{KNO}_{3}$ & 0.02 & Vitamin & $1 \mathrm{~mL} \cdot \mathrm{L}^{-1}$ \\
\hline Trace element & $1 \mathrm{~mL} \cdot \mathrm{L}^{-1}$ & & \\
\hline \multicolumn{4}{|c|}{ Trace element solution } \\
\hline $\mathrm{CaCl}_{2} \cdot 2 \mathrm{H}_{2} \mathrm{O}$ & 1.00 & $\mathrm{Na}_{2} \mathrm{MoO}_{4} \cdot 2 \mathrm{H}_{2} \mathrm{O}$ & 0.10 \\
\hline $\mathrm{CoSO}_{4} .7 \mathrm{H}_{2} \mathrm{O}$ & 1.80 & $\mathrm{Na}_{2} \mathrm{SeO}_{3}$ & 0.002 \\
\hline $\mathrm{CuSO}_{4} .5 \mathrm{H}_{2} \mathrm{O}$ & 0.10 & $\mathrm{Na}_{2} \mathrm{WO}_{4} \cdot 2 \mathrm{H}_{2} \mathrm{O}$ & 0.004 \\
\hline $\mathrm{FeSO}_{4} .5 \mathrm{H}_{2} \mathrm{O}$ & 0.87 & $\mathrm{NaCl}$ & 10.00 \\
\hline $\mathrm{H}_{3} \mathrm{BO}_{3}$ & 0.10 & $\mathrm{NiCl}_{2} \cdot 6 \mathrm{H}_{2} \mathrm{O}$ & 0.30 \\
\hline $\mathrm{KAl}\left(\mathrm{SO}_{4}\right)_{2} \cdot 12 \mathrm{H}_{2} \mathrm{O}$ & 0.20 & Nitrilotriacetic acid & 15.00 \\
\hline $\mathrm{MgSO}_{4} .5 \mathrm{H}_{2} \mathrm{O}$ & 25.61 & $\mathrm{ZnSO}_{4} .5 \mathrm{H}_{2} \mathrm{O}$ & 1.57 \\
\hline $\mathrm{MnSO}_{4} .5 \mathrm{H}_{2} \mathrm{O}$ & 5.00 & & \\
\hline \multicolumn{4}{|c|}{ Vitamin solution } \\
\hline Biotin & 0.02 & Nicotinic acid & 0.05 \\
\hline $\begin{array}{l}\text { Cyanocobalamine } \\
\text { (vitamin B12) }\end{array}$ & 0.001 & $\begin{array}{l}\text { p-Aminobenzoic acid } \\
(\mathrm{Na}-\text { salt })\end{array}$ & 0.05 \\
\hline $\begin{array}{l}\text { Pantothenate } \\
\text { (Ca-salt) }\end{array}$ & 0.05 & Pyridocine- $\mathrm{HCl}$ & 0.10 \\
\hline Folic acid & 0.02 & Riboflavine (vitamin B2) & 0.05 \\
\hline $\begin{array}{l}\text { Lipoic acid (thioctic } \\
\text { acid) }\end{array}$ & 0.05 & Thiamine $\mathrm{HCl}$ ( vitamin $\mathrm{B} 1$ ) & 0.05 \\
\hline
\end{tabular}


TABLE S6.2 Biodegradation of pharmaceuticals $\left(\mathrm{C} / \mathrm{C}_{0}\right)$ with $\mathrm{Mn}(\mathrm{II})$-oxidizing bacteria

\begin{tabular}{llll}
\hline Pharmaceutical & Biodegradation & Pharmaceutical & Biodegradation \\
\hline Caffeine & 1.05 & Metoprolol & 1.14 \\
Carbamazepine & 1.06 & Naproxen & 0.96 \\
Diclofenac & 0.95 & Propranolol & 1.12 \\
Ibuprofen & 0.90 & & \\
\hline
\end{tabular}

TABLE S6.3 Abiotic removal of pharmaceuticals $\left(\mathrm{C} / \mathrm{C}_{0}\right)$ under anaerobic conditions in the blank groups

\begin{tabular}{cccc}
\hline Pharmaceutical & Removal & Pharmaceutical & Removal \\
\hline Caffeine & 1.00 & Metoprolol & 1.00 \\
Carbamazepine & 1.00 & Naproxen & 1.00 \\
Diclofenac & 1.00 & Propranolol & 0.95 \\
Ibuprofen & 1.00 & & \\
\hline
\end{tabular}

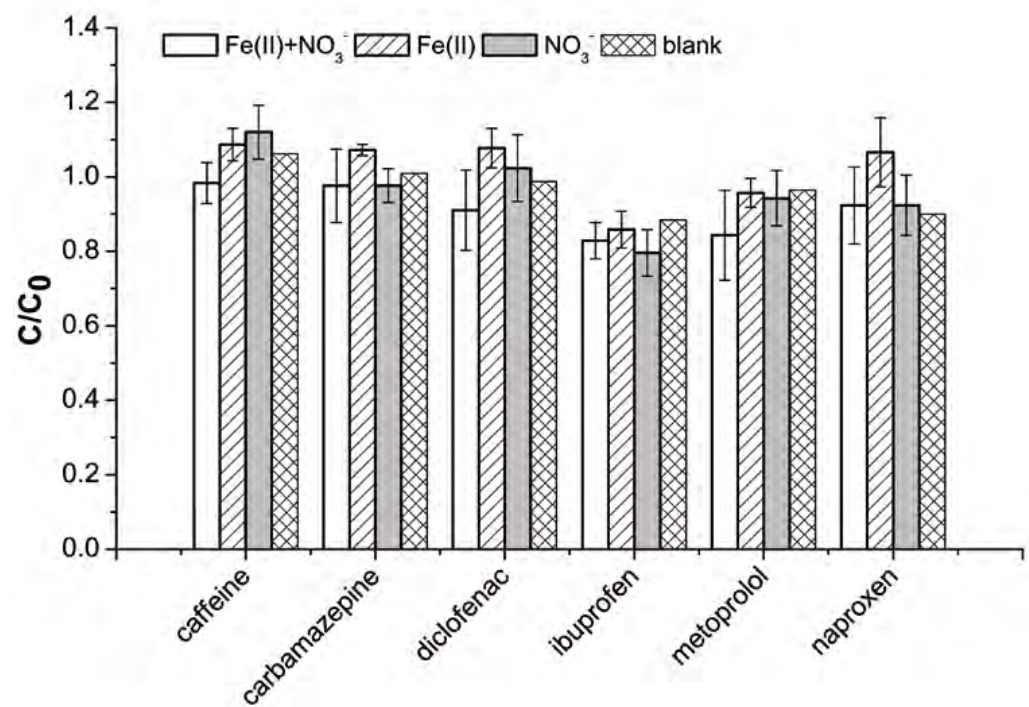

FIGURE S6.1 Degradation of pharmaceuticals in the abiotic groups during the biological $\mathrm{Fe}(\mathrm{III})$ production within 150 days. Experimental conditions: $[\mathrm{Fe}(\mathrm{II})]_{0}=1.2 \mathrm{mM},\left[\mathrm{NO}_{3}{ }^{-}\right]_{0}=$ $0.2 \mathrm{mM}$, [pharmaceutical $]_{0}=1 \mathrm{mg} \cdot \mathrm{L}^{-1}, \mathrm{~T}=30^{\circ} \mathrm{C}, \mathrm{pH}=7$, shaking speed $120 \mathrm{rpm}$. Error bar stands for the standard deviation 


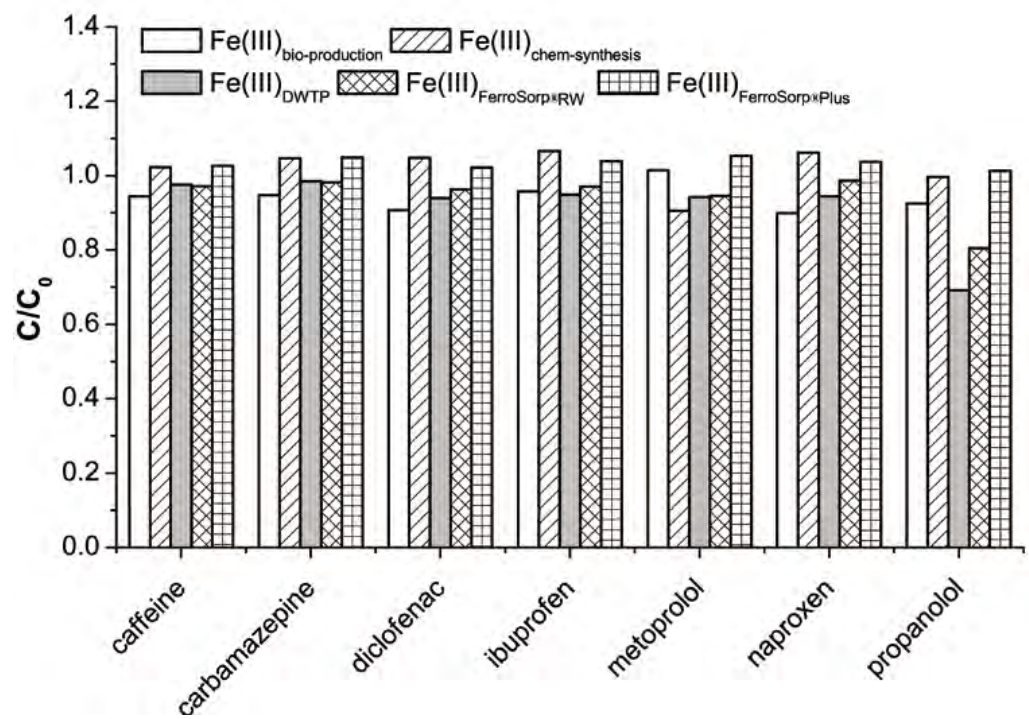

FIGURE S6.2 Abiotic removal of pharmaceuticals under anaerobic conditions with different $\mathrm{Fe}(\mathrm{III})$ powder within 5 days. $\mathrm{Fe}(\mathrm{III})_{\text {bio-production }}=$ biologically produced $\mathrm{Fe}(\mathrm{III}), \mathrm{Fe}(\mathrm{III})_{\text {chem- }}$ synthesis $=$ chemically synthesized $\mathrm{Fe}(\mathrm{III}), \mathrm{Fe}(\mathrm{III})_{\mathrm{DWTP}}=\mathrm{Fe}(\mathrm{III})$ from drinking water treatment plant, Fe(III) FerroSorp $® R W_{\text {RW }}=\mathrm{Fe}(\mathrm{III})$-based sorbent, FerroSorp ${ } \mathrm{RW}, \mathrm{Fe}(\mathrm{III})_{\text {FerroSorp } ® \text { Plus }}=$ $\mathrm{Fe}(\mathrm{III})$-based sorbent, FerroSorp ${ }^{\circledR P l u s . ~ E x p e r i m e n t a l ~ c o n d i t i o n s: ~}[\mathrm{Fe}(\mathrm{III})]_{0}=20 \mathrm{mM}$. Pharmaceutical $]_{0}=0.5 \mathrm{mg} \cdot \mathrm{L}-1$, phosphate buffer $\mathrm{pH}=7, \mathrm{~T}=30^{\circ} \mathrm{C}$

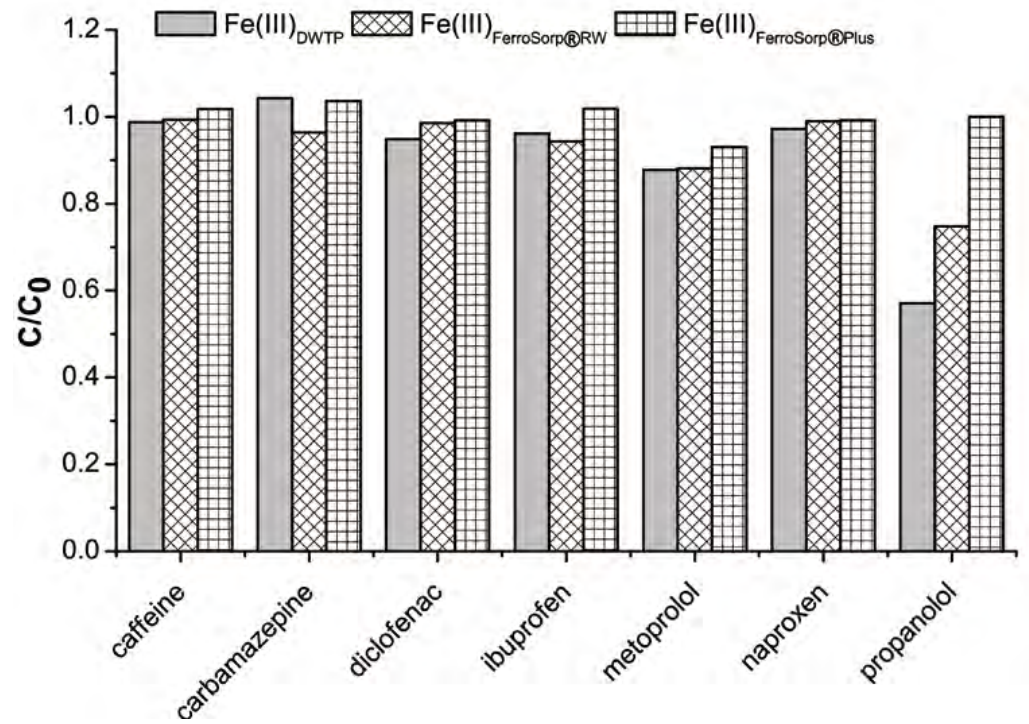

FIGURE S6.3 Abiotic removal of pharmaceuticals under anaerobic conditions with different $\mathrm{Fe}(\mathrm{III})$ granule within 5 days. Fe(III) $)_{\text {DWTP }}=\mathrm{Fe}$ (III) from drinking water treatment plant, $\mathrm{Fe}(\mathrm{III})_{\text {FerroSorp } \circledast \mathrm{RW}}=\mathrm{Fe}(\mathrm{III})$-based sorbent, FerroSorp ${ }^{\circledR R W}, \mathrm{Fe}(\mathrm{III})_{\text {FerroSorp } ® \text { Plus }}=\mathrm{Fe}(\mathrm{III})$-based sorbent, FerroSorp ${ }^{\circledR P l u s}$. Experimental conditions: $[\mathrm{Fe}(\mathrm{III})]_{0}=20 \mathrm{mM}$. Pharmaceutical $]_{0}=0.5$ $\mathrm{mg} \cdot \mathrm{L}^{-1}$, phosphate buffer $\mathrm{pH}=7, \mathrm{~T}=30^{\circ} \mathrm{C}$ 


\section{Bibliography}


1. Ahmed, M. M.; Chiron, S., Solar photo-Fenton like using persulphate for carbamazepine removal from domestic wastewater. Water Research 2014, 48, 229-236.

2. Aitken, M.; Kleinrock, M. Global medicines use in 2020: Outlook and implications; IMS Insitution for Health Informatics: 2015.

3. American Water Works Association, Water Treatment (Fourth Edition) American Water Works Association: USA, 2011.

4. Anderson, R. T.; Rooney-Varga, J. N.; Gaw, C. V.; Lovley, D. R., Anaerobic benzene oxidation in the $\mathrm{Fe}(\mathrm{III})$ reduction zone of petroleum contaminated aquifers. Environmental Science \& Technology 1998, 32, (9), 1222-1229.

5. Andreozzi, R.; Campanella, L.; Fraysse, B.; Garric, J.; Gonnella, A.; Lo Giudice, R.; Marotta, R.; Pinto, G.; Pollio, A., Effects of advanced oxidation processes (AOPs) on the toxicity of a mixture of pharmaceuticals. Water Science and Technology 2004, 50, (5), 23-28.

6. Archer, E.; Petrie, B.; Kasprzyk-Hordern, B.; Wolfaardt, G. M., The fate of pharmaceuticals and personal care products (PPCPs), endocrine disrupting contaminants (EDCs), metabolites and illicit drugs in a WWTW and environmental waters. Chemosphere 2017, 174, 437-446.

7. Auvinen, H.; Gebhardt, W.; Linnemann, V.; Du Laing, G.; Rousseau, D. P. L., Laboratory- and full-scale studies on the removal of pharmaceuticals in an aerated constructed wetland: effects of aeration and hydraulic retention time on the removal efficiency and assessment of the aquatic risk. Water Science and Technology 2017.

8. Babuponnusami, A.; Muthukumar, K., Advanced oxidation of phenol: A comparison between Fenton, electro-Fenton, sono-electro-Fenton and photo-electro-Fenton processes. Chemical Engineering Journal 2012, 183, 1-9.

9. Babuponnusami, A.; Muthukumar, K., A review on Fenton and improvements to the Fenton process for wastewater treatment. Journal of Environmental Chemical Engineering 2014, 2, (1), 557-572.

10. Badawy, M. I.; Wahaab, R. A.; El-Kalliny, A. S., Fenton-biological treatment processes for the removal of some pharmaceuticals from industrial wastewater. Journal of Hazardous Materials 2009, 167, (1-3), 567-574.

11. Bae, S.; Song, S. U.; Kim, D.; Lee, W., Oxidative degradation of pharmaceutical by Fenton-like reaction using pyrite and $\mathrm{H}_{2} \mathrm{O}_{2}$. Abstracts of Papers of the American Chemical Society 2012, 244.

12. Bao, X. L.; Qiang, Z. M.; Ling, W. C.; Chang, J. H., Sonohydrothermal synthesis of $\mathrm{MFe}_{2} \mathrm{O}_{4}$ magnetic nanoparticles for adsorptive removal of tetracyclines from water. Separation and Purification Technology 2013, 117, 104-110.

13. Barbieri, M.; Carrera, J.; Sanchez-Vila, X.; Ayora, C.; Cama, J.; Kock-Schulmeyer, M.; de Alda, M. L.; Barcelo, D.; Brunet, J. T.; Garcia, M. H., Microcosm experiments to control anaerobic redox conditions when studying the fate of organic micropollutants in aquifer material. Journal of Contaminant Hydrology 2011, 126, (3-4), 330-345.

14. Barrett, K. A.; McBride, M. B., Oxidative degradation of glyphosate and aminomethylphosphonate by manganese oxide. Environmental Science \& Technology 2005, 39, (23), 9223-9228. 
15. Bautitz, I. R.; Velosa, A. C.; Nogueira, R. F. P., Zero valent iron mediated degradation of the pharmaceutical diazepam. Chemosphere 2012, 88, (6), 688-692.

16. Bellusci, M.; La Barbera, A.; Padella, F.; Mancuso, M.; Pasquo, A.; Grollino, M. G.; Leter, G.; Nardi, E.; Cremisini, C.; Giardullo, P.; Pacchierotti, F., Biodistribution and acute toxicity of a nanofluid containing manganese iron oxide nanoparticles produced by a mechanochemical process. International Journal of Nanomedicine 2014, 9, 1919 1929.

17. Benitez, F. J.; Acero, J. L.; Real, F. J.; Roldan, G., Ozonation of pharmaceutical compounds: Rate constants and elimination in various water matrices. Chemosphere 2009, 77, (1), 53-59.

18. Benjamin, M. M.; Lawler, D. F., Water Quality Engineering: Physical / Chemical Treatment Processes. John Wiley \& Sons, Inc: Hoboken, NJ, 2013.

19. Bernard, S.; Chazal, P.; Mazet, M., Removal of organic compounds by adsorption on pyrolusite $\left(\beta-\mathrm{MnO}_{2}\right)$. Water Research 1997, 31, (5), 1216-1222.

20. Besse, J. P.; Garric, J., Human pharmaceuticals in surface waters: Implementation of a prioritization methodology and application to the French situation. Toxicology Letters 2008, 176, (2), 104-123.

21. Betancur-Corredor, B.; Soltan, J.; Penuela, G. A., Mineralization of ibuprofen and humic acid through catalytic ozonation. Ozone-Science \& Engineering 2016, 38, (3), 203-210.

22. Boonnorat, J.; Techkarnjanaruk, S.; Honda, R.; Prachanurak, P., Effects of hydraulic retention time and carbon to nitrogen ratio on micro-pollutant biodegradation in membrane bioreactor for leachate treatment. Bioresource Technology 2016, 219, (Supplement C), 53-63.

23. Bos, R., Spoelwaterbehandeling in Emmen. $\mathrm{H}_{2} \mathrm{O}$ 1996, 29, (21), 624-628.

24. Brambilla, G.; Martelli, A., Update on genotoxicity and carcinogenicity testing of 472 marketed pharmaceuticals. Mutation Research-Reviews 2009, 681, (2-3), 209-229.

25. Bratby, J., Coagulation and flocculation in water and wastewater treatment. IWA Publishing: London, 2006.

26. Brausch, J. M.; Connors, K. A.; Brooks, B. W.; Rand, G. M., Human pharmaceuticals in the aquatic environment: A review of recent toxicological studies and considerations for toxicity testing. Reviews of Environmental Contamination and Toxicology, Vol 218 2012, 218, 1-99.

27. Brillas, E.; Sires, I.; Oturan, M. A., Electro-Fenton process and related electrochemical technologies based on Fenton's reaction chemistry. Chemical Reviews 2009, 109, (12), 6570-6631.

28. Budd, G. C.; Hess, A. F.; Shorney-Darby, H.; Neemann, J. J.; Spencer, C. M.; Bellamy, J. D.; Hargette, P. H. C. F. p. d. F., Coagulation applications for new treatment goals. Journal (American Water Works Association) 2004, 96, (2), 102-113.

29. Cao, L. T. T.; Kodera, H.; Abe, K.; Imachi, H.; Aoi, Y.; Kindaichi, T.; Ozaki, N.; Ohashi, A., Biological oxidation of $\mathrm{Mn}(\mathrm{II})$ coupled with nitrification for removal and recovery of minor metals by downflow hanging sponge reactor. Water Research 2015, 68, 545 553. 
30. Castro, M. J. L.; Ojeda, C.; Cirelli, A. F., Advances in surfactants for agrochemicals. Environmental Chemistry Letters 2014, 12, (1), 85-95.

31. Chelliapan, S.; Sallis, P. J., Removal of organic compound from pharmaceutical wastewater using advanced oxidation processes. Journal of Scientific \& Industrial Research 2013, 72, (4), 248-254.

32. Chen, G.; Zhao, L.; Dong, Y. H., Oxidative degradation kinetics and products of chlortetracycline by manganese dioxide. Journal of Hazardous Materials 2011, 193, 128-138.

33. Chen, M. J.; Cao, F.; Li, F. B.; Liu, C. S.; Tong, H.; Wu, W. J.; Hu, M., Anaerobic transformation of DDT related to iron (III) reduction and microbial community structure in paddy soils. Journal of Agricultural and Food Chemistry 2013, 61, (9), 2224-2233.

34. Chen, W. R.; Ding, Y.; Johnston, C. T.; Teppen, B. J.; Boyd, S. A.; Li, H., Reaction of lincosamide antibiotics with manganese oxide in aqueous solution. Environmental Science \& Technology 2010, 44, (12), 4486-4492.

35. Chen, W. R.; Huang, C. H., Transformation of tetracyclines mediated by Mn(II) and $\mathrm{Cu}(\mathrm{II})$ ions in the presence of oxygen. Environmental Science \& Technology 2009, 43, (2), 401-407.

36. Chen, Z. X.; Wang, T.; Jin, X. Y.; Chen, Z. L.; Megharaj, M.; Naidu, R., Multifunctional kaolinite-supported nanoscale zero-valent iron used for the adsorption and degradation of crystal violet in aqueous solution. Journal of Colloid and Interface Science 2013, 398, 59-66.

37. Cheng, X.; Chen, B.; Cui, Y.; Sun, D.; Wang, X., Iron (III) reduction-induced phosphate precipitation during anaerobic digestion of waste activated sludge. Separation and Purification Technology 2015, 143, (Supplement C), 6-11.

38. Chieng, N.; Rades, T.; Aaltonen, J., An overview of recent studies on the analysis of pharmaceutical polymorphs. Journal of Pharmaceutical and Biomedical Analysis 2011, $55,(4), 618-644$.

39. Clara, M.; Kreuzinger, N.; Strenn, B.; Gans, O.; Kroiss, H., The solids retention timea suitable design parameter to evaluate the capacity of wastewater treatment plants to remove micropollutants. Water Research 2005, 39, (1), 97-106.

40. Collado, S.; Quero, D.; Laca, A.; Diaz, M., Fe ${ }^{2+}$-Catalyzed Wet Oxidation of Phenolic Acids under Different $\mathrm{pH}$ Values. Industrial \& Engineering Chemistry Research 2010, 49, (24), 12405-12413.

41. Crane, M.; Watts, C.; Boucard, T., Chronic aquatic environmental risks from exposure to human pharmaceuticals. Science of the Total Environment 2006, 367, (1), 23-41.

42. Crane, R. A.; Scott, T. B., Nanoscale zero-valent iron: Future prospects for an emerging water treatment technology. Journal of Hazardous Materials 2012, 211, 112-125.

43. Cruz-Morato, C.; Ferrando-Climent, L.; Rodriguez-Mozaz, S.; Barcelo, D.; MarcoUrrea, E.; Vicent, T.; Sarra, M., Degradation of pharmaceuticals in non-sterile urban wastewater by Trametes versicolor in a fluidized bed bioreactor. Water Research 2013, $47,(14), 5200-5210$. 
44. Cui, X. Y.; Zeng, P.; Qiu, G. L.; Liu, Y. Q.; Song, Y. H.; Xie, X. L.; Han, L., Pilot-scale treatment of pharmaceutical berberine wastewater by Fenton oxidation. Environmental Earth Sciences 2015, 73, (9), 4967-4977.

45. Cundy, A. B.; Hopkinson, L.; Whitby, R. L. D., Use of iron-based technologies in contaminated land and groundwater remediation: A review. Science of the Total Environment 2008, 400, (1-3), 42-51.

46. Dai, G. H.; Huang, J.; Chen, W. W.; Wang, B.; Yu, G.; Deng, S. B., Major pharmaceuticals and personal care products (PPCPs) in wastewater treatment plant and receiving water in Beijing, China, and associated ecological risks. Bulletin of Environmental Contamination and Toxicology 2014, 92, (6), 655-661.

47. De la Cruz, N.; Esquius, L.; Grandjean, D.; Magnet, A.; Tungler, A.; de Alencastro, L. F.; Pulgarin, C., Degradation of emergent contaminants by $\mathrm{UV}, \mathrm{UV} / \mathrm{H}_{2} \mathrm{O}_{2}$ and neutral photo-Fenton at pilot scale in a domestic wastewater treatment plant. Water Research 2013, 47, (15), 5836-5845.

48. de Velosa, A. C.; Nogueira, R. F. P., 2,4-Dichlorophenoxyacetic acid (2,4-D) degradation promoted by nanoparticulate zerovalent iron (nZVI) in aerobic suspensions. Journal of Environmental Management 2013, 121, 72-79.

49. de Wilt, A.; Butkovskyi, A.; Tuantet, K.; Leal, L. H.; Fernandes, T. V.; Langenhoff, A.; Zeeman, G., Micropollutant removal in an algal treatment system fed with source separated wastewater streams. Journal of Hazardous Materials 2016, 304, 84-92.

50. Delgado, L. F.; Charles, P.; Glucina, K.; Morlay, C., The removal of endocrine disrupting compounds, pharmaceutically activated compounds and cyanobacterial toxins during drinking water preparation using activated carbon-A review. Science of the Total Environment 2012, 435, 509-525.

51. Deng, Y.; Ezyske, C. M., Sulfate radical-advanced oxidation process (SR-AOP) for simultaneous removal of refractory organic contaminants and ammonia in landfill leachate. Water Research 2011, 45, (18), 6189-6194.

52. Ding, L.-J.; An, X.-L.; Li, S.; Zhang, G.-L.; Zhu, Y.-G., Nitrogen loss through anaerobic ammonium oxidation coupled to iron reduction from paddy soils in a chronosequence. Environmental Science \& Technology 2014, 48, (18), 10641-10647.

53. Dorer, C.; Vogt, C.; Neu, T. R.; Stryhanyuk, H.; Richnow, H. H., Characterization of toluene and ethylbenzene biodegradation under nitrate-, iron (III)- and manganese (IV)reducing conditions by compound-specific isotope analysis. Environmental Pollution 2016, 211, 271-281.

54. Dougherty, J. A.; Swarzenski, P. W.; Dinicola, R. S.; Reinhard, M., Occurrence of herbicides and pharmaceutical and personal care products in surface water and groundwater around Liberty Bay, Puget Sound, Washington. Journal of Environmental Quality 2010, 39, (4), 1173-1180.

55. Elsner, M.; Schwarzenbach, R. P.; Haderlein, S. B., Reactivity of Fe(II)-bearing minerals toward reductive transformation of organic contaminants. Environmental Science \& Technology 2004, 38, (3), 799-807.

56. European Commission, Amending Directives 2000/60/EC and 2008/105/EC as regards priority substances in the field of water policy. In Commission, E., Ed. Brussels, 2011. 
57. European Federation of Pharmaceutical Industries and Association The pharmaceutical industriy in figures: Edition 2016; European Federation of Pharmaceutical Industries and Associations: Brussels, 2016.

58. Eurpoean Union Directive 91/271/EEC of the European Parliament and of the Council. Retrieved from http://eur-lex.europa.eu/legalcontent/EN/TXT/PDF/?uri=CELEX:31991L0271\&from=EN. Accessed: 23, 09, 2017.

59. Eurpoean Union Directive 98/83/EC of the European Parliament and of the Council. Retrieved from http://eurlex.europa.eu/LexUriServ/LexUriServ.do?uri=OJ:L:1998:330:0032:0054:EN:PDF. Accessed: 23, 09, 2017.

60. Eurpoean Union Directive 2013/39/EU of the European Parliament and of the Council. Retrieved from http://eurlex.europa.eu/LexUriServ/LexUriServ.do?uri=OJ:L:2013:226:0001:0017:EN:PDF. Accessed: 23, 09, 2017.

61. Feitosa-Felizzola, J.; Hanna, K.; Chiron, S., Adsorption and transformation of selected human-used macrolide antibacterial agents with iron (III) and manganese (IV) oxides. Environmental Pollution 2009, 157, (4), 1317-1322.

62. Fick, J.; Soderstrom, H.; Lindberg, R. H.; Phan, C.; Tysklind, M.; Larsson, D. G. J., Contamination of surface, ground, and drinking water from pharmaceutical production. Environmental Toxicology and Chemistry 2009, 28, (12), 2522-2527.

63. Filip, J.; Zboril, R.; Schneeweiss, O.; Zeman, J.; Cernik, M.; Kvapil, P.; Otyepka, M., Environmental applications of chemically pure natural ferrihydrite. Environmental Science \& Technology 2007, 41, (12), 4367-4374.

64. Forrez, I.; Carballa, M.; Fink, G.; Wick, A.; Hennebel, T.; Vanhaecke, L.; Ternes, T.; Boon, N.; Verstraete, W., Biogenic metals for the oxidative and reductive removal of pharmaceuticals, biocides and iodinated contrast media in a polishing membrane bioreactor. Water Research 2011, 45, (4), 1763-1773.

65. Forrez, I.; Carballa, M.; Verbeken, K.; Vanhaecke, L.; Schlusener, M.; Ternes, T.; Boon, N.; Verstraete, W., Diclofenac oxidation by biogenic manganese oxides. Environmental Science \& Technology 2010, 44, (9), 3449-3454.

66. Froehner, S.; Piccioni, W.; Machado, K. S.; Aisse, M. M., Removal capacity of caffeine, hormones, and bisphenol by aerobic and anaerobic sewage treatment. Water Air and Soil Pollution 2011, 216, (1-4), 463-471.

67. Furgal, K. M.; Meyer, R. L.; Bester, K., Removing selected steroid hormones, biocides and pharmaceuticals from water by means of biogenic manganese oxide nanoparticles in situ at ppb levels. Chemosphere 2015, 136, 321-326.

68. Gao, A. F.; Gao, H.; Wan, J. M.; Wu, C. S., Treatment Pharmaceutical Wastewater Using Fenton Oxidation, Ultraviolet, and Ultrasound Processes. Fresenius Environmental Bulletin 2013, 22, (2), 449-454.

69. Gao, J.; Hedman, C.; Liu, C.; Guo, T.; Pedersen, J. A., Transformation of sulfamethazine by manganese oxide in aqueous solution. Environmental Science \& Technology 2012, 46, (5), 2642-2651. 
70. Gao, S. S.; Zhao, Z. W.; Xu, Y. P.; Tian, J. Y.; Qi, H.; Lin, W.; Cui, F. Y., Oxidation of sulfamethoxazole (SMX) by chlorine, ozone and permanganate-A comparative study. Journal of Hazardous Materials 2014, 274, 258-269.

71. Garrido-Ramirez, E. G.; Sivaiah, M. V.; Barrault, J.; Valange, S.; Theng, B. K. G.; Ureta-Zanartu, M. S.; Mora, M. D., Catalytic wet peroxide oxidation of phenol over iron or copper oxide-supported allophane clay materials: Influence of catalyst $\mathrm{SiO}_{2} / \mathrm{Al}_{2} \mathrm{O}_{3}$ ratio. Microporous and Mesoporous Materials 2012, 162, 189-198.

72. Gauthier, H.; Yargeau, V.; Cooper, D. G., Biodegradation of pharmaceuticals by Rhodococcus rhodochrous and Aspergillus niger by co-metabolism. Science of the Total Environment 2010, 408, (7), 1701-1706.

73. Ghafoori, S.; Shah, K. K.; Mehrvar, M.; Chan, P. K., Pharmaceutical wastewater treatment using granular activated carbon and $\mathrm{UV} / \mathrm{H}_{2} \mathrm{O}_{2}$ processes: Experimental analysis and modelling. Canadian Journal of Chemical Engineering 2014, 92, (7), 1163-1173.

74. Ghattas, A. K.; Fischer, F.; Wick, A.; Ternes, T. A., Anaerobic biodegradation of (emerging) organic contaminants in the aquatic environment. Water Research 2017, 116, 268-295.

75. Ghauch, A.; Ayoub, G.; Naim, S., Degradation of sulfamethoxazole by persulfate assisted micrometric $\mathrm{Fe}^{0}$ in aqueous solution. Chemical Engineering Journal 2013, 228 , (Supplement C), 1168-1181.

76. Ghauch, A.; Tuqan, A.; Assia, H. A., Antibiotic removal from water: Elimination of amoxicillin and ampicillin by microscale and nanoscale iron particles. Environmental Pollution 2009, 157, (5), 1626-1635.

77. Ghernaout, D.; Naceur, M. W., Ferrate(VI): In situ generation and water treatment - A review. Desalination and Water Treatment 2011, 30, (1-3), 319-332.

78. Gilroy, E. A. M.; Klinck, J. S.; Campbell, S. D.; McInnis, R.; Gillis, P. L.; de Solla, S. R., Toxicity and bioconcentration of the pharmaceuticals moxifloxacin, rosuvastatin, and drospirenone to the unionid mussel Lampsilis siliquoidea. Science of the Total Environment 2014, 487, 537-544.

79. Godoy, A. A.; Kummrow, F.; Pamplin, P. A. Z., Occurrence, ecotoxicological effects and risk assessment of antihypertensive pharmaceutical residues in the aquatic environment - A review. Chemosphere 2015, 138, (Supplement C), 281-291.

80. Golan-Rozen, N.; Chefetz, B.; Ben-Ari, J.; Geva, J.; Hadar, Y., Transformation of the recalcitrant pharmaceutical compound carbamazepine by Pleurotus ostreatus: Role of cytochrome P450 monooxygenase and manganese peroxidase. Environmental Science \& Technology 2011, 45, (16), 6800-6805.

81. Gomez-Toribio, V.; Garcia-Martin, A. B.; Martinez, M. J.; Martinez, A. T.; Guillen, F., Induction of extracellular hydroxyl radical production by white-rot fungi through quinone redox cycling. Applied and Environmental Microbiology 2009, 75, (12), 39443953.

82. Gotvajn, A. Z.; Zagorc-Koncan, J.; Tisler, T., Pretreatment of highly polluted pharmaceutical waste broth by wet air oxidation. Journal of Environmental Engineering 2007, 133, (1), 89-94. 
83. Gray, M. J.; Malati, M. A., Adsorption from aqueous solution by $\delta$-manganese dioxide II. Adsorption of some heavy metal cations. Journal of Chemical Technology and Biotechnology 1979, 29, (3), 135-144.

84. Grcic, I.; Papic, S.; Zizek, K.; Koprivanac, N., Zero-valent iron (ZVI) Fenton oxidation of reactive dye wastewater under UV-C and solar irradiation. Chemical Engineering Journal 2012, 195, 77-90.

85. Grebel, J. E.; Charbonnet, J. A.; Sedlak, D. L., Oxidation of organic contaminants by manganese oxide geomedia for passive urban stormwater treatment systems. Water Research 2016, 88, 481-491.

86. Gros, M.; Cruz-Morato, C.; Marco-Urrea, E.; Longrée, P.; Singer, H.; Sarrà, M.; Hollender, J.; Vicent, T.; Rodriguez-Mozaz, S.; Barceló, D., Biodegradation of the Xray contrast agent iopromide and the fluoroquinolone antibiotic ofloxacin by the white rot fungus Trametes versicolor in hospital wastewaters and identification of degradation products. Water Research 2014, 60, (Supplement C), 228-241.

87. Guan, X. H.; He, D.; Ma, J.; Chen, G. H., Application of permanganate in the oxidation of micropollutants: A mini review. Frontiers of Environmental Science \& Engineering in China 2010, 4, (4), 405-413.

88. Han, G. H.; Hur, H. G.; Kim, S. D., Ecotoxicological risk of pharmaceuticals from wastewater treatment plants in Korea: Occurrence and toxicity to Daphnia magna. Environmental Toxicology and Chemistry 2006, 25, (1), 265-271.

89. Han, Z. T.; Sani, B.; Akkanen, J.; Abel, S.; Nybom, I.; Karapanagioti, H. K.; Werner, D., A critical evaluation of magnetic activated carbon's potential for the remediation of sediment impacted by polycyclic aromatic hydrocarbons. Journal of Hazardous Materials 2015, 286, 41-47.

90. Hartmann, M.; Kullmann, S.; Keller, H., Wastewater treatment with heterogeneous Fenton-type catalysts based on porous materials. Journal of Materials Chemistry 2010, 20, (41), 9002-9017.

91. Hasan, Z.; Jeon, J.; Jhung, S. H., Adsorptive removal of naproxen and clofibric acid from water using metal-organic frameworks. Journal of Hazardous Materials 2012, 209, 151-157.

92. He, K.; Yin, Q.; Liu, A.; Echigo, S.; Itoh, S.; Wu, G., Enhanced anaerobic degradation of amide pharmaceuticals by dosing ferroferric oxide or anthraquinone-2, 6-disulfonate. Journal of Water Process Engineering 2017, 18, (Supplement C), 192-197.

93. He, Y.; Xu, J.; Zhang, Y.; Guo, C.; Li, L.; Wang, Y., Oxidative transformation of carbamazepine by manganese oxides. Environmental Science and Pollution Research 2012, 19, (9), 4206-4213.

94. He, Y. J.; Langenhoff, A. A. M.; Sutton, N. B.; Rijnaarts, H. H. M.; Blokland, M. H.; Chen, F. R.; Huber, C.; Schroder, P., Metabolism of ibuprofen by Phragmites australis: Uptake and phytodegradation. Environmental Science \& Technology 2017, 51, (8), 4576-4584.

95. He, Y. J.; Sutton, N. B.; Rijnaarts, H. H. H.; Langenhoff, A. A. M., Degradation of pharmaceuticals in wastewater using immobilized $\mathrm{TiO}_{2}$ photocatalysis under simulated solar irradiation. Applied Catalysis B: Environmental 2016, 182, 132-141. 
96. Hendratna, A. The application of $\mathrm{MnO}_{2}$ and $\mathrm{KMnO}_{4}$ for persistent organic compounds and COD removals in wastewater treatment process. KTH Royal Institute of Technology in Stockholm, Stockholm, 2011.

97. Hennebel, T.; De Gusseme, B.; Boon, N.; Verstraete, W., Biogenic metals in advanced water treatment. Trends in Biotechnology 2009, 27, (2), 90-98.

98. Ho, L.; Lambling, P.; Bustamante, H.; Duker, P.; Newcombe, G., Application of powdered activated carbon for the adsorption of cylindrospermopsin and microcystin toxins from drinking water supplies. Water Research 2011, 45, (9), 2954-2964.

99. Hosseini, A. M.; Tungler, A.; Bakos, V., Wet oxidation properties of process waste waters of fine chemical and pharmaceutical origin. Reaction Kinetics Mechanisms and Catalysis 2011, 103, (2), 251-260.

100. Hou, M. T.; Tang, Y.; Xu, J.; Pu, Y.; Lin, A. J.; Zhang, L. L.; Xiong, J. P.; Yang, X. J.; Wan, P. Y., Nitrate reduction in water by aluminum-iron alloy particles catalyzed by copper. Journal of Environmental Chemical Engineering 2015, 3, (4), 2401-2407.

101. Hu, L.; Martin, H. M.; Arcs-Bulted, O.; Sugihara, M. N.; Keatlng, K. A.; Strathmann, T. J., Oxidation of carbamazepine by Mn(VII) and Fe(VI): Reaction kinetics and mechanism. Environmental Science \& Technology 2009, 43, (2), 509-515.

102. Hu, L. H.; Martin, H. M.; Strathmann, T. J., Oxidation kinetics of antibiotics during water treatment with potassium permanganate. Environmental Science \& Technology 2010, 44, (16), 6416-6422.

103. Hu, L. H.; Stemig, A. M.; Wammer, K. H.; Strathmann, T. J., Oxidation of antibiotics during water treatment with potassium permanganate: Reaction pathways and deactivation. Environmental Science \& Technology 2011, 45, (8), 3635-3642.

104. Huang, Y. X.; Keller, A. A., Magnetic nanoparticle adsorbents for emerging organic contaminants. Acs Sustainable Chemistry \& Engineering 2013, 1, (7), 731-736.

105. Huber, M. M.; Canonica, S.; Park, G. Y.; Von Gunten, U., Oxidation of pharmaceuticals during ozonation and advanced oxidation processes. Environmental Science \& Technology 2003, 37, (5), 1016-1024.

106. Huerta-Fontela, M.; Galceran, M. T.; Ventura, F., Occurrence and removal of pharmaceuticals and hormones through drinking water treatment. Water Research 2011, $45,(3), 1432-1442$.

107. Hug, S. J.; Leupin, O., Iron-catalyzed oxidation of arsenic (III) by oxygen and by hydrogen peroxide: $\mathrm{pH}$-dependent formation of oxidants in the Fenton reaction. Environmental Science \& Technology 2003, 37, (12), 2734-2742.

108. Huguet, M.; Deborde, M.; Papot, S.; Gallard, H., Oxidative decarboxylation of diclofenac by manganese oxide bed filter. Water Research 2013, 47, (14), 5400-5408.

109. Huguet, M.; Simon, V.; Gallard, H., Transformation of paracetamol into 1,4benzoquinone by a manganese oxide bed filter. Journal of Hazardous Materials 2014, 271, 245-251.

110. Huo, S.-H.; Yan, X.-P., Metal-organic framework MIL-100 (Fe) for the adsorption of malachite green from aqueous solution. Journal of Materials Chemistry 2012, 22, (15), 7449-7455. 
111. Hussain, S.; Shaikh, S.; Farooqui, M., COD reduction of waste water streams of active pharmaceutical ingredient - Atenolol manufacturing unit by advanced oxidation-Fenton process. Journal of Saudi Chemical Society 2013, 17, (2), 199-202.

112. Ikehata, K.; El-Din, M. G., Aqueous pesticide degradation by hydrogen peroxide/ultraviolet irradiation and Fenton-type advanced oxidation processes: a review. Journal of Environmental Engineering and Science 2006, 5, (2), 81-135.

113. Ikehata, K.; Naghashkar, N. J.; Ei-Din, M. G., Degradation of aqueous pharmaceuticals by ozonation and advanced oxidation processes: A review. Ozone-Science \& Engineering 2006, 28, (6), 353-414.

114. Isarain-Chavez, E.; Arias, C.; Cabot, P. L.; Centellas, F.; Rodriguez, R. M.; Garrido, J. A.; Brillas, E., Mineralization of the drug beta-blocker atenolol by electro-Fenton and photoelectro-Fenton using an air-diffusion cathode for $\mathrm{H}_{2} \mathrm{O}_{2}$ electrogeneration combined with a carbon-felt cathode for $\mathrm{Fe}^{2+}$ regeneration. Applied Catalysis B: Environmental 2010, 96, (3-4), 361-369.

115. Jahn, M. K.; Haderlein, S. B.; Meckenstock, R. U., Anaerobic degradation of benzene, toluene, ethylbenzene, and o-xylene in sediment-free iron-reducing enrichment cultures. Applied and Environmental Microbiology 2005, 71, (6), 3355-3358.

116. Jain, A.; Ong, S. P.; Hautier, G.; Chen, W.; Richards, W. D.; Dacek, S.; Cholia, S.; Gunter, D.; Skinner, D.; Ceder, G.; Persson, K. A., The Materials Project: A materials genome approach to accelerating materials innovation. APL Materials 2013, 1, (1), 011002 .

117. Jamalluddin, N. A.; Abdullah, A. Z., Reactive dye degradation by combined $\mathrm{Fe}(\mathrm{III}) / \mathrm{TiO}_{2}$ catalyst and ultrasonic irradiation: Effect of $\mathrm{Fe}(\mathrm{III})$ loading and calcination temperature. Ultrasonics Sonochemistry 2011, 18, (2), 669-678.

118. Jelić, A.; Petrović, M.; Barceló, D., Pharmaceuticals in drinking water. In Emerging Organic Contaminants and Human Health, Barceló, D., Ed. Springer Berlin Heidelberg: Berlin, Heidelberg, 2012; pp 47-70.

119. Ji, Y. F.; Ferronato, C.; Salvador, A.; Yang, X.; Chovelon, J. M., Degradation of ciprofloxacin and sulfamethoxazole by ferrous-activated persulfate: Implications for remediation of groundwater contaminated by antibiotics. Science of the Total Environment 2014, 472, 800-808.

120. Jia, Y.; Aagaard, P.; Breedveld, G. D., Sorption of triazoles to soil and iron minerals. Chemosphere 2007, 67, (2), 250-258.

121. Jiang, J.-Q.; Zhou, Z.; Patibandla, S.; Shu, X., Pharmaceutical removal from wastewater by ferrate(VI) and preliminary effluent toxicity assessments by the zebrafish embryo model. Microchemical Journal 2013, 110, (Supplement C), 239-245.

122. Jiang, J. Q., Research progress in the use of ferrate (VI) for the environmental remediation. Journal of Hazardous Materials 2007, 146, (3), 617-623.

123. Jiang, J. Q., Advances in the development and application of ferrate(VI) for water and wastewater treatment. Journal of Chemical Technology and Biotechnology 2014, 89, (2), 165-177.

124. Jiang, J. Q.; Zhou, Z. W., Removal of pharmaceutical residues by ferrate (VI). Plos One 2013, $8,(2)$. 
125. Jiang, L. Y.; Chen, J. M.; Zhu, R. Y.; Huang, C.; Ji, H., Degradation kinetics and estrogenic activity of $17 \beta$-estradiol removal by aqueous manganese dioxide. Journal of Environmental Science and Health, Part A - Toxic/Hazardous Substances and Environmental Engineering 2010, 45, (8), 938-945.

126. Jiang, S.; Kim, D.-G.; Kim, J.; Ko, S.-O., Characterization of the biogenic manganese oxides produced by Pseudomonas putida strain MnB1. Environmental Engineering Research 2010, 15, (4), 183-190.

127. Jin, K.; Park, J.; Lee, J.; Yang, K. D.; Pradhan, G. K.; Sim, U.; Jeong, D.; Jang, H. L.; Park, S.; Kim, D.; Sung, N.-E.; Kim, S. H.; Han, S.; Nam, K. T., Hydrated manganese (II) phosphate $\left(\mathrm{Mn}_{3}\left(\mathrm{PO}_{4}\right)_{2} \cdot 3 \mathrm{H}_{2} \mathrm{O}\right)$ as a water oxidation catalyst. Journal of the American Chemical Society 2014, 136, (20), 7435-7443.

128. Johnson, A. C.; Dumont, E.; Williams, R. J.; Oldenkamp, R.; Cisowska, I.; Sumpter, J. P., Do concentrations of ethinylestradiol, estradiol, and diclofenac in European rivers exceed proposed EU environmental quality standards? Environmental Science \& Technology 2013, 47, (21), 12297-12304.

129. Jones, O. A.; Lester, J. N.; Voulvoulis, N., Pharmaceuticals: a threat to drinking water? Trends in Biotechnology 2005, 23, (4), 163-167.

130. Kagle, J.; Porter, A. W.; Murdoch, R. W.; Rivera-Cancel, G.; Hay, A. G., Chapter 3 Biodegradation of Pharmaceutical and Personal Care Products. In Advances in Applied Microbiology, Academic Press: 2009; Vol. 67, pp 65-108.

131. Kallel, M.; Belaid, C.; Mechichi, T.; Ksibi, M.; Elleuch, B., Removal of organic load and phenolic compounds from olive mill wastewater by Fenton oxidation with zerovalent iron. Chemical Engineering Journal 2009, 150, (2-3), 391-395.

132. Kang, K. H.; Dec, J.; Park, H.; Bollag, J. M., Effect of phenolic mediators and humic acid on cyprodinil transformation in presence of birnessite. Water Research 2004, 38, (11), 2737-2745.

133. Keenan, C. R.; Sedlak, D. L., Ligand-enhanced reactive oxidant generation by nanoparticulate zero-valent iron and oxygen. Environmental Science \& Technology 2008, 42, (18), 6936-6941.

134. Keller, A. A.; Garner, K.; Miller, R. J.; Lenihan, H. S., Toxicity of nano-zero valent iron to freshwater and marine organisms. Plos One 2012, 7, (8).

135. Khadse, G. K.; Patni, P. M.; Labhasetwar, P. K., Removal of iron and manganese from drinking water supply. Sustainable Water Resources Management 2015, 1, (2), 157-165.

136. Khan, N. A.; Hasan, Z.; Jhung, S. H., Adsorptive removal of hazardous materials using metal-organic frameworks (MOFs): A review. Journal of Hazardous Materials 2013, 244, 444-456.

137. Kharisov, B. I.; Dias, H. V. R.; Kharissova, O. V.; Jimenez-Perez, V. M.; Perez, B. O.; Flores, B. M., Iron-containing nanomaterials: synthesis, properties, and environmental applications. RSC Advances 2012, 2, (25), 9325-9358.

138. Khin, M. M.; Nair, A. S.; Babu, V. J.; Murugan, R.; Ramakrishna, S., A review on nanomaterials for environmental remediation. Energy \& Environmental Science 2012, $5,(8), 8075-8109$. 
139. Klavarioti, M.; Mantzavinos, D.; Kassinos, D., Removal of residual pharmaceuticals from aqueous systems by advanced oxidation processes. Environment International 2009, 35, (2), 402-417.

140. Kochi, J. K., Mechanisms of Organic Oxidation and Reduction by Metal Complexes. Science 1967, 155, (3761), 415-\&.

141. Komlos, J.; Kukkadapu, R. K.; Zachara, J. M.; Jaffe, P. R., Biostimulation of iron reduction and subsequent oxidation of sediment containing Fe-silicates and Fe-oxides: Effect of redox cycling on Fe(III) bioreduction. Water Research 2007, 41, (13), 29963004.

142. Kong, L. N.; Wei, W.; Zhao, Q. F.; Wang, J. Q.; Wan, Y., Active coordinatively unsaturated manganese monoxide-containing mesoporous carbon catalyst in wet peroxide oxidation. Acs Catalysis 2012, 2, (12), 2577-2586.

143. Kouraichi, R.; Delgado, J. J.; Lopez-Castro, J. D.; Stitou, M.; Rodriguez-Izquierdo, J. M.; Cauqui, M. A., Deactivation of $\mathrm{Pt} / \mathrm{MnOx}-\mathrm{CeO}_{2}$ catalysts for the catalytic wet oxidation of phenol: Formation of carbonaceous deposits and leaching of manganese. Catalysis Today 2010, 154, (3-4), 195-201.

144. Kouzbour, S.; El Azher, N.; Gourich, B.; Gros, F.; Vial, C.; Stiriba, Y., Removal of manganese (II) from drinking water by aeration process using an airlift reactor. Journal of Water Process Engineering 2017, 16, (Supplement C), 233-239.

145. Kowalski, K. P.; Sogaard, E. G., Implementation of zero-valent iron (ZVI) into drinking water supply - Role of the ZVI and biological processes. Chemosphere 2014, 117, 108114.

146. Kuan, W. H.; Hu, C. Y.; Liu, B. S.; Tzou, Y. M., Degradation of antibiotic amoxicillin using 1 x 1 molecular sieve-structured manganese oxide. Environmental Technology 2013, 34, (16), 2443-2451.

147. Kümmerer, K., Pharmaceuticals in the environment: Sources, fate, effects and risks. Springer: Berlin, 2004.

148. Küster, A.; Adler, N., Pharmaceuticals in the environment: scientific evidence of risks and its regulation. Philosophical Transactions of the Royal Society B: Biological Sciences 2014, 369, (1656).

149. la Farre, M.; Perez, S.; Kantiani, L.; Barcelo, D., Fate and toxicity of emerging pollutants, their metabolites and transformation products in the aquatic environment. Trac-Trends in Analytical Chemistry 2008, 27, (11), 991-1007.

150. Laine, D. F.; Blumenfeld, A.; Cheng, I. F., Mechanistic study of the ZEA organic pollutant degradation system: Evidence for $\mathrm{H}_{2} \mathrm{O}_{2}, \mathrm{HO} \cdot$ center dot, and the homogeneous activation of $\mathrm{O}_{2}$ by $\mathrm{Fe}^{\mathrm{II}}$ EDTA. Industrial \& Engineering Chemistry Research 2008, 47, (17), 6502-6508.

151. Langenhoff, A.; Inderfurth, N.; Veuskens, T.; Schraa, G.; Blokland, M.; KujawaRoeleveld, K.; Rijnaarts, H., Microbial removal of the pharmaceutical compounds ibuprofen and diclofenac from wastewater. Biomed Research International 2013.

152. Langenhoff, A. A. M.; BrouwersCeiler, D. L.; Engelberting, J. H. L.; Quist, J. J.; Wolkenfelt, J. G. P. N.; Zehnder, A. J. B.; Schraa, G., Microbial reduction of manganese coupled to toluene oxidation. Fems Microbiology Ecology 1997, 22, (2), 119-127. 
153. Langenhoff, A. A. M.; Zehnder, A. J. B.; Schraa, G., Behaviour of toluene, benzene and naphthalene under anaerobic conditions in sediment columns. Biodegradation 1996, 7, (3), 267-274.

154. Lee, C.; Kim, J. Y.; Lee, W. I.; Nelson, K. L.; Yoon, J.; Sedlak, D. L., Bactericidal effect of zero-valent iron nanoparticles on Escherichia coli. Environmental Science \& Technology 2008, 42, (13), 4927-4933.

155. Lee, Y.; Zimmermann, S. G.; Kieu, A. T.; von Gunten, U., Ferrate (Fe(VI)) application for municipal wastewater treatment: A novel process for simultaneous micropollutant oxidation and phosphate removal. Environmental Science \& Technology 2009, 43, (10), 3831-3838.

156. Leung, H. W.; Jin, L.; Wei, S.; Tsui, M. M. P.; Zhou, B.; Jiao, L.; Cheung, P. C.; Chun, Y. K.; Murphy, M. B.; Lam, P. K. S., Pharmaceuticals in tap water: human health risk assessment and proposed monitoring framework in China. Environmental Health Perspectives 2013, 121, (7), 839.

157. Levec, J.; Pintar, A., Catalytic wet-air oxidation processes: A review. Catalysis Today 2007, 124, (3-4), 172-184.

158. Li, L.; Fan, M. H.; Brown, R. C.; Van Leeuwen, J. H.; Wang, J. J.; Wang, W. H.; Song, Y. H.; Zhang, P. Y., Synthesis, properties, and environmental applications of nanoscale iron-based materials: A review. Critical Reviews in Environmental Science and Technology 2006, 36, (5), 405-431.

159. Li, S. L.; Wang, W.; Liu, Y. Y.; Zhang, W. X., Zero-valent iron nanoparticles (nZVI) for the treatment of smelting wastewater: A pilot-scale demonstration. Chemical Engineering Journal 2014, 254, 115-123.

160. Li, W.; Nanaboina, V.; Zhou, Q. X.; Korshin, G. V., Effects of Fenton treatment on the properties of effluent organic matter and their relationships with the degradation of pharmaceuticals and personal care products. Water Research 2012, 46, (2), 403-412.

161. Li, W. C., Occurrence, sources, and fate of pharmaceuticals in aquatic environment and soil. Environmental Pollution 2014, 187, (Supplement C), 193-201.

162. Li, X.; Hou, L.; Liu, M.; Zheng, Y.; Yin, G.; Lin, X.; Cheng, L.; Li, Y.; Hu, X., Evidence of nitrogen loss from anaerobic ammonium oxidation coupled with ferric iron reduction in an intertidal wetland. Environmental Science \& Technology 2015, 49, (19), 1156011568 .

163. Li, Y.; Wei, D.; Du, Y., Oxidative transformation of levofloxacin by $\delta-\mathrm{MnO}_{2}$ : Products, pathways and toxicity assessment. Chemosphere 2015, 119, (Supplement C), 282-288.

164. Li, Z.; Sobek, A.; Radke, M., Fate of pharmaceuticals and their transformation products in four small European rivers receiving treated wastewater. Environmental Science \& Technology 2016, 50, (11), 5614-5621.

165. Li, Z. H.; Fitzgerald, N. M.; Albert, Z.; Schnabl, A.; Jiang, W. T., Contrasting mechanisms of metoprolol uptake on kaolinite and talc. Chemical Engineering Journal 2015, 272, 48-57.

166. Lima, D. R. S.; Baêta, B. E. L.; Aquino, S. F.; Libânio, M.; Afonso, R. J. C. F., Removal of pharmaceuticals and endocrine disruptor compounds from natural waters by clarification associated with powdered activated carbon. Water, Air, \& Soil Pollution 2014, 225, (11), 2170. 
167. Lin, K.; Liu, W.; Gan, J., Oxidative removal of bisphenol A by manganese dioxide: Efficacy, products, and pathways. Environmental Science \& Technology 2009, 43, (10), 3860-3864.

168. Liu, C.; He, Y.; Li, F.; Wang, H., Preparation of poly ferric sulfate and the application in micro-polluted raw water treatment. Journal of the Chinese Advanced Materials Society 2013, 1, (3), 210-218.

169. Liu, W.; Langenhoff, A. A. M.; Sutton, N. B.; Rijnaarts, H. H. M., Application of manganese oxides under anoxic conditions to remove diclofenac from water. Submitted.

170. Liu, W.; Sutton, N. B.; Rijnaarts, H. H. M.; Langenhoff, A. A. M., Pharmaceutical removal from water with iron- or manganese-based technologies: A review. Critical Reviews in Environmental Science and Technology 2016, 46, (19-20), 1584-1621.

171. Liu, W.; Sutton, N. B.; Rijnaarts, H. H. M.; Langenhoff, A. A. M., Anaerobic biodegradation of pharmaceutical compounds coupled to dissimilatory manganese (IV) or iron (III) reduction. In preparation.

172. Liu, W.; Sutton, N. B.; Rijnaarts, H. H. M.; Langenhoff, A. A. M., Anoxic conditions are favourable for abiotic diclofenac removal from water with manganese oxides. Submitted.

173. Liu, X.; Wang, J.; Duan, L.; Song, Y.; Hu, X.; Wei, J., Enhancing the production of butyric acid from sludge fermentation with an emphasis on zinc, cobalt, cuprum, ferrum and manganese. Environmental Earth Sciences 2015, 73, (9), 5057-5066.

174. Lonappan, L.; Brar, S. K.; Das, R. K.; Verma, M.; Surampalli, R. Y., Diclofenac and its transformation products: Environmental occurrence and toxicity - A review. Environment International 2016, 96, 127-138.

175. Lovley, D., Dissimilatory $\mathrm{Fe}(\mathrm{III})$ - and $\mathrm{Mn}(\mathrm{IV})$-reducing prokaryotes. In The Prokaryotes: Prokaryotic Physiology and Biochemistry, Rosenberg, E.; DeLong, E. F.; Lory, S.; Stackebrandt, E.; Thompson, F., Eds. Springer Berlin Heidelberg: Berlin, Heidelberg, 2013; pp 287-308.

176. Lovley, D. R., Dissimilatory Fe(III) and Mn(IV) Reduction. Microbiological Reviews 1991, 55, (2), 259-287.

177. Lovley, D. R.; Holmes, D. E.; Nevin, K. P., Dissimilatory Fe(III) and Mn(IV) reduction. Advances in Microbial Physiology 2004, 49, 219-286.

178. Lovley, D. R.; Phillips, E. J. P., Organic matter mineralization with reduction of ferric iron in anaerobic sediments. Applied and Environmental Microbiology 1986, 51, (4), 683-689.

179. Lovley, D. R.; Phillips, E. J. P., Novel mode of microbial energymetabolism: Organic carbon oxidation coupled to dissimilatory reduction of iron or manganese. Applied and Environmental Microbiology 1988, 54, (6), 1472-1480.

180. Lu, L.; Li, J.; Yu, J.; Song, P.; Ng, D. H. L., A hierarchically porous $\mathrm{MgFe}_{2} \mathrm{O}_{4} / \gamma-\mathrm{Fe}_{2} \mathrm{O}_{3}$ magnetic microspheres for efficient removals of dye and pharmaceutical from water. Chemical Engineering Journal 2016, 283, (Supplement C), 524-534.

181. Lu, Y.; Hernandez, P.; Abegunde, D.; Edejer, T., The world medicines situation 2011. Medicine expenditures. World Health Organization, Geneva 2011.

182. Luo, Y. L.; Guo, W. S.; Ngo, H. H.; Nghiem, L. D.; Hai, F. I.; Zhang, J.; Liang, S.; Wang, 
X. C. C., A review on the occurrence of micropollutants in the aquatic environment and their fate and removal during wastewater treatment. Science of the Total Environment 2014, 473, 619-641.

183. Lv, A. H.; Hu, C.; Nie, Y. L.; Qu, J. H., Catalytic ozonation of toxic pollutants over magnetic cobalt and manganese co-doped gamma- $\mathrm{Fe}_{2} \mathrm{O}_{3}$. Applied Catalysis $B$ : Environmental 2010, 100, (1-2), 62-67.

184. Lv, A. H.; Hu, C.; Nie, Y. L.; Qu, J. H., Catalytic ozonation of toxic pollutants over magnetic cobalt-doped $\mathrm{Fe}_{3} \mathrm{O}_{4}$ suspensions. Applied Catalysis B: Environmental 2012, $117,246-252$.

185. Ma, J.; Sui, M. H.; Chen, Z. L.; Wang, L. N., Degradation of refractory organic pollutants by catalytic ozonation - Activated carbon and Mn-loaded activated carbon as catalysts. Ozone-Science \& Engineering 2004, 26, (1), 3-10.

186. Mackulak, T.; Mosný, M.; Grabic, R.; Golovko, O.; Koba, O.; Birošová, L., Fentonlike reaction: A possible way to efficiently remove illicit drugs and pharmaceuticals from wastewater. Environmental Toxicology and Pharmacology 2015, 39, (2), 483-488.

187. Madhavan, J.; Panneerselvam, S.; Anandan, S.; Zhou, M. F.; Grieser, F.; Ashokkumar, M., Ultrasound assisted photocatalytic degradation of diclofenac in an aqueous environment. Chemosphere 2010, 80, (7), 747-752.

188. Madras, G.; McCoy, B. J., Temperature effects during Ostwald ripening. Journal of Chemical Physics 2003, 119, (3), 1683-1693.

189. Maeng, S. K.; Choi, B. G.; Lee, K. T.; Song, K. G., Influences of solid retention time, nitrification and microbial activity on the attenuation of pharmaceuticals and estrogens in membrane bioreactors. Water Research 2013, 47, (9), 3151-3162.

190. Mahmoodi, N. M., Manganese ferrite nanoparticle: Synthesis, characterization, and photocatalytic dye degradation ability. Desalination and Water Treatment 2015, 53, (1), 84-90.

191. Mailler, R.; Gasperi, J.; Coquet, Y.; Deshayes, S.; Zedek, S.; Cren-Olive, C.; Cartiser, N.; Eudes, V.; Bressy, A.; Caupos, E.; Moilleron, R.; Chebbo, G.; Rocher, V., Study of a large scale powdered activated carbon pilot: Removals of a wide range of emerging and priority micropollutants from wastewater treatment plant effluents. Water Research 2015, 72, 315-330.

192. Marco-Urrea, E.; Perez-Trujillo, M.; Vicent, T.; Caminal, G., Ability of white-rot fungi to remove selected pharmaceuticals and identification of degradation products of ibuprofen by Trametes versicolor. Chemosphere 2009, 74, (6), 765-772.

193. Marco-Urrea, E.; Radjenovic, J.; Caminal, G.; Petrovic, M.; Vicent, T.; Barcelo, D., Oxidation of atenolol, propranolol, carbamazepine and clofibric acid by a biological Fenton-like system mediated by the white-rot fungus Trametes versicolor. Water Research 2010, 44, (2), 521-532.

194. Martin, J.; Camacho-Munoz, D.; Santos, J. L.; Aparicio, I.; Alonso, E., Occurrence of pharmaceutical compounds in wastewater and sludge from wastewater treatment plants: Removal and ecotoxicological impact of wastewater discharges and sludge disposal. Journal of Hazardous Materials 2012, 239, 40-47. 
195. Martins, R. C.; Cardoso, M.; Dantas, R. F.; Sans, C.; Esplugas, S.; Quinta-Ferreira, R. M., Catalytic studies for the abatement of emerging contaminants by ozonation. Journal of Chemical Technology and Biotechnology 2015, 90, (9), 1611-1618.

196. Maszkowska, J.; Stolte, S.; Kumirska, J.; Lukaszewicz, P.; Mioduszewska, K.; Puckowski, A.; Caban, M.; Wagil, M.; Stepnowski, P.; Bialk-Bielinska, A., Betablockers in the environment: Part I. Mobility and hydrolysis study. Science of the Total Environment 2014, 493, 1112-1121.

197. Maszkowska, J.; Stolte, S.; Kumirska, J.; Lukaszewicz, P.; Mioduszewska, K.; Puckowski, A.; Caban, M.; Wagil, M.; Stepnowski, P.; Bialk-Bielinska, A., Betablockers in the environment: Part II. Ecotoxicity study. Science of the Total Environment 2014, 493, 1122-1126.

198. Matamoros, V.; Hijosa, M.; Bayona, J. M., Assessment of the pharmaceutical active compounds removal in wastewater treatment systems at enantiomeric level. Ibuprofen and naproxen. Chemosphere 2009, 75, (2), 200-205.

199. Matilainen, A.; Vepsäläinen, M.; Sillanpää, M., Natural organic matter removal by coagulation during drinking water treatment: A review. Advances in Colloid and Interface Science 2010, 159, (2), 189-197.

200. Meerburg, F.; Hennebel, T.; Vanhaecke, L.; Verstraete, W.; Boon, N., Diclofenac and 2anilinophenylacetate degradation by combined activity of biogenic manganese oxides and silver. Microbial Biotechnology 2012, 5, (3), 388-395.

201. Melero, J. A.; Martinez, F.; Botas, J. A.; Molina, R.; Pariente, M. I., Heterogeneous catalytic wet peroxide oxidation systems for the treatment of an industrial pharmaceutical wastewater. Water Research 2009, 43, (16), 4010-4018.

202. Meng, Y. T.; Zheng, Y. M.; Zhang, L. M.; He, J. Z., Biogenic Mn oxides for effective adsorption of $\mathrm{Cd}$ from aquatic environment. Environmental Pollution 2009, 157, (8-9), 2577-2583.

203. Metcalf, L.; Eddy, H. P.; Tchobanoglous, G., Wastewater engineering: Treatment, disposal, and reuse. McGraw-Hill: New York, 2004.

204. Michael, I.; Hapeshi, E.; Michael, C.; Varela, A. R.; Kyriakou, S.; Manaia, C. M.; FattaKassinos, D., Solar photo-Fenton process on the abatement of antibiotics at a pilot scale: Degradation kinetics, ecotoxicity and phytotoxicity assessment and removal of antibiotic resistant enterococci. Water Research 2012, 46, (17), 5621-5634.

205. Mohapatra, D. P.; Brar, S. K.; Tyagi, R. D.; Picard, P.; Surampalli, R. Y., Analysis and advanced oxidation treatment of a persistent pharmaceutical compound in wastewater and wastewater sludge-carbamazepine. Science of the Total Environment 2014, 470, (Supplement C), 58-75.

206. Mohatt, J. L.; Hu, L. H.; Finneran, K. T.; Strathmann, T. J., Microbially mediated abiotic transformation of the antimicrobial agent sulfamethoxazole under iron-reducing soil conditions. Environmental Science \& Technology 2011, 45, (11), 4793-4801.

207. Monteiro, S. C.; Boxall, A. B., Occurrence and fate of human pharmaceuticals in the environment. Rev Environ Contam Toxicol 2010, 202, 53-154.

208. Murray, J. W., The surface chemistry of hydrous manganese dioxide. Journal of Colloid and Interface Science 1974, 46, (3), 357-371. 
209. Murray, J. W., The interaction of metal ions at the manganese dioxide-solution interface. Geochimica et Cosmochimica Acta 1975, 39, (4), 505-519.

210. Muter, O.; Plerkons, I.; Selga, T.; Berzins, A.; Gudra, D.; Radovica-Spalvina, I.; Fridmanis, D.; Bartkevics, V., Removal of pharmaceuticals from municipal wastewaters at laboratory scale by treatment with activated sludge and biostimulation. Science of the Total Environment 2017, 584, (Supplement C), 402-413.

211. Neta, P.; Huie, R. E.; Ross, A. B., Rate constants for reactions of inorganic radicals in aqueous solution. Journal of Physical and Chemical Reference Data 1988, 17, (3), $1027-1284$.

212. Neyens, E.; Baeyens, J., A review of classic Fenton's peroxidation as an advanced oxidation technique. Journal of Hazardous Materials 2003, 98, (1-3), 33-50.

213. Nfodzo, P.; Choi, H., Sulfate radicals destroy pharmaceuticals and personal care products. Environmental Engineering Science 2011, 28, (8), 605-609.

214. Ng, K. K.; Shi, X.; Ng, H. Y., Evaluation of system performance and microbial communities of a bioaugmented anaerobic membrane bioreactor treating pharmaceutical wastewater. Water Research 2015, 81, (Supplement C), 311-324.

215. Nielsen, J. L.; Nielsen, P. H., Microbial nitrate-dependent oxidation of ferrous iron in activated sludge. Environmental Science \& Technology 1998, 32, (22), 3556-3561.

216. Noubactep, C., Comments on "Sorption of triazoles to soil and iron minerals" by Y. Jia et al. [Chemosphere 67 (2007) 250-258]. Chemosphere 2008, 71, (4), 802-806.

217. Noubactep, C., A critical review on the process of contaminant removal in $\mathrm{Fe}^{0}-\mathrm{H}_{2} \mathrm{O}$ systems. Environmental Technology 2008, 29, (8), 909-920.

218. Noubactep, C., The fundamental mechanism of aqueous contaminant removal by metallic iron. Water $S a$ 2010, 36, (5), 663-670.

219. Oaks, J. L.; Gilbert, M.; Virani, M. Z.; Watson, R. T.; Meteyer, C. U.; Rideout, B. A.; Shivaprasad, H. L.; Ahmed, S.; Chaudhry, M. J. I.; Arshad, M.; Mahmood, S.; Ali, A.; Khan, A. A., Diclofenac residues as the cause of vulture population decline in Pakistan. Nature 2004, 427, (6975), 630-633.

220. Ociński, D.; Jacukowicz-Sobala, I.; Mazur, P.; Raczyk, J.; Kociołek-Balawejder, E., Water treatment residuals containing iron and manganese oxides for arsenic removal from water - Characterization of physicochemical properties and adsorption studies. Chemical Engineering Journal 2016, 294, (Supplement C), 210-221.

221. Ogier, J., Fenton process for contaminant control: Investigation of $\mathrm{OH}$ radical formation with two water types. KWR Watercycle Research Institute: Nieuwegein, 2008.

222. Olmez-Hanci, T.; Arslan-Alaton, I.; Dursun, D., Investigation of the toxicity of common oxidants used in advanced oxidation processes and their quenching agents. Journal of Hazardous Materials 2014, 278, 330-335.

223. Olvera-Vargas, H.; Oturan, N.; Brillas, E.; Buisson, D.; Esposito, G.; Oturan, M. A., Electrochemical advanced oxidation for cold incineration of the pharmaceutical ranitidine: Mineralization pathway and toxicity evolution. Chemosphere 2014, 117, 644-651. 
224. Olvera-Vargas, H.; Oturan, N.; Oturan, M. A.; Brillas, E., Electro-Fenton and solar photoelectro-Fenton treatments of the pharmaceutical ranitidine in pre-pilot flow plant scale. Separation and Purification Technology 2015, 146, 127-135.

225. Onesios, K. M.; Yu, J. T.; Bouwer, E. J., Biodegradation and removal of pharmaceuticals and personal care products in treatment systems: A review. Biodegradation 2009, 20, (4), 441-466.

226. Oulhote, Y.; Mergler, D.; Barbeau, B.; Bellinger, D. C.; Bouffard, T.; Brodeur, M. E.; Saint-Amour, D.; Legrand, M.; Sauve, S.; Bouchard, M. F., Neurobehavioral function in school-age children exposed to manganese in drinking water. Environmental Health Perspectives 2014, 122, (12), 1343-1350.

227. Ouvrard, S.; Simonnot, M.-O.; Sardin, M., Reactive behavior of natural manganese oxides toward the adsorption of phosphate and arsenate. Industrial \& Engineering Chemistry Research 2002, 41, (11), 2785-2791.

228. Pan, B. C.; Han, F. C.; Nie, G. Z.; Wu, B.; He, K.; Lu, L., New strategy to enhance phosphate removal from water by hydrous manganese oxide. Environmental Science \& Technology 2014, 48, (9), 5101-5107.

229. Pankow, J. F., Aquatic Chemistry Concepts. Taylor \& Francis: USA, 1991.

230. Pantelidou, N. A.; Theologides, C. P.; Olympiou, G. G.; Savva, P. G.; Vasquez, M. I.; Costa, C. N., Catalytic removal of pharmaceutical compounds in water medium under an $\mathrm{H}_{2}$ stream over various metal-supported catalysts: A promising process. Desalination and Water Treatment 2015, 53, (12), 3363-3370.

231. Park, H. S.; Koduru, J. R.; Choo, K. H.; Lee, B., Activated carbons impregnated with iron oxide nanoparticles for enhanced removal of bisphenol A and natural organic matter. Journal of Hazardous Materials 2015, 286, 315-324.

232. Park, W.; Nam, Y.-K.; Lee, M.-J.; Kim, T.-H., Anaerobic ammonia-oxidation coupled with $\mathrm{Fe}^{3+}$ reduction by an anaerobic culture from a piggery wastewater acclimated to $\mathrm{NH}_{4}{ }^{+} / \mathrm{Fe}^{3+}$ medium. Biotechnology and Bioprocess Engineering 2009, 14, (5), 680-685.

233. Parrella, A.; Lavorgna, M.; Criscuolo, E.; Russo, C.; Fiumano, V.; Isidori, M., Acute and chronic toxicity of six anticancer drugs on rotifers and crustaceans. Chemosphere 2014, 115, 59-66.

234. Paul, D.; Paul, K., Genotoxicity: A real concern of the pharmaceutical industry. World Journal of Pharmacy and Pharmaceutical Sciences 2014, 4, (2), 1124-1153.

235. Phenrat, T.; Long, T. C.; Lowry, G. V.; Veronesi, B., Partial oxidation ("aging") and surface modification decrease the toxicity of nanosized zerovalent iron. Environmental Science \& Technology 2009, 43, (1), 195-200.

236. Phillips, D. H.; Arlt, V. M., Genotoxicity: damage to DNA and its consequences. In Molecular, Clinical and Environmental Toxicology: Volume 1: Molecular Toxicology, Birkhäuser Basel: Basel, 2009; pp 87-110.

237. Piepenbrock, A.; Schröder, C.; Kappler, A., Electron transfer from humic substances to biogenic and abiogenic Fe(III) oxyhydroxide minerals. Environmental Science \& Technology 2014, 48, (3), 1656-1664.

238. Pignatello, J. J.; Oliveros, E.; MacKay, A., Advanced oxidation processes for organic contaminant destruction based on the Fenton reaction and related chemistry. Critical Reviews in Environmental Science and Technology 2006, 36, (1), 1-84. 
239. Postawa, A.; Hayes, C.; Criscuoli, A.; Macedonio, F.; Angelakis, A. N.; Rose, J. B.; Maier, A.; McAvoy, D. C., Best practice guide on the control of iron and manganese in water supply. IWA publishing: London, UK, 2013.

240. Pradyot, P., Preliminary separation methods. In Dean's analytical chemistry handbook, Second Edition, McGraw Hill: 2004.

241. Pruden, A.; Pei, R. T.; Storteboom, H.; Carlson, K. H., Antibiotic resistance genes as emerging contaminants: Studies in northern Colorado. Environmental Science \& Technology 2006, 40, (23), 7445-7450.

242. Qin, F.-X.; Jia, S.-Y.; Liu, Y.; Li, H.-Y.; Wu, S.-H., Adsorptive removal of bisphenol A from aqueous solution using metal-organic frameworks. Desalination and Water Treatment 2015, 54, (1), 93-102.

243. Quadra, G. R.; de Souza, H. O.; Costa, R. D.; Fernandez, M. A. D., Do pharmaceuticals reach and affect the aquatic ecosystems in Brazil? A critical review of current studies in a developing country. Environmental Science and Pollution Research 2017, 24, (2), 1200-1218.

244. Quinlivan, P. A.; Li, L.; Knappe, D. R. U., Effects of activated carbon characteristics on the simultaneous adsorption of aqueous organic micropollutants and natural organic matter. Water Research 2005, 39, (8), 1663-1673.

245. Rao, Y. F.; Qu, L.; Yang, H. S.; Chu, W., Degradation of carbamazepine by Fe(II)activated persulfate process. Journal of Hazardous Materials 2014, 268, 23-32.

246. Ratke, L.; Voorhees, P. W., Growth and coarsening: Ostwald ripening in material processing. Springer Science \& Business Media: Berlin, 2013.

247. Raychoudhury, T.; Scheytt, T., Potential of zerovalent iron nanoparticles for remediation of environmental organic contaminants in water: A review. Water Science and Technology 2013, 68, (7), 1425-1439.

248. Remucal, C. K.; Ginder-Vogel, M., A critical review of the reactivity of manganese oxides with organic contaminants. Environmental Science-Processes \& Impacts 2014, $16,(6), 1247-1266$.

249. Renou, S.; Thomas, J. S.; Aoustin, E.; Pons, M. N., Influence of impact assessment methods in wastewater treatment LCA. Journal of Cleaner Production 2008, 16, (10), 1098-1105.

250. Rentz, J. A.; Turner, I. P.; Ullman, J. L., Removal of phosphorus from solution using biogenic iron oxides. Water Research 2009, 43, (7), 2029-2035.

251. Rey, A.; Faraldos, M.; Casas, J. A.; Zazo, J. A.; Bahamonde, A.; Rodriguez, J. J., Catalytic wet peroxide oxidation of phenol over Fe/AC catalysts: Influence of iron precursor and activated carbon surface. Applied Catalysis B: Environmental 2009, 86, (1-2), 69-77.

252. Rice, E. W.; Bridgewater, L.; American Public Health Association; American Water Works Association; Water Environment Federation, Standard Methods for the Examination of Water and Wastewater, 22nd Edition. American Public Health Association: 2012.

253. Rijnaarts, H. H. M.; Norde, W.; Bouwer, E. J.; Lyklema, J.; Zehnder, A. J. B., Reversibility and mechanism of bacterial adhesion. Colloids and Surfaces B: Biointerfaces 1995, 4, (1), 5-22. 
254. Rijnaarts, H. H. M.; Norde, W.; Lyklema, J.; Zehnder, A. J. B., DLVO and steric contributions to bacterial deposition in media of different ionic strengths. Colloids and Surfaces B: Biointerfaces 1999, 14, (1-4), 179-195.

255. Rivera-Utrilla, J.; Sanchez-Polo, M.; Ferro-Garcia, M. A.; Prados-Joya, G.; OcampoPerez, R., Pharmaceuticals as emerging contaminants and their removal from water. A review. Chemosphere 2013, 93, (7), 1268-1287.

256. Rodriguez-Alvarez, T.; Rodil, R.; Quintana, J. B.; Trinanes, S.; Cela, R., Oxidation of non-steroidal anti-inflammatory drugs with aqueous permanganate. Water Research 2013, 47, (9), 3220-3230.

257. Rodríguez, R.; Espada, J. J.; Pariente, M. I.; Melero, J. A.; Martínez, F.; Molina, R., Comparative life cycle assessment (LCA) study of heterogeneous and homogenous Fenton processes for the treatment of pharmaceutical wastewater. Journal of Cleaner Production 2016, 124, (Supplement C), 21-29.

258. Roig, B., Pharmaceuticals in the environment: Current Knowledge and need assessment to reduce presence and impact. IWA Publishing: USA, 2010.

259. Ruamchat, T.; Hayashi, R.; Ngamprasertsith, S.; Oshima, Y., A novel on-site system for the treatment of pharmaceutical laboratory wastewater by supercritical water oxidation. Environmental sciences: an international journal of environmental physiology and toxicology 2005, 13, (5), 297-304.

260. Rubert, K. F.; Pedersen, J. A., Kinetics of oxytetracycline reaction with a hydrous manganese oxide. Environmental Science \& Technology 2006, 40, (23), 7216-7221.

261. Salas, E. C.; Berelson, W. M.; Hammond, D. E.; Kampf, A. R.; Nealson, K. H., The influence of carbon source on the products of dissimilatory iron reduction. Geomicrobiology Journal 2009, 26, (7), 451-462.

262. Samaras, V. G.; Stasinakis, A. S.; Thomaidis, N. S.; Mamais, D.; Lekkas, T. D., Fate of selected emerging micropollutants during mesophilic, thermophilic and temperature cophased anaerobic digestion of sewage sludge. Bioresource Technology 2014, 162, 365372.

263. Sanderson, H.; Brain, R. A.; Johnson, D. J.; Wilson, C. J.; Solomon, K. R., Toxicity classification and evaluation of four pharmaceuticals classes: antibiotics, antineoplastics, cardiovascular, and sex hormones. Toxicology 2004, 203, (1-3), 27-40.

264. Santiago, A. F. J.; Sousa, J. F.; Guedes, R. C.; Jeronimo, C. E. M.; Benachour, M., Kinetic and wet oxidation of phenol catalyzed by non-promoted and potassiumpromoted manganese/cerium oxide. Journal of Hazardous Materials 2006, 138, (2), 325-330.

265. Santosa, I.; Grossmana, M. J.; Sartorattob, A.; Ponezib, A. N.; Durranta, L. R., Degradation of the recalcitrant pharmaceuticals carbamazepine and $17 \alpha-$ ethinylestradiol by ligninolytic fungi. Chemical Engineering 2012, 27, 169-174.

266. Sanz, J. L.; Köchling, T., Molecular biology techniques used in wastewater treatment: An overview. Process Biochemistry 2007, 42, (2), 119-133.

267. Sawayama, S., Possibility of anoxic ferric ammonium oxidation. Journal of Bioscience and Bioengineering 2006, 101, (1), 70-72. 
268. Schmidt, N.; Page, D.; Tiehm, A., Biodegradation of pharmaceuticals and endocrine disruptors with oxygen, nitrate, manganese (IV), iron (III) and sulfate as electron acceptors. Journal of Contaminant Hydrology 2017, 203, 62-69.

269. Schmoll, O.; Howard, G.; Chilton, J.; Chorus, I., Protecting groundwater for health: Managing the quality of drinking-water sources. IWA Publishing: UK, 2006.

270. Segura, Y.; Martinez, F.; Melero, J. A., Effective pharmaceutical wastewater degradation by Fenton oxidation with zero-valent iron. Applied Catalysis B: Environmental 2013, 136, 64-69.

271. Segura, Y.; Martinez, F.; Melero, J. A.; Fierro, J. L. G., Zero valent iron (ZVI) mediated Fenton degradation of industrial wastewater: Treatment performance and characterization of final composites. Chemical Engineering Journal 2015, 269, 298305.

272. Senko, J. M.; Dewers, T. A.; Krumholz, L. R., Effect of oxidation rate and Fe(II) state on microbial nitrate-dependent Fe(III) mineral formation. Applied and Environmental Microbiology 2005, 71, (11), 7172-7177.

273. Shah, N. S.; He, X. X.; Khan, H. M.; Khan, J. A.; O'Shea, K. E.; Boccelli, D. L.; Dionysiou, D. D., Efficient removal of endosulfan from aqueous solution by UVC/peroxides: A comparative study. Journal of Hazardous Materials 2013, 263, 584-592.

274. Sharma, V. K.; Kazama, F.; Jiangyong, H.; Ray, A. K., Ferrates (iron (VI) and iron (V)): environmentally friendly oxidants and disinfectants. Journal of water and health 2005, $3,(1), 45-58$.

275. Shemer, H.; Kunukcu, Y. K.; Linden, K. G., Degradation of the pharmaceutical metronidazole via UV, Fenton and photo-Fenton processes. Chemosphere 2006, 63, (2), 269-276.

276. Shin, J. Y.; Cheney, M. A., Abiotic transformation of atrazine in aqueous suspension of four synthetic manganese oxides. Colloids and Surfaces a-Physicochemical and Engineering Aspects 2004, 242, (1-3), 85-92.

277. Shirazi, E.; Torabian, A.; Nabi-Bidhendi, G., Carbamazepine removal from groundwater: Effectiveness of the $\mathrm{TiO}_{2} / \mathrm{UV}$, nanoparticulate zero-valent iron, and fenton (nZVI/ $\mathrm{H}_{2} \mathrm{O}_{2}$ ) processes. Clean-Soil Air Water 2013, 41, (11), 1062-1072.

278. Silverstein, R. M.; Webster, F. X.; Kiemle, D. J.; Bryce, D. L., Spectrometric identification of organic compounds. John wiley \& sons: USA, 2014.

279. Silvy, N. J., The Wildlife Techniques Manual. Johns Hopkins University Press: USA, 2012; Vol. 1.

280. Simazaki, D.; Kubota, R.; Suzuki, T.; Akiba, M.; Nishimura, T.; Kunikane, S., Occurrence of selected pharmaceuticals at drinking water purification plants in Japan and implications for human health. Water Research 2015, 76, 187-200.

281. Singh, K. K.; Senapati, K. K.; Borgohain, C.; Sarma, K. C., Newly developed $\mathrm{Fe}_{3} \mathrm{O}_{4}-$ $\mathrm{Cr}_{2} \mathrm{O}_{3}$ magnetic nanocomposite for photocatalytic decomposition of 4-chlorophenol in water. Journal of Environmental Sciences 2017, 52, 333-340.

282. Sires, I.; Garrido, J. A.; Rodriguez, R. M.; Brillas, E.; Oturan, N.; Oturan, M. A., Catalytic behavior of the $\mathrm{Fe}^{3+} / \mathrm{Fe}^{2+}$ system in the electro-Fenton degradation of the antimicrobial chlorophene. Applied Catalysis B: Environmental 2007, 72, (3-4), 382394. 
283. Snyder, R. D.; Green, J. W., A review of the genotoxicity of marketed pharmaceuticals. Mutation Research-Reviews 2001, 488, (2), 151-169.

284. Snyder, V. A.; Akaiwa, N.; Alkemper, J.; Voorhees, P. W., The influence of temperature gradients on Ostwald ripening. Metallurgical and Materials Transactions a-Physical Metallurgy and Materials Science 1999, 30, (9), 2341-2348.

285. Sousa, J. M.; Macedo, G.; Pedrosa, M.; Becerra-Castro, C.; Castro-Silva, S.; Pereira, M. F. R.; Silva, A. M. T.; Nunes, O. C.; Manaia, C. M., Ozonation and UV $254 \mathrm{~nm}$ radiation for the removal of microorganisms and antibiotic resistance genes from urban wastewater. Journal of Hazardous Materials 2017, 323, (Part A), 434-441.

286. Spasiano, D.; Marotta, R.; Di Somma, I.; Andreozzi, R.; Caprio, V., Fe(III)photocatalytic partial oxidation of benzyl alcohol to benzaldehyde under UV-solar simulated radiation. Photochemical \& Photobiological Sciences 2013, 12, (11), 19912000.

287. Srinivasan, R.; Sorial, G. A., Treatment of taste and odor causing compounds 2-methyl isoborneol and geosmin in drinking water: A critical review. Journal of Environmental Sciences 2011, 23, (1), 1-13.

288. Stabnikov, V. P.; Tay, S. T. L.; Tay, D. K.; Ivanov, V. N., Effect of iron hydroxide on phosphate removal during anaerobic digestion of activated sludge. Applied Biochemistry and Microbiology 2004, 40, (4), 376-380.

289. Stadler, L. B.; Su, L. J.; Moline, C. J.; Ernstoff, A. S.; Aga, D. S.; Love, N. G., Effect of redox conditions on pharmaceutical loss during biological wastewater treatment using sequencing batch reactors. Journal of Hazardous Materials 2015, 282, 106-115.

290. Stasinakis, A. S., Review on the fate of emerging contaminants during sludge anaerobic digestion. Bioresource Technology 2012, 121, 432-440.

291. Straub, K. L.; Benz, M.; Schink, B., Iron metabolism in anoxic environments at near neutral pH. Fems Microbiology Ecology 2001, 34, (3), 181-186.

292. Straub, K. L.; Benz, M.; Schink, B.; Widdel, F., Anaerobic, nitrate-dependent microbial oxidation of ferrous iron. Applied and Environmental Microbiology 1996, 62, (4), 14581460.

293. Stroes-Gascoyne, S.; Kramer, J. R.; Snodgrass, W. J., Preparation, characterization and aging of $\delta-\mathrm{MnO}_{2}$, for use in trace metal speciation studies. Applied Geochemistry 1987, 2, (2), 217-226.

294. Stumm, W.; Morgan, J. J., Aquatic chemistry: Chemical equilibria and rates in natural waters. John Wiley \& Sons: Hoboken, NJ, 2013; Vol. 105.

295. Su, J.; Deng, L.; Huang, L.; Guo, S.; Liu, F.; He, J., Catalytic oxidation of manganese (II) by multicopper oxidase $\mathrm{CueO}$ and characterization of the biogenic Mn oxide. Water Research 2014, 56, (Supplement C), 304-313.

296. Sui, M. H.; Xing, S. C.; Sheng, L.; Huang, S. H.; Guo, H. G., Heterogeneous catalytic ozonation of ciprofloxacin in water with carbon nanotube supported manganese oxides as catalyst. Journal of Hazardous Materials 2012, 227, 227-236.

297. Sui, Q.; Cao, X.; Lu, S.; Zhao, W.; Qiu, Z.; Yu, G., Occurrence, sources and fate of pharmaceuticals and personal care products in the groundwater: A review. Emerging Contaminants 2015, 1, (1), 14-24. 
298. Sun, J.; Luo, Q.; Wang, D. H.; Wang, Z. J., Occurrences of pharmaceuticals in drinking water sources of major river watersheds, China. Ecotoxicology and Environmental Safety 2015, 117, 132-140.

299. Tan, W. F.; Lu, S. J.; Liu, F.; Feng, X. H.; He, J. Z.; Koopall, L. K., Determination of the point-of-zero, charge of manganese oxides with different methods including an improved salt titration method. Soil Science 2008, 173, (4), 277-286.

300. Taylor, K. M. L.; Rieter, W. J.; Lin, W. B., Manganese-based nanoscale metal-organic frameworks for magnetic resonance imaging. Journal of the American Chemical Society 2008, 130, (44), 14358-+.

301. Tebo, B. M.; Bargar, J. R.; Clement, B. G.; Dick, G. J.; Murray, K. J.; Parker, D.; Verity, R.; Webb, S. M., Biogenic manganese oxides: Properties and mechanisms of formation. Annual Review of Earth and Planetary Sciences 2004, 32, 287-328.

302. Tekin, H.; Bilkay, O.; Ataberk, S. S.; Balta, T. H.; Ceribasi, I. H.; Sanin, F. D.; Dilek, F. B.; Yetis, U., Use of Fenton oxidation to improve the biodegradability of a pharmaceutical wastewater. Journal of Hazardous Materials 2006, 136, (2), 258-265.

303. Ternes, T.; Joss, A.; Oehlmann, J., Occurrence, fate, removal and assessment of emerging contaminants in water in the water cycle (from wastewater to drinking water). Water Research 2015, 72, 1-2.

304. Tiedeken, E. J.; Tahar, A.; McHugh, B.; Rowan, N. J., Monitoring, sources, receptors, and control measures for three European Union watch list substances of emerging concern in receiving waters - A 20 year systematic review. Science of the Total Environment 2017, 574, 1140-1163.

305. Tiwari, D.; Lee, S.-M., Ferrate (VI) in the treatment of wastewaters: A new generation green chemical. In Waste Water-Treatment and Reutilization, Einschlag, F. S. n. G., Ed. InTech: Available from: http://www.intechopen.com/books/waste-watertreatment-andreutilization/ferrate-vi-in-the-treatment-of-wastewaters-a-new-generation-greenchemical, 2011.

306. Tixier, C.; Singer, H. P.; Oellers, S.; Muller, S. R., Occurrence and fate of carbamazepine, clofibric acid, diclofenac, ibuprofen, ketoprofen, and naproxen in surface waters. Environmental Science \& Technology 2003, 37, (6), 1061-1068.

307. Tobiason, J. E.; Bazilio, A.; Goodwill, J.; Mai, X.; Nguyen, C., Manganese removal from drinking water sources. Current Pollution Reports 2016, 2, (3), 168-177.

308. Todd, P. A.; Sorkin, E. M., Diclofenac Sodium - a Reappraisal of Its Pharmacodynamic and Pharmacokinetic Properties, and Therapeutic Efficacy. Drugs 1988, 35, (3), 244285.

309. Tong, A. Y. C.; Braund, R.; Warren, D. S.; Peake, B. M., TiO2-assisted photodegradation of pharmaceuticals - A review. Central European Journal of Chemistry 2012, 10, (4), 989-1027.

310. Tratnyek, P. G.; Johnson, R. L., Nanotechnologies for environmental cleanup. Nano Today 2006, 1, (2), 44-48.

311. Trovo, A. G.; Nogueira, R. F. P.; Aguera, A.; Fernandez-Alba, A. R.; Sirtori, C.; Malato, S., Degradation of sulfamethoxazole in water by solar photo-Fenton. Chemical and toxicological evaluation. Water Research 2009, 43, (16), 3922-3931. 
312. Tu, J. J.; Yang, Z. D.; Hu, C.; Qu, J. H., Characterization and reactivity of biogenic manganese oxides for ciprofloxacin oxidation. Journal of Environmental Sciences 2014, 26, (5), 1154-1161.

313. Ukrainczyk, L.; Mcbride, M. B., Oxidation of phenol in acidic aqueous suspensions of manganese oxides. Clays and Clay Minerals 1992, 40, (2), 157-166.

314. US Environmental Protection Agency Contaminant Candidate List 3 - CCL 3. Retrieved from http://www2.epa.gov/ccl/contaminant-candidate-list-3-ccl-3\#maincontent (November 10),

315. Üzüm, Ç.; Shahwan, T.; Eroğlu, A. E.; Hallam, K. R.; Scott, T. B.; Lieberwirth, I., Synthesis and characterization of kaolinite-supported zero-valent iron nanoparticles and their application for the removal of aqueous $\mathrm{Cu}^{2+}$ and $\mathrm{Co}^{2+}$ ions. Applied Clay Science 2009, 43, (2), 172-181.

316. Veloutsou, S.; Bizani, E.; Fytianos, K., Photo-Fenton decomposition of beta-blockers atenolol and metoprolol; study and optimization of system parameters and identification of intermediates. Chemosphere 2014, 107, 180-186.

317. Verlicchi, P.; Al Aukidy, M.; Zambello, E., Occurrence of pharmaceutical compounds in urban wastewater: Removal, mass load and environmental risk after a secondary treatment-A review. Science of the Total Environment 2012, 429, (Supplement C), 123-155.

318. Verma, A. K.; Dash, R. R.; Bhunia, P., A review on chemical coagulation/flocculation technologies for removal of colour from textile wastewaters. Journal of Environmental Management 2012, 93, (1), 154-168.

319. Vieno, N.; Sillanpaa, M., Fate of diclofenac in municipal wastewater treatment plant A review. Environment International 2014, 69, 28-39.

320. Villacis-Garcia, M.; Villalobos, M.; Gutierrez-Ruiz, M., Optimizing the use of natural and synthetic magnetites with very small amounts of coarse $\mathrm{Fe}(0)$ particles for reduction of aqueous Cr(VI). Journal of Hazardous Materials 2015, 281, 77-86.

321. Villalobos, M.; Sposito, G.; Bargar, J. R., $\mathrm{Pb}$ (II) reactivity on a biogenic Mn oxide: Evidence of inner-sphere bonding at internal and external sites. Abstracts of Papers of the American Chemical Society 2004, 227, U1217-U1217.

322. Villalobos, M.; Toner, B.; Bargar, J.; Sposito, G., Characterization of the manganese oxide produced by Pseudomonas putida strain MnB1. Geochimica et Cosmochimica Acta 2003, 67, (14), 2649-2662.

323. Villatoro-Monzon, W. R.; Mesta-Howard, A. M.; Razo-Flores, E., Anaerobic biodegradation of BTEX using $\mathrm{Mn}(\mathrm{IV})$ and $\mathrm{Fe}(\mathrm{III})$ as alternative electron acceptors. Water Science and Technology 2003, 48, (6), 125-131.

324. Vogel, T. M.; Criddle, C. S.; Mccarty, P. L., Transformations of halogenated aliphatic compounds. Environmental Science \& Technology 1987, 21, (8), 722-736.

325. Wan, J.; Deng, H.; Shi, J.; Zhou, L.; Su, T., Synthesized magnetic manganese ferrite nanoparticles on activated carbon for sulfamethoxazole removal. Clean - Soil, Air, Water 2014, 42, (9), 1199-1207.

326. Wang, C. C.; Li, J. R.; Lv, X. L.; Zhang, Y. Q.; Guo, G. S., Photocatalytic organic pollutants degradation in metal-organic frameworks. Energy \& Environmental Science 2014, 7, (9), 2831-2867. 
327. Wang, H.; Yao, H.; Sun, P. Z.; Li, D. S.; Huang, C. H., Transformation of tetracycline antibiotics and $\mathrm{Fe}(\mathrm{II})$ and $\mathrm{Fe}(\mathrm{III})$ species induced by their complexation. Environmental Science \& Technology 2016, 50, (1), 145-153.

328. Wang, H.; Yao, H.; Sun, P. Z.; Pei, J.; Li, D. S.; Huang, C. H., Oxidation of tetracycline antibiotics induced by Fe(III) ions without light irradiation. Chemosphere 2015, 119, 1255-1261.

329. Wang, J.; Sun, W.; Zhang, Z. H.; Jiang, Z.; Wang, X. F.; Xu, R.; Li, R. H.; Zhang, X. D., Preparation of Fe-doped mixed crystal $\mathrm{TiO}_{2}$ catalyst and investigation of its sonocatalytic activity during degradation of azo fuchsine under ultrasonic irradiation. Journal of Colloid and Interface Science 2008, 320, (1), 202-209.

330. Wang, J.; Wang, S., Removal of pharmaceuticals and personal care products (PPCPs) from wastewater: A review. Journal of Environmental Management 2016, 182, (Supplement C), 620-640.

331. Wang, P.; Shi, Q. H.; Shi, Y. F.; Clark, K. K.; Stucky, G. D.; Keller, A. A., Magnetic permanently confined micelle arrays for treating hydrophobic organic compound contamination. Journal of the American Chemical Society 2009, 131, (1), 182-188.

332. Wang, S. B.; Wang, X. C., Multifunctional metal-organic frameworks for photocatalysis. Small 2015, 11, (26), 3097-3112.

333. Wang, Y. Q.; Cheng, R. M.; Wen, Z.; Zhao, L. J., Synthesis and characterization of single-crystalline $\mathrm{MnFe}_{2} \mathrm{O}_{4}$ ferrite nanocrystals and their possible application in water treatment. European Journal of Inorganic Chemistry 2011, (19), 2942-2947.

334. Watts, R. J.; Sarasa, J.; Loge, F. J.; Teel, A. L., Oxidative and reductive pathways in manganese-catalyzed Fenton's reactions. Journal of Environmental Engineering 2005, $131,(1), 158-164$.

335. Weelink, S. A. B.; van Doesburg, W.; Saia, F. T.; Rijpstra, W. I. C.; Roling, W. F. M.; Smidt, H.; Stams, A. J. M., A strictly anaerobic betaproteobacterium Georgfuchsia toluolica gen. nov., sp nov degrades aromatic compounds with $\mathrm{Fe}(\mathrm{III}), \mathrm{Mn}(\mathrm{IV})$ or nitrate as an electron acceptor. Fems Microbiology Ecology 2009, 70, (3), 575-585.

336. Wei, H.; Hu, D.; Su, J.; Li, K. B., Intensification of levofloxacin sono-degradation in a $\mathrm{US} / \mathrm{H}_{2} \mathrm{O}_{2}$ system with $\mathrm{Fe}_{3} \mathrm{O}_{4}$ magnetic nanoparticles. Chinese Journal of Chemical Engineering 2015, 23, (1), 296-302.

337. Wen, X. H.; Jia, Y. N.; Li, J. X., Enzymatic degradation of tetracycline and oxytetracycline by crude manganese peroxidase prepared from Phanerochaete chrysosporium. Journal of Hazardous Materials 2010, 177, (1-3), 924-928.

338. Wilde, M. L.; Mahmoud, W. M. M.; Kümmerer, K.; Martins, A. F., Oxidationcoagulation of $\beta$-blockers by $\mathrm{K}_{2} \mathrm{Fe}^{\mathrm{VI}} \mathrm{O}_{4}$ in hospital wastewater: Assessment of degradation products and biodegradability. Science of the Total Environment 2013, 452, (Supplement C), 137-147.

339. Wilt, A. d.; He, Y.; Sutton, N. B.; Langenhoff, A. A. M.; Rijnaarts, H. H. M., Sorption and biodegradation of six pharmaceutically active compounds under four different redox conditions. Submitted.

340. World Health Organization, Calcium and magnesium in drinking-water: Public health significance. World Health Organization: Spain, 2009. 
341. World Health Organization, Guidelines for drinking-water quality - 4th Edition. IWA Publishing: Malta, 2011.

342. World Health Organization, Pharmaceuticals in drinking-water. WHO Press: Switzerland, 2012.

343. World Health Organization, Antimicrobial resistance: global report on surveillance. World Health Organization: France, 2014.

344. Xia, S. Q.; Gu, Z. L.; Zhang, Z. Q.; Zhang, J.; Hermanowicz, S. W., Removal of chloramphenicol from aqueous solution by nanoscale zero-valent iron particles. Chemical Engineering Journal 2014, 257, 98-104.

345. Xing, Z. P.; Sun, D. Z., Treatment of antibiotic fermentation wastewater by combined polyferric sulfate coagulation, Fenton and sedimentation process. Journal of Hazardous Materials 2009, 168, (2-3), 1264-1268.

346. Xu, L.; Xu, C.; Zhao, M. R.; Qiu, Y. P.; Sheng, G. D., Oxidative removal of aqueous steroid estrogens by manganese oxides. Water Research 2008, 42, (20), 5038-5044.

347. Yan, J. C.; Lei, M.; Zhu, L. H.; Anjum, M. N.; Zou, J.; Tang, H. Q., Degradation of sulfamonomethoxine with $\mathrm{Fe}_{3} \mathrm{O}_{4}$ magnetic nanoparticles as heterogeneous activator of persulfate. Journal of Hazardous Materials 2011, 186, (2-3), 1398-1404.

348. Yan, Q.; Gao, X.; Chen, Y. P.; Peng, X. Y.; Zhang, Y. X.; Gan, X. M.; Zi, C. F.; Guo, J. S., Occurrence, fate and ecotoxicological assessment of pharmaceutically active compounds in wastewater and sludge from wastewater treatment plants in Chongqing, the Three Gorges Reservoir Area. Science of the Total Environment 2014, 470, 618-630.

349. Yang, B.; Ying, G. G.; Zhao, J. L.; Liu, S.; Zhou, L. J.; Chen, F., Removal of selected endocrine disrupting chemicals (EDCs) and pharmaceuticals and personal care products (PPCPs) during ferrate(VI) treatment of secondary wastewater effluents. Water Research 2012, 46, (7), 2194-2204.

350. Yang, L.; Hu, C.; Nie, Y. L.; Qu, J. H., Catalytic ozonation of selected pharmaceuticals over mesoporous alumina-supported manganese oxide. Environmental Science \& Technology 2009, 43, (7), 2525-2529.

351. Yang, Y.; Ok, Y. S.; Kim, K.-H.; Kwon, E. E.; Tsang, Y. F., Occurrences and removal of pharmaceuticals and personal care products (PPCPs) in drinking water and water/sewage treatment plants: A review. Science of the Total Environment 2017, 596, (Supplement C), 303-320.

352. Yao, W. S.; Millero, F. J., Adsorption of phosphate on manganese dioxide in seawater. Environmental Science \& Technology 1996, 30, (2), 536-541.

353. Yao, Y. J.; Cai, Y. M.; Lu, F.; Wei, F. Y.; Wang, X. Y.; Wang, S. B., Magnetic recoverable $\mathrm{MnFe}_{2} \mathrm{O}_{4}$ and $\mathrm{MnFe}_{2} \mathrm{O}_{4}$-graphene hybrid as heterogeneous catalysts of peroxymonosulfate activation for efficient degradation of aqueous organic pollutants. Journal of Hazardous Materials 2014, 270, 61-70.

354. Ye, Y.; Feng, Y.; Bruning, H.; Yntema, D.; Rijnaarts, H. H. M., Photocatalytic degradation of metoprolol by $\mathrm{TiO}_{2}$ nanotube arrays and UV-LED: Effects of catalyst properties, operational parameters, commonly present water constituents, and photoinduced reactive species. Applied Catalysis B: Environmental 2018, 220, (Supplement C), 171-181. 
355. Zelmanov, G.; Semiat, R., Iron (3) oxide-based nanoparticles as catalysts in advanced organic aqueous oxidation. Water Research 2008, 42, (1), 492-498.

356. Zelmanov, G.; Semiat, R., Iron $(2,3)$ oxides based nano-particles as catalysts in advanced organic aqueous oxidation. Desalination and Water Treatment 2009, 6, (1-3), 190-191.

357. Zhan, W.; Wang, X. C.; Li, D. S.; Ren, Y. Z.; Liu, D. Q.; Kang, J. X., Catalytic wet air oxidation of high concentration pharmaceutical wastewater. Water Science and Technology 2013, 67, (10), 2281-2286.

358. Zhang, H.; Huang, C. H., Adsorption and oxidation of fluoroquinolone antibacterial agents and structurally related amines with goethite. Chemosphere 2007, 66, (8), 15021512 .

359. Zhang, H. C.; Chen, W. R.; Huang, C. H., Kinetic modeling of oxidation of antibacterial agents by manganese oxide. Environmental Science \& Technology 2008, 42, (15), 55485554 .

360. Zhang, H. C.; Huang, C. H., Oxidative transformation of triclosan and chlorophene by manganese oxides. Environmental Science \& Technology 2003, 37, (11), 2421-2430.

361. Zhang, H. C.; Huang, C. H., Oxidative transformation of fluoroquinolone antibacterial agents and structurally related amines by manganese oxide. Environmental Science \& Technology 2005, 39, (12), 4474-4483.

362. Zhang, H. C.; Huang, C. H., Reactivity and transformation of antibacterial N-oxides in the presence of manganese oxide. Environmental Science \& Technology 2005, 39, (2), 593-601.

363. Zhang, L.; Hendrickx, T. L. G.; Kampman, C.; Temmink, H.; Zeeman, G., Co-digestion to support low temperature anaerobic pretreatment of municipal sewage in a UASBdigester. Bioresource Technology 2013, 148, (Supplement C), 560-566.

364. Zhang, L.; Hu, J.; Zhu, R.; Zhou, Q.; Chen, J., Degradation of paracetamol by pure bacterial cultures and their microbial consortium. Applied Microbiology and Biotechnology 2013, 97, (8), 3687-3698.

365. Zhang, L. L.; Tu, J. J.; Lyu, L.; Hu, C., Enhanced catalytic degradation of ciprofloxacin over Ce-doped OMS-2 microspheres. Applied Catalysis B: Environmental 2016, 181, 561-569.

366. Zhang, M.; Zheng, P.; Li, W.; Wang, R.; Ding, S.; Abbas, G., Performance of nitratedependent anaerobic ferrous oxidizing (NAFO) process: A novel prospective technology for autotrophic denitrification. Bioresource Technology 2015, 179, 543-548.

367. Zhang, W.; Huang, M.-h.; Qi, F.-f.; Sun, P.-z.; Van Ginkel, S. W., Effect of trace tetracycline concentrations on the structure of a microbial community and the development of tetracycline resistance genes in sequencing batch reactors. Bioresource Technology 2013, 150, (Supplement C), 9-14.

368. Zhang, Y.; Yang, Y.; Zhang, Y.; Zhang, T.; Ye, M., Heterogeneous oxidation of naproxen in the presence of $\alpha-\mathrm{MnO}_{2}$ nanostructures with different morphologies. Applied Catalysis B: Environmental 2012, 127, (Supplement C), 182-189.

369. Zhang, Y. J.; Geissen, S. U.; Gal, C., Carbamazepine and diclofenac: Removal in wastewater treatment plants and occurrence in water bodies. Chemosphere 2008, 73, (8), 1151-1161. 
370. Zhao, H.; Cui, H.-J.; Fu, M.-L., Synthesis of core-shell structured $\mathrm{Fe}_{3} \mathrm{O}_{4} @ \alpha-\mathrm{MnO}_{2}$ microspheres for efficient catalytic degradation of ciprofloxacin. RSC Advances 2014, 4, (74), 39472-39475.

371. Zheng, Y. In Pretreatment of pharmaceutical wastewater by catalytic wet air oxidation (CWAO), Water Resource and Environmental Protection (ISWREP), 2011 International Symposium, IEEE: 2011; pp 1316-1318.

372. Zhou, G.-W.; Yang, X.-R.; Li, H.; Marshall, C. W.; Zheng, B.-X.; Yan, Y.; Su, J.-Q.; Zhu, Y.-G., Electron shuttles enhance anaerobic ammonium oxidation coupled to iron (III) reduction. Environmental Science \& Technology 2016, 50, (17), 9298-9307.

373. Zhou, M. H.; Yu, J. G.; Cheng, B., Effects of Fe-doping on the photocatalytic activity of mesoporous $\mathrm{TiO}_{2}$ powders prepared by an ultrasonic method. Journal of Hazardous Materials 2006, 137, (3), 1838-1847.

374. Zhou, N. A.; Lutovsky, A. C.; Andaker, G. L.; Ferguson, J. F.; Gough, H. L., Kinetics modeling predicts bioaugmentation with Sphingomonad cultures as a viable technology for enhanced pharmaceutical and personal care products removal during wastewater treatment. Bioresource Technology 2014, 166, (Supplement C), 158-167.

375. Zhou, T.; Lim, T. T.; Li, Y. Z.; Lu, X. H.; Wong, F. S., The role and fate of EDTA in ultrasound-enhanced zero-valent iron/air system. Chemosphere 2010, 78, (5), 576-582.

376. Zhou, Y. M.; Gao, B.; Zimmerman, A. R.; Chen, H.; Zhang, M.; Cao, X. D., Biocharsupported zerovalent iron for removal of various contaminants from aqueous solutions. Bioresource Technology 2014, 152, 538-542.

377. Zhu, W.; Nan, Y.; Huang, T.; Wu, F., The mechanism, thermodynamic and kinetic characteristics of the microbial reduction of goethite mediated by anthraquinone-2sulfonate. Geomicrobiology Journal 2013, 30, (10), 928-940.

378. Zou, L. Y.; Li, Y.; Hung, Y.-T., Wet air oxidation for waste treatment. In Advanced Physicochemical Treatment Technologies, Humana Press: Totowa, NJ, 2007; pp 575610.

379. Zouboulis, A. I.; Moussas, P. A.; Vasilakou, E., Polyferric sulphate: Preparation, characterisation and application in coagulation experiments. Journal of Hazardous Materials 2008, 155, (3), 459-468. 
Appendices 


\section{摘要}

水体中的药品残留物主要来自于制药工业和公众的日常使用。这 种污染物在地表水, 地下水, 城市污水和饮用水中以极低的浓度存 在。目前, 已经有水中药品残留物及其代谢产物不利影响的研究, 包 括对人类和生态系统的毒性，以及耐药性。为了防止这些不利的影 响, 需要通过各种技术手段去除水体中的药品残留物, 包括使用在有 氧气存在（好氧）和没有氧气存在（厌氧）环境下的非生物去除和生 物降解技术。厌氧技术通常更具有可持续性和吸引力, 因为这些技术 与好氧技术相比能耗更低, 产生的诸如温室气体等的污染物更少。利 用锰和铁的厌氧降解技术在饮用水处理和污水处理过程中具有明显的 优势。研究利用锰和铁的厌氧技术去除水中的药品残留物, 并将其发 展成一项水处理工艺很有前景。本论文研究了利用锰和铁处理水中药 品残留物的厌氧技术，包括生物降解和非生物去除。论文第一章主要 阐述了本论文研究的必要性和动机。

论文第二章对能够去除水中药品残留物的与锰和铁相关的技术进 行了回顾。根据出去机理, 这些技术被分为了 3 类: 物理化学技术, 化学技术, 以及生物相关技术。之前的研究表明, 利用锰和铁的相关 技术能够高效的除去水中的药品残留物, 去除效率因技术而异。之后 我对各项技术的非特异性、处理条件、产生的中间产物和副产物以及 含锰和铁的化合物的影响进行比较, 对于这些技术的优缺点进行了评 估。第二章还介绍了一些能够在将来用于药品残留物去除的新兴锰和 铁相关技术。其中异化锰铁还原技术因其的运行条件接近自然条件, 并且最终能够将污染物完全矿化等优势, 而成为极具吸引力, 可持续 性, 以及低成本的药品残留物处理技术。

论文第三章主要研究了利用异化金属还原出去药品的厌氧生物降 解, 以及不同类型的锰和铁对药品生物降解的影响。此研究中使用的 微生物是经过美特普洛和化学方法制备的四价锰驯化的底泥混合物。 这些微生物能够在 42 天内利用化学制备的无定形态的四价锰去除 $26 \%$ 的咖啡因和 $52 \%$ 的萗普生。此外, 这些微生物还能利用给水厂产 生的四价锰。经过 196 天的培养，这些微生物能够去除 $96 \%$ 的美特普 
洛和 31\%的普荎洛尔。这些微生物同样能够利用三价铁作为电子受体 去除美特普洛。实验结果表明这些微生物利用不可溶性的化学制备的 三价铁和可溶性的柠檬酸铁取得 $57 \%$ 和 52\%的去除率。在整个研究 过程中, 所有实验的非生物对照组都没有明显的药品残留物的去除, 这表明生物降解是利用异化金属还原出去药品厌氧技术的主要机理。

论文第四章比较了好氧环境和厌氧环境对于利用二氧化锰出去药 品残留物的影响。结果表明厌氧环境能够促进双氯芬酸的去除, 但却 会抑制美特普洛和普萗洛尔的去除。在纯水中, 厌氧环境下二氧化锰 对双氯芬酸的去除率为 $78 \%$, 高于好氧环境下的 $59 \%$ 。在 $50 \mathrm{mM}$ 的 磷酸盐缓冲液中, 二氧化锰能够在好氧环境下将双氯芬酸完全去除, 而其在厌氧环境下的去除率与在纯水中没有区别。初步研究表明, 酸 性条件（pH 4-5）对二氧化锰厌氧去除双氯芬酸有利。同时, 相比于 二氧化锰晶体, 无定形态的二氧化锰更适合用于双氯芬酸的去除。有 上述结果得知, 药品的化学结构和性质, 二氧化锰的性质以及二氧化 镇的表面活性位是决定厌氧环境下利用二氧化锰对药品的出去了程 度。

论文第五章进一步研究了厌氧环境下利用二氧化锰去除双氯芬酸 的过程。实验结果表明, 将实验温度从 $10^{\circ} \mathrm{C}$ 提高到 $30^{\circ} \mathrm{C}$ 能够提高双 氯芬酸的去除。然而当温度再次提升到 $40^{\circ} \mathrm{C}$ 时, 双氯芬酸的出去收 到了抑制。这可能是由奥氏熟化，或者老化，或者两者共同造成的。 增加二氧化锰的相对量能够提高双氯芬酸的去除。但是当二氧化锰与 双氯芬酸的物质的量的比从 2200: 1 提高到 8900: 1 时, 双氯芬酸的 去除没有进一步增加。这可能是由于二氧化锰氧化双氯芬酸的能力有 限。金属离子对双氯芬酸的去除有强烈的抑制作用, 并遵循以下顺 序: $\mathrm{Mn}^{2+}>\mathrm{Ca}^{2+} \approx \mathrm{Mg}^{2+}>\mathrm{Fe}^{3+}$ 。金属离子能够吸附在二氧化镍的表 面, 并和双氯芬酸竞争二氧化镇表面的活性位。磷酸盐对双氯芬酸的 去除有不同的作用: 在低浓度时, 磷酸盐回抑制双氯芬酸的去除, 而 在高浓度时回促进去除。腐殖酸能够显著的提高二氧化锰对双氯芬酸 的去除。只是由于腐殖酸能够释放二氧化锰表面被其他物质占据的活 性位, 并激活新的活性位。 
为了能够将药品去除过程中使用过的锰和铁再次使用, 论文第六 章研究了限制氧气浓度环境下四价锰的生物产生过程, 以及硝酸盐还 原条件下三价铁的生物产生过程。在限制氧气浓度的条件下, 二价锰 氧化菌成功产生出四价锰, 并且产生的四价锰固体为无定形态的。二 价锰氧化菌不能降解药品物质。在非生物去除部分, 厌氧环境中, 给 水厂产生的四价锰能够有效的去除美特普洛和普菜洛尔。通过生物 过程, 三价铁也曾成功的在硝酸盐还原条件下制备。这种三价铁固体 也是无定形态的。在此生物铁氧化过程中, 没有发现药品的去除。对 比研究中使用的各种三价铁化合物, 只有给水厂生产的三价铁和一种 三价铁吸附剂能够去除普菜洛尔。

论文的最后一章对本论文的实验结果进行了讨论, 并且对利用锰 和铁处理水中药品残留物的厌氧技术的实际应用提供了见解（第七 章）。利用锰和铁处理水中药品残留物的机理主要包括吸附, 化学氧 化和生物降解。在不通的处理技术中, 各种机理对药品残留物去除的 贡献不同。对于不同去除过程的评估比较主要基于对药品残留物的去 除效果, 环境状态和运行条件, 去除过程的可持续性, 以及不同镇和 铁化合物的应用。本论文的实验结果证明, 利用锰和铁处理水中的厌 氧技术可以去除水中的药品残留物。为了将这一过程转化为实际的水 处理单元, 未来的研究需要经过三个步骤: (1) 探索利用锰和铁处 理水中药品残留物的厌氧技术的极限; (2) 在可控范围内进行小规 模的实验模拟; (3) 中试实验。此外, 论文中也提出了一些其他相 关的研究课题。总的来说, 利用锰和铁的厌氧技术可以通过生物和非 生物的过程去除水体中的药品残留物。这一过程有希望发展成高效, 经济, 环境友好并且可持续发展的水中药品残留物去除技术。 


\section{Publications}

Liu, W.; Sutton, N. B.; Rijnaarts, H. H. M.; Langenhoff, A. A. M., Pharmaceutical removal from water with iron- or manganese-based technologies: A review. Critical Reviews in Environmental Science and Technology 2016, 46, (19-20), 1584-1621.

Liu, W.; Sutton, N. B.; Rijnaarts, H. H. M.; Langenhoff, A. A. M., Anoxic conditions are favourable for abiotic diclofenac removal from water with manganese oxides. Submitted.

Liu, W.; Langenhoff, A. A. M.; Sutton, N. B.; Rijnaarts, H. H. M., Application of manganese oxides under anoxic conditions to remove diclofenac from water. Submitted.

Liu, W.; Sutton, N. B.; Rijnaarts, H. H. M.; Langenhoff, A. A. M., Anaerobic biodegradation of pharmaceutical compounds coupled to dissimilatory manganese (IV) or iron (III) reduction. In preparation.

Li, H.; Peng, D.; Liu, W.; Wei, J.; Wang, Z.; Wang, B., $\mathrm{N}_{2} \mathrm{O}$ generation and emission from two biological nitrogen removal plants in China. Desalination and Water Treatment 2016, 57, (25), 11800-11806

\section{Presentations}

Liu, W.; Sutton, N. B.; Rijnaarts, H. H. M.; Langenhoff, A. A. M. (2017) "Diclfoenac removal under anoxic condition with manganese oxides" $10^{\text {th }}$ Micropol and Ecohazard Conference 2017, September 17-20, 2017, Vienna, Austria (Oral)

Liu, W.; Sutton, N. B.; Rijnaarts, H. H. M.; Langenhoff, A. A. M. (2016), "Under anoxic condition, abiotic removal of pharmaceuticals with $\mathrm{MnO}_{2}$ " The China-Netherlands Environmental Technology Symposium \& Doctoral Forum, June 12-13, 2016, Xi'an, China (Oral) 
Liu, W.; Sutton, N. B.; Rijnaarts, H. H. M.; Langenhoff, A. A. M. (2016) "Pharmaceutical removal from water with Fe(III) or Mn(IV)", The CHINED-4D Environmental Solutions Symposium, June 6-7, 2016, Beijing, China (Oral and Poster)

Liu, W.; Sutton, N. B.; Rijnaarts, H. H. M.; Langenhoff, A. A. M. (2015) "Pharmaceutical removal from water with Fe(III) or Mn(IV)" 9th Micropol and Ecohazard Conference 2015, November 22-25, 2017, Singapore, Singapore (Poster)

Liu, W.; Sutton, N. B.; Rijnaarts, H. H. M.; Langenhoff, A. A. M. (2015) "Pharmaceutical removal from water with Fe(III) or Mn(IV)", Environmental Technology for Impact 2015, April 29-30, 2015, Wageningen, the Netherlands (Oral) 


\section{Acknowledgement}

At this time when I am finishing my $\mathrm{PhD}$, I can't help to recalling my life in the Netherlands. I am not able to complete the whole work myself without help from my promoter and supervisors, my colleagues, my friends, and my family.

My first appreciation goes to my supervision team, the "Golden Triangel" - Huub, Alette, and Nora. Huub, you are the person who shows me what a scientist is like and teaches me how to think and work as an independent scientist. Your unique capacity to identify critical information about my research, and sharp view of the top science have contributed significantly to my development over the last four years. Thank you for your tremendous support and your guidance to my career. Alette, from the start of my PhD work you gave me space to plan and run the project independently, supporting my practical work as well as my life in the Netherlands, believing in my ability to take responsibilities on managing my project. Thank you for helping me develop as a qualified researcher. I also thank you for starting the amazing group dinner, in which I always had delicious food and tons of fun. Nora, thank you for your supporting me in my experiments and my research work when Alette is absent. After you officially became me co-promoter, your knowledge and intellect impressed me. I have learned a lot from you not only on research but also on how to enjoy the life. I would also like to thank Thomas ter Laak from KWR for his supervision and support at the beginning of my $\mathrm{PhD}$.

This thesis would not be possible without a strong support from the ETE laboratory team. I appreciate the help from Hans, Jan Kubiak, Livio, Jean, Ilse, Katja, Vinnie, and Bert. All of you have helped to brainstorm the solutions to all of challenges in my experiments. I would like to thank all my and students, Yanbo, Menghan, Lydia, Yiyuan, Marijn, Rebecca, and Julia, for their work in the laboratory which contribute directly or indirectly to the content of this thesis. Thank you very much! 
Without people in ETE, it is impossible for me to complete the thesis and propositions so smoothly. First of all, I would like to thank Liesbeth, $\mathrm{Gea}$, and other members of secretary team for their support of my $\mathrm{PhD}$ project from the administration side. You helped me organize all the meetings, rooms, and most important, all the money.

The atmosphere of "togetherness" at ETE is important to the success of my PhD. I would like to first thank the people in the micro-pollutant team: Arnoud, Thomas, Yujie, Yin, Yujia, Andrii, AndreaBrunsch, Luara, Andrea Aldas Vargas, and Elackiya for their irreplacable support and conversations in the lab and in the meeting. I would also like to acknowledge all of my great office mates, lunch friends, borrel buddies, and other ETEers. I enjoy the food, the beer, the talk, as well as the department trip because of you: Aken, Andrii, Annemerel, Annemiek, Bao Park, Bruna, Carlos, Casper, Celia, Chunjing, Daria, David, Delaram, Els, Emilius, Grietije, Gunther, Hardy, Indra, Jan Vreeburg, Jan Weijma, Jinye, Joeri Willet, Justine, Kanjana, Kasia, kasper, Koen, Laima, Lei, Leire, Lucia, Ludo, Miriam, Momo, Pim, Pradip, Renata, Rosaane, Rosaane, Roxani, Shenao, Shengle, Shiyang, Shoukou, Silivi, Tania, Tim, Viola, Yifan, Yingdi, Yvonne, Zhimou, Zhuobiao and other people I don't mention here. Special appreciation goes to Danis, Sanne, Livio and Harry, without your inspiration, I am not able to submit my proposition and my thesis on time. My "paranimfen", Dandan and Azie, thank you for willing to support me during my public defence.

I would like to appreciate my Chinese friend in WUR: Yifan Zhu, Shijiang, Ying, Huicui, Wenbiao, Tao, and Xiaoshen. Even we don't meet very often, I always know that I can find you when I need. Thank you very much. I would like to appreciate my friends outside of Wageningen: Bao Li, Deqing, Heng, Lunqi, Yuexin, and Zhiyi. You distract me from the stress of continuous lab work and endless manuscript preparation and revisions. You help me find my true heart inside. 
I would like to appreciate my friends in China. We are sharing the sweet and sad moments during the PhD. Special thanks go to Huijuan who helped me on the Chinese summary.

My family have given me huge support to help me survive the grey winter in the Netherlands, and every challenge in my life even though you don't understand my work at all. You always support me to chase my own goal, follow my own path, and being myself. You cares about me more than anything else in the world and that is the most valuable treasure in my life.

I would also like to thank Guolin Yang for the providing the cover of this thesis.

我要感谢我的家人。虽然你们不懂我的研究, 但是你们仍旧全 心全意的支持我。你们的支持让我成功度过荷兰寒冷灰暗的冬天，和 生命中的每一个挑战。是你们支持我追求自己的目标，追寻自己的道 路, 最终实现自我价值。你们把我当成世界上最宝贵的财富, 你们也 是我生命中最宝贵的东西。

感谢杨国磷为本论文提供封面图片。 


\section{About the author}

Wenbo Liu was born on September 11, 1987, in Qingdao, China. In 2006, he started to study Environmental Engineering at the Wuhan University of Technology. In 2010, he finished his thesis about "Pollution

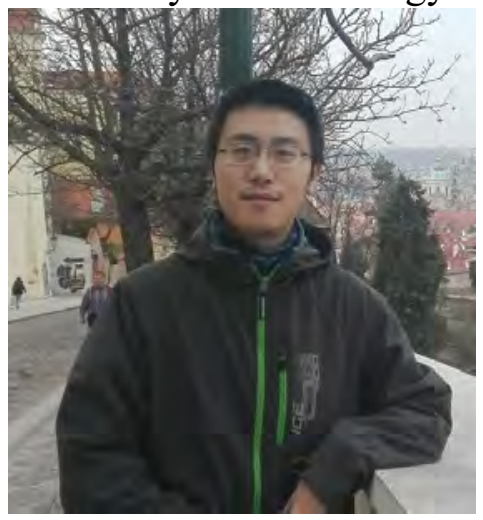

loading evaluation from both Urban life and industrial sources and its forecast in the Hubei region of Three Gorges Reservoir area." The work belonged to Major Science and Technology Program for Water Pollution Control and Treatment (2009ZX07104-001). Based on the methods provided in this work, two peer-reviewed papers were published in Chinese. In 2010, he started his MSc program in Xi'an University of Architecture and Technology, supervised by Professor Dangcong Peng. He studied the project about non- $\mathrm{CO}_{2}$ greenhouse gas emission from wastewater treatment processes. Also, he worked on the topics of ammonia removal under anaerobic conditions. During his MSc period, he attended the "3rd International Symposium of the Environmental Leaders" and presented part of his work about using the iron to remove ammonia via an oral presentation. In 2013, his submitted his thesis titled "Non-carbon dioxide greenhouse gas emission from different municipal wastewater treatment processes". After successfully applied the scholarship from China Scholarship Council (CSC, File No. 201308610161), he started his $\mathrm{PhD}$ program in Environmental Technology, Wageningen University and Research in September 2013. In 2017, he finished his thesis about pharmaceutical degradation in manganese or iron-mediate systems. 


\section{SENSE}

Netherlands Research School for the

Socio-Economic and Natural Sciences of the Environment

\section{I P L O M A}

For specialised PhD training

The Netherlands Research School for the Socio-Economic and Natural Sciences of the Environment (SENSE) declares that

\section{Wenbo Liu}

born on 11 September 1987 in Shandong, China

has successfully fulfilled all requirements of the Educational Programme of SENSE.

Wageningen, 26 January 2017

the Chairman of the SENSE board

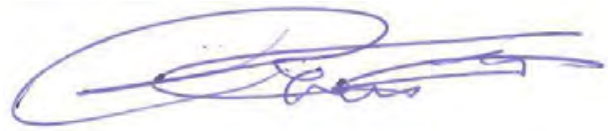

Prof. dr. Huub Rijnaarts the SENSE Director of Education

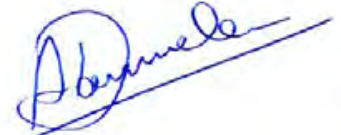

Dr. Ad van Dommelen

The SENSE Research School has been accredited by the Royal Netherlands Academy of Arts and Sciences (KNAW)

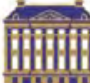

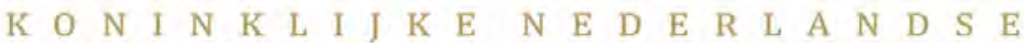




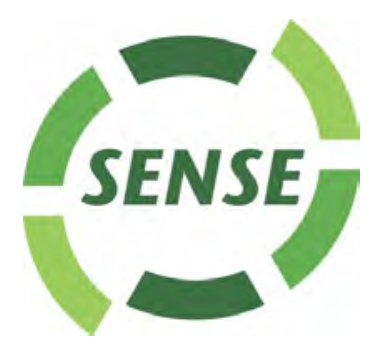

The SENSE Research School declares that Mr Wenbo Liu has successfully fulfilled all requirements of the Educational PhD Programme of SENSE with a work load of $38 \mathrm{EC}$, including the following activities:

\section{SENSE PhD Courses}

- Environmental research in context (2014)

- SENSE writing week (2015)

- Research in context activity: 'Co-organizing the CHI-NED 4D Dialogue Seminar and a PhD study trip to China' (2016)

\section{Other PhD and Advanced MSc Courses}

- Project and time management, Wageningen University (2013)

- Teaching and supervising thesis students, Wageningen University (2014)

- Techniques for writing and presenting a scientific paper, Wageningen University (2014)

- Francqui inaugural and further lectures by David Sedlak, Ghent University (2015)

- Toxicant identification in water, sediment and biota, Helmholtz Interdisciplinary Graduate School for Environmental Research (2016)

o Presenting with impact, Wageningen University (2016)

\section{Management and Didactic Skills Training}

- Assisting practical of the BSc course 'Introduction Environmental Technology' (20152016)

- Supervising five MSc students with theses entitled:

- 'Pharmaceutical Removal with Fe(III) or Mn(IV) from water' (2014)

- 'Abiotic removal of pharmaceuticals with $\mathrm{MnO}_{2}$ '(2015)

- 'Pharmaceutical removal with manganese oxides' (2015)

- 'Bio-regeneration of $\mathrm{Mn}(\mathrm{IV})$ and $\mathrm{Fe}(\mathrm{III})$ ' (2016)

- 'Biodegradation of selected $\beta$-blockers by dissimilatory reduction of $\mathrm{Mn}(\mathrm{IV})^{\prime}$ (2017)

- Supervising two BSc students with theses entitled:

- 'Abiotic removal of pharmaceuticals with manganese as reactive compound' (2015)

- 'The effects of co-solutes on pharmaceutical biodegradation with $\mathrm{MnO}_{2}$ ' (2017)

\section{Oral Presentations}

- Pharmaceutical removal from water with Fe(III) or Mn(IV). Environmental Technology for Impact, 29-30 April 2015, Wageningen, The Netherlands

- Diclofenac removal with manganese oxides under anoxic conditions. $10^{\text {th }}$ Micropol and Ecohazard Conference, 17-20 September 2017, Vienna, Austria

SENSE Coordinator PhD Education 
The support provided by China Scholarship Council (CSC) for the research of Wenbo Liu at Wageninge University is kindly acknowledged.

Final support from Wageningen University for printing this thesis is gratefully acknowledged.

Photoes of cover and invitation is taken by Guolin Yang 
iv

$\psi \psi$

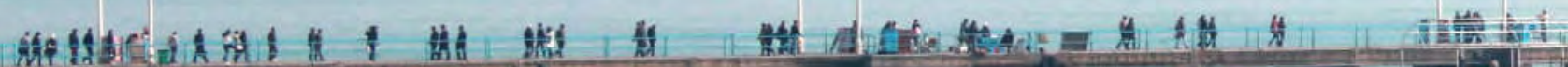

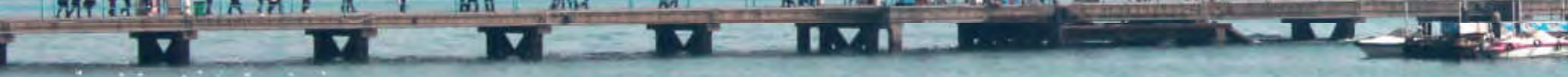

